\title{
AVALIAÇÃO DA EFICIÊNCIA PRODUTIVA E ENERGÉTICA DE SISTEMAS DE CLIMATIZAÇÃO EM GALPÕES TIPO "FREESTALL" PARA CONFINAMENTO DE GADO LEITEIRO
}

\section{MAURICIO PERISSINOTTO}

\author{
Dissertação apresentada à Escola Superior de \\ Agricultura "Luiz de Queiroz", Universidade de São \\ Paulo, para obtenção de título de Mestre em \\ Agronomia, Área de Concentração: Física do \\ Ambiente Agrícola. \\ PIRACICABA \\ Estado de São Paulo - Brasil \\ Dezembro - 2003
}




\title{
AVALIAÇÃO DA EFICIÊNCIA PRODUTIVA E ENERGÉTICA DE SISTEMAS DE CLIMATIZAÇÃO EM GALPÕES TIPO “FREESTALL” PARA CONFINAMENTO DE GADO LEITEIRO
}

\section{MAURICIO PERISSINOTTO}

Engenheiro Agrônomo

Orientadora: Profa. Dra. DANIELLA JORGE DE MOURA

\author{
Dissertação apresentada à Escola Superior de \\ Agricultura "Luiz de Queiroz", Universidade de São \\ Paulo, para obtenção de título de Mestre em \\ Agronomia, Área de Concentração: Física do \\ Ambiente Agrícola. \\ PIRACICABA \\ Estado de São Paulo - Brasil \\ Dezembro - 2003
}


Dados Internacionais de Catalogação na Publicação (CIP) DIVISÃO DE BIBLIOTECA E DOCUMENTAÇÃO - ESALQ/ USP

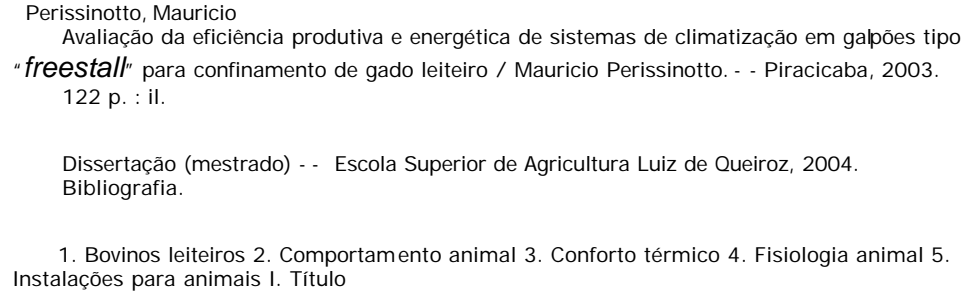

CDD 636.214

\section{"Permitida a cópia total ou parcial deste documento, desde que citada a fonte - $\mathrm{O}$ autor"}


Aos meus pais, Waldomiro e Regina, exemplos de vida e luta, cujo amor e dedicação elevam-me a cada instante.

\section{MINHA HOMENAGEM}

A minha noiva, Renata Aparecida Delamuta, pelo amor, cumplicidade, apoio, carinho e incentivo.

OFEREÇO E DEDICO 


\section{AGRADECIMENTOS}

A Deus, que me iluminou e me deu forças nos momentos em que mais precisei para vencer os obstáculos surgidos durante esse percurso.

À Escola Superior de Agricultura "Luiz de Queiroz", pelas tantas oportunidades oferecidas.

À Professora Dra. Daniella Jorge de Moura, pela orientação, amizade, confiança, incentivo e entusiasmo na execução deste trabalho, responsável pelo meu crescimento pessoal e científico.

Ao Professor Dr. Iran José Oliveira da Silva, pelos ensinamentos, sugestões, amizade e incansável apoio àrealização deste trabalho.

Aos Srs. Jorge e Carlos Gonzales, donos da fazenda Campestre, pela atenção, confiança, sugestões e colaboração para o desenvolvimento deste trabalho, viabilizando a instalação e execução do experimento a campo.

Aos professores do Programa de Pós-Graduação em Física do Ambiente Agrícola, pelos ensinamentos e oportunidade de realização do curso.

Aos professores Quirijn de Jong Van Lier, Flávio Augusto Portela Santos e Holmer Savastano Júnior, pelos ensinamentos, sugestões para a melhoria e engrandecimento deste trabalho.

Aos amigos Soraia Vanessa Matarazzo, Viviane Pandorfi e Sérgio Fernandes pelo apoio na instalação e execução do experimento.

Aos colegas do Núcleo de Pesquisa em Ambiência, Héliton Pandorfi, Edilaine Regina Pereira, José Luís Martins, Kelly Botigeli Sevegnani, Sulivan Perieira Alves, José Antônio Bonfino, Ivan Wladimir Caro, pela amizade e apoio direto e indireto na realização deste trabalho. 
Aos colegas do Curso de Pós-Graduação em Física do Ambiente Agrícola, pelo convívio e amizade durante a realização do curso.

Aos meus irmãos Marcello, Márcio e Mariana Perissinotto e a meu sobrinho Marcello Perissinotto Júnior, pela amizade, apoio e carinho.

Aos meus Avós Ézio e Clara pelo incentivo, e carinho.

Aos meus Tios (as) e primos (as), que tanto me incentivaram e me apoiaram durante a realização do curso.

À Coordenação de Aperfeiçoamento de Pessoal de Nível Superior - CAPES, pela concessão da bolsa de estudos. 


\section{SUMÁRIO}

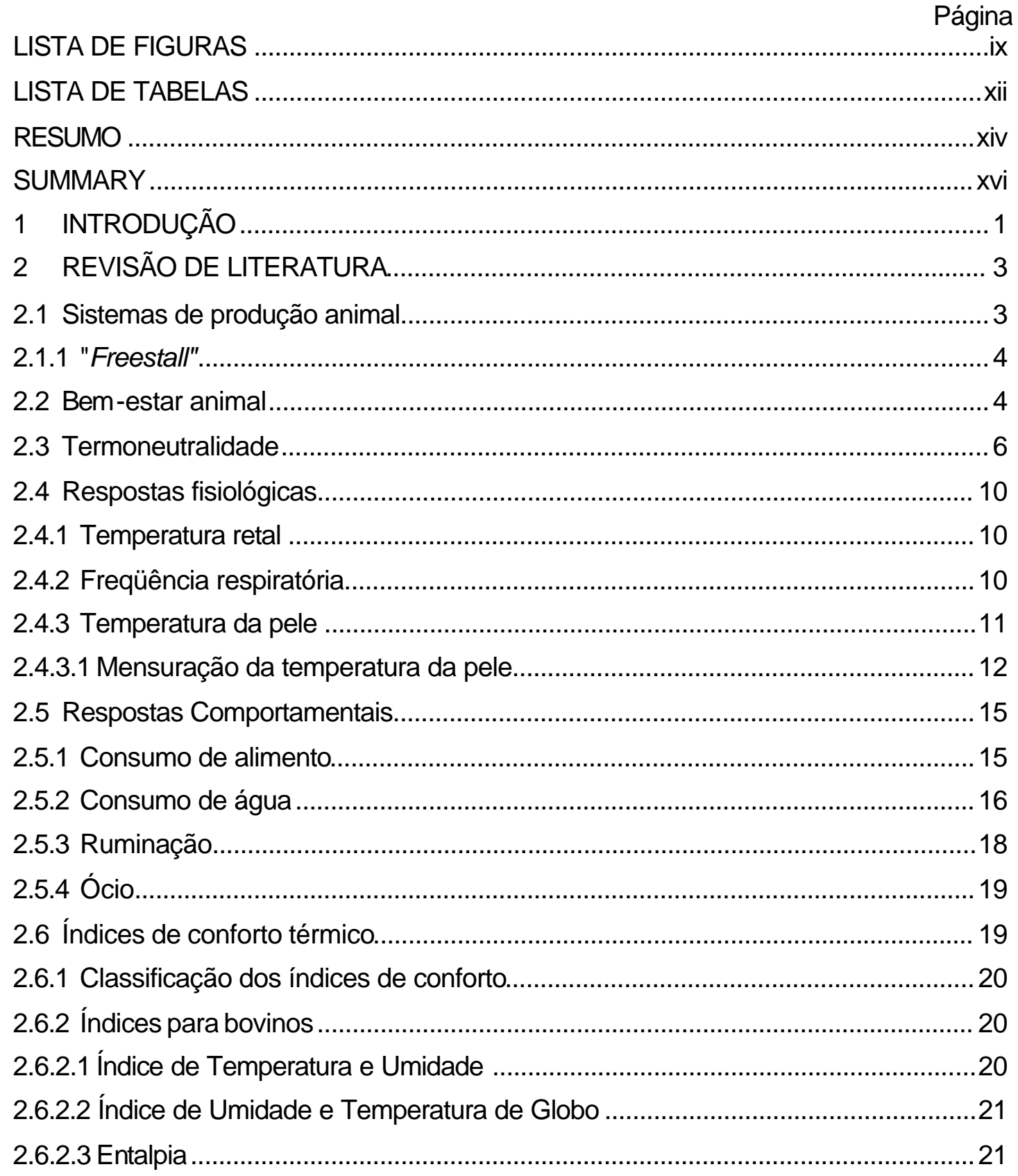




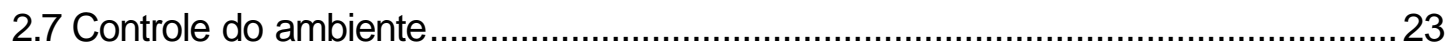

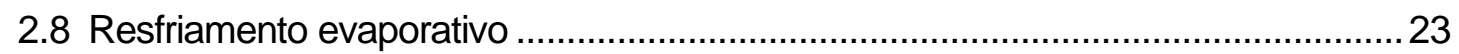

2.8.1 Sistema de nebulização e sua influência no animal ...........................................25

2.8.2 Sistema de aspersão e sua influência no animal ................................................27

2.8.3 Aspersão x nebulização e sua influência no animal .............................................30

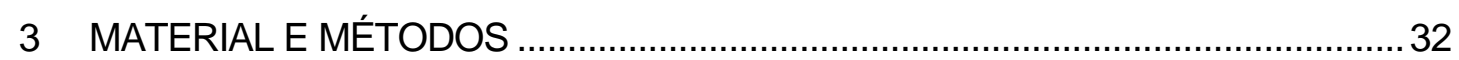

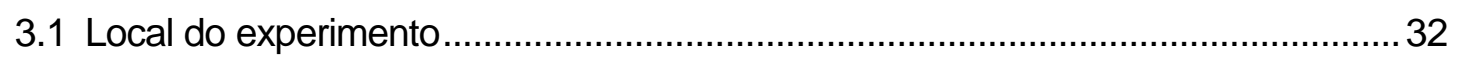

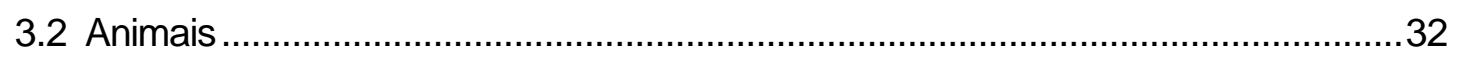

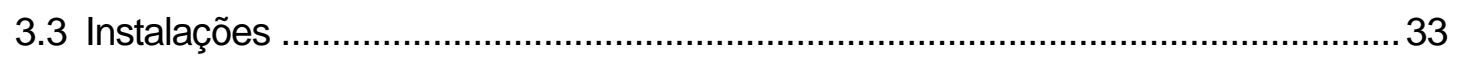

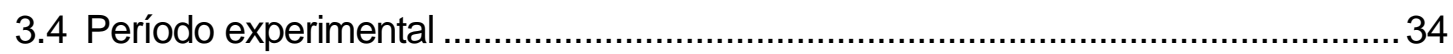

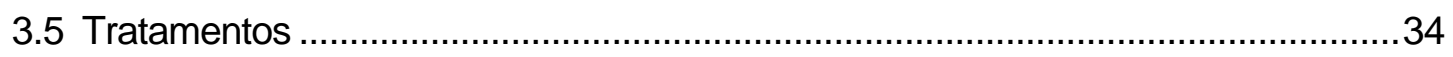

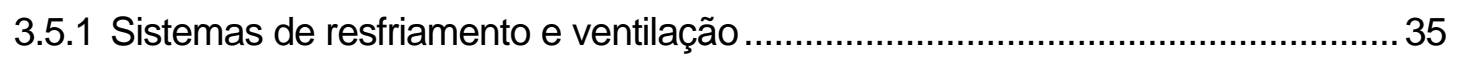

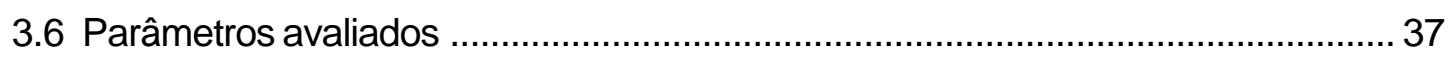

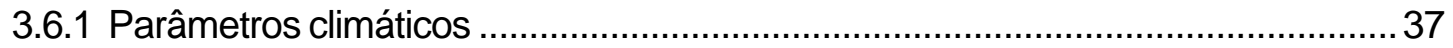

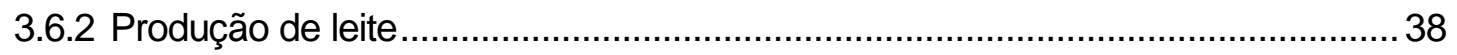

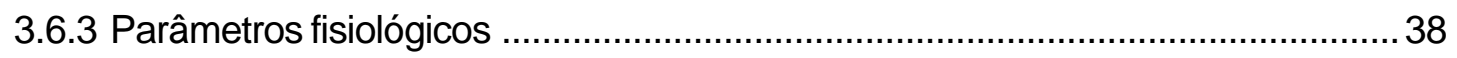

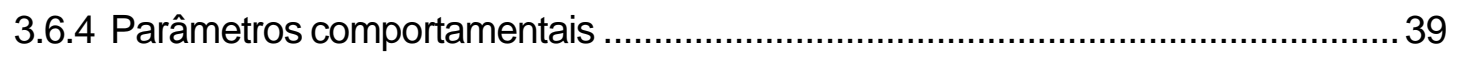

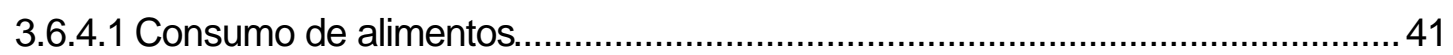

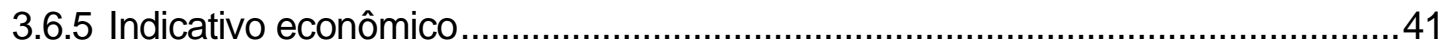

3.6.5.1 Consumo de água pelos sistemas de climatização ..........................................41

3.6.5.2 Consumo de energia pelos sistemas de climatização ...................................... 42

3.7 Análise da fundamentação científica e métodos empregados .............................. 42

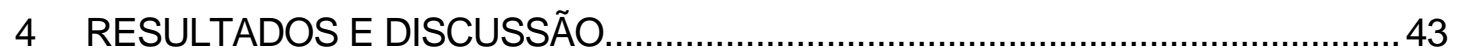

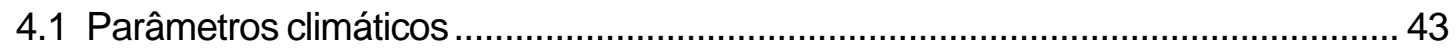

4.1.1 Temperatura máxima e mínima (Tmax e Tmin)................................................. 46

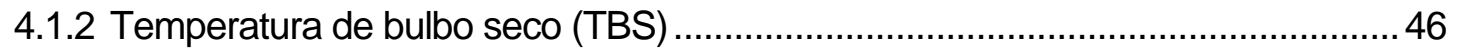

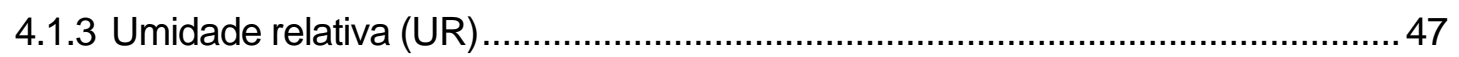

4.1.4 Temperatura de globo negro (TG) ............................................................ 49

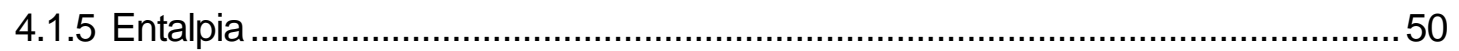

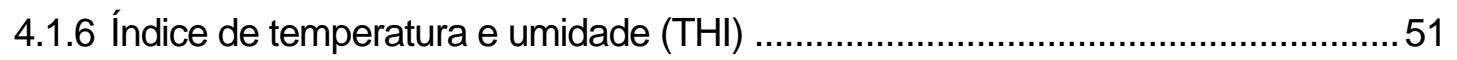

4.1.7 Índice de temperatura de globo e umidade (BGHI) ......................................... 52

4.2 Parâmetros fisiológicos ........................................................................................ 53

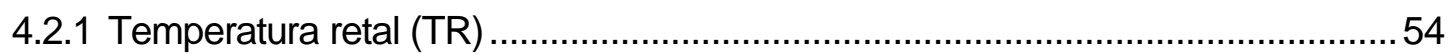




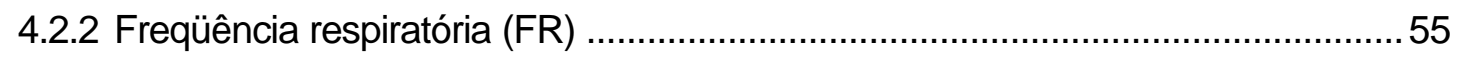

4.2.3 Temperatura da superfície do pelame (TP) ...................................................56

4.2.3.1 Temperatura da superfície do pelame branco (TPB) .......................................56

4.2.3.2 Temperatura da superfície do pelame preto (TPP) ........................................5

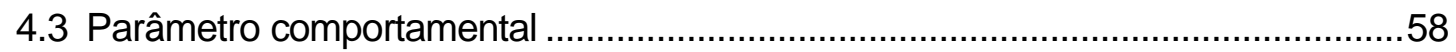

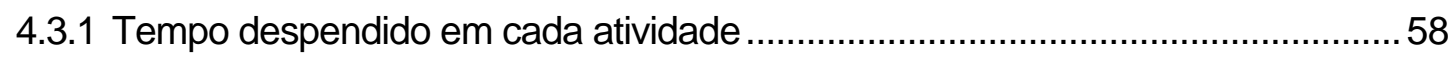

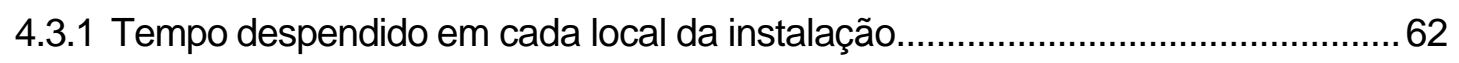

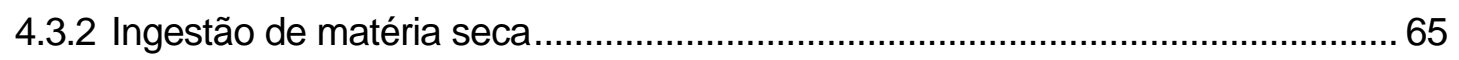

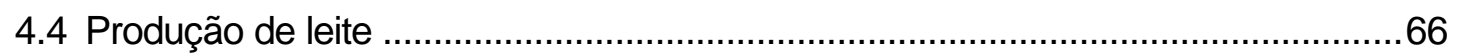

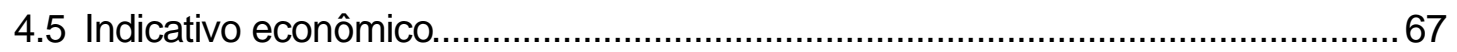

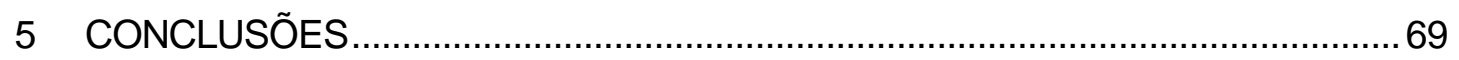

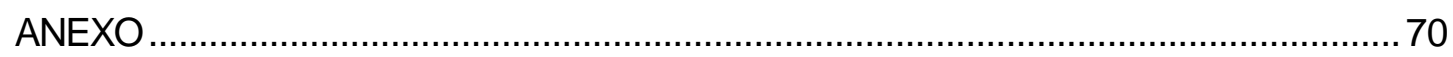

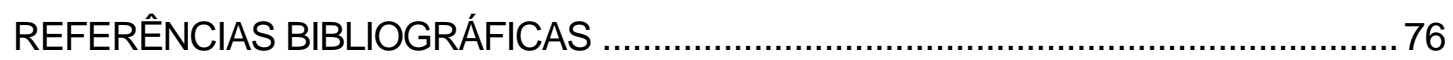

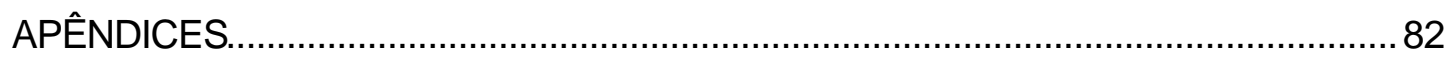




\section{LISTA DE FIGURAS}

Página

1 Estressores climáticos e seus efeitos no desempenho do animal ...................... 7

2 Distribuição espectral da radiação do corpo negro a temperaturas diferentes a partir da Lei de Planck ................................................................. 12

3 Esquema genérico de um pirômetro de radiação.............................................. 14

4 Esquema de funcionamento de pirômetros de radiação total e infravermelho.

5 Desempenho do resfriamento adiabático evaporativo mostrado pelo gráfico psicrométrico

6 Vista externa da instalação utilizada no estudo. ............................................. 33

7 Divisão dos animais dentro dos galpões de "freestall". .........................................35

8 Vista dos ventiladores utilizados no experimento sobre a linha de cocho e sobre as camas

9 Vista do sistema de aspersão (a) e nebulização (b) utilizados no experimento.

10 Vista da mini-estação meteorológica instalada dentro da istalação (a) e do abrigo meteorológico instalado próximo a instalação (b)

11 Vista da coleta da temperatura retal (a) e da temperatura do pelame (b) de um dos animais selecionados para a coleta de dados fisiológicos.

12 Vista de uma vídeo-câmera instalada sobre o bebedouro (a) e detalhe da vídeo-câmera 
13 Microconputador equipado com placa de captura de imagens para a coleta e armazenamento das imagens das vídeo-câmeras..

14 Médias de temperatura de bulbo seco, nos diferentes tratamentos e no ambiente externo, nos horários analisados 46

15 Médias de umidade relativa, nos diferentes tratamentos e no ambiente externo, nos horários analisados.

16 Médias de temperatura de globo negro, nos diferentes tratamentos, nos horários analisados

17 Médias de entalpia, nos diferentes tratamentos e no ambiente externo, nos horários analisados

18 Médias do THI, nos diferentes tratamentos e no ambiente externo, nos horários analisados

19 Médias do BGHI, nos diferentes tratamentos, nos horários analisados

20 Médias da temperatura retal dos animais, nos diferentes tratamentos, nos horários analisados

21 Médias da freqüência respiratória dos animais, nos diferentes tratamentos, nos horários analisados

22 Médias de temperatura da superfície da pele branca dos animais, nos diferentes tratamentos, nos horários analisados

23 Médias de temperatura da superfície da pele preta dos animais, nos diferentes tratamentos, nos horários analisados

24 Tempo, em minutos, em que os animais realizaram cada atividade nos diferentes tratamentos

25 Porcentagem do tempo em que os animais realizaram cada atividade, nos tratamentos estudados.

26 Tempo, em minutos, em que os animais permanecem em cada local dentro do "freestall', nos tratamentos estudados. 
27 Porcentagem do tempo em que os animais permanecem em cada local dentro do "freestall", nos tratamentos estudados... 


\section{LISTA DE TABELAS}

Página

1 Vantagens e desvantagens do sistema tipo "freestall".

2 Efeitos da temperatura do ar e da umidade relativa sobre a produção de leite em diferentes raças leiteiras

3 Valores médios de vaca européia em ambiente confortável e aquecido.

4 Consumo de água por vacas holandesas em diferentes temperaturas ambientes e em diferentes estágios de produção.

5 Aumento na produção de leite de vacas em diferentes estágios de lactação submetidas à ventilação associada a nebulização dentro do freestall

6 Efeito do uso de aspersores de água e ventiladores no resfriamento de vacas leiteiras.

7 Média diária das variáveis climáticas durante o período experimental.

8 Média das variáveis climáticas no intervalo horário das $9 \mathrm{~h}$ ̀े $17 \mathrm{~h}$ durante o período experimental.

9 Médias das variáveis fisiológicas dos animais no período experimental Produção de leite.

10 Média do tempo, em minutos, em que os animais realizaram cada atividade nos diferentes tratamentos

11 Média do tempo, em porcentagem, em que os animais realizaram cada atividade nos diferentes tratamentos

12 Média do tempo, em minutos, em que os animais permanecem em 
cada local dentro da instalação, nos diferentes tratamentos .

13 Média do tempo, em porcentagem, em que os animais permanecem em cada local dentro da instalação, nos diferentes tratamentos

14 Médias de ingestão de matéria seca pelos animais, nos diferentes tratamentos

15 Médias de produção de leite, nos diferentes tratamentos, durante o período experimental 


\title{
Avaliação da eficiência produtiva e energética de sistemas de climatização em galpões tipo "freestalr" para confinamento de gado leiteiro
}

\author{
Autor: MAURICIO PERISSINOTTO \\ Orientadora: Profa. Dra. DANIELLA JORGE DE MOURA
}

\section{RESUMO}

O presente trabalho teve como objetivo geral avaliar a eficiência técnica e econômica do sistema de resfriamento adiabático evaporativo (SRAE) na produção intensiva de leite e como objetivos específicos avaliar a eficiência térmica dos sistemas de resfriamento (aspersão e nebulização), conjugados com a ventilação forçada, na resposta produtiva dos animais, na redução do estresse térmico, seus reflexos no microclima interno e sua eficiência econômica quanto ao consumo de energia e de água. O experimento foi realizado em uma fazenda comercial de produção leiteira, localizada no interior do Estado de São Paulo. Em cada tratamento foram utilizados 10 animais da raça Holandesa em produção, selecionados de acordo com a produção e período de lactação, alojados em sistema de "freestall'. Dos animais selecionados cinco foram utilizados para a tomada dos dados fisiológicos dos animais (freqüência respiratória, temperatura retal e temperatura do pelame branco e preto, medidos nos horários das 9, 11, 13, 15 e 17 horas, durante nove dias não consecutivos), e cinco animais foram utilizados para a avaliação comportamental (localização e atividades dentro da instalação), sendo para tanto utilizadas vídeo - câmeras das 9 às 17 horas 
durante seis dias. O período experimental compreendeu vinte e oito dias consecutivos do mês de novembro de 2003, sendo sete dias utilizados para a adaptação dos animais aos tratamentos testados e vinte e um dias para a coleta de dados. Os dados climáticos (temperatura e umidade relativa do ar e temperatura de globo negro) em cada tratamento e externo àinstalação foram registradas a cada 15 minutos ao longo das 24 horas por um data logger $\mathrm{HOBO}^{\circledR}$, possibilitando o cálculo do Índice de Temperatura e Umidade (THI), do Índice de Globo Negro e Umidade (BGHI) e da entalpia $(H)$. Foram utilizados ventiladores com capacidade de movimentar o ar a 2,5 m.s ${ }^{-1}$ que, assim como os sistemas de aspersão e nebulização, foram controlados por um termostato e distribuídos ao longo da linha de cocho das instalações. As variáveis respostas consideradas foram: produção de leite, consumo de alimento pelos animais, comportamento dos animais, consumo de água e de energia pelos sistemas de resfriamento e dados fisiológicos dos animais. A avaliação dos dados foi realizada por um delineamento experimental em blocos ao acaso, utilizando-se na análise estatística a comparação de médias pelo teste de Tukey ao nível de 1\%. Para a análise geral dos resultados foi utilizado o pacote estatístico SAS (SAS User guide: Statistics (release 6.03). SAS Inst. Inc., 1990). Considerando que os tratamentos estudados: aspersão e nebulização associadas à ventilação forçada promoveram um consumo alimentar semelhante (diferença de $3,0 \mathrm{~kg} \mathrm{MS}^{-1}$.animal ${ }^{-1}$. mês ${ }^{-1}$ ) observou-se que o sistema de resfriamento com aspersão apesar de apresentar um consumo de água e energia maior (7535,7 litros.animal ${ }^{-1} \cdot \mathrm{mês}^{-1}$ e $13,15 \mathrm{~kW} \cdot \mathrm{h}^{-1}$.animal ${ }^{-1} \cdot \mathrm{mês}^{-1}$, respectivamente) promoveu um aumento na produção de leite de $3 \%$ (18,0 litros/animal/mês) ocasionando um aumento na receita mensal total de aproximadamente 5,8\% por animal quando comparado ao sistema de nebulização. 


\title{
Evaluation of productive and energetic efficiency of climatization system in dairy cattle free-stall
}

\author{
Author: MAURICIO PERISSINOTTO \\ Adviser: Profa. Dra. DANIELLA JORGE DE MOURA
}

\section{ABSTRACT}

This work aimed to evaluate the economical and technical efficiency of evaporative adiabatic cooling system (EACS) for intensive milk production. Its specific objectives were to evaluate thermal efficiency of chilling systems (aspersion and sprinkler) associated with forced air fan on productive traits, heat stress reduction, internal micro-climate, and economical advantages in relation to water and energy expenses. Experiment was carried out in a commercial dairy cattle farm located in a small city of São Paulo State. In each treatment were used 10 dairy-Holstein cows sorted according to their milk production and lactation order, in a free-stall system. Among these cows, five were selected for collecting physiological data (respiratory frequency, rectal temperature and temperature in white and black pelage) at 9:00 a.m., 11:00 a.m., 1:00 p.m., 3:00 p.m. and 5:00 p.m. during nine non-consecutive days. Other five animals were evaluated for their behavior (localization and activities inside facilities) through video-cameras from 9:00 a.m. to 5:00 p.m. during six days. Experimental period was twenty-eight consecutive days of November 2003, being the first seven days for animal adaptation and the last twenty-one for data collection. Climate data (relative air temperature and humidity, and dark globe temperature), in each treatment and 
outside of facility, were taken in intervals of 15 minutes during 24 hours by $\mathrm{HOBO}^{\circledR}$ data logger, which permitted to calculate the Humidity and Temperature Index (HTI), Humidity and Dark Globe Index (HDGl) and Enthalpy (E). Fan with $2.5 \mathrm{~m} . \mathrm{s}^{-1}$ of air mobility capacity associated to aspersion and sprinkler systems, were controlled by thermostat and distributed following feeder line of free-stall. Production variables considered were: milk production, feed intake, animal behavior, water and energy consumption of cooling system, and animal physiological traits. Data evaluation was realized in a completely randomized block design using in statistical analysis Tukey's test with $1 \%$ of significance level. General analysis of results was performed through SAS proceedings. Considering that treatments promoted similar feed intake (the difference was $3.0 \mathrm{~kg} \mathrm{DM}$ animal ${ }^{-1}$. month $^{-1}$ ), the chilling system associated to aspersion led to an increase (18.0 liters.animal ${ }^{-1}$. month $^{-1}$ ) in $3 \%$ milk production in spite of its higher consumption of water and energy (7535.7 liters.animal ${ }^{-1} \cdot$ month $^{-1}$ and $2.3 \mathrm{~kW} \cdot \mathrm{h}^{-}$ ${ }^{1}$.animal ${ }^{-1} \cdot$ month $^{-1}$, respectively). As consequence, it was observed an increase of $4.7 \%$ in total mensal profit in relation to sprinkler system. 


\section{INTRODUÇÃO}

O animal é uma máquina biológica que pode expressar todo o seu potencial quando trabalha em condições ambientais ótimas. Quando essas condições não são adequadas, geralmente ocorre um reflexo negativo na produtividade.

Verificase a necessidade de aprimorar ainda mais a pecuária leiteira nos trópicos, onde muitas vezes a produção de leite é muito baixa. O problema principal está na adaptação das raças leiteiras de origem européia, que, devido a sua alta produtividade, muitas vezes sofrem problemas de alterações fisiológicas e comportamentais provocadas pelo estresse térmico, causando redução na produção de leite.

As alternativas para manter ou melhorar o desempenho e o bem-estar dos animais em climas quentes necessariamente envolvem a metabolização de energia $\mathrm{e}$ sua liberação para o ambiente, através dos processos de trocas térmicas entre 0 animal e o ambiente (Johnson, 1987).

O resfriamento evaporativo das instalações, particularmente para o confinamento de gado leiteiro, tem se expandido rapidamente devido a sua relativa simplicidade, praticidade técnica e relação custo/benefício favorável, proporcionando incrementos significativos na produção de leite (Armstrong \& Welchert, 1994).

Um ponto que merece destaque atualmente se refere à eficiência econômica dos sistemas de resfriamento no consumo de energia e água. Essa problemática vem se tornando cada vez mais importante e já não pode ser deixada de lado, visto a situação crítica que o país começou a enfrentar quanto à disponibilidade de água e energia, situação esta que só tende a piorar, necessitando que todos os setores atentem para a adoção de métodos mais econômicos em água e energia.

A necessidade de estabelecer critérios para a adoção de sistemas de resfriamento é crescente ao nível dos produtores. Depara-se com várias ofertas 
comerciais de pacotes milagrosos, porém sem nenhuma eficiência técnica ou econômica. Diante dessa situação, o Núcleo de Pesquisa em Ambiência (NUPEA ESALQ) desenvolve uma linha temática para sanar esse tipo de gargalo tecnológico na área de climatização para bovinos leiteiros. Apesar de um balizamento baseado na literatura internacional, verifica-se uma inexistência de pesquisas direcionadas para as condições brasileiras.

Diante do exposto e, complementando as pesquisas que vêm sendo realizadas pelo NUPEA, este trabalho tem como objetivo geral avaliar a eficiência técnica e econômica do sistema de resfriamento adiabático evaporativo (SRAE) na produção intensiva de leite.

Por outro lado, os objetivos específicos serão a avaliação dos sistemas de resfriamento (aspersão e nebulização), conjugados com a ventilação forçada, quanto à eficiência térmica na resposta produtiva dos animais; quanto à eficiência na melhoria do microclima interno das instalações e seus reflexos na redução do estresse térmico; e quanto à eficiência econômica, no consumo de energia e água dos sistemas adotados. 


\section{REVISÃO DE LITERATURA}

\subsection{Sistemas de produção animal}

Com o crescimento da população mundial a partir do início do século $\mathrm{XX}$, 0 consumo de proteína animal aumentou consideravelmente. A partir da década de 60 , as antigas criações extensivas e de fundo de quintal intensificaram-se, alojando um maior número de animais em espaços mais reduzidos. Isto tornou possível o grande aumento na produção de alimentos de origem animal para consumo humano (Silva et al., 2003).

Determinar qual melhor sistema a ser utilizado não é uma tarefa fácil, já que envolve vários fatores. Porém há de se avaliar as respostas do animal a esses ambientes de criação, levando-se em consideração não somente os dados de produtividade, mas também vários outros aspectos que envolvem a produção.

No entanto, as condições da criação intensiva exigiram a adaptação fisiológica e comportamental dos animais, que devem ser estudadas para avaliar os sistemas de manejo. Muitos dos atuais problemas na criação de animais não podem ser solucionados por pesquisas em nutrição, fisiologia ou controle de doenças; necessitando de investigações do comportamento animal para que se possa ter progresso.

Se hoje o tema de maior evidência na pecuária é a rastreabilidade, compreendida pela necessidade de cada animal apresentar sua identificação para atender æ̀s exigências de importadores de produtos de origem animal, o bem-estar animal é o próximo item da lista. Na União Européia, bovinos, suínos e aves já ganharam legislação específica, que determina desde o volume de produção por metro quadrado æ̀s práticas de nutrição, sanidade e abate, seguindo um conjunto de normativas. Como a UE é o principal mercado de exportações de produtos de origem 
animal, a qualquer momento chegarão por aqui as novas regras de produção necessárias para atender æ̀̀ exigências dos compradores europeus, como ocorre hoje em relação àrastreabilidade (Silva et al., 2003).

\subsection{1 "Freestall"}

A expressão "freestall", ou estabulação livre, devese ao fato de as vacas ficarem soltas dentro de uma área cercada, sendo parte dela livre para alimentação e exercícios e a outra parte, dividida em baias individuais forradas com cama, destinada ao descanso dos animais.

A alimentação das vacas, geralmente, é $100 \%$ no cocho, que pode ou não ser coberto, na forma de ração total.

É um sistema utilizado para vacas de alto a médio índice $\left(20-25 \mathrm{~kg} \mathrm{dia}^{-1}\right)$ de produção individual (Camargo, 1991). Como o custo de produção é alto, esse sistema não compensa ser utilizado para vacas com produção de leite abaixo de $20 \mathrm{~kg} \cdot \mathrm{dia}^{-1}$. A Tabela 1 mostra algumas vantagens e desvantagens da utilização do sistema tipo "freestall'.

Tabela 1. Vantagens e desvantagens do sistema tipo "freestall'

\begin{tabular}{ll}
\hline \multicolumn{1}{c}{ Vantagens } & \multicolumn{1}{c}{ Desvantagens } \\
\hline Custo operacional econômico & Custo de construção alto \\
Fácil mecanização & Menor atenção individual \\
Animais se exercitam regularmente & Maior competição \\
Alta flexibilidade para organizar diferentes & Vacas mais sujas por falha no manejo de \\
manejos de alimentação, grupos etc. & limpeza \\
\hline
\end{tabular}
Fonte: Camargo (1991)

\subsection{Bemestar animal}

Juntamente com as questões ambientais e a segurança alimentar, o bem-estar animal vem sendo considerado entre os três maiores desafios. O confinamento foi o caminho para reduzir trabalho, perda energética dos animais, ganhar espaço e controle 
ambiental. Agravam-se, então, problemas de comportamento e bem-estar animal. Um animal que não esteja em condição de bem-estar não irá desenvolver seu potencial produtivo em sua magnitude, mesmo que condições sanitárias e nutricionais estejam aparentemente satisfeitas. Em condições de limitação de espaço, alta densidade animal, presença de microorganismos, condições de temperatura e luminosidade inadequadas, ruídos, dentre outros, o animal ficará impossibilitado de desenvolver seu sistema natural de comportamento (Machado Filho, 1988).

Para uma abordagem mais acurada, é preciso definir do que trata o bem-estar animal. Este termo tem sido objeto de diferentes definições por diferentes autores. De acordo com Hurnik (1992), o bem-estar animal é o "estado de harmonia entre o animal e seu ambiente, caracterizado por condições físicas e fisiológicas ótimas e alta qualidade de vida do animal". De acordo com Broom (1991), o bem-estar se refere ao estado de um indivíduo em relação ao seu ambiente. Se o organismo falha ou tem dificuldade de se adaptar ao ambiente, isso é uma indicação de bem-estar incipiente.

O bem-estar animal, portanto, pode ser considerado como uma demanda para que um sistema seja defensável eticamente e aceitável socialmente. Segundo Warriss (2000), as pessoas desejam obter alimentos de origem animal com "qualidade ética", isto é, alimentos oriundos de animais que foram mantidos em todo o ciclo de produção em sistemas que promovam o seu bem-estar, e que sejam sustentáveis e ambientalmente corretos.

Segundo Fraser (1999), a maioria das tentativas dos cientistas de conceituar o bem-estar animal resume-se em três questões principais:

a) os animais devem sentir-se bem, não serem submetidos ao medo, àdor ou estados desagradáveis de forma intensa ou prolongada;

b) os animais devem funcionar bem, no sentido de saúde, crescimento e funcionamento comportamental e fisiológico normal;

c) os animais devem levar vida natural, através do desenvolvimento e do uso de suas adaptações naturais.

Uma definição de bem-estar bastante utilizada atualmente foi estabelecida pela FAWC (Farm Animal Welfare Council) (citada por Chevillon, 2000), na Inglaterra, mediante o reconhecimento das cinco liberdades inerentes aos animais:

1. a liberdade fisiológica (ausência de fome e de sede);

2. a liberdade ambiental (edificações adaptadas); 
3. a liberdade sanitária (ausência de doenças e de fraturas);

4. a liberdade comportamental (possibilidade de exprimir comportamentos normais);

5. a liberdade psicológica (ausência de medo e de ansiedade).

Existem diversas abordagens para avaliar o bem-estar animal. Algumas enfatizam os atributos físicos (crescimento e saúde), mentais (prazer ou sofrimento) e a naturalidade que reflete a proximidade ou a distância do ambiente natural (Appley \& Weary, 2000), mas todos os critérios estão baseados em demonstrar alguma evidência de mudança (Barnett \& Hemsworth, 1990).

$\mathrm{Na}$ prática da etologia, o bem-estar é avaliado por meio de indicadores fisiológicos e comportamentais. As medidas fisiológicas associadas ao estresse têm sido usadas baseando-se na premissa de que, se o estresse aumenta, o bem-estar diminui. Já os indicadores comportamentais são baseados especialmente na ocorrência de comportamentos anormais, e de comportamentos que se afastam do comportamento no ambiente natural.

O estresse é um termo geral que implica uma ameaça àqual o corpo precisa se ajustar (Van Borell, 1995). Segundo Fraser et al. (1975), diz-se que um animal está em estado de estresse, se é necessário que se façam ajustes anormais ou extremos em sua fisiologia ou comportamento para ajustar-se a aspectos adversos do seu ambiente e manejo. Essa adaptação envolve uma série de respostas neuroendócrinas, fisiológicas e comportamentais que funcionam para tentar manter a homeostase, o equilíbrio de suas funções, e a integração desses três sistemas (Barnett \& Hemsworth, 1990 e Van Borell, 1995).

\subsection{Termoneutralidade}

O principal fator a ser considerado para se garantir o conforto ao animal, em países tropicais e subtropicais, é minimizar os efeitos do estresse térmico. As condições climáticas nessas regiões são um grande desafio aos produtores, por alterarem os três processos vitais dos animais: a manutenção, a reprodução e a produção de leite (Head, 1995).

O estresse climático é função da temperatura do ar, umidade relativa, radiação solar, vento, temperatura corporal e intensidade/duração do agente estressor, podendo resultar em decréscimo na produção de leite e distúrbios reprodutivos. A interação 
entre os fatores causadores do estresse térmico e os fatores resultantes do mesmo pode ser observada na Figura 1.

\section{ESTRESSE CLIMÁTICO (EC)}

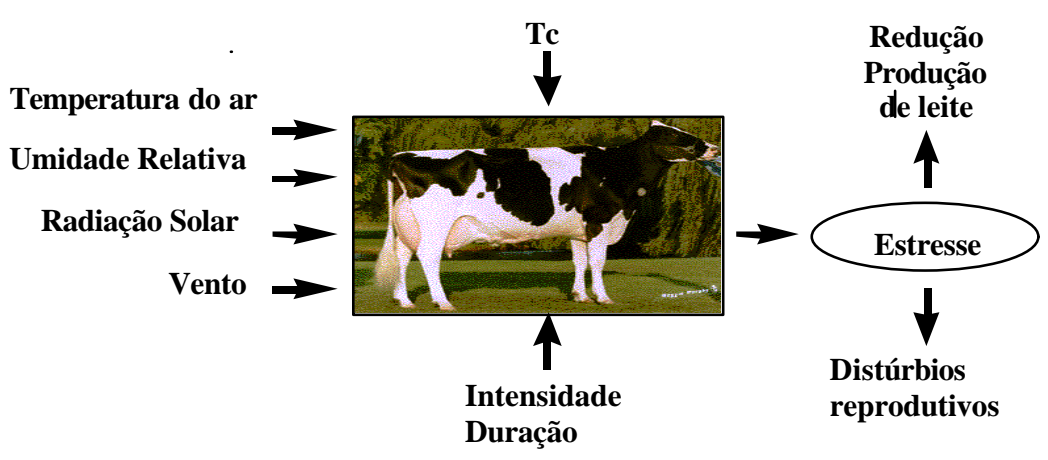

EC = f (Tc, Tar, UR, RS, vento, intensidade/duração estressor)

Figura 1 - Estressores climáticos e seus efeitos no desempenho do animal

Os bovinos são animais homeotérmicos, isto é, são capazes de manter a temperatura corporal independentemente das variações da temperatura ambiente. Os animais mantêm a homeotermia por meio de trocas de calor com o meio ambiente, lançando mão de mecanismos fisiológicos, metabólicos e comportamentais.

Os bovinos, dependendo da raça, nível de produção, estádio fisiológico e plano nutricional, apresentam uma faixa de temperatura ambiente na qual se encontram em conforto térmico, isto é, não sofrem estresse por frio ou calor, sendo denominada de zona termoneutra. Nesta faixa, o sistema termorregulador não é acionado, seja para fazer termólise ou termogênese, assim, o gasto de energia para manutenção é mínimo, resultando em máxima eficiência produtiva (Baccari, 1998).

A temperatura ótima para a produção de leite depende da espécie, raça e grau de tolerância ao calor e ao frio. De modo geral, a zona de termoneutralidade (ZTN) de vacas Holandesas, em lactação, em termos de temperatura do ar, varia de $4^{\circ} \mathrm{C}$ a $26^{\circ} \mathrm{C}$, (Huber, 1990). A temperatura crítica superior para vacas em lactação Pardas Suíças e Jersey pode chegar a $27^{\circ} \mathrm{C}$ e $29^{\circ} \mathrm{C}$, respectivamente (Hafez, citado por Baccari, 1998). Já para vaca Zebu, a temperatura crítica superior varia entre $30^{\circ} \mathrm{C}$ e $35^{\circ} \mathrm{C}$ (Bianca, citada por Baccari, 1998). Dessa forma, pode-se concluir que, em um país de clima tropical/subtropical como o Brasil, as vacas leiteiras, principalmente de raça 
Holandesa, estarão a maior parte do ano submetidas a temperaturas maiores do que as desejadas.

As vacas possuem quatro mecanismos básicos de perda de calor agrupados em meios evaporativos e não-evaporativos. Os meios não-evaporativos incluem condução, convecção e radiação. Esses meios requerem um diferencial de temperatura entre o animal e o meio ambiente, o que nem sempre acontece em condições de clima quente. A perda de calor por condução se efetua por contato e passa sempre do corpo mais quente para o mais frio. Assim, quando a temperatura da pele (TP) (ou da superfície do corpo) é mais elevada do que a do ambiente, o organismo cederá calor æ̀ moléculas do ar. No processo de convecção o ar entra em contato com a pele e aquece-se, tornando-se menos denso, deslocando-se em direção ascendente, dando lugar a outras moléculas do ar, ainda frias, que entram em contato com a superfície do corpo, onde serão aquecidas, dando continuidade ao processo de troca térmica. Se a temperatura do ar for mais elevada do que a da superfície do corpo, este ganhará calor, invertendo-se o mecanismo. A movimentação do ar, renovando mais rapidamente a camada de ar em contato com a superfície do corpo, também aumentará o gradiente de troca de calor por convecção. A perda de calor por radiação consiste na emissão de ondas eletromagnéticas (radiação infravermelha, calorífica) do corpo do animal a outros objetos (paredes, etc.) ou vice-versa, sendo sempre do corpo com temperatura maior para o de temperatura menor, sem aquecer 0 ar por onde passa e, portanto, não dependendo da movimentação do ar do local (Baccari, 2001).

A quarta via de perda de calor compreende os meios evaporativos. Este tipo de perda é importante em temperaturas superiores a $29^{\circ} \mathrm{C}$. A partir de valores acima dessa temperatura, $85 \%$ da perda de calor se dá através de meios evaporativos (transpiração e respiração). A perda de calor por esses meios é praticamente independente da temperatura do ar, no entanto, depende da umidade externa. Se a umidade relativa do ar for alta, há necessidade de movimentá-lo, através de ventilação forçada (Machado, 1998).

Vacas em lactação na Califórnia, no verão de 1977, experimentaram estresse térmico severo por um período de quase uma semana. Durante esse período, as máximas de temperatura diárias variaram de $31^{\circ} \mathrm{C}$ a $35,5^{\circ} \mathrm{C}$ e a mínima, de $21^{\circ} \mathrm{C}$. A umidade relativa do ar média variou entre $90 \%$ a 95\%. Aproximadamente 700 animais morreram devido ao estresse pelo calor, e a produção de todas as vacas foi 
substancialmente reduzida (Buffington et al., 1981). A Tabela 2 mostra o efeito da interação temperatura $X$ umidade relativa na produção de diferentes raças leiteiras.

Tabela 2. Efeitos da temperatura do ar e da umidade relativa sobre a produção de leite em diferentes raças leiteiras

\begin{tabular}{ccccc}
\hline Temperatura & Umidade & \multicolumn{2}{c}{ Raça (\% relativa de produção de leite) } \\
\cline { 3 - 5 } o $~$ & $\%$ & Holandesa $^{*}$ & Jersey & Pardo-Suíça \\
\hline 24 & 38 & 100 & 100 & 100 \\
24 & 76 & 96 & 99 & 99 \\
34 & 46 & 63 & 68 & 84 \\
34 & 80 & 41 & 56 & 71 \\
\hline
\end{tabular}

* Diferenças na produção de leite baseadas na porcentagem da produção normal a $24^{\circ} \mathrm{C}$ e $38 \%$ de umidade relativa (Johnson \& Vanjonack, citado por Baccari, 1998).

Os animais têm sido submetidos aos mais variados tipos de clima, cultura e práticas de manejo. Segundo Ashrae (1985), o ambiente físico exerce forte influência sobre o desempenho animal, uma vez que abrange elementos meteorológicos que afetam os mecanismos de transferência de calor e, assim, a regulação do balanço térmico entre o animal e o meio.

Uma vez que a carga térmica total resulta da produção de calor metabólico mais o calor ambiental, vacas de alta produção, as quais apresentam metabolismo intenso devido àingestão de grandes quantidades de nutrientes, têm maior dificuldade para manter a temperatura corporal em níveis normais (Head, 1989).

O ambiente térmico representa, portanto, um fator de restrição para a eficiência máxima de produção, principalmente nos sistemas intensivos. Tem sido considerado que a maior influência do estresse pelo calor sobre a produção de leite é exercida pela diminuição no consumo de alimentos (matéria seca) e conseqüente redução na ingestão de energia metabolizável. Essas alterações são realizadas pelo animal com o objetivo de reduzir a produção ou promover a perda de calor e manter a homeostase (Huber, 1990). Porém, a diminuição na produção de leite, como resposta ao estresse térmico não leva à perda total da produção, mas, uma vez cessada a condição de estresse, a quantidade de leite volta a aumentar, porém se faz lentamente e sem retornar ao nível anterior ao estresse. 


\subsection{Respostas fisiológicas}

\subsubsection{Temperatura retal}

A temperatura corporal resulta do equilíbrio entre o ganho e a perda de calor do corpo, isto é, do equilíbrio entre a quantidade de calor produzida no organismo, ou por ele absorvida, e a quantidade liberada para o ambiente. A temperatura corporal é um evento biológico de ocorrência periódica, obedecendo a um ritmo ou ciclo circadiano, ou seja, um ciclo que se repete a cada 24 h, com máxima entre 17 h e 19 h e a mínima entre $4 \mathrm{~h}$ e $6 \mathrm{~h}$ (Baccari, 2001). A capacidade do animal de resistir æ̀s condições de estresse calórico tem sido avaliada fisiologicamente por alterações na temperatura retal e freqüência respiratória.

O equilíbrio entre o ganho e a perda de calor do corpo pode ser inferido pela temperatura retal (TR). A medida da temperatura retal é usada freqüentemente como índice de adaptabilidade fisiológica aos ambientes quentes, pois seu aumento mostra que os mecanismos de liberação de calor tornaram-se insuficientes (Mota, citado por Martello et al., 2002).

Segundo Martello et al. (2002), a temperatura retal sofre interação com a hora do dia, apresentando um maior valor durante o período da tarde em relação ao da manhã, variando também com a categoria animal analisada, sendo que as novilhas apresentam, na maior parte do dia, temperatura retal maior em comparação æ̀̀ vacas.

A temperatura retal normal da vaca leiteira, em termoneutralidade e em repouso, varia, geralmente, entre $38,0^{\circ} \mathrm{C}$ e $39,5^{\circ} \mathrm{C}$ (Gibbons citado por Baccari, 2001).

\subsubsection{Freqüência respiratória}

$\mathrm{Na}$ defesa contra o estresse pelo calor, os bovinos recorrem a mecanismos adaptativos fisiológicos de perda de calor corporal para tentar evitar a hipertermia. Assim, aumentam a freqüência respiratória (FR), apresentando taquipnéia, como complemento ao aumento da taxa de produção de suor (taxa de sudorese), constituindo ambos, importantes meios de perda de calor do corpo por evaporação (termólise evaporativa respiratória e cutânea). A taquipnéia é o primeiro sinal visível como resposta ao estresse pelo calor, embora se situe em terceiro lugar na seqüência 
dos mecanismos de adaptação fisiológica, pois a vasodilatação periférica e o aumento da sudorese ocorrem previamente (Baccari, 2001).

A perda de calor pelo trato respiratório, assim como pela pele, implica em um processo de mudança de estado físico, de líquido para vapor, o que ocorre com o ar umedecido nas vias respiratórias superiores, assim como com o suor. Tal processo se torna possível devido ao calor latente de vaporização. O gasto de energia dispendido pelas vacas para eliminar calor do corpo, principalmente pelo aumento da freqüência respiratória e, também, pelo trabalho das glândulas sudoríparas para produzir mais suor, é um dos fatores que explica a menor produção de leite sob estresse térmico, pois parte da energia do organismo é desviada do processo produtivo para a manutenção do equilíbrio fisiológico (homeostase) (Baccari, 2001).

Segundo Hahn et al., citados por Martello et al. (2002), a freqüência de 60 mov.min. ${ }^{-1}$ indica animais com ausência de estresse térmico ou que este é mínimo; mas quando ultrapassam 120 mov. min. ${ }^{-1}$, refletem carga excessiva de calor e, acima de 160 mov.min. ${ }^{-1}$, medidas de emergência devem ser tomadas, como, por exemplo, molhar os animais.

\subsubsection{Temperatura da pele}

A pele protege o organismo do calor e do frio e sua temperatura depende, principalmente, das condições ambientes de temperatura, umidade e vento e das condições fisiológicas, como a vascularização e a evaporação do suor. Assim contribui para a manutenção da temperatura corporal mediante trocas de calor com o ambiente. Em temperaturas mais amenas, os bovinos dissipam calor para o ambiente, através da pele, por radiação, condução e convecção, ou seja, ocorre a perda de calor sensível. Sob estresse pelo calor, as perdas sensíveis são diminuídas, e o principal processo de perda de calor é o da evaporação. Segundo Martello et al. (2002), a temperatura da pele de vacas Holandesas alojadas em instalações climatizadas pode variar de $31,6^{\circ} \mathrm{C}$ (æ̀ 6 h) a 34,7ํㅡ (æ̀ 13 h), sem indicar que o animal está sofrendo estresse por calor.

\subsubsection{Mensuração da te mperatura da pele}


Todos os corpos com temperatura superior a $0 \mathrm{~K}$ emitem energia. $\mathrm{A}$ energia emitida aumenta à medida que a temperatura do objeto aumenta. Esse fato permite que se possa fazer medições de temperatura a partir de medições da energia emitida, particularmente se essa energia for infravermelha ou visível (Ampéres Automation, 2003).

A amplitude (intensidade) de energia radiada pode ser expressa como função do comprimento de onda a partir da Lei de Planck. A Figura 2 representa as curvas de emissão de energia a temperaturas diferentes. A área sob cada curva representa o total da energia radiada a essa temperatura.

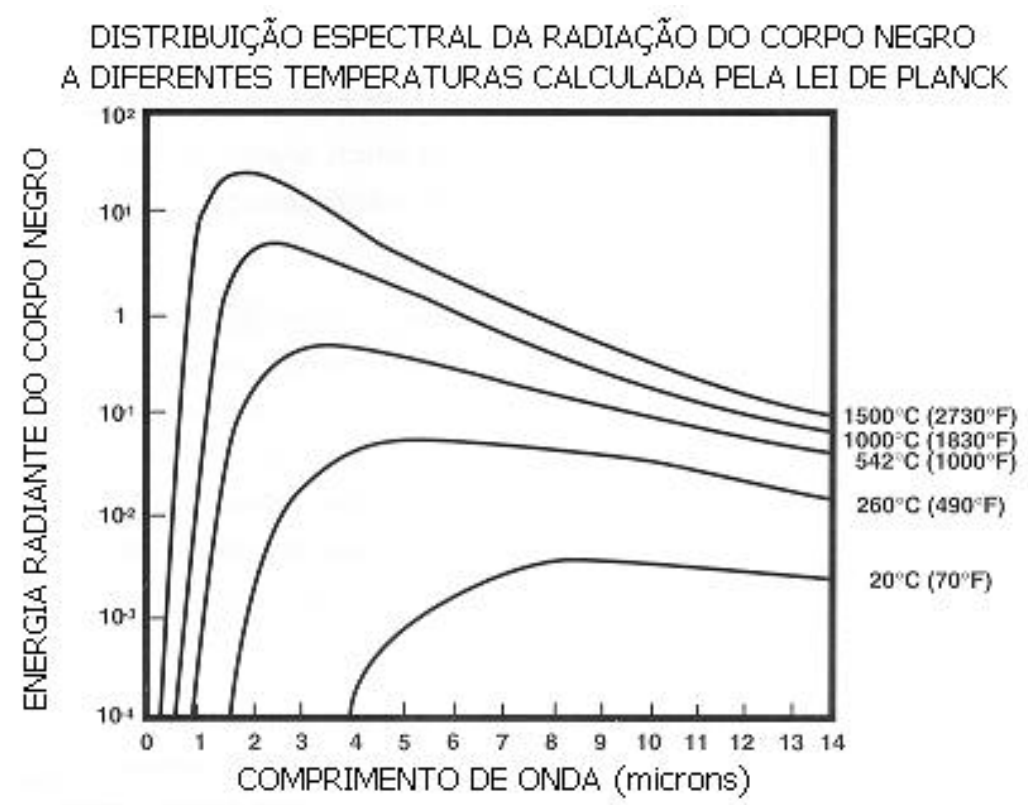

Figura 2 - Distribuição espectral da radiação do corpo negro a temperaturas diferentes a partir da Lei de Planck

À medida que a temperatura aumenta, constatam-se dois fatos: a amplitude da curva aumenta, aumentando a área; e o ponto de maior energia desloca-se para valores de comprimento de ondas menores. Essa relação é descrita pela Lei do Deslocamento de Wien: $(\lambda$ máx $/ \mathrm{m})=2,89 \times(\mathrm{T} / \mathrm{K})^{\wedge} 3$

Um conceito importante é a emissividade $(E)$, ou seja, o quociente entre a energia que um corpo radia a uma dada temperatura e a energia que o corpo negro radia a essa mesma temperatura. $\mathrm{A}$ emissividade do corpo negro é, então, igual a 1. Para corpos reais, a emissividade está compreendida entre 0 e 1. Assim, a 
emissividade mede a capacidade de um corpo emitir energia. Analogamente, define-se a refletividade $(R)$ que mede a capacidade de um corpo refletir energia, a transmissividade $(\mathrm{T})$ que mede a capacidade de um corpo transmitir energia, e a absorvidade $(A)$ que mede a capacidade de um corpo absorver energia. A relação entre $A, R$ e $T$ é de complementaridade: $A+R+T=1$

$\mathrm{Na}$ prática, os valores habituais são $A=70 \%, R=20 \%, T=10 \%$. Se um objeto estiver em estado de equilíbrio térmico, então a energia que está a absorver é igual à energia que está a emitir $(A=E)$. Tem-se então a relação: $E+R+T=1$

Porém, a energia recebida pelo sensor pode não refletir a verdadeira temperatura do objeto. A refletividade $R$ e a transmissividade $T$ são conceitos associados ànatureza do objeto (opaco ou translúcido) e æ̀s condições atmosféricas na zona entre sensor e objeto. A superfície ideal para efetuar medições de temperatura seria então o corpo negro, isto é, um objeto com $E=1$ e $R=T=0$. Na prática, contudo, a maioria dos corpos são corpos cinzentos (têm a mesma emissividade em todos os comprimentos de onda) ou corpos não-cinzentos (a emissividade varia com o comprimento de onda/temperatura):

Os instrumentos de medição de temperatura dividem-se em duas classes, segundo Ampéres Automation (2003):

a) instrumentos nos quais o elemento de medição está em contato com o corpo cuja temperatura se quer medir (transferência de calor por condução). Como exemplo têm-se os termômetros àdilatação de líquido, àdilatação de gás, àpar termoelétrico etc.;

b) instrumentos em que o elemento sensível não está em contato com o corpo cuja temperatura se quer medir (transferência de calor por radiação). Neste grupo têm-se os pirômetros àradiação e os pirômetros ópticos.

Um pirômetro funciona através da captação, por uma lente, da radiação emitida por um corpo quente, que aquece um elemento sensível àtemperatura (Figura 3). 


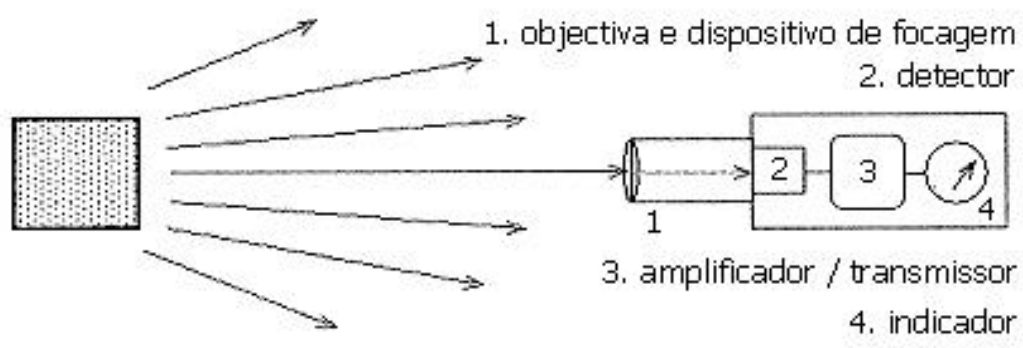

Figura 3 - Esquema genérico de um pirômetro de radiação

Existem vários tipos de pirômetros de radiação que se enquadram em duas classes: pirômetros de banda larga e pirômetros de banda estreita. No primeiro, usa-se uma relação exponencial entre a energia total da radiação emitida e a temperatura. No segundo, usa-se a variação da emissão de energia de radiação monocromática com a temperatura.

Dentro dos pirômetros de banda larga encontram-se os pirômetros de radiação total e infravermelho. Nesses aparelhos, a radiação proveniente de um objeto é coletada pelo espelho esférico e focada num detector de banda larga $D$, que emite um sinal, que é função da temperatura. O valor de temperatura indicado é um valor médio da temperatura dos corpos que se encontram dentro do seu campo de visão, sendo, portanto, a sua abertura uma característica importante, como pode ser visto na Figura 4.

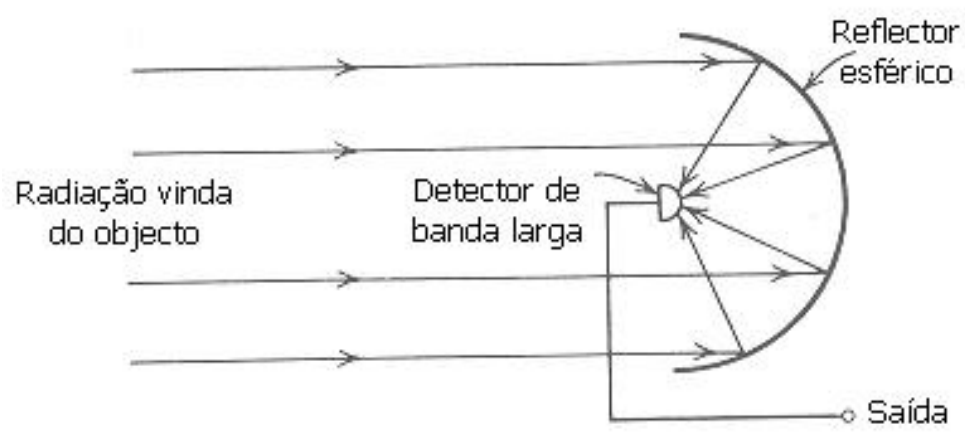

Figura 4 - Esquema de funcionamento de pirômetros de radiação total e infravermelho

$\mathrm{Na}$ prática, as medições de temperatura a distância devem ser feitas em ambientes em que a atmosfera seja "transparente" $(R=0)$, e ajustando a resposta espectral do sensor a uma banda de comprimentos de onda na qual o objeto seja 
opaco ( $\mathrm{T}=0$ ). Se, por exemplo, um objeto tiver $\mathrm{E}=0,7$ então ele só estará emitindo $70 \%$ da energia disponível, pelo que o pirômetro indicaria uma temperatura inferior àreal. Por isso, os pirômetros estão equipados com um mecanismo que ajusta a amplificação do sinal do sensor de modo a corrigir essa perda de energia (Ampéres Automation, 2003).

\subsection{Respostas Comportamentais}

Os animais se comportam segundo determinados padrões. Esses padrões são definidos como um segmento organizado de atitudes que possui uma função especial. Pode ser um ato único ou uma série de atividades e usualmente representam uma resposta do animal a algum estímulo ambiental. Uma dada alteração ambiental estimula mais que uma resposta comportamental, mas o animal aprende a usar aquela que mostra ser mais eficiente. Os animais exibem seus padrões de comportamento ciclicamente, uma vez que estes ocorrem em respostas aos desafios externos e internos, muitos dos quais seguem ciclos regulares (Curtis, citado por Pires et al., 1998b).

O estresse calórico pode ser evidenciado pelas alterações no comportamento do animal. Em alguns casos, mudanças nos padrões do comportamento são as únicas indicações de que o estresse está presente (Pires et al., 1998a).

\subsubsection{Consumo de alimento}

As vacas apresentam respostas ao estresse calórico que merecem destaque, como a redução da ingestão de alimentos. Essa reação, relacionada diretamente ao nível metabólico e à produção de calor, é a grande responsável pela redução na produção de leite, como pode ser observado na Tabela 3. 
Tabela 3. Valores médios de vaca européia em ambiente confortável e aquecido

\begin{tabular}{lcc}
\hline \multicolumn{1}{c}{ VARIAVEL } & $\mathrm{A} 18^{\circ} \mathrm{C}$ & $\mathrm{A} 30^{\circ} \mathrm{C}$ \\
\hline Produção de calor metabólico (kcal/hora) & 841 & 629 \\
Temperatura retal $\left({ }^{\circ} \mathrm{C}\right)$ & 38,6 & 39,9 \\
Freqüência respiratória (movim./min.) & 32 & 94 \\
Consumo de água $(\mathrm{kg} / \mathrm{dia})$ & 57,9 & 74,7 \\
Taxa de sudação $\left(\mathrm{g} / \mathrm{m}^{2} / \mathrm{h}\right)$ & 94,6 & 150,6 \\
Taxa respiratória $\left(\mathrm{g} / \mathrm{m}^{3} / \mathrm{h}\right)$ & 60,6 & 90,9 \\
Consumo de concentrados $(\mathrm{kg} / \mathrm{dia})$ & 9,7 & $9,2(-5,1 \%)$ \\
Consumo de feno $(\mathrm{kg} / \mathrm{dia})$ & 5,8 & $4,5(-22,4 \%)$ \\
Produção de leite $(\mathrm{kg} / \mathrm{dia})$ & 18,4 & $15,7(-14,6 \%)$ \\
Massa corporal $(\mathrm{kg})$ & 486 & 482 \\
\hline
\end{tabular}

Fonte: Adaptado de Mcdowell, citado por Titto et al.,1998.

Experimentos realizados na Embrapa Gado de Leite, com vacas Holandesas, confinadas em 'freestall', mostraram que, num período de observação referente a três anos, o tempo médio despendido com alimentação foi de $5 \mathrm{~h}$ e 10 min no inverno, e $4 \mathrm{~h}$ e 25 min no verão. Considerando o tempo total de $24 \mathrm{~h}$, esses animais permaneceram $21 \%$ desse tempo alimentando-se, no inverno, e 18\% no verão (Pires et al., 1998b)

Em um experimento conduzido por Frazzi \& al. (1998), em que os animais permaneciam sob ambiente climatizado durante os meses mais quentes do ano (julho a setembro), foram verificadas diferenças no comportamento dos animais que receberam o tratamento. Os animais permaneceram por longos períodos descansando nas camas do "freestall" ou nas áreas adjacentes aos cochos de alimentação, semelhante ao que ocorre, quando as temperaturas são mais amenas. Sob condição de estresse, os animais tendem a permanecer no interior do "freestall" nas horas mais quentes do dia para obter abrigo dos raios solares. Sob estresse térmico, os animais permanecem por muito mais tempo em pé que deitados e reduzem as atividades físicas (permanência de mais tempo em ócio).

\subsubsection{Consumo de água}

Uma das formas de defesa dos animais contra as temperaturas elevadas é a ingestão de água. $\mathrm{O}$ organismo dos animais é constituído em peso por, 
aproximadamente, $2 / 3$ de água. Tal fato mostra a importância da presença da água em todos os processos vitais e a necessidade de oferecêla em quantidade suficiente e qualidade desejável, qualquer que seja o tipo de criação (Macari, 1995).

A água, por apresentar elevado calor específico, pode absorver o calor liberado na reação de queima de carboidratos e gordura. Além disso, evapora-se rapidamente, removendo muitas unidades calóricas do organismo. A água é o nutriente necessário em maior quantidade e possui propriedades físicas que lhe permitem atuar como meio de transporte para os demais nutrientes e produtos do metabolismo, além de intensificar as reaç ões celulares (Sguizzardi, 1979). A água ingerida pelos bovinos tem a função de nutrir o tecido celular e a de compensar as perdas ocorridas pelo leite, fezes, urina, saliva, evaporação (suor e respiração), atuando também na manutenção da homeotermia, regulando a temperatura do corpo e dos órgãos internos (Campos, 2000).

Vacas em lactação necessitam de mais água em relação a seu peso vivo do que as outras categorias de animais, pois o leite contém $87 \%$ de água. Para se ter uma idéia da real importância desse líquido, o corpo do gado adulto apresenta de 55\% a $70 \%$ deste elemento, chegando essa porcentagem a $80 \%$ a $85 \%$ no animal jovem e até $90 \%$ no recém-nascido. Os animais podem perder até $100 \%$ de seu tecido adiposo (gordura) e mais de $50 \%$ de sua proteína corporal que eles sobrevivem, mas, perdendo de 10 a 12\% de sua água corporal, chegam a óbito (Campos, 2000).

O consumo de água por vaca em lactação depende de vários fatores: estado fisiológico, produção de leite, peso corporal, raça, consumo de matéria seca, composição da dieta, ambiente, clima e qualidade da água. Durante os meses mais quentes, as vacas sofrem estresse pelo calor e pela elevação da umidade relativa do ar, aumentando o consumo de água, com elevação na excreção de urina e alterando a composição dos dejetos. O hábito no consumo de água segue o de consumo de alimento, sendo que o pico de consumo coincide com o pico de consumo de matéria seca, mesmo quando o alimento é oferecido várias vezes por dia. Picos de consumo são também observados após as ordenhas, quando podem representar $40 \%$ a $50 \%$ do consumo total diário (Campos, 2000).

O animal dispõe de mecanismos para combater o excesso de temperatura, como o aumento da freqüência respiratória, sudação, redução da ingestão de alimentos, aumento da ingestão de água e diminuição da atividade nas horas mais 
quentes do dia. $\mathrm{O}$ aumento na ingestão de água em condições de estresse calórico visa à reposição das perdas sudativas e respiratórias, além de um possível resfriamento corporal, através do contato da água, mais fria que o corpo, com as mucosas do trato digestivo (Titto et al., 1998). Segundo Degaspari \& Piekarski, 1998, as vacas em lactação necessitam um acréscimo na ingestão diária, de acordo com a produção. Na produção de leite, são necessários $4-5$ litros de água para cada quilo a ser produzido.

O consumo de água por vacas Holandesas em diferentes temperaturas ambientes e em diferentes estágios de produção pode ser visto na Tabela 4.

Tabela 4. Consumo de água por vacas Holandesas em diferentes temperaturas ambientes e em diferentes estágios de produção

\begin{tabular}{lccc}
\hline Temperatura $\left(^{\circ} \mathrm{C}\right)$ & 10 & 21 & 32 \\
\hline \multicolumn{1}{c}{ Estágio de produção } & & Consumo de água & \\
Secas de $635 \mathrm{~kg}$ & 25 & 31 & 33 \\
Final de lactação & 37 & 48 & 55 \\
Produzindo $18 \mathrm{~kg} /$ dia & 65 & 81 & 100 \\
Produzindo $36 \mathrm{~kg} /$ dia & 103 & 130 & 170 \\
Fonte: Agrodata Vídeo, 1998. & &
\end{tabular}

Pode-se observar, através da Tabela 4, que o consumo de água aumenta proporcionalmente ao aumento da temperatura ambiente e ao aumento da produção de leite.

\subsubsection{Ruminação}

A ruminação é uma atividade que permite a regurgitação, mastigação e passagem do alimento previamente ingerido, para o interior do rúmen. $O$ tempo total de ruminação pode variar de $4 \mathrm{~h}$ a $9 \mathrm{~h}$, sendo divididos em períodos com duração de poucos minutos a uma hora ou mais (Fraser \& Broom, citados por Pires et al., 1998b).

Dentre os fatores que prejudicam a ruminação, pode-se citar pânico, raiva, ansiedade, doença ou clima. Segundo Shultz, citado por Pires et al. (1998b), observou- 
se uma maior porcentagem de vacas ruminando no inverno $(25,2 \%)$, seguido da primavera $(22,6 \%)$ e verão $(21,9 \%)$.

\subsection{4 Ócio}

O período em que os animais não estão comendo, ruminando ou ingerindo água, é definido como ócio. Vacas em lactação, confinadas em "freestall", permanecem mais tempo em ócio no período de verão (10 h e $35 \mathrm{~min}$ ), quando comparado com o inverno ( $9 \mathrm{~h}$ e $33 \mathrm{~min}$ ), mostrando que, no verão, os animais substituem atividades relacionadas com o comportamento alimentar (ingestão e ruminação) pelo ócio, numa provável tentativa de reduzir a produção de calor metabólico (Pires et al., 1998b).

\section{6 Índices de conforto térmico}

Foram desenvolvidos, para caracterizar ou quantificar as zonas de conforto térmico adequadas æ̀̀ diferentes espécies animais, apresentando em uma única variável, tanto os fatores que caracterizam o ambiente térmico que circunda o animal, como o estresse que tal ambiente possa estar causando no mesmo. No desenvolvimento de um índice de conforto térmico levam-se em conta os fatores meteorológicos relevantes para a criação de certo animal e ressalta-se o peso que cada fator possui dentro desse índice, conforme sua importância relativa também ao animal.

As respostas dos animais ao estresse térmico são fisiológicas e comportamentais, variando de espécie para espécie e dentro da espécie, na qual variam conforme o estágio de desenvolvimento do animal. Devido a essas variações, os índices desenvolvidos para determinada espécie e fase de crescimento, em determinado ambiente físico, nem sempre podem ser aplicados a outros animais nem utilizados em regiões com características climáticas diferentes das do local de origem do índice.

\subsubsection{Classificação dos índices de conforto}


Segundo Nääs, (1998) os índices de conforto podem ser classificados de acordo com a maneira com que foram desenvolvidos em:

- índices biofísicos: seu desenvolvimento é baseado nas trocas de calor entre o corpo e o ambiente, correlacionando os elementos de conforto com as trocas de calor que os originam.

- $\quad$ índices fisiológicos: baseiam-se nas relações fisiológicas originadas por condições conhecidas de temperatura ambiente, temperatura radiante média, umidade do ar e velocidade do ar.

- índices subjetivos: são baseados nas sensações subjetivas de conforto experimentadas em condições em que os elementos de conforto térmico variam.

\subsection{2 Índices para bovinos}

\subsubsection{1 Índice de Temperatura e Umidade (TH) (Johnson, 1987)}

Foi desenvolvido, inicialmente, para humanos, mas observou-se que as mesmas variáveis psicrométricas causadoras do desconforto térmico em humanos também causam certo desconforto em vacas leiteiras, o que pode acarretar decréscimos na produção de leite. De acordo com Buffington et al. (1981), este índice de conforto é o mais comum existente, sendo desenvolvido originalmente por Thom (1958). A equação para o cálculo deste índice é dada por:

$$
\mathrm{THI}=\mathrm{Tbs}+0,36 \mathrm{Tpo}+41,7
$$

em que:

Tbs - temperatura de bulbo seco, ${ }^{\circ} \mathrm{C}$;

Tbu - temperatura de bulbo úmido, ${ }^{\circ} \mathrm{C}$;

Tpo - temperatura de ponto de orvalho, ${ }^{\circ} \mathrm{C}$.

Um THI igual ou menor a 70 expressa uma condição normal; um valor entre 71 e 78 é crítico; entre 79 e 83 , a situação é de perigo e, acima de 83 , uma situação de emergência está presente (Hahn, 1982). Porém, é preciso levar-se em consideração 
que, quanto mais especializado for o animal, maior será sua sensibilidade ao desconforto térmico.

\subsubsection{2 Índice de Umidade e Temperatura de Globo (BGHI) (Buffington \& al., 1981)}

Foi desenvolvido como um índice de conforto térmico para vacas leiteiras expostas a ambientes com radiação solar direta e indireta.

Este índice integra a temperatura de bulbo seco, umidade, nível de radiação e movimentação do ar. A equação que descreve o BGHI é:

$$
\mathrm{BGHI}=\mathrm{Tg}+0,36 \mathrm{Tpo}+41,5
$$

Onde:

- $\mathrm{Tg}=$ temperatura do termômetro de globo negro, $\stackrel{\circ}{ } \mathrm{C}$;

- $\quad$ Tpo $=$ temperatura do ponto de orvalho, ${ }^{\circ} \mathrm{C}$.

Temperaturas retais e taxa respiratória de vacas leiteiras são diretamente relacionadas com o $\mathrm{BGHI}$, enquanto a produção de leite e a eficiência reprodutiva estão inversamente relacionadas.

\subsubsection{Entalpia}

O conhecimento das condições de umidade e temperatura do ar é de grande importância. Além do conforto térmico, que depende mais da quantidade de vapor presente no ar do que propriamente da temperatura, outros ramos da atividade humana, como, por exemplo, a conservação de alimentos em câmaras frigoríficas, dependem da manutenção da umidade relativa adequada no ambiente (Martinelli Jr, 2000).

Por definição, ar seco é a mistura dos gases que constituem o ar atmosférico com exclusão do vapor d'água, isto é, quando todo o vapor d'água e os contaminantes são removidos do ar atmosférico. A mistura ar seco - vapor d'água é denominada de ar úmido ou de mistura binária de ar seco e vapor d'água. A quantidade de vapor d'água presente na mistura pode variar de zero até um valor correspondente à 
condição de saturação. Isso corresponde àquantidade máxima de vapor d'água que o ar pode suportar em determinada condição de temperatura (Martinelli Jr, 2000).

Diversas propriedades termodinâmicas fundamentais estão associadas ̀̀s propriedades do ar úmido de maneiras diferentes. Três propriedades estão associadas àtemperatura: temperatura do bulbo seco (Tbs), temperatura termodinâmica do bulbo úmido (Tbu) e temperatura do ponto de orvalho (To). Algumas propriedades termodinâmicas caracterizam a quantidade de vapor d'água presente no ar úmido: pressão de vapor $(\mathrm{Pv})$, razão de umidade $(\mathrm{x})$, umidade relativa $(\varphi)$ e grau de saturação $(\mu)$. Outras propriedades de fundamental importância, relacionadas com o volume ocupado pelo ar e com a energia do ar, respectivamente, são o volume específico $(v)$ e a entalpia (h) (Martinelli Jr, 2000).

A entalpia e o volume específico são propriedades da mistura ar seco - vapor d'água, mas, por conveniência, são expressas com base em uma unidade de massa de ar seco.

A entalpia da mistura ar seco - vapor d'água (h) é a energia do ar úmido por unidade de massa de ar seco ( $\mathrm{kJ} . \mathrm{kg}$ de $\operatorname{ar}$ seco $^{-1}$ ), acima de uma temperatura de referência. Na prática, a temperatura de referência utilizada para o cálculo da entalpia é $\circ 0^{\circ} \mathrm{C}$, de tal forma que o conteúdo de energia do ar seco a essa temperatura é considerado zero (Martinelli Jr, 2000).

A equação para o cálculo da entalpia foi descrita por Villa Nova (1999), citado por Furlan (2001), como:

$$
H=6,7+0,243 \times t+\left\{U R / 100 \times 10^{\wedge}[(7,5 \times t) /(237,3+t)]\right\}
$$

onde:

$\mathrm{H}=$ entalpia $\left(\mathrm{kcal} / \mathrm{kg}\right.$ ar $\left.\mathrm{seco}^{-1}\right)$;

$\mathrm{t}=$ temperatura ambiente (bulbo seco) $\left({ }^{\circ} \mathrm{C}\right)$;

$\mathrm{UR}=$ umidade relativa do ar (\%).

Entalpia é uma variável física que indica a quantidade de energia contida em uma mistura de vapor d'água. Portanto, nos casos de mudança de umidade relativa, para uma mesma temperatura, a energia envolvida nesse processo se altera, e, conseqüentemente, a troca térmica que ocorre no ambiente também sofre alteração (Nääs et al., citados por Martello et al.,2002). 


\subsection{Controle do ambiente}

Dentre os problemas estratégicos ligados à produção animal, encontra-se o projeto das instalações para o confinamento dos animais. Em alguns casos, esse item pode ser responsável pelo insucesso do sistema produtivo, sendo assim seu estudo de fundamental importância.

Devido às diferenças climáticas existentes entre os diferentes países, e até mesmo entre suas regiões, os sistemas e a tecnologia existentes devem ser adaptados às condições locais. Segundo Silva (1999), não há um pacote que possa ser usado em todos os países, nem em todo o território nacional, pois devem ser considerados a raça dos animais, a fase de desenvolvimento, o nível tecnológico, o nível de produção, as características climáticas e de relevo das regiões, os sistemas e instalações já existentes, entre outros. Outro ponto importante é a antecipação dos problemas, evitando-se que se recorra a soluções somente na época mais crítica do ano, porém, em algumas áreas, o controle é necessário durante todo o ano, embora o calor se acentue no verão.

O controle eficiente do ambiente pode empregar sistemas naturais e artificiais (Silva, 1999). Métodos de controle naturais envolvem arborização ao redor das instalações, galpões abertos, altura adequada do pé direito, escolha adequada do local, orientação longitudinal da instalação na direção leste-oeste, cobertura reflectiva, beirais amplos e presença de lanternim. Já os mecanismos artificiais, se referem, basicamente, a sistemas de resfriamento adiabático evaporativo (SRAE), ou seja, sistemas mecânicos para redução da temperatura do ambiente com a utilização de vapor d'água como elemento de refrigeração. A água é um excelente agente resfriador devido a sua alta capacidade calórica e ao elevado calor latente de vaporização (Silva, 1999).

\subsection{Resfriamento evaporativo}

O resfriamento evaporativo é, essencialmente, um processo de saturação adiabática (não há perda nem ganho de calor), que tem seqüência ao longo de uma linha de temperatura de bulbo úmido constante no gráfico psicrométrico (Figura 5). 0 ponto referente ao estado A representa o ar não saturado na fase inicial de 
acionamento do SRAE. Se houvesse saturação, o ponto se deslocaria até B; entretanto isso não ocorre devido à eficiência dos sistemas, deslocando-se somente até C. Neste processo, a temperatura do bulbo úmido permanece constante, mas ocorre redução na temperatura do bulbo seco com conseqüente aumento na umidade relativa.

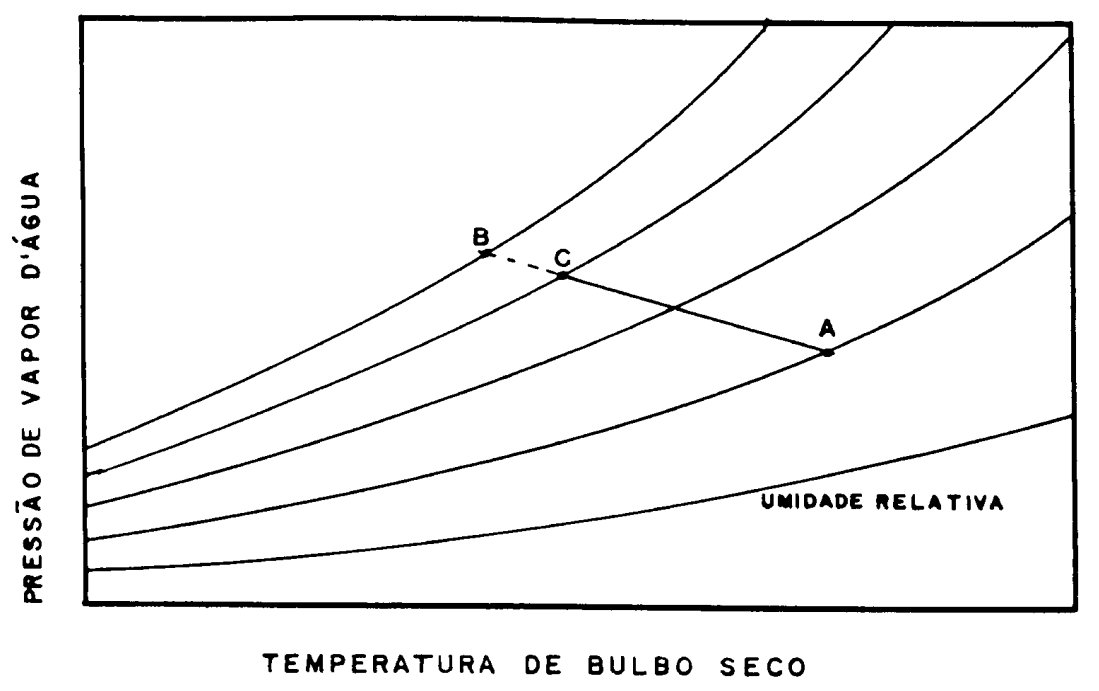

Figura 5 - Desempenho do resfriamento adiabático evaporativo mostrado pelo gráfico psicrométrico (Silva, 1998)

O ar a ser resfriado é posto em contato com água em temperatura igual à temperatura de bulbo úmido do ar. O calor sensível do ar inicialmente evapora a água, abaixando a temperatura de bulbo seco do ar e sendo convertido em calor latente no vapor adicionado (Baêta \& Souza, 1997 e Abreu et al., 1999).

Nenhum calor externo é adicionado durante o processo, e o conteúdo total de calor não varia. Há simplesmente uma mudança adiabática de calor sensível para calor latente. Há, porém, uma alteração ambiental a partir da mudança de estado da água e da mudança na temperatura da mistura ar-vapor, que melhora de forma considerável as condições de conforto. Ao passar do estado líquido para o gasoso, a água retira do ambiente cerca de $584 \mathrm{kcal}$ para cada $\mathrm{kg}$ de água evaporada, dependendo da temperatura do ambiente (Silva, 1998).

O sistema de resfriamento adiabático evaporativo (SRAE) pode ser aplicado em diversos mecanismos: nebulização, microaspersão e aspersão nos animais ou telhados, conseguindo-se reduções de até $6^{\circ} \mathrm{C}$ na temperatura interna das instalações 
(em climas secos). Porém, há um problema relacionado a regiões com alta umidade relativa, onde o acionamento do sistema deve ser intermitente, evitando excessiva umidade relativa, também prejudicial aos animais (Silva, 1999).

Os sistemas de resfriamento evaporativo são agrupados em "misting" (nebulização de baixa a média pressão), 'fogging" (nebulização de alta pressão) e "sprinkling" (aspersão). A diferença entre os sistemas "misting" e "fogging" é basicamente o tamanho das gotas.

\subsubsection{Sistema de nebulização e sua influência no animal}

O sistema "fogging" é o método mais eficiente de resfriamento do ar pelo menor tamanho das gotas, porém é mais caro do que o "misting" e requer maior manutenção. Nos sistemas de nebulização, pequenas gotas de água são aspergidas no ar, resfriando-o, ao evaporarem. Quando o animal inala o ar resfriado, há troca de calor com o ar mais fresco e conseqüentemente remoção de calor do corpo. A grande vantagem do sistema de nebulização em relação à aspersão é que, quando bem ajustado, mantém o piso seco (Bucklin \& Bray, 1998).

Um nebulizador bem calibrado, com água limpa, é capaz de dividir uma gota d'água em aproximadamente 611 gotículas com diâmetro de 0,5 milímetros, possibilitando um aumento da área de abrangência do sistema (Marques, 1992).

A linha de nebulização deve ser instalada separadamente da linha de ventilação, o que promove maior movimentação de ar, e a uma altura razoável (aproximadamente três metros). Maiores eficiências são encontradas em nebulização com alta pressão ("fogging"), em que o tamanho das gotículas é reduzido, aumentando a área coberta com o mesmo volume de calda e também o tempo em que a mesma permanecerá flutuando antes de atingir o solo, favorecendo a evaporação. Há necessidade de dimensionamento para cada tipo de instalação, calculando-se tamanho e número de bicos, número de linhas, posicionamento das linhas e cálculo da intermitência de funcionamento do sistema, evitando o aumento excessivo da umidade relativa do ar. A instalação aleatória pode causar aumento da umidade relativa, prejudicando os animais (Silva, 1999).

Estudos conduzidos na Flórida por Bray et al. (1994) mostraram um aumento de $11,7 \%$ na produção de leite de vacas estabuladas em "freestall" climatizado com 
ventiladores e nebulizadores. O sistema foi montado em cima do cocho de alimentação. A ventilação foi contínua, com uma velocidade do ar de $3 \mathrm{~m} \cdot \mathrm{s}^{-1}$, e controlada por um termostato que a fazia parar quando a temperatura atingia $22,2^{\circ} \mathrm{C}$. Os nebulizadores se localizaram abaixo dos ventiladores, sendo dimensionados para não molhar a cama, sendo controlados por um termostato e por um timer, que os acionavam a intervalos de $1,5 \mathrm{~min}$ a cada $15 \mathrm{~min}$, quando a temperatura se encontrava

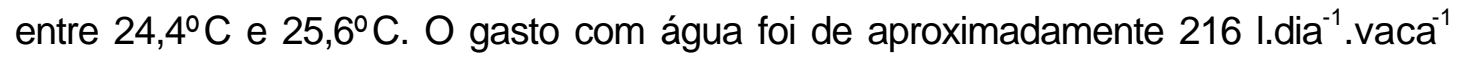
para o sistema de resfriamento, proporcionando resultados satisfatórios. Porém, a escolha adequada dos bicos e do intervalo de tempo de aplicação da nebulização pode diminuir o gasto com água para 70,7 I.vaca $^{-1} \cdot$ dia $^{-1}$, mantendo um adequado resfriamento para as vacas.

Armstrong \& Welchert (1994) observaram um aumento na produção em leite de vacas submetidas ao sistema de resfriamento adiabático evaporativo, usando ventilação associada à nebulização dentro do "freestall", em clima semi-árido e com umidade relativa do ar em aproximadamente 30\% (Tabela 5).

De acordo com a Tabela 5, a utilização de sistemas de acondicionamento térmico em instalações, com a finalidade de manter o conforto térmico de vacas leiteiras, proporciona ganhos em produção mais significativos, quando se utilizam animais mais especializados e quando o ambiente se encontra a temperaturas mais elevadas (Armstrong \& Welchert, 1994). 
Tabela 5. Aumento na produção de leite de vacas em diferentes estágios de lactação submetidas àventilação associada ànebulização dentro do "freestall"

\begin{tabular}{|c|c|}
\hline $\begin{array}{l}\text { Diferentes estágios de produção e } \\
\text { diferentes temperaturas diárias }\end{array}$ & $\begin{array}{c}\text { Aumento na produção } \\
\text { de leite (\%) }\end{array}$ \\
\hline \multicolumn{2}{|l|}{ Animais com produção $>38,5 \mathrm{~kg}$} \\
\hline$+40,5^{\circ} \mathrm{C}$ & 4 \\
\hline $35-40^{\circ} \mathrm{C}$ & 3,2 \\
\hline$+34,5^{\circ} \mathrm{C}$ & 2,8 \\
\hline \multicolumn{2}{|l|}{ Animais com produção entre 29,5 e $38,5 \mathrm{~kg}$} \\
\hline$+40,5^{\circ} \mathrm{C}$ & 3,5 \\
\hline $35-40 \div \mathrm{C}$ & 2,8 \\
\hline $\begin{array}{l}+34,5^{\circ} \mathrm{C} \\
\text { Animais com produção }<29,5 \mathrm{~kg}\end{array}$ & 2,5 \\
\hline$+40,5^{\circ} \mathrm{C}$ & 3,2 \\
\hline $35-40^{\circ} \mathrm{C}$ & 2,6 \\
\hline \multicolumn{2}{|c|}{ Produção de leite nos 120 dias da lactação (total kg leite) } \\
\hline$+40,5^{\circ} \mathrm{C}$ & $1,4(168)$ \\
\hline $35-40^{\circ} \mathrm{C}$ & $0,9(108)$ \\
\hline$+34,5^{\circ} \mathrm{C}$ & $0,6(72)$ \\
\hline
\end{tabular}

Fonte: Armstrong \& Welchert, 1994.

\subsubsection{Sistema de aspersão e sua influência no animal}

A aspersão não tem a finalidade de resfriar o ar, pois usa gotas largas para molhar o pêlo e a pele das vacas. O animal se resfria com a evaporação da água da pele e dos pêlos, permitindo que o mesmo perca calor com mais eficiência do que quando se utiliza apenas o suor. A aspersão, quando associada àventilação natural ou forçada, aumenta a eficiência do resfriamento, por acelerar o processo de evaporação, e evita que a pulverização das gotas ocorra em um só local e molhe a cama (Bucklin \& Bray, 1998).

O sistema de resfriamento por aspersão/ventilação, quando é usado intermitentemente e o piso tem uma boa drenagem, evita o aumento de casos de mastite ou problemas respiratórios. Quando combinado ao sombreamento, reduz as perdas diárias da produção de vacas leiteiras em verões quentes e secos (Bucklin \& Bray, 1998). Em climas úmidos, a ventilação é usada para aumentar a taxa de 
evaporação para o ar da superfície da pele. Em climas com umidade menor, ou climas com verões bem ventilados, a própria ventilação natural pode ser suficiente para garantir a perda de calor dos animais por evaporação (Chastain \& Turner, 1994). Ittner et al., citados por Baêta \& Souza (1997), relataram que a movimentação do ar por ventiladores proporciona aumento significativo no ganho diário de peso de novilhas mestiças "Hereford". Porém, quando a temperatura do ar é excessivamente alta, a simples movimentação do ar por ventiladores não é efetiva na promoção do resfriamento.

Com o objetivo de reduzir a temperatura do ar ambiente, favorecendo as trocas sensíveis de calor, o SRAE visa a aumentar a dissipação de calor na forma evaporativa e convectiva. Muitos trabalhos de pesquisa mostraram os benefícios (devido ao aumento de consumo de alimento e conseqüente aumento de produção) do uso de sistemas de chuveiros ou aspersores sobre animais, associados à ventilação forçada de ar. Esse sistema é bastante eficaz porque aumenta a capacidade de perda de calor, através de evaporação e resfriamento. Além disso, ele pode ser posicionado em vários locais das instalações: sala de espera (antes da ordenha), área de alimentação, áreas de sombra, etc. (Bucklin et al., 1991).

Segundo Chastain \& Turner (1994), vacas submetidas àventilação associada à aspersão em local sombreado conseguem reduzir o efeito do estresse calórico na produção diária e apresentam um aumento de 7,8\% no consumo de alimento, um aumento de $12 \%$ na produção de leite $\left(2,5 \mathrm{~kg} \cdot \mathrm{dia}^{-1}\right)$, uma diminuição de $0,2^{\circ} \mathrm{C}$ a $0,5^{\circ} \mathrm{C}$ da temperatura retal e uma redução de $29 \%$ na taxa respiratória.

Para o controle do sistema de resfriamento, pode ser usado um termostato com um ajuste de tempo, que ativa o sistema, quando a temperatura chega a $25,6^{\circ} \mathrm{C}$. Quando a ventilação é utilizada, ela é continuamente empregada abaixo dessa temperatura. A aspersão é utilizada intermitentemente através de um timer, e os períodos de aspersão são de $1 \mathrm{~min}$ a $3 \mathrm{~min}$, quando a umidade do ar está baixa, seguidos de 4,5 min a $15 \mathrm{~min}$ de parada no sistema (Chastain \& Turner, 1994). Este

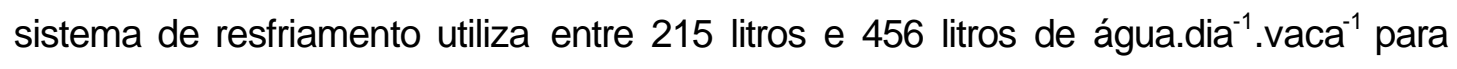
manter um conforto eficiente, e o uso de água aumenta em $84 \%$ o custo do sistema. A seguir, seguem algumas recomendações desses pesquisadores quanto àutilização do sistema de resfriamento: 
- a velocidade do ar promovida pelos ventiladores deve variar de $1 \mathrm{~m} \cdot \mathrm{s}^{-1}$ a 2,2 $\mathrm{m} \cdot \mathrm{s}^{-1}$, dependendo da direção do fluxo de ar.

- o sombreamento proporciona a obtenção do máximo benefício do resfriamento evaporativo direto, reduzindo o gasto de água do sistema em $26 \%$.

- o sistema não é recomendado para a redução da temperatura durante a noite. Para essas horas, apenas a ventilação é suficiente, proporcionando uma redução no uso diário de água.

- a duração do tempo do ciclo do resfriamento depende da umidade relativa, das condições de umidade da pelagem dos animais e da carga radiante total incidente no animal.

O grau de umedecimento das camadas da pele e pêlos dos animais, sob a chuva ou aspersão de água, depende das propriedades de repulsão de água daquelas camadas, especialmente do modo como protegem o corpo e da secreção sebácea que as cobrem (Blaxter, citado por Baccari, 1998). Como a capacidade de suar dos bovinos de origem européia é relativamente limitada, é aconselhável provê-los de um mecanismo artificial de sudorese, promovendo, artificialmente, o resfriamento evaporativo a partir da pele, levando à diminuição da temperatura corporal e estimulando o centro do apetite no hipotálamo. Em conseqüência, o animal ingere maior quantidade de alimentos, e a produção de leite esperada aumenta.

No sistema de aspersores sobre os animais, associados à ventilação, o tamanho das gotículas deve ser tal que promova umedecimento dos pêlos do animal; os aspersores devem possuir um raio de ação de $180^{\circ}$ e situados àdistância de $2,5 \mathrm{~m}$ entre si. Os ventiladores devem ser posicionados entre $3 \mathrm{~m} \mathrm{e} 4 \mathrm{~m}$ do solo e inclinados $20^{\circ}$ a $30^{\circ}$ para facilitar a circulação de ar no dorso dos animais. O sistema pode ser ligado automaticamente, quando a temperatura atinge valores acima de $27^{\circ} \mathrm{C}$ ( Head, 1995).

Segundo Bucklin et al. (1991), o resfriamento das vacas, através do uso de aspersores de água associados àventilação forçada, proporciona resultados benéficos com relação ao consumo de alimento, produção de leite, temperatura retal, temperatura do leite e respiração das vacas por minuto (Tabela 6).

Resultados positivos da aspersão de água, em locais sombreados para vacas holandesas, também foram obtidos no México (aspersão das $12 \mathrm{~h}$ æ̀ $13 \mathrm{~h}$ ) com aumento de 7\% na produção de leite; nos EUA, região de Missouri (aspersão das $11 \mathrm{~h}$ 
às $17 \mathrm{~h} 30$ min quando a temperatura excedeu $27^{\circ} \mathrm{C}$ ), com aumento de 700 gramas de leite.dia ${ }^{-1}$.vaca ${ }^{-1}$; e na Austrália (aspersão quando a temperatura excedeu $26^{\circ} \mathrm{C}$ ), com aumento de $4,8 \mathrm{~kg}$ de leite.dia ${ }^{-1} \cdot$ vaca $^{-1}$, sempre comparando-se a animais que não receberam a aspersão (Silva, 1999).

Tabela 6. Efeito do uso de aspersores de água e ventiladores no resfriamento de vacas leiteiras

\begin{tabular}{lccc}
\hline \multicolumn{1}{c}{ RESPOSTA } & CONTROLE & RESFRIADA & DIFERENÇA \\
\hline Consumo de alimento & kg / dia & kg / dia & $\%$ \\
Flórida (matéria seca) & 17,8 & 19,1 & 7,1 \\
Missouri (alimento) & 32,9 & 35,2 & 7,1 \\
Alabama (matéria seca) & 16,6 & 18,7 & 12,7 \\
Kentucky (alimento) & 35,0 & 38,2 & 9,2 \\
Produção de leite & & & \\
Flórida & 18,1 & 20,2 & 11,6 \\
Missouri & 23,4 & 25,5 & 8,6 \\
Israel & 33,1 & 35,5 & 7,1 \\
Alabama & 22,5 & 23,6 & 4,9 \\
Kentucky & 22,8 & 26,4 & 15,8 \\
Temperatura retal & $\circ \mathbf{C}$ & $\circ \mathbf{C}$ & $-\mathbf{C}$ \\
Missouri & 39,2 & 38,8 & $-0,4$ \\
Kentucky & 39,2 & 38,7 & $-0,5$ \\
Temperatura do leite & $\circ \mathbf{C}$ & $\circ \mathbf{C}$ & $\circ \mathbf{C}$ \\
Missouri & 39,1 & 38,6 & $-0,5$ \\
Respiração / minuto & & & \\
Florida & 96 & 57 & $-41 \%$ \\
Kentucky & 91 & 75 & $-18 \%$ \\
Alabama & 73 & 51 & $-30 \%$ \\
\hline Fona: Buckina
\end{tabular}

Fonte: Bucklin et al., 1991.

\subsubsection{Aspersão x nebulização e sua influência no animal}

A primeira medida a ser tomada, para oferecer instalações confortáveis em climas quentes e úmidos, para a maioria dos animais, é providenciar ventilação e sombra adequadas. Sistemas de refrigeração são necessários para se alcançar produções máximas, e os métodos evaporativos são eficientes e econômicos. Os sistemas de aspersão e de ventilação são muito efetivos e de baixo custo, mas 
provocam gastos adicionais de água e energia. Os sistemas de nebulização/ventilação também são efetivos, mas são muito dispendiosos e requerem manutenção mais constante, quando comparados aos sistemas de refrigeração por aspersão/ventilação. A maior vantagem do sistema de resfriamento nebulização/ventilação é que, quando bem ajustados, toda a água é evaporada, e não há desperdícios.

Pesquisas conduzidas por Frazzi et al. (1998) obtiveram os mesmos resultados de Lin et al. (1998), e concluíram que a utilização de sistemas de acondicionamento ambiental em instalações para vacas leiteiras proporciona a diminuição da temperatura retal, a redução da taxa respiratória, a melhora no rendimento produtivo e nas características do leite das horas mais quentes do dia, se comparadas com vacas de instalações que possuem apenas ventilação natural. Observou-se também que os animais procuram sombra nas horas mais quentes do dia. Em estábulos sem climatização, as vacas permanecem mais tempo deitadas e deixam a área de alimentação mais rápido, diminuindo o consumo de matéria seca como alternativa para diminuir a produção de calor metabólico, e conseqüentemente ocorre a diminuição da produção de leite. 


\section{MATERIAL E MÉTODOS}

\subsection{Local do experimento}

A pesquisa desenvolvida faz parte de uma linha de pesquisa na área de climatização em bovinos leiteiros, desenvolvida pelo Núcleo de Pesquisa em Ambiência - NUPEA - ESALQ/USP.

O experimento foi conduzido em rebanho leiteiro comercial de gado holandês no município de São Pedro, SP. O período experimental eve início no dia 01 de novembro e término no dia 28 de novembro de 2003. O município de São Pedro encontra-se na latitude $22^{\circ} 32^{\prime} 55^{\prime \prime}$ Sul e longitude 47 54' 50" Oeste, estando a cerca de $580 \mathrm{~m}$ altitude. Tem um clima CWA da classificação Koppen, ou seja, quente e úmido, com estação chuvosa no verão e seco no inverno. A temperatura média anual é de $22^{\circ} \mathrm{C}$, a pluviosidade média anual está próxima de $1200 \mathrm{~mm}$, e os ventos predominantes vêem do sudeste.

\subsection{Animais}

Foram utilizadas 20 vacas Holandesas multíparas, em lactação, com peso médio de $650 \mathrm{~kg}$. Os animais foram selecionados de acordo com a produção de leite (média de 20 litros animal $^{-1}$.dia ${ }^{-1}$ ) e dias de lactação (média de 180 dias), sendo então, divididos ao acaso em dois grupos de 10 animais, mantidos em abrigo do tipo "freestall', recebendo um tipo de climatização cada grupo. As vacas permaneceram durante todo o dia com livre acesso æ̀ baias e demais áreas do abrigo, mas sem acesso àpastagem. 
A fazenda possui cerca de 450 animais em lactação, tendo uma produção total de leite de aproximadamente 9000 litros por dia, que é vendido para diversas empresas de acordo com o preço. Utiliza-se inseminação artificial em todo o rebanho.

\subsection{Instalações}

O "freestall" utilizado possui $120 \mathrm{~m}$ de comprimento e largura total de $28 \mathrm{~m}$, tendo capacidade de alojar 240 animais adultos, divididos em quatro lotes com aproximadamente 60 animais cada. Possui aproximadamente $9 \mathrm{~m}$ de altura na parte central e 3,5 m nas laterais. O corredor central possui 2,92 m de largura e o telhado é coberto com telha de barro. A Figura 6 mostra a vista externa da instalação.

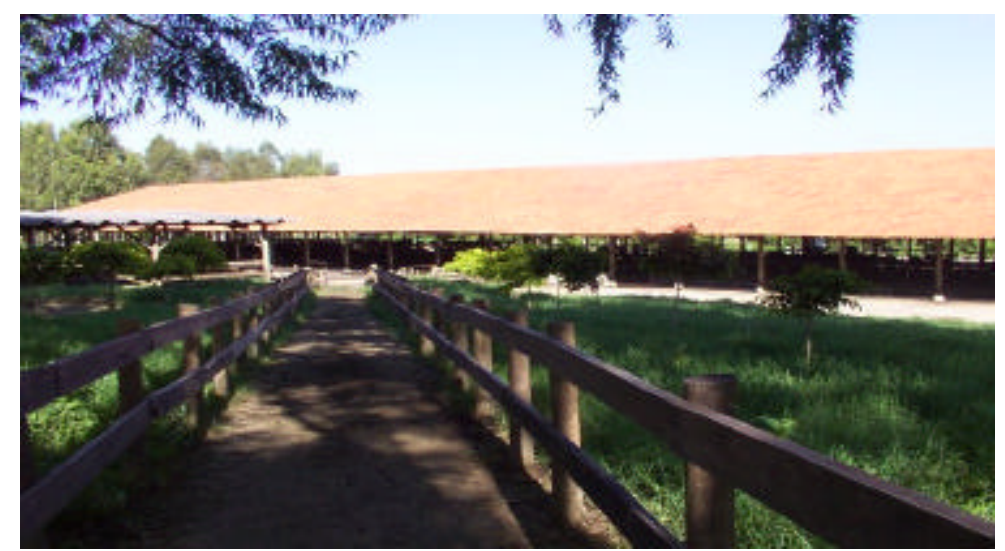

Figura 6 - Vista e externa da instalação utilizada no estudo

O piso é de concreto e possui ranhuras de aproximadamente $0,5 \mathrm{~cm}$ espaçados $7 \mathrm{~cm}$ entre si, sendo que a limpeza é feita três vezes ao dia, no momento em que os animais vão para a ordenha. O resíduo da limpeza do "freestall" é armazenado em um tanque, sendo jogado 1 vez ao dia nas áreas de produção de forragem por uma carreta de distribuição associada a um trator.

A cama de descanso dos animais possui $1,10 \mathrm{~m}$ de largura e 2,12 $\mathrm{m}$ de comprimento. Sua altura maior é de $32 \mathrm{~cm}$, e a menor, $22 \mathrm{~cm}$. As camas estão localizadas aproximadamente no centro do lote, sendo um grupo distante $3,82 \mathrm{~m}$ do cocho de alimentação e outro grupo de camas distante $3,52 \mathrm{~m}$ da lateral da instalação. 
O número total de camas por lote é 64 , sendo divididas em 2 blocos de 32, dispostos frente a frente.

Para chegar àsala de ordenha, os animais percorrem um corredor de cerca de $80 \mathrm{~m}$ de comprimento por $2 \mathrm{~m}$ de largura, sendo gasto nesse percurso aproximadamente $1 \mathrm{~min}$ e $55 \mathrm{seg}$.

A ordenha é feita nos horários da 3, 10 e 17 h, em um sistema tipo carrossel, sendo que o tempo de ordenha é, em média, 10 min por animal. $O$ animal permanece por aproximadamente $30 \mathrm{~min}$ na sala de espera, que tem capacidade para alojar todos os animais do lote e é equipada com ventiladores e aspersores, evitando o estresse térmico dos animais no período que antecede a ordenha.

\subsection{Período experimental}

O estudo teve a duração de vinte e oito dias consecutivos do mês de novembro de 2003. Utilizaram-se os sete primeiros dias do experimento para a adaptação dos animais aos sistemas de climatização a serem testados. Durante os vinte e um dias restantes monitoraram-se as condições climáticas de cada tratamento e externas à instalação, sendo selecionados, desse período, nove dias não consecutivos para a tomada dos dados fisiológicos, e seis dias consecutivos para a coleta dos dados comportamentais dos animais.

\subsection{Tratamentos}

Para avaliar a eficiência do sistema de resfriamento, trabalhou-se com 2 tratamentos, sendo distribuídos de acordo com a Figura 7:

- Tratamento 01 - Sistema de aspersão associado àventilação forçada na linha do cocho e ventilação forçada na cama;

- Tratamento 02 - Sistema de nebulização associado àventilação forçada na linha do cocho e ventilação forçada na cama. 


\begin{tabular}{|l|l|l|}
\hline Bebedouro & Bebedouro & Bebedouro \\
\hline Lote 4 & & \\
\#\#\#\#\#\#\#\#\#\#\#\#\#\#\#\# camas \#\#\#\#\#\#\#\#\#\#\#\#\#\#\#\# \\
\hline
\end{tabular}

\begin{tabular}{|c|c|c|}
\hline Bebedouro & Bebedouro & Bebedouro \\
\hline \multicolumn{3}{|c|}{$\begin{array}{l}\text { Lote } 5 \\
\text { \#\#\#\#\#\#\#\#\#\#\#\#\#\#\# camas \#\#\#\#\#\#\#\#\#\#\#\#\#\#\#\# } \\
\text { Tratamento 2: NEBULIZAÇÃO + VENTILAÇÃO }\end{array}$} \\
\hline & de alime & \\
\hline
\end{tabular}

\begin{tabular}{|l|l|l|}
\hline \multicolumn{3}{|c|}{ Cocho de alimentação } \\
\hline \multicolumn{3}{|c|}{ Tratamento 1: ASPERSÃo + VENTILAÇÃo } \\
\#\#\#\#\#\#\#\#\#\#\#\#\#\#\#\#\# camas \#\#\#\#\#\#\#\#\#\#\#\#\#\#\#\# \\
Lote 3 & Bebedouro & Bebedouro \\
\hline Bebedouro & &
\end{tabular}

\begin{tabular}{|l|l|l|}
\hline \multicolumn{3}{|c|}{ Cocho de alimentação } \\
\hline \\
\begin{tabular}{lll} 
\#\#\#\#\#\#\#\#\#\#\#\#\#\#\# camas \#\#\#\#\#\#\#\#\#\#\#\#\#\#\# \\
Lote 6 & Bebedouro & Bebedouro \\
\hline Bebedouro & &
\end{tabular}
\end{tabular}

Figura 7 - Divisão dos animais dentro do galpão de "freestall"

\subsubsection{Sistemas de resfriamento e ventilação}

Foram utilizados ventiladores da marca CASP ${ }^{\circledR}$ tipo VA 92 plus, espaçados a cada $11 \mathrm{~m}$, equipados com motor de $1 / 2 \mathrm{CV}$, vazão de $300 \mathrm{~m}^{3}, 495 \mathrm{RPM}$, diâmetro de $0,46 \mathrm{~m}$, peso aproximado de $32 \mathrm{~kg}$, com capacidade de produzir movimentação de ar de até 2,5 m.s $\mathrm{s}^{-1}$ na altura do dorso do animal. Os ventiladores instalados na área de alimentação dos animais foram montados a 2,5 m de altura, e os instalados na área de descanso a 2,0 m de altura (Figura 8).

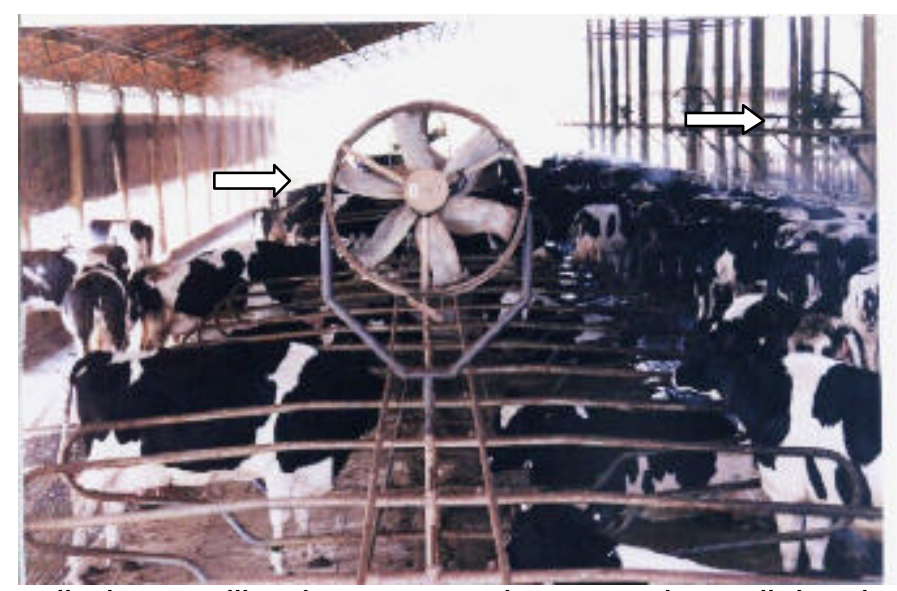

Figura 8 - Vista dos ventiladores utilizados no experimento sobre a linha de cocho e sobre as camas

Os sistemas de aspersão (Figura 9 (a)) e nebulização (Figura 9 (b)) foram montados logo abaixo dos ventiladores, sobre o cocho de alimentação dos animais, 
sendo constituídos por canos de PVC, com espaçamento entre bicos de $1 \mathrm{~m} \mathrm{e}$, assim como os ventiladores, tiveram o funcionamento controlado por um termostato e um timer. O sistema era acionado, quando a temperatura ambiente ultrapassava $24^{\circ} \mathrm{C}$ e desligado, quando alcançava valores inferiores a $22^{\circ} \mathrm{C}$. A intermitência do sistema de aspersão foi de $12 \mathrm{~min}$, sendo que o sistema permaneceu ligado durante $60 \mathrm{seg}$, e desligado durante $11 \mathrm{~min}$. O sistema de nebulização foi regulado para funcionar com uma intermitência de $1 \mathrm{~min}$, ficando ligado $20 \mathrm{seg}$ e desligado $40 \mathrm{seg}$. A intermitência de ambos os sistemas foi determinada através de testes preliminares.
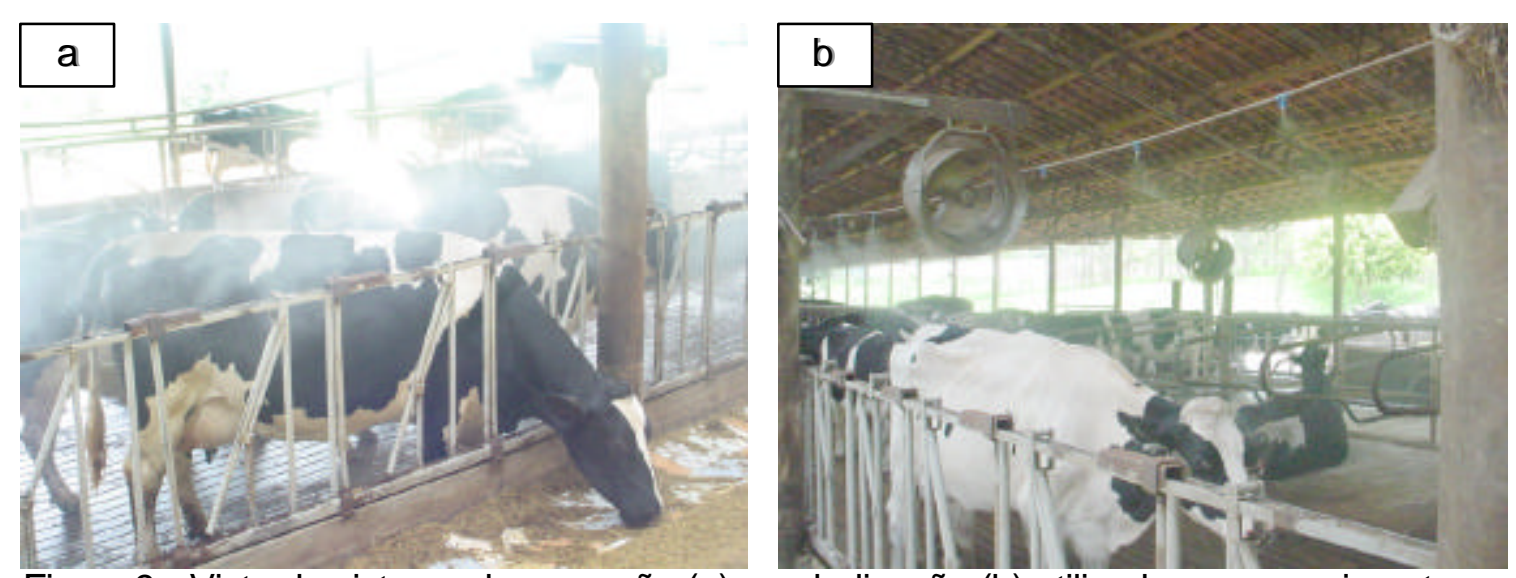

Figura 9 - Vista do sistema de aspersão (a) e nebulização (b) utilizados no experimento

O sistema de aspersão foi equipado com 60 bicos, eqüidistantes $1 \mathrm{~m}$ entre si, com vazão de 30 I.hora $^{-1}$ por bico, e atuou resfriando os animais, através do favorecimento da perda de calor para a água, visto que os animais tiveram a superfície da pele molhada, como pode ser visto na Figura 9 (a). Por outro lado, o sistema de nebulização foi equipado com 60 bicos, eqüidistantes $1 \mathrm{~m}$ entre si, com vazão de 2,5 I.hora $^{-1}$ por bico, e agiu resfriando o ambiente e favorecendo um abaixamento da temperatura interna das instalações, visto que a água evaporava antes de molhar os animais, como pode ser visto na Figura 9 (b), proporcionando, assim, uma sensação de conforto térmico aos animais. Para ter o acionamento independente do restante da instalação, cada sistema foi equipado com uma bomba da marca Schneider ${ }^{\circledR}$, modelo P-11/4AL, com motor trifásico. O consumo da bomba instalada no tratamento com aspersão era de $1,48 \mathrm{~kW} \cdot \mathrm{h}^{-1}$ e o da bomba instalada no tratamento com nebulização de $0,74 \mathrm{~kW} \cdot \mathrm{h}^{-1}$. 


\subsection{Parâmetros avaliados}

\subsubsection{Parâmetros climáticos}

As variáveis meteorológicas coletadas no interior e no exterior da instalação foram temperatura, umidade relativa do ar e temperatura de globo negro (data logger $\mathrm{HOBO}^{\circledR}$ ). Para a coleta dos dados internos, fixou-se a mini-estação meteorológica a aproximadamente $3 \mathrm{~m}$ de altura dentro da instalação (Figura 10 (a)), e na coleta dos dados externos, utilizou-se de um abrigo meteorológico de 1,50 m de altura, instalado em uma área gramada próxima à instalação (Figura 10 (b)). As leituras foram realizadas a cada $15 \mathrm{~min}$ ao longo das $24 \mathrm{~h}$, sendo selecionados para análise os dados correspondentes ao período em que os sistemas de climatização geralmente permaneciam ligados, ou seja, das 9 æ̀ 17 horas.

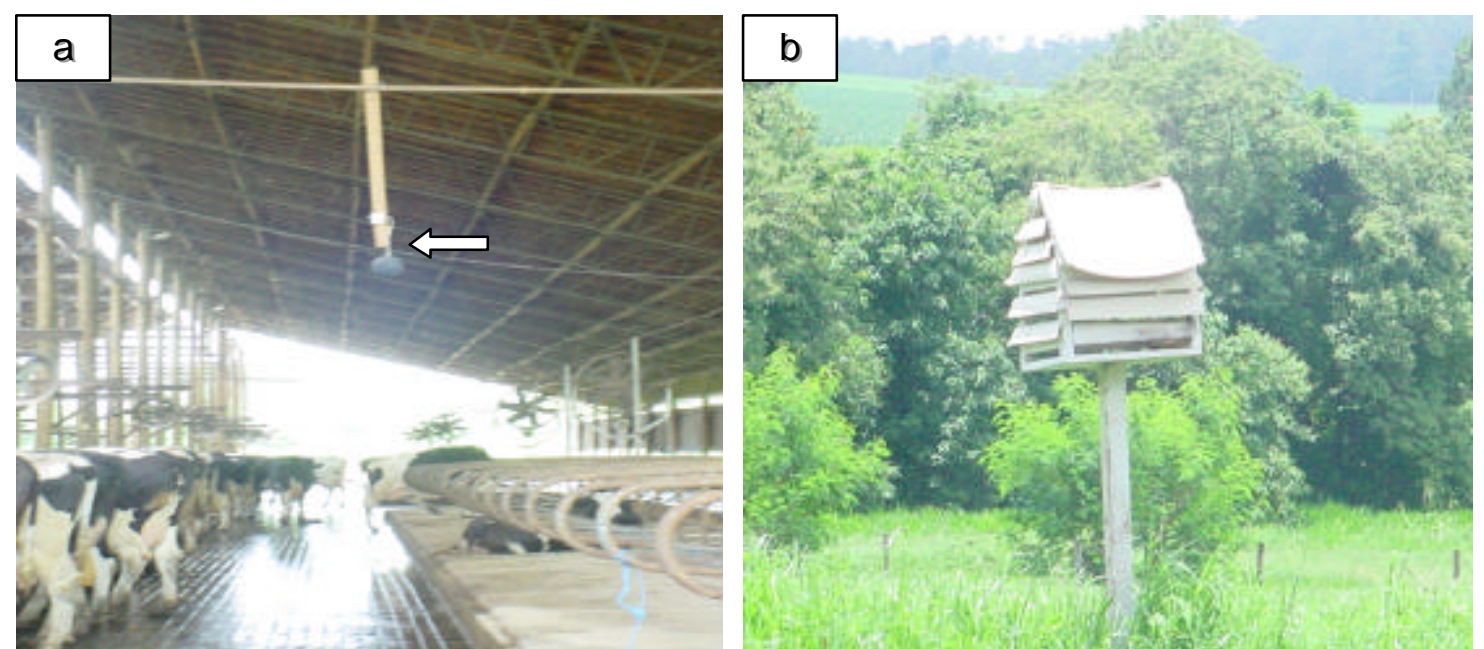

Figura 10 - Vista da mini-estação meteorológica instalada dentro da instalação (a) e do abrigo meteorológico instalado próximo àinstalação (b)

Com esses valores, foram calculados os seguintes índices de conforto térmico para a determinação da eficiência dos sistemas: índice de temperatura e umidade (THI), índice globo negro e umidade (BGHI) e entalpia $(\mathrm{H})$. 


\subsubsection{Produção de leite}

Os animais receberam água e alimento àvontade durante todo o período de experimento. Foram realizadas 3 ordenhas diárias (3, 10 e $17 \mathrm{~h})$, sendo analisada a produção de leite dos dez animais previamente selecionados para cada tratamento. Os dados foram registrados de acordo com o controle da granja.

\subsubsection{Parâmetros fisiológicos}

Os dados fisiológicos monitorados foram temperatura retal (termômetro clínico digital inserido no reto) (Figura 11 (a)), freqüência respiratória (contagem dos movimentos da região do flanco, durante $15 \mathrm{seg}$ ) e temperatura do pelame branco e preto (termômetro de infravermelho) (Figura 11 (b)), realizadas æ̇̀ 9, 11, 13, 15 e $17 \mathrm{~h}$, com o objetivo de avaliar o perfil ao longo do dia. Na tomada dos dados de temperatura do pelame utilizou-se o valor de 0,5 de emissividade para o pelame branco e o valor de 0,95 para o preto. A coleta dos dados fisiológicos foi feita durante nove dias não consecutivos do período experimental, sendo utilizados para essa coleta cinco animais por tratamento, escolhidos ao acaso no grupo dos dez animais previamente selecionados.
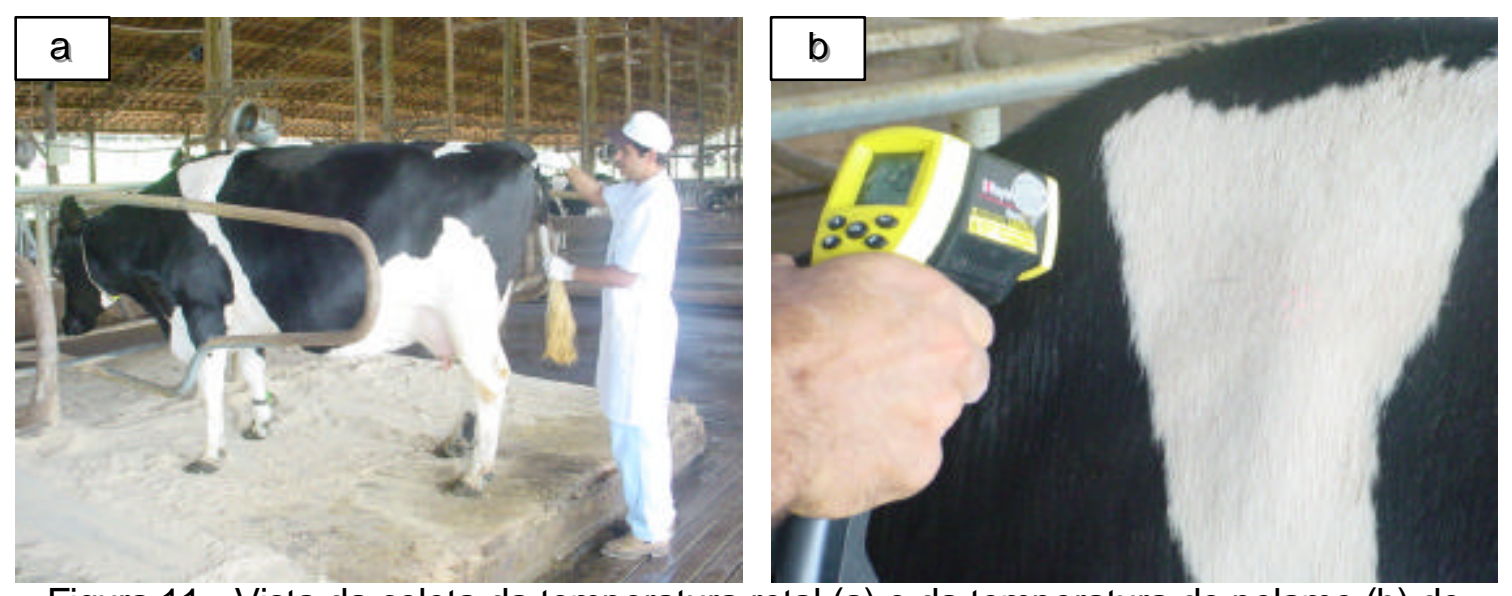

Figura 11 - Vista da coleta da temperatura retal (a) e da temperatura do pelame (b) de um dos animais selecionados para a coleta dos dados fisiológicos 


\subsubsection{Parâmetros comportamentais}

Para a análise do comportamento dos animais, foram selecionados, ao acaso, cinco animais de cada grupo, que foram identificados com colares e acompanhados continuamente das 9 æ̀ $17 \mathrm{~h}$, por vídeo - câmeras coloridas com lente de 2,45 mm (Figura 12 (a) e (b)), dispostas estrategicamente no galpão de "freestall", ligadas diretamente a um microcomputador (Figura 13) equipado com placa de captura de imagens. As imagens foram registradas diariamente e analisadas em intervalos de 10 min, sendo gerenciadas pelo software "TopWay", armazenando as informações num banco de dados para posterior análise. Durante o período da ordenha, não foram registrados os dados de comportamento.

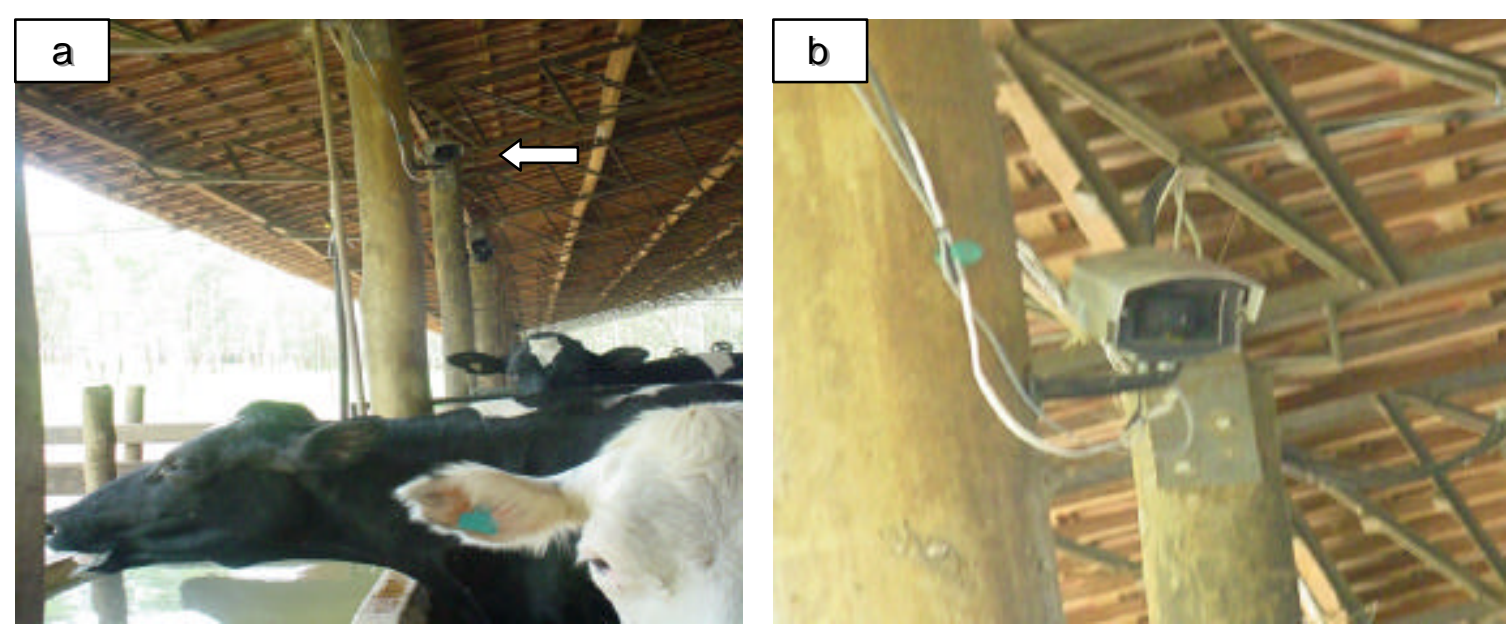

Figura 12 - Vista de uma vídeo-câmera instalada sobre o bebedouro (a) e detalhe da vídeo-câmera

Os padrões comportamentais foram avaliados de acordo com a localização dos animais dentro da instalação e de acordo com as atividades desenvolvidas por esses animais.

De acordo com a localização dos animais, foram avaliados os seguintes padrões comportamentais:

1 - presença na área de cocho;

2 - presença na área de bebedouro;

3 - presença na cama próximo àclimatização;

4 - presença na cama oposta àclimatização; 
5 - presença no corredor próximo àclimatização;

6 - presença no corredor oposto àclimatização.

Por outro lado, os padrões comportamentais avaliados de acordo com as atividades dos animais, foram:

1 - comendo;

2 -bebendo;

3 -ruminando;

4 -em ócio;

5 -em pé;

6 - deitado.

Figura 13 - Microconputador equipado com placa de captura de imagens para a coleta e armazenamento das imagens das vídeo-câmeras

Através do acompanhamento das atividades dos animais, foi possível verificar o tempo, em minutos e em porcentagem, em que os animais passaram exercendo as diferentes atividades.

Esses dados são de suma importância para a avaliação do bem-estar dos animais frente æ̀s condições ambientais impostas aos mesmos. 


\subsubsection{Consumo de alimentos}

O cocho de alimentação perfaz toda a extensão do "freestall" e possui largura de $66 \mathrm{~cm}$, profundidade de $17 \mathrm{~cm}$ e altura de $51 \mathrm{~cm}$, sendo seu interior totalmente azulejado.

A alimentação é fornecida 3 vezes ao dia, aproximadamente $1 \mathrm{~h}$ antes da ordenha do primeiro lote de animais, ou seja, à 2, 9 e $16 \mathrm{~h}$, sendo sua composição padronizada e constituída de silagem de Tifton, polpa cítrica, silagem de milho, milho úmido, silagem de alfafa pré-secada, caroço de algodão e concentrado

Foi registrado diariamente o consumo de alimentos dos animais, por diferença de peso entre o que era fornecido e a sobra, sendo esse valor dividido pelo número de animais do lote, obtendo-se, assim, o consumo diário por animal.

Para a determinação dos dados de ingestão de matéria seca (MS) amostrou-se semanalmente o alimento, que foi analisado no laboratório do departamento de Zootecnia da ESALQ.

\subsubsection{Indicativo econômico}

Para a análise econômica de cada sistema de climatização, considerou-se o custo com a instalação dos equipamentos semelhantes em ambos os sistemas, sendo assim, não discutiu-se este custo na análise da receita. Para os cálculos considerou-se o custo com energia elétrica e com água despendido em cada sistema e também o gasto com a alimentação dos animais. Considerou-se a média do preço pago ao produtor de leite tipo $\mathrm{B}$, comercializado na região de São Pedro, SP, no mês do experimento.

\subsubsection{Consumo de água pelos sistemas de climatização}

Foi avaliado o consumo de água de cada sistema de resfriamento, através da multiplicação da vazão dos bicos pelo número de vezes que o sistema foi ligado diariamente. Assim foi determinado o consumo de água ao longo do dia, nos sistemas testados. Esses dados foram registrados diariamente e avaliados em função da 
redução de temperatura do ambiente interno, uma vez que o termostato controlou o acionamento do sistema.

\subsubsection{Consumo de energia pelos sistemas de climatização}

Foi registrado o consumo de energia diária, para o acionamento dos sistemas de ventilação forçada e resfriamento, por meio de um multímetro. Assim foi determinado o consumo de energia ao longo do dia, tanto no sistema de nebulização como no de aspersão.

\subsection{Análise da fundamentação científica e métodos empregados:}

O período de coleta de dados constou de 21 dias em que foram avaliados dados referentes à variáveis ambientais, fisiológicas, produtivas e comportamentais.

O delineamento experimental adotado foi 0 de blocos casualizados, considerando como blocos os dias de análise, e os tratamentos, os diferentes tipos de climatização. Para o estudo de comparação das médias, adotou-se o teste de Tukey. Os resultados de análise estatística foram obtidos por meio do programa estatístico "Statistical Analysis System" (SAS, 1992). 


\section{RESULTADOS E DISCUSSÃO}

\subsection{Parâmetros climáticos}

A Tabela 7 apresenta a média das variáveis ambientais, ou seja, da temperatura de bulbo seco (Tbs), da umidade relativa (UR), da temperatura de globo negro (TG) e das temperaturas mínima e máxima, além dos índices de conforto calculados a partir dessas variáveis, que são o índice de temperatura e umidade (THI), o índice de temperatura de globo negro e umidade (BGHI) e a entalpia, durante o período experimental, nos tratamentos estudados e no ambiente externo àinstalação.

Os resultados da análise estatística apresentados na Tabela 7 mostram que o TN (tratamento com nebulização) proporcionou uma redução significativa do THI e da entalpia, em comparação ao TA (tratamento com aspersão) e com o EXT (ambiente externo), sendo que estes últimos não diferiram significativamente entre si para essas variáveis climáticas. A Tbs foi maior no EXT, porém, sem diferença significativa com o TA, que também não apresentou diferença com relação ao TN. A umidade relativa foi significativamente maior no TN, seguido do TA e, por fim, do EXT. O TA não diferiu do TN com relação a TG e a Tmin, que também não se diferenciou do ambiente externo. O BGHI foi estatísticamente superior no TA com relação ao TN. A Tmax do TA e do TN não diferiram entre si, porém, foram inferiores a do EXT. 
Tabela 7. Média diária das variáveis climáticas durante o período experimental

\begin{tabular}{|c|c|c|c|}
\hline \multirow[t]{2}{*}{ Variáveis climáticas } & \multicolumn{3}{|c|}{ Tratamentos } \\
\hline & Aspersão & Nebulização & Externo \\
\hline & (TA) & (TN) & (EXT) \\
\hline Temperatura de bulbo seco $\left({ }^{\circ} \mathrm{C}\right)(\mathrm{Tbs})$ & $24,1^{\mathrm{ab}}$ & $23,7^{b}$ & $24,4^{a}$ \\
\hline Umidade relativa (\%) (UR) & $69,9^{b}$ & $71,0^{a}$ & $69,0^{c}$ \\
\hline Temperatura de globo negro $\left({ }^{\circ} \mathrm{C}\right)(\mathrm{TG})$ & $24,3^{a}$ & $23,9^{a}$ & \\
\hline Índice de temperatura e umidade (THI) & $72,4^{a}$ & $71,9^{b}$ & $72,7^{\mathrm{a}}$ \\
\hline Índice de globo negro e umidade (BGHI) & $72,4^{a}$ & $71,9^{b}$ & \\
\hline Entalpia (kJ/kg de ar seco) & $74,9^{a}$ & $74,5^{b}$ & $75,8^{a}$ \\
\hline Temperatura mínima $\left({ }^{\circ} \mathrm{C}\right)$ (Tmin) & $19,7^{\mathrm{a}}$ & $193^{a}$ & $19,8^{a}$ \\
\hline Temperatura máxima $\left({ }^{\circ} \mathrm{C}\right)(\mathrm{Tmax})$ & $29,4^{b}$ & $29,0^{b}$ & $30,6^{a}$ \\
\hline
\end{tabular}

a,b,c - Médias seguidas de letras distintas na mesma linha diferem $(p<0,05)$ pelo teste Tukey.

A Tabela 8 apresenta a média das variáveis ambientais, durante o período experimental, no intervalo horário das $9 \mathrm{~h}$ às $17 \mathrm{~h}$, nos tratamentos estudados e no ambiente externo àinstalação. Para o cálculo dessas médias, selecionou-se o intervalo horário citado acima, por este corresponder ao período em que os sistemas de climatização geralmente ficaram ligados e, também, foi o período em que se coletou as variáveis fisiológicas e comportamentais dos animais.

Os resultados da análise estatística apresentados na Tabela 8 mostram que 0 TN proporcionou uma redução significativa da Tbs, e da entalpia, com relação ao TA e com o EXT, sendo que estes últimos não diferiram significativamente entre si para essas variáveis climáticas. $A$ umidade relativa foi significativamente maior no TN com relação ao TA, porém, não diferiu do EXT. O TA também não diferiu do EXT com relação àUR. A TG e o BGHI foram estatísticamente superiores no TA com relação ao TN. Com relação ao THI, observa-se um ambiente mais estressante no EXT, porém, sem diferença significativa com o TA, e, finalmente, com o TN, que também não apresentou diferença com relação ao TA. A Tmax do TA e do TN não diferiram entre si, porém foram inferiores à do EXT. Por outro lado, a Tmin rão apresentou diferença entre os ambientes estudados. 
Tabela 8. Média das variáveis climáticas no intervalo horário das 9 h às 17 h durante 0 período experimental

\begin{tabular}{|c|c|c|c|}
\hline Variáveis climáticas & & Tratamentos & \\
\hline & $\begin{array}{c}\text { Aspersão } \\
\text { (TA) }\end{array}$ & $\begin{array}{c}\text { Nebulização } \\
\text { (TN) }\end{array}$ & $\begin{array}{c}\text { Externo } \\
\text { (EXT) }\end{array}$ \\
\hline Temperatura de bulbo seco $\left({ }^{\circ} \mathrm{C}\right)(\mathrm{Tbs})$ & $27,0^{a}$ & $26,6^{\mathrm{b}}$ & $27,3^{a}$ \\
\hline Umidade relativa (\%) (UR) & $59,8^{b}$ & $60,3^{a}$ & $60,0^{a b}$ \\
\hline Temperatura de globo negro $\left({ }^{\circ} \mathrm{C}\right)(\mathrm{TG})$ & $27,5^{\mathrm{a}}$ & $27,1^{\mathrm{b}}$ & \\
\hline Índice de temperatura e umidade (THI) & $75,1^{\mathrm{ab}}$ & $74,7^{b}$ & $75,6^{a}$ \\
\hline Índice de globo negro e umidade (BGHI) & $75,5^{a}$ & $75,0^{b}$ & \\
\hline Entalpia (kJ/kg de ar seco) & $77,7^{\mathrm{a}}$ & $77,0^{\mathrm{b}}$ & $78,0^{a}$ \\
\hline Temperatura mínima $\left({ }^{\circ} \mathrm{C}\right)$ (Tmin) & $19,7^{\mathrm{a}}$ & $193^{a}$ & $19,8^{a}$ \\
\hline Temperatura máxima $\left({ }^{\circ} \mathrm{C}\right)(\mathrm{Tmax})$ & $29,4^{b}$ & $29,0^{b}$ & $30,6^{a}$ \\
\hline
\end{tabular}

Analisando os resultados obtidos em relação a Tbs e $\mathrm{Tg}$ e aos índices de conforto térmico avaliados (BGHI e THI) e, observou-se que o efeito do resfriamento evaporativo do tratamento com nebulização possibilitou uma redução dos mesmos. $O$ mesmo foi observado para a entalpia (quantidade de calor presente por unidade de ar seco), que foi reduzida no TN. A umidade relativa, como era de se esperar, aumentou no TN, devido a maior quantidade de vapor d'água produzida pelo sistema, enquanto as variáveis ambientais Tmin e Tmax, não diferiram significativamente, quando analisados os horários em que os sistemas permaneceram ligados.

Os resultados obtidos estão de acordo com Brucklin \& Bray, 1998, pois o sistema de aspersão não tem a finalidade de resfriar o ar, e sim de usar gotas largas de água para molhar o pêlo e a pele das vacas.

\subsubsection{Temperatura máxima e mínima (Tmax e Tmin)}

As médias da temperatura máxima e da temperatura mínima, durante o período experimental, apresentadas na Tabela 8, mostram um diferencial de temperatura ao 
longo do dia de $9,7^{\circ} \mathrm{C}$ para ambos os sistemas de climatização testados, e de 10,8 ํ C para o ambiente externo.

Uma análise das Tmax médias obtidas no período permite concluir que foram atingidas temperaturas bem superiores æ̀े consideradas adequadas pela literatura (Huber, 1990) para a manutenção da homeotermia de vacas Holandesas em lactação, principalmente no ambiente externo à instalação, ressaltando a importância da utilização de abrigos bem planejados, quando se deseja produção leiteira em ambientes tropicais.

\subsubsection{Temperatura de bulbo seco (TBS)}

A Figura 14 apresenta os valores médios da temperatura de bulbo seco (Tbs) nos tratamentos estudados e no ambiente externo, obtidos durante o período experimental nos horários analisados.

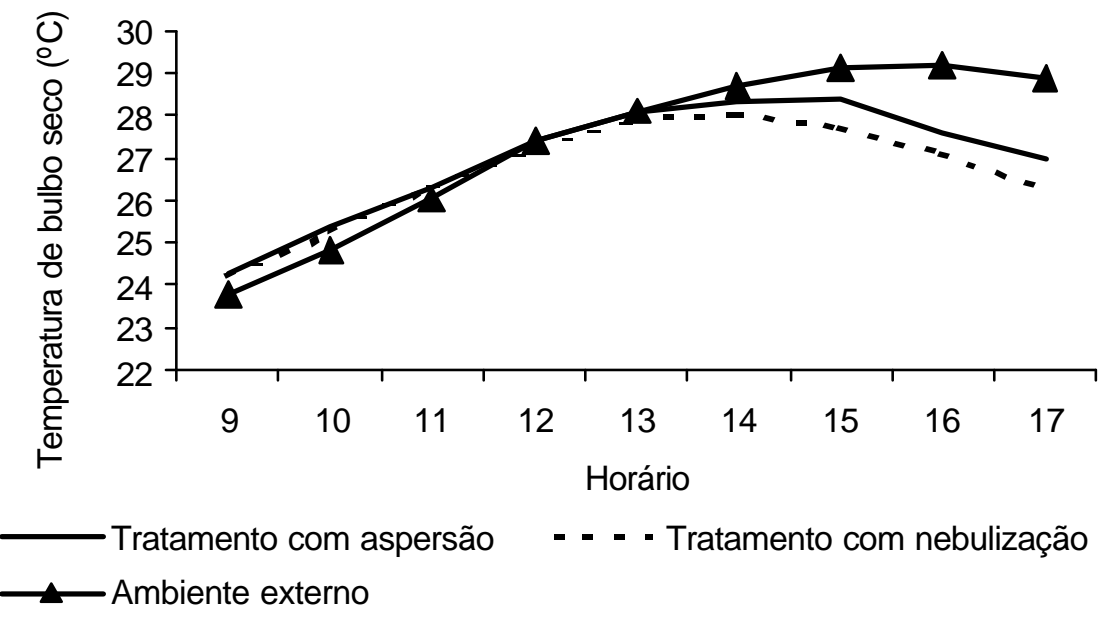

Figura 14 - Médias de temperatura de bulbo seco, nos diferentes tratamentos e no ambiente externo, nos horários analisados

No horário das 9:00 h, com valores médios de 24,3, 24,2 e 23,8드. para os tratamentos com aspersão, nebulização e para o ambiente externo, respectivamente, não se observou diferença significativa entre os ambientes estudados.

Nos horários das 10:00 h, com médias de 25,3, 25,3 e 24,8ำ $\mathrm{C}, 11: 00 \mathrm{~h}(23,6$, 23,6 e $\left.26,0^{\circ} \mathrm{C}\right), 12: 00 \mathrm{~h}\left(27,4,27,2\right.$ e $\left.27,4^{\circ} \mathrm{C}\right), 13: 00 \mathrm{~h}\left(28,1,27,9\right.$ e $\left.28,1^{\circ} \mathrm{C}\right), 14: 00 \mathrm{~h}$ 
$\left(28,4,28,0\right.$ e $\left.28,7^{\circ} \mathrm{C}\right)$ e no horário das $17: 00$ h com médias de $27,0,26,3$ e 28,8ํㅡ, para os tratamentos com aspersão, nebulização e para 0 ambiente externo, respectivamente, também não se observou diferença significativa entre os ambientes estudados.

Às 15:00 h, horário correspondente àmaior entalpia externa média do período, o sistema de climatização equipado com nebulização propiciou valor médio de Tbs $\left(27,7^{\circ} \mathrm{C}\right)$ significativamente inferior ao tratamento com aspersão e ao ambiente externo, sendo essa redução de 0,7 e 1,4 ํㅡ (2,5 e 4,8\%), respectivamente. O TA não diferiu do EXT nesse horário. Observa-se que o sistema de nebulização se mostrou eficiente na redução da temperatura ambiente, exatamente no horário em que o ambiente externo se encontrava com a maior quantidade de calor por unidade de ar seco (entalpia).

Às 16:00 h, o ambiente externo, com Tbs médio de $29,2^{\circ} \mathrm{C}$, esteve 1,6 e $2,1^{\circ} \mathrm{C}$ (5,5 e 7,2\%) superior ao TA e ao TN, respectivamente. O TA e o TN não diferiram entre si no referido horário.

\subsubsection{Umidade relativa (UR)}

Através da Figura 15, pode-se verificar os valores médios da umidade relativa do ar (UR) nos tratamentos estudados e no ambiente externo, obtidos durante o período experimental, nos horários analisados. 


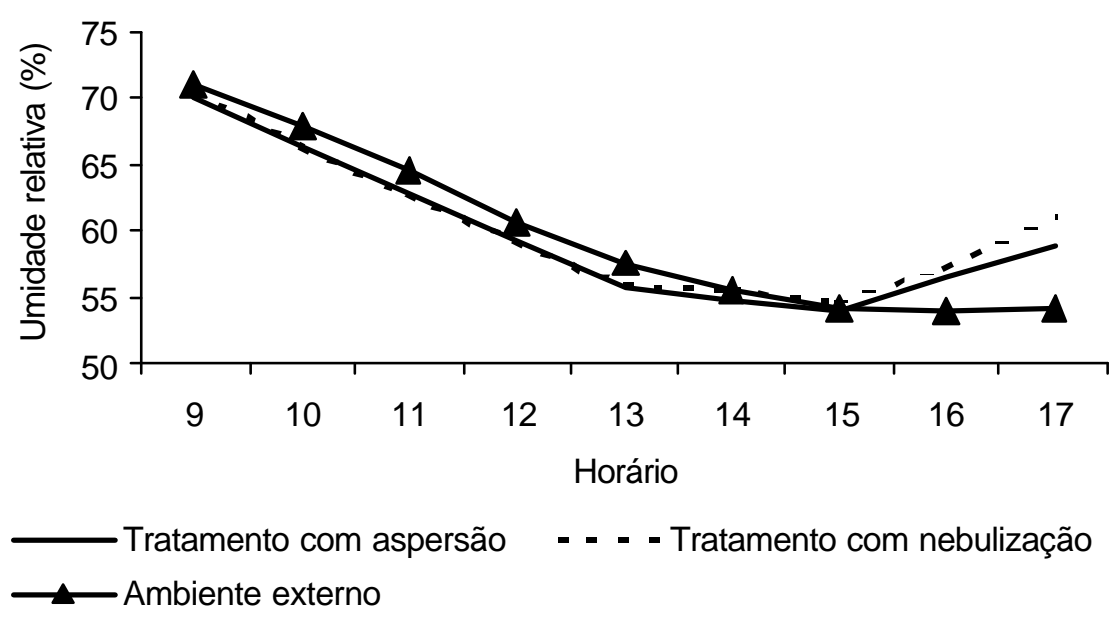

Figura 15 - Médias de umidade relativa, nos diferentes tratamentos e no ambiente externo, nos horários analisados

Nos horários das 9:00 h (70,0, 70,6 e 71,1\%), 10:00 h (66,2, 66,2 e 67,9\%), $11: 00$ h $(62,9,62,7$ e 64,7\%), 12:00 h (59,3, 59,3 e 60,6\%), 14:00 h (54,7, 55,5 e $55,5 \%), 15: 00$ h $(54,0,54,6$ e $54,1 \%)$ e $16: 00$ h, com médias $56,4,57,3$ e 54,0\% para os tratamentos com aspersão, nebulização e para o ambiente externo, respectivamente, não se observou diferença significativa entre os ambientes estudados.

No horário das 13:00 h, o ambiente externo, com UR média de 57,7\%, foi significativamente superior ao TA (55,7\%) e ao TN (55,9\%), atingindo um aumento, em porcentagem, de 3,5 e 3,1\%, respectivamente. O TA e o TN não diferiram entre si nesse horário. Esse fato pode se dado pela ocorrência de chuva no período estudado, já que se trata de valores climáticos médios.

Às 17:00 h, horário em que a Tbs externa já estava caindo, o TN, com $61 \%$ de UR média, apresentou valores significativamente superiores ao EXT, que obteve $54,2 \%$, sendo este acréscimo, em porcentagem, de 11,2\%. Por outro lado, o TA não foi significativamente diferente tanto do TN como do EXT, para esse horário. 


\subsubsection{Temperatura de globo negro (TG)}

A Figura 16 apresenta os valores médios da temperatura de globo negro (TG) nos tratamentos estudados, obtidos durante o período experimental nos horários analisados.

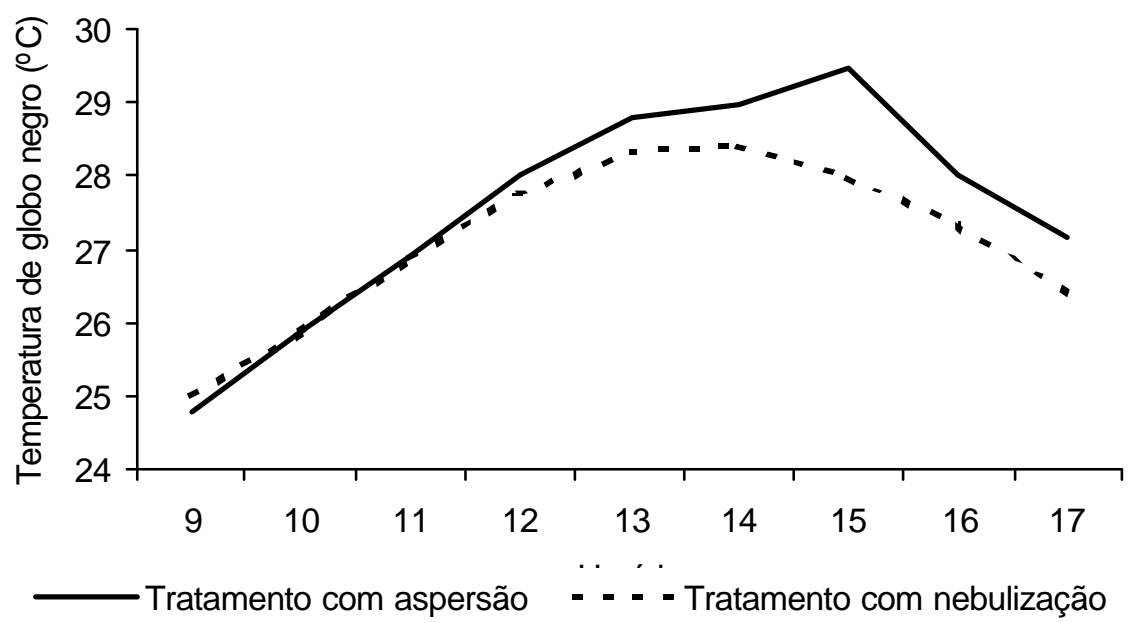

Figura 16 - Médias de temperatura de globo negro, nos diferentes tratamentos, nos horários analisados

A temperatura de globo negro não se diferenciou significativamente no período da manhã entre os sistemas de climatização estudados. As médias encontradas para o TA e para o TN, respectivamente, foram de 24,8 e $25,0^{\circ} \mathrm{C}(9: 00 \mathrm{~h}), 25,9$ e $25,9^{\circ} \mathrm{C}$ (10:00 h), 26,9 e $26,9^{\circ} \mathrm{C}(11: 00 \mathrm{~h})$ e 28,0 e $27,7^{\circ} \mathrm{C}$ (12:00 h).

No período da tarde, quando as entalpias externas foram mais altas, a TG média do TA foi sempre significantemente superior ao TN, sendo que æ̇ 13:00 $\mathrm{h}$ $\left(28,8^{\circ} \mathrm{C}\right)$ esta superioridade foi de $0,5^{\circ} \mathrm{C}$, às $14: 00 \mathrm{~h}\left(29,0^{\circ} \mathrm{C}\right)$ foi de $0,6^{\circ} \mathrm{C}$, æ̀ $15: 00 \mathrm{~h}$ $\left(29,4^{\circ} \mathrm{C}\right)$ foi de $1,4^{\circ} \mathrm{C}$, ̀̀ $16: 00 \mathrm{~h}\left(28,0^{\circ} \mathrm{C}\right)$ de $0,7^{\circ} \mathrm{C}$ e às $17: 00 \mathrm{~h}$ também $0,7^{\circ} \mathrm{C}$ superior. 


\subsubsection{Entalpia}

Podemos observar, pela Figura 17, os valores médios da quantidade de calor no ar, ou seja, da entalpia, nos tratamentos estudados e no ambiente externo, obtidos durante o período experimental nos horários analisados.

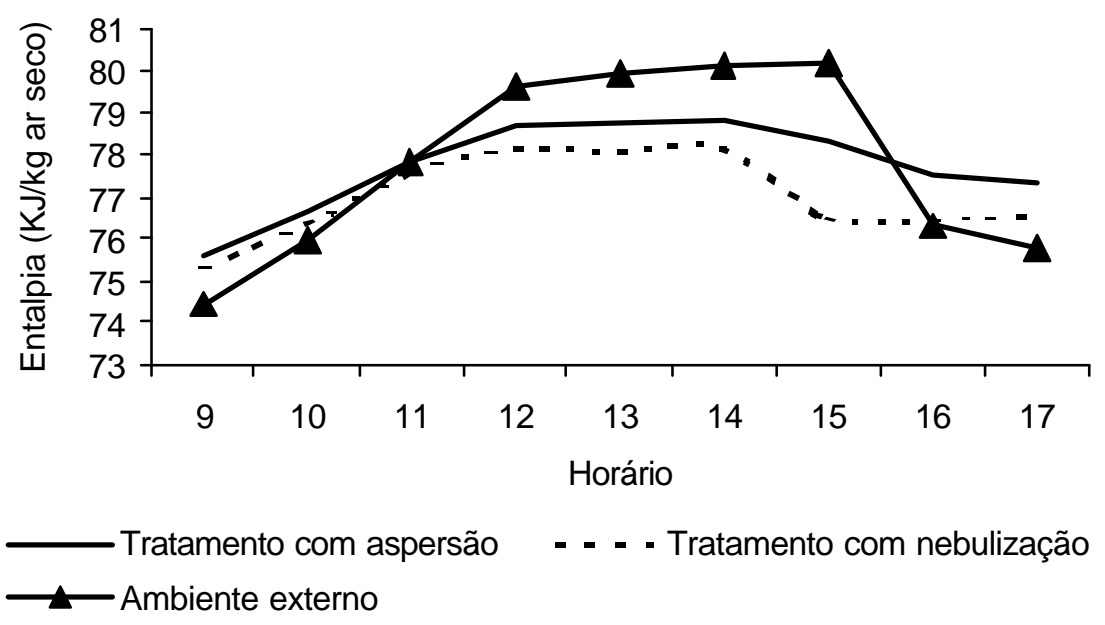

Figura 17 - Médias de entalpia, nos diferentes tratamentos e no ambiente externo, nos horários analisados

A quantidade de calor no ar não apresentou diferença significativa durante o período da manhã e final da tarde entre os ambientes estudados. Verificaram-se valores de 75,6, 75,3 e 74,5 kJ/kg de ar seco (9:00 h), 76,7, 76,3 e 75,9 kJ/kg de ar seco (10:00 h), 77,8, 77,6 e 77,8 kJ/kg de ar seco (11:00 h), 78,7, 78,1 e 79,6 kJ/kg de ar seco (12:00 h), 77,5, 76,4 e 76,3 kJ/kg de ar seco (16:00 h) e 77,3, 76,5 e 75,8 kJ/kg de ar seco $(17: 00 \mathrm{~h})$, para os tratamentos com aspersão, nebulização e para o ambiente externo, respectivamente.

No horário das 13:00 h e 14: 00 h, a entalpia média do EXT (79,9 e 80,1 kJ/kg de ar seco, respectivamente) foi significativamente superior 1,9 e 2,0 kJ/kg de ar seco (2,4 e 2,5\%), respectivamente, em relação ao TN. O TA, com 78,8 kJ/kg de ar seco em ambos os horários, não apresentou diferença significativa em relação aos outros ambientes estudados. 
Às 15:00 h, a entalpia média do EXT, com 80,2 kJ/kg de ar seco, foi significativamente mais elevada que os ambientes equipados com sistema de climatização, em que se encontraram $1,9 \circ \mathrm{O}(2,4 \%)$ e $3,3 \circ \mathrm{O}(4,6 \%) \mathrm{kJ} / \mathrm{kg}$ de ar seco menores que o que o EXT para o TA e oTN, respectivamente, que, por sua vez, se diferenciaram estatísticamente entre si.

\subsection{6 Índice de temperatura e umidade (THI)}

A Figura 18 nos mostra as médias do índice de temperatura e umidade (THI), nos diferentes tratamentos e no ambiente externo, obtidos durante o período experimental nos horários analisados.

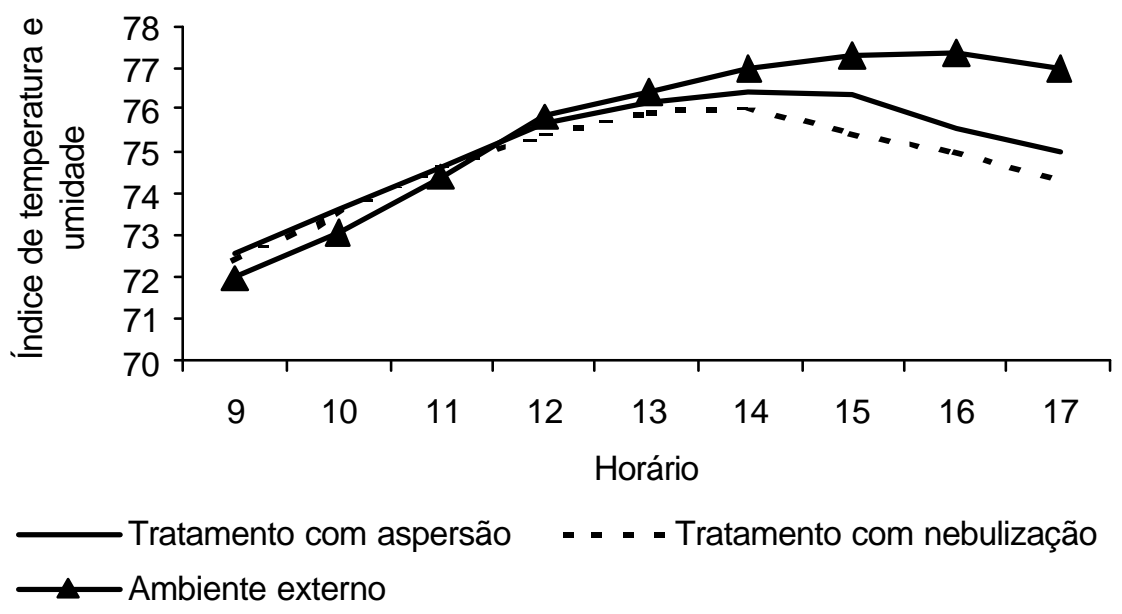

Figura 18 - Médias do THI, nos diferentes tratamentos e no ambiente externo, nos horários analisados

O índice de temperatura e umidade também não apresentou diferença significativa no período da manhã entre os ambientes estudados, apresentando valores para os tratamentos com aspersão, nebulização e para o ambiente externo, respectivamente, de 72,6, 72,4 e 72,0 (9:00 h), 73,6, 73,5 e 73,1 (10:00 h), 74,6, 74,6 e 74,4 (11:00 h) e 75,6, 75,4 e 75,8 (12:00h). No início da tarde, observou-se o mesmo comportamento do período da manhã, sendo os valores obtidos para as 13:00 h de 76,2, 75,9 e 76,4 para os tratamentos com aspersão, nebulização e para o ambiente externo, respectivamente. 
Nos demais horários analisados do período da tarde, o EXT foi sempre superior em relação aos ambientes equipados com sistema de climatização, com exceção feita ao horário das 14:00 h, em que o EXT $(77,0)$ não diferiu estatisticamente do TA $(76,4)$, porém, foi significativamente superior ao TN $(76,0)$ em $1,3 \%$. O TA e o TN não diferiram entre si.

No horário das 15:00 h, o TN, com valor de 75,4, foi significativamente inferior $(2,5 \%$ e $1,3 \%)$ em relação ao EXT $(77,3)$ e ao TA $(76,4)$, respectivamente. O valor médio da THI do TA foi 1,2\% inferior ao EXT.

Às 16:00 h e ⿱亠े 17:00 h, o TA e o TN não obtiveram valores estatisticamente diferentes entre si, porém, diferiram do EXT. Os valores médios do THI para esses horários foram: 75,6, 75,0 e 77,3, æ̀ 16:00 h, e 75,0, 74,3 e 77,0, æ̀ 17:00 h, para os tratamentos com aspersão, nebulização e para o ambiente externo, respectivamente.

\subsection{7 Índice de temperatura de globo e umidade (BGHI)}

A Figura 19 mostra as médias do índice de globo negro e umidade (BGHI), nos diferentes tratamentos, obtidos durante $\mathrm{o}$ período experimental nos horários analisados.

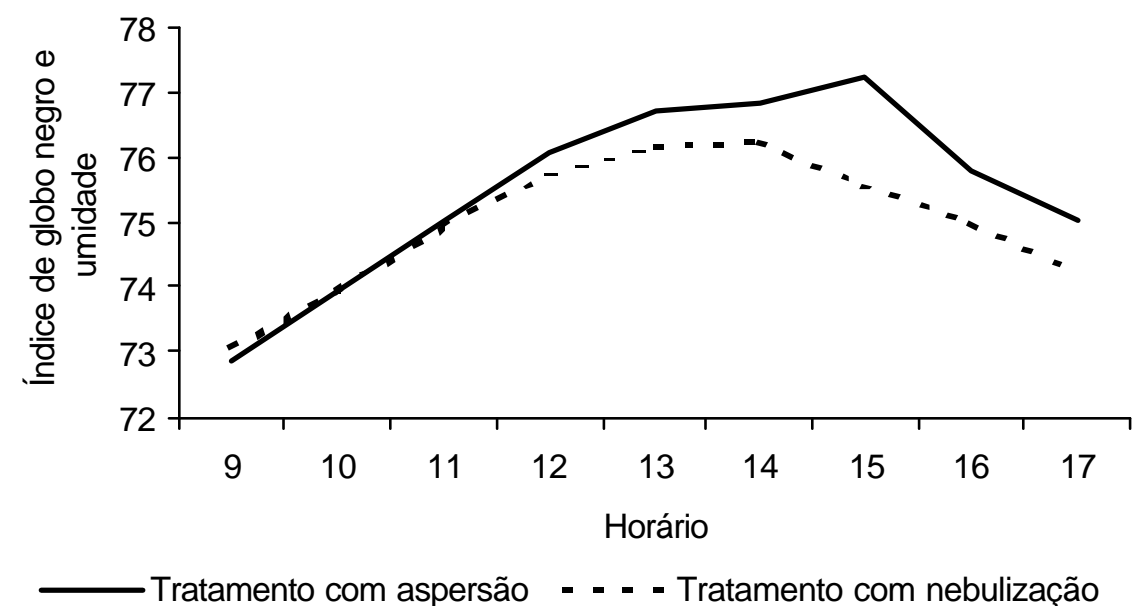

Figura 19 - Médias do BGHI, nos diferentes tratamentos, nos horários analisados

O índice de temperatura de globo negro e umidade, como era esperado, seguiu o comportamento da temperatura de globo negro, não se diferenciando 
significativamente, no período da manhã, entre os sistemas de climatização estudados. As médias encontradas para o TA e para o TN, respectivamente, foram de 72,9 e 73,1 (9:00 h), 74,0 e 73,9 (10:00 h), 75,0 e 74,9 (11:00 h) e 76,1 e 75,7 (12:00 h).

No período da tarde, o BGHI médio também seguiu o comportamento da TG, sendo que TA foi sempre significativamente superior ao TN. Às 13:00 h $(76,7)$ essa

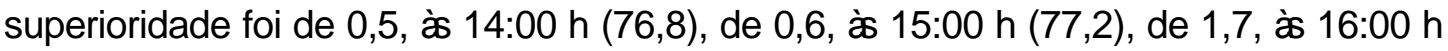
$(75,8)$, de 0,8 e æ̀ $17: 00 \mathrm{~h}$, de 0,8 .

O cálculo dos índices de conforto térmico com os valores de temperatura de bulbo seco $\left(24,0^{\circ} \mathrm{C}\right)$ e da umidade relativa $(38 \%)$, considerada ideal pela literatura (Baccari, 1998, citando Johnson \& Vanjonack), na qual vacas leiteiras apresentam produção normal, nos fornecerá os valores de aproximadamente 70 de THI, 68 de BGHI e $72 \mathrm{~kJ} / \mathrm{kg}$ de ar seco de entalpia. Esses dados apresentam valores inferiores aos obtidos na análise climática dos tratamentos estudados, porém, verificou-se que, mesmo assim, não houve alteração na condição normal de termorregulação dos animais, concordando com os resultados obtidos por Martello (2002), segundo a qual, faz-se necessário investigações adicionais acerca dos limites críticos destes índices para vacas em lactação criadas em regiões de clima tropical.

\subsection{Parâmetros fisiológicos}

A Tabela 9 apresenta as médias das variáveis fisiológicas dos animais, ou seja, da temperatura retal (TR), da freqüência respiratória (FR), da temperatura do pelame branco (TPB) e da temperatura do pelame preto (TPP), obtidas durante os nove dias de coleta de dados fisiológicos.

Através da análise da Tabela 9, observou-se que o tratamento que utiliza a aspersão associada à ventilação forçada, para o acondicionamento térmico das instalações, proporciona a obtenção das variáveis fisiológicas dos animais sempre inferiores aos encontrados no sistema que utiliza a nebulização associada àventilação forçada, porém, em nenhuma das variáveis foi encontrada diferença estatística significativa entre os tratamentos. 
Tabela 9. Médias das variáveis fisiológicas dos animais no período experimental

\begin{tabular}{lcc}
\hline Variáveis fisiológicas & \multicolumn{2}{c}{ Tratamentos } \\
\hline & Aspersão & Nebulização \\
Temperatura retal $\left({ }^{\circ} \mathrm{C}\right)$ & $38,4^{\mathrm{a}}$ & $38,5^{\mathrm{a}}$ \\
Freqüência respiratória $\left(\right.$ mov.min $\left.^{-1}\right)$ & $55^{\mathrm{a}}$ & $56^{\mathrm{a}}$ \\
Temperatura do pelame branco $\left({ }^{\circ} \mathrm{C}\right)$ & $34,0^{\mathrm{a}}$ & $35,4^{\mathrm{a}}$ \\
Temperatura do pelame preto $\left({ }^{\circ} \mathrm{C}\right)$ & $31,5^{\mathrm{a}}$ & $32,6^{\mathrm{a}}$ \\
\hline a,b - Médias seguidas de letras distintas na mesma linha diferem $(\mathrm{p}<0,05)$ \\
pelo teste Tukey.
\end{tabular}

O fato do sistema de aspersão resfriar diretamente o animal, com a evaporação da água da pele e pêlos, que foi otimizada pela associação com a ventilação forçada, fez com que as respostas fisiológicas dos animais submetidos a este tratamento, fossem mais favoráveis que as obtidas no TN.

Esses resultados concordam com os obtidos por Chastain \& Turner (1994), Bucklin \& Bray (1994), Frazzi et al. (1998) e Lin et al. (1998), que avaliaram a eficiência da aspersão nas respostas fisiológicas de vacas leiteiras Holandesas.

\subsubsection{Temperatura retal (TR)}

A Figura 20 mostra as médias da temperatura retal dos animais, nos diferentes tratamentos, obtidos durante os nove dias de coleta de dados, nos horários analisados.

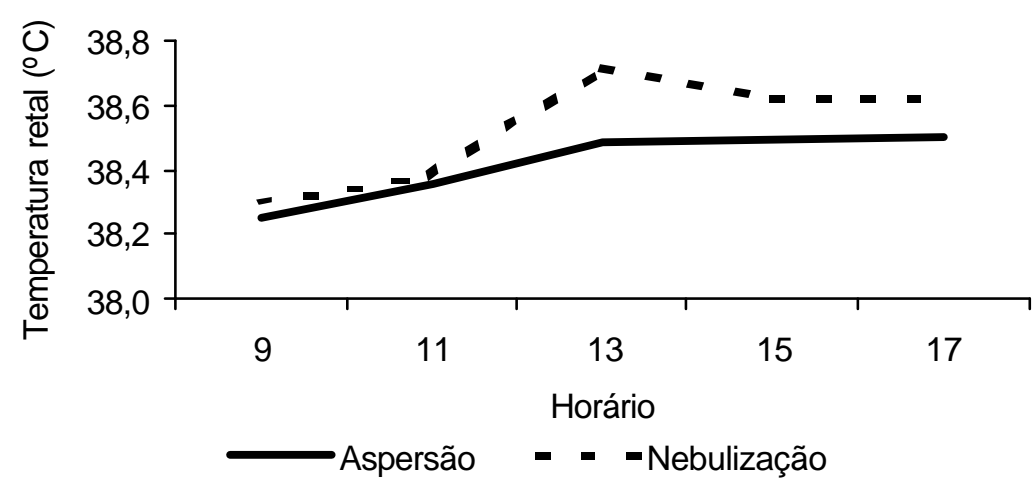

Figura 20 - Médias da temperatura retal dos animais, nos diferentes tratamentos, nos horários analisados 
A observação da temperatura retal média dos animais mostra uma tendência de elevação durante o decorrer do dia, para ambos os tratamentos estudados, concordando com os resultados obtidos por Martello (2002). No tratamento com nebulização a TR atinge valores superiores aos encontrados no tratamento com aspersão, durante todos os horários analisados, com exceção do horário das 11:00 h, em que os valores se igualam, porém, essa diferença não foi estatisticamente significativa. Os valores médios encontrados para o TA e para o TN foram, respectivamente: 38,2 e $38,3^{\circ} \mathrm{C}(9: 00 \mathrm{~h}), 38,4$ e $38,4^{\circ} \mathrm{C}(11: 00 \mathrm{~h}), 38,5$ e $38,7^{\circ} \mathrm{C}$ (13:00h), 38,5 e $38,6^{\circ} \mathrm{C}(15: 00 \mathrm{~h})$ e 38,5 e $38,6^{\circ} \mathrm{C}(17: 00 \mathrm{~h})$.

\subsubsection{Freqüência respiratória (FR)}

A Figura 21 mostra as médias da freqüência dos respiratória animais, nos diferentes tratamentos, obtidos durante os nove dias de coleta de dados, nos horários analisados.

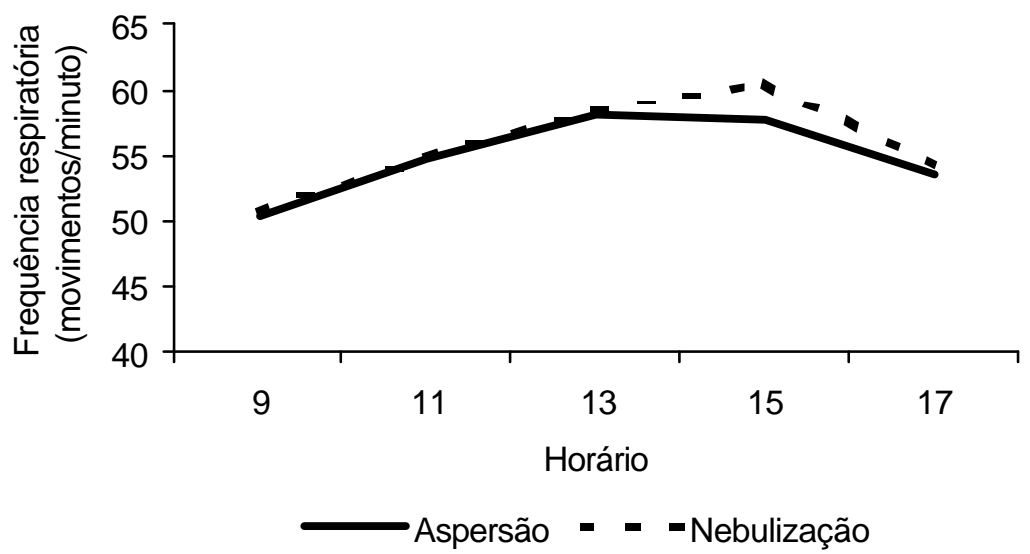

Figura 21 - Médias da freqüência respiratória dos animais, nos diferentes tratamentos, nos horários analisados

A freqüência respiratória média dos animais apresentou uma tendência semelhante à TR, ou seja, de elevação durante o decorrer do dia, para ambos os tratamentos estudados. No tratamento com nebulização, a FR atingiu valores superiores aos encontrados no tratamento com aspersão, durante os horários da 9:00 
h e 15:00 h, com os respectivos valores de 50 e 51 e de 58 e 61 movimentos por minuto, para o TA e para o TN, respectivamente, porém, essa diferença não foi estatisticamente significativa. O maior valor de $F R$, à 9:00 $h$, no $T N$, pode ser explicado por ser um horário de maior umidade relativa, e æ̀ 15:00 h por ser o horário de maior entalpia externa, sabendo-se que tanto altos valores de UR como altos valores de entalpia são estressantes para os animais em estudo. Nos demais horários analisados, o valor da FR entre os tratamentos igualou-se, sendo esses valores médios: 55 (11:00 h), 58 (13:00 h) e 54 movimentos por minuto (17:00 h).

\subsubsection{Temperatura da superfície do pelame (TP)}

\subsubsection{Temperatura da superfície do pelame branco (TPB)}

A Figura 22 mostra as médias da temperatura do pelame branco dos animais, nos diferentes tratamentos, obtidos durante os nove dias de coleta de dados, nos horários analisados.

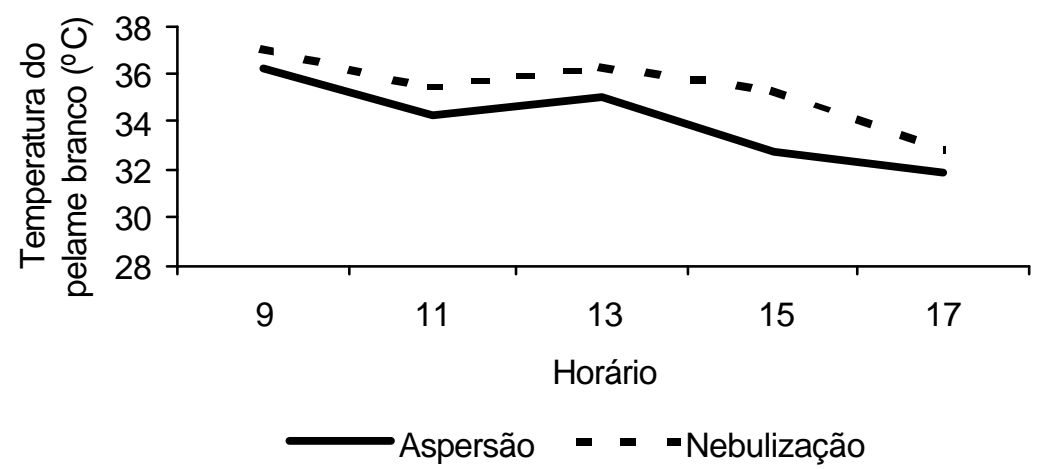

Figura 22 - Médias de temperatura da superfície da pele branca dos animais, nos diferentes tratamentos, nos horários analisados

A observação da temperatura média do pelame branco dos animais mostra uma tendência de diminuição durante o decorrer do dia, para ambos os tratamentos estudados. No tratamento com nebulização, assim como ocorreu com a TR e com a FR, a TPB atingiu valores superiores aos encontrados no tratamento com aspersão, durante todos os horários analisados. Nos horários das 9:00 h $\left(36,2\right.$ e 37, $\left.1^{\circ} \mathrm{C}\right), 11: 00 \mathrm{~h}$ $\left(34,2\right.$ e $\left.35,5^{\circ} \mathrm{C}\right)$ e $17: 00 \mathrm{~h}\left(31,9\right.$ e $\left.32,8^{\circ} \mathrm{C}\right)$, para os tratamentos com aspersão e 
nebulização, respectivamente, essa diferença não foi estatisticamente significativa. Encontrou-se diferença estatística significativa entre os sistemas de climatização nos horários das 13:00 h $(35,0$ e 36,3) e 15:00 h $(32,7$ e 35,3) para os tratamentos com aspersão e nebulização, respectivamente.

O fato da TPB diminuir ao longo do dia se explica pela maior porcentagem de animais próximos ao sistema de climatização, durante o período mais quente do dia, apresentando uma variação média de $4,3^{\circ} \mathrm{C}$ para ambos os tratamentos estudados.

\subsubsection{Temperatura da superfície do pelame preto (TPP)}

A Figura 23 mostra as médias da temperatura do pelame preto dos animais, nos diferentes tratamentos, obtidos durante os nove dias de coleta de dados, nos horários analisados.

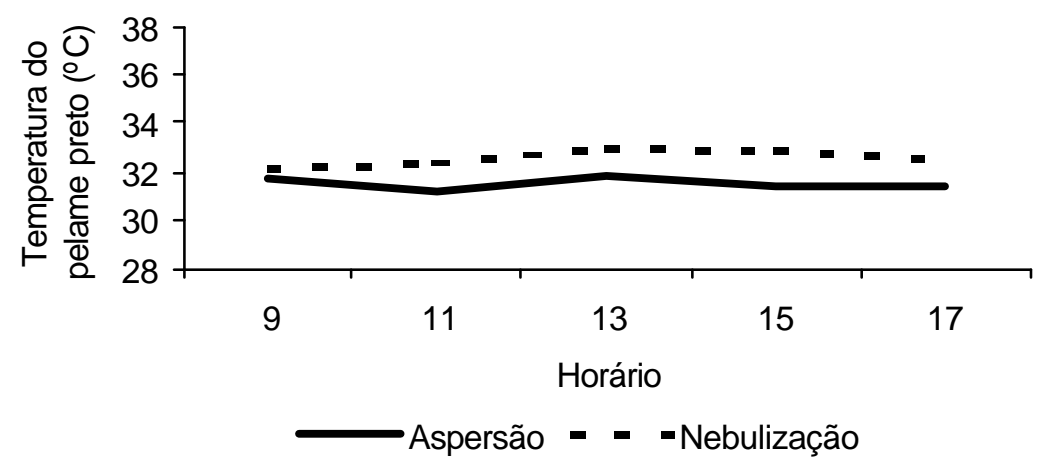

Figura 23 - Médias de temperatura da superfície da pele preta dos animais, nos diferentes tratamentos, nos horários analisados

A observação da temperatura média do pelame preto dos animais mostra pouca variação no decorrer do dia, para ambos os tratamentos estudados, sendo a diferença entre a maior e a menor temperatura coletada de $0,6^{\circ} \mathrm{C}$ para o $\mathrm{TA}$ e $0,8^{\circ} \mathrm{C}$ para o $\mathrm{TN}$. No tratamento com nebulização, assim como ocorreu com as demais variáveis fisiológicas estudadas, a TPP atingiu valores superiores aos encontrados no tratamento com aspersão, durante todos os horários analisados. Da mesma forma, em todos os horários analisados não se observou diferença estatística entre os sistemas de climatização testados. As médias de TPP encontradas para os tratamentos com 
aspersão e nebulização, respectivamente, foram: 31,7 e $32,2^{\circ} \mathrm{C}(9: 00 \mathrm{~h}), 31,2$ e $32,3^{\circ} \mathrm{C}$

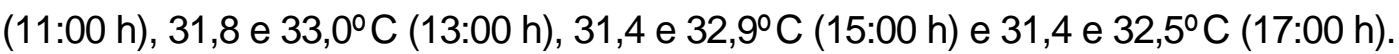

A TPP praticamente não variou ao longo do dia no TA e no TN, e foi menor que a TPB, ficando por volta de $32^{\circ} \mathrm{C}$. Segundo Silva et al. (2001), a quantidade de radiação transmitida através do pelame depende da coloração e também das características estruturais do pelame (espessura da capa; comprimento, diâmetro, número e inclinação dos pêlos), pelas quais é definido o trajeto médio de um fóton pela massa de pêlos (L). A maior transmissão é proporcionada por pelames brancos com altos valores de $L$, ao passo que pelames negros em geral apresentam transmissão nula ou muito baixa. Desta forma, o pelame preto tendo uma maior absorção, e menor transmissão, acaba trocando menos calor com o ambiente que o pelame branco, mantendo uma menor temperatura, devido ao contato com o resfriamento, e tendo uma menor variação ao longo do dia.

\subsection{Parâmetro comportamental}

\subsubsection{Tempo despendido em cada atividade}

A tabela 10 apresenta a média do tempo, em minutos, em que os cinco animais selecionados para a análise comportamental realizaram cada atividade, ou seja, o tempo em que permaneceram comendo, bebendo, ruminando e em ócio e o tempo em que estiveram em pé e deitados, nos diferentes tratamentos, e as diferenças estatísticas entre os sistemas de climatização avaliados. O tempo médio em que os animais foram monitorados pelas vídeo-câmeras foi de 6 h $40 \mathrm{~min}$ (400 min), sendo que, durante o período da ordenha, não foram registrados os dados de comportamento.

De acordo com a Tabela 10 e com a Figura 24, o tempo em ruminação e o tempo gasto no bebedouro não apresentaram diferenças estatísticas significativas entre os sistemas de climatização estudados, sendo despendido 120 e 107,4 min em ruminação e 20 e 17 min bebendo, nos tratamentos com aspersão e nebulização, respectivamente. A literatura apresenta vários trabalhos que apontam o aumento no consumo de água em altas temperaturas, porém, como não se observaram diferenças 
significativas na temperatura ambiente dos dois tratamentos, não foram observadas, conseqüentemente, diferenças significativas no tempo de consumo de água entre os tratamentos.

Observou-se que os animais do TA passaram significativamente mais tempo comendo (120 min), em relação aos 66,1 min do TN, e um menor tempo em ócio (140 min), em relação aos 209,5 min do TN. Resultados semelhantes foram obtidos por Frazzi et al. (1998) e Lin et al. (1998), que observaram um aumento no tempo despendido no cocho em vacas que recebiam resfriamento por aspersão, reduzindo, conseqüentemente, o tempo em ócio e de permanência nas camas.

Tabela 10. Média do tempo, em minutos, em que os animais realizaram cada atividade nos diferentes tratamentos

\begin{tabular}{lcc}
\hline Atividades & \multicolumn{2}{c}{ Tratamentos } \\
\hline \multirow{3}{*}{ Comendo } & Aspersão & Nebulização \\
Bebendo & $120,0^{a}$ & $66,1^{\mathrm{b}}$ \\
Ruminando & $20,0^{\mathrm{a}}$ & $17,0^{\mathrm{a}}$ \\
Ócio & $120,0^{\mathrm{a}}$ & 107,4 \\
Em pé & $230,0^{\mathrm{a}}$ & $209,5^{\mathrm{a}}$ \\
Deitado & $188,3^{\mathrm{b}}$ \\
a,o - Médias seguidas de letras distintas na mesma linha diferem \\
(p<0,05) pelo teste Tukey.
\end{tabular}

Encontrou-se, também, diferença significativa entre o tempo em que os animais permaneceram em pé e deitados, sendo encontrados os valores de 230,0 e 188,3 min em pé e 170 e 211,7 min deitados para os tratamentos com aspersão e nebulização, respectivamente.

A Figura 24 mostra a média do tempo, em minutos, em que os animais selecionados para a análise comportamental realizaram cada atividade, nos diferentes tratamentos. 


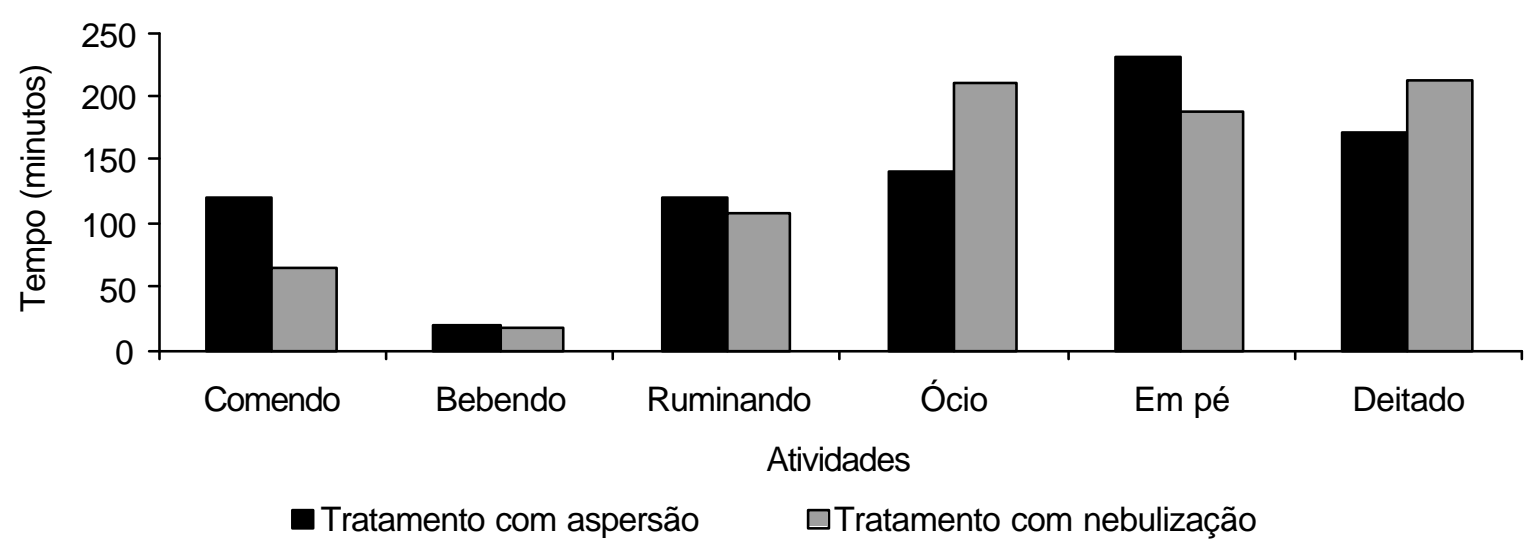

Figura 24 - Tempo, em minutos, em que os animais realizaram cada atividade nos diferentes tratamentos

A tabela 11 apresenta a média do tempo, em porcentagem, em que os cinco animais selecionados para a análise comportamental realizaram cada atividade, nos diferentes tratamentos.

Tabela 11. Média do tempo, em porcentagem, em que os animais realizaram cada atividade nos diferentes tratamentos

\begin{tabular}{lcc}
\hline Atividades & \multicolumn{2}{c}{ Tratamentos } \\
\hline \multirow{3}{*}{ Comendo } & Aspersão & Nebulização \\
Bebendo & $50,0^{\mathrm{a}}$ & $16,5^{\mathrm{b}}$ \\
Ruminando & $30,0^{\mathrm{a}}$ & $4,2^{\mathrm{a}}$ \\
Ócio & $35,0^{\mathrm{b}}$ & $26,8^{\mathrm{a}}$ \\
Em pé & $57,5^{\mathrm{a}}$ & $47,1^{\mathrm{b}}$ \\
Deitado & $42,5^{\mathrm{b}}$ & $52,9^{\mathrm{a}}$ \\
\hline a,o- Médias seguidas de letras distintas na mesma linha diferem \\
(p<0,05) pelo teste Tukey.
\end{tabular}

A análise da Tabela 11 e da Figura 25, como já era esperado, mostra a mesma tendência, para a porcentagem de tempo, da encontrada no tempo em minutos em cada atividade, ou seja, o tempo em ruminação e o tempo gasto no bebedouro não 
apresentaram diferença estatística significativa entre os sistemas de climatização estudados, despendendo 30,0 e 26,8\% do tempo em ruminação e 5,0 e 4,2\% do tempo bebendo, nos tratamentos com aspersão e nebulização, respectivamente.

A Figura 25 mostra a média do tempo, em porcentagem, em que os animais selecionados para a análise comportamental realizaram cada atividade, nos diferentes tratamentos.

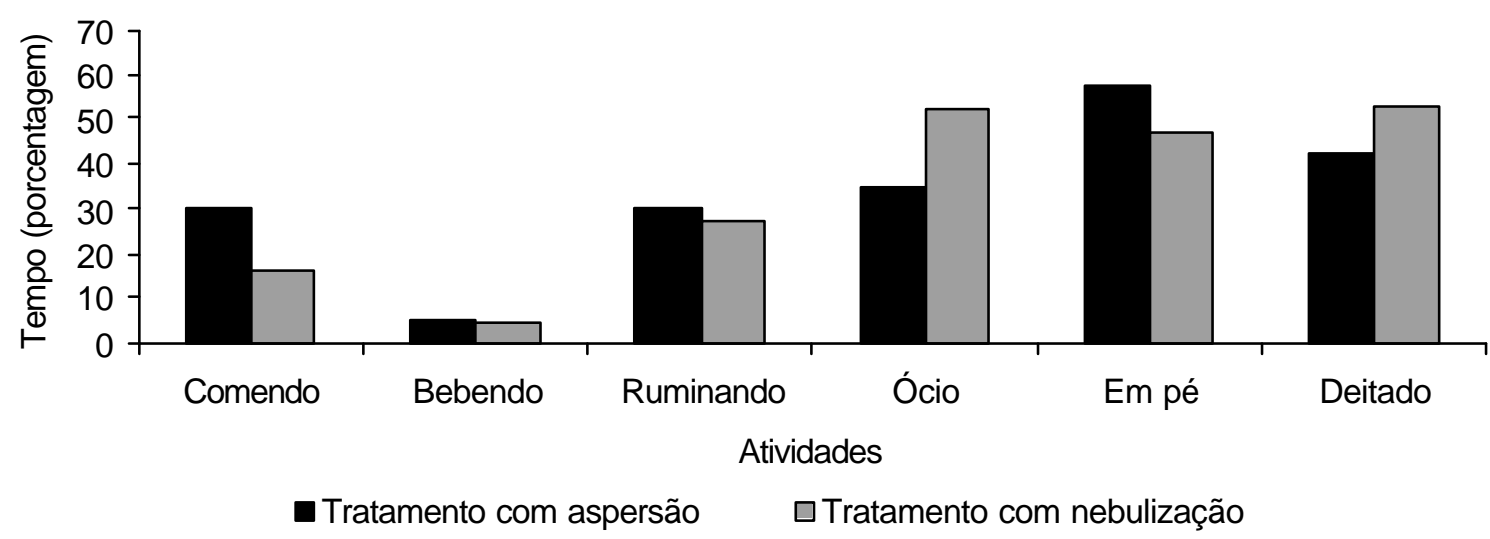

Figura 25 - Porcentagem do tempo em que os animais realizaram cada atividade, nos tratamentos estudados

Os animais do TA passaram significativamente mais tempo comendo (30\%), em relação aos 16,5 min do TN, e um menor tempo em ócio (35\%), em relação aos 52,4\% do TN.

Houve diferença significativa entre a porcentagem do tempo em que os animais permaneceram em pé e deitados, sendo encontrados os valores de 57,5 e 47,1\% em pé e 42,5 e $52,9 \%$ deitados para os tratamentos com aspersão e nebulização, respectivamente.

Observa-se que a aspersão de água sobre os animais na linha de cocho estimula-os, principalmente, a permanecerem nessa área por um maior período de tempo, possibilitando a redução do tempo em ócio. Em experimento conduzido por Frazzi et al. (1998), observou-se que, em estábulos sem climatização, as vacas permanecem mais tempo deitadas e deixam a área de alimentação mais rápido. 


\subsubsection{Tempo despendido em cada local da instalação}

A tabela 12 apresenta a média do tempo, em minutos, em que os animais selecionados para a análise comportamental permaneceram em cada local dentro da instalação, ou seja, o tempo em que permaneceram na área do cocho, no bebedouro, na linha de camas próxima à climatização, na linha de camas oposta à linha de climatização (visto que as camas se dividem em 2 blocos dispostos frente a frente), no corredor próximo àclimatização e no corredor distante da climatização, nos diferentes tratamentos.

Tabela 12. Média do tempo, em minutos, em que os animais permanecem em cada local, dentro da instalação, nos diferentes tratamentos

\begin{tabular}{lcc}
\hline Atividades & \multicolumn{2}{c}{ Tratamentos } \\
\hline \multirow{2}{*}{ Na área de cocho } & $115,0^{\mathrm{a}}$ & $66,0^{\mathrm{b}}$ \\
Na área do bebedouro & $24,0^{\mathrm{a}}$ & $16,0^{\mathrm{a}}$ \\
Cama próxima àclimatização & $164,0^{\mathrm{a}}$ & $156,0^{\mathrm{a}}$ \\
Cama oposta àclimatização & $29,0^{\mathrm{b}}$ & $66,0^{\mathrm{a}}$ \\
Corredor próximo àclimatização & $52,0^{\mathrm{a}}$ & $67,0^{\mathrm{a}}$ \\
Corredor oposto àclimatização & $16,0^{\mathrm{b}}$ & $29,0^{\mathrm{a}}$ \\
a,o - Médias seguidas de letras distintas na mesma linha diferem $(p<0,05)$ \\
pelo teste Tukey.
\end{tabular}

O tempo gasto na área de cocho difere entre os sistemas de climatização estudados, verificando-se que os animais do TA gastam mais tempo se alimentando (115 min) em relação aos animais do TN (66 min), concordando com os resultados obtidos com relação ao tempo despendido em cada atividade.

O tempo no bebedouro não foi estatisticamente diferente entre os tratamentos, observando 24 min gastos nesse local pelos animais do TA e 16 min pelos do TN. Vale enfatizar que os bebedouros se localizavam no lado oposto ao cocho, distantes da climatização, o que pode ter desestimulado a presença dos animais nos bebedouros. 
A Figura 26 mostra a média do tempo, em minutos, em que os animais selecionados para a análise comportamental permaneceram em cada local, dentro da instalação, nos diferentes tratamentos.

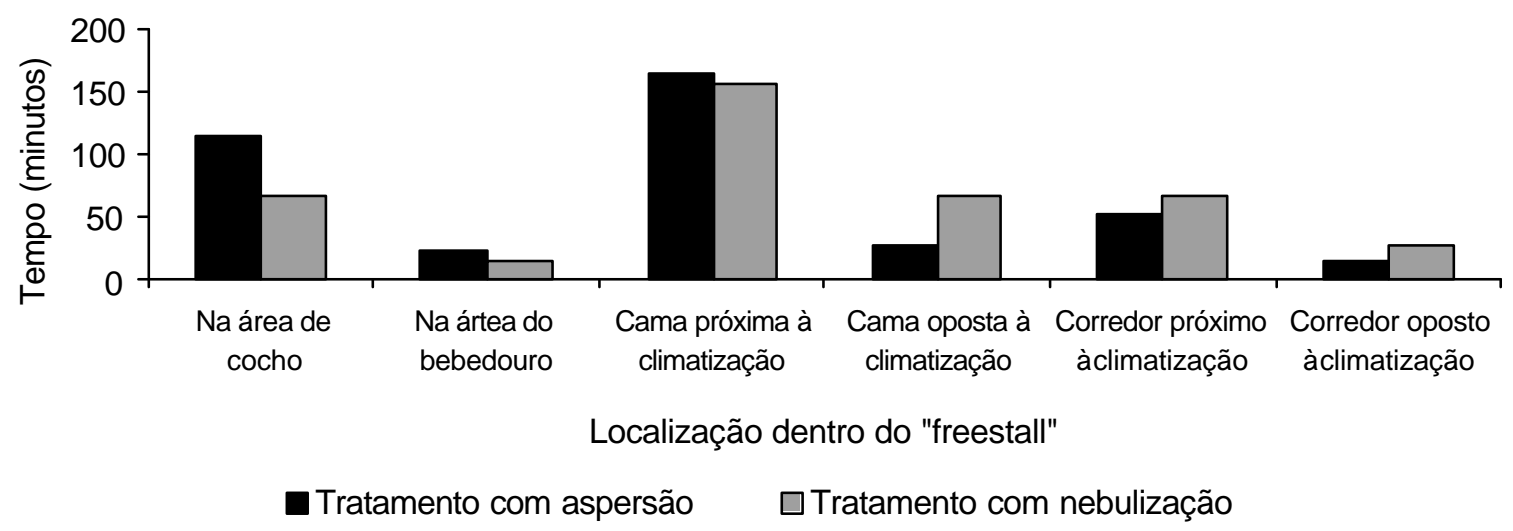

Figura 26 - Tempo, em minutos, em que os animais permanecem em cada local, dentro do "freestall', nos tratamentos estudados

O lado climatizado da instalação foi o mais visitado, em ambos os tratamentos, sem diferença significativa entre estes, com valores de 164,0 e 156,0 min no corredor com climatização e 52,0 e 67,0 min na cama com climatização, para os tratamentos com aspersão e nebulização, respectivamente. Observa-se que o TA atraiu os animais por muito mais tempo para sua proximidade que o $\mathrm{TN}$, justamente pela sensação de frescor propiciado aos mesmos pela água em contato com o corpo do animal, através da sua evaporação.

O lado da instalação sem climatização foi significativamente mais visitado pelos animais do TN, com tempos de 66,0 min na cama sem climatização, contra 29,0 min do TA, e 29,0 min no corredor sem climatização, em comparação aos 16,0 min gastos pelos animais do TA. Esse fato ocorreu exatamente pela maior atração do TA para as proximidades do sistema de climatização.

A tabela 13 apresenta a média do tempo, em porcentagem, em que os animais selecionados para a análise comportamental permaneceram em cada local, dentro da instalação, nos diferentes tratamentos.

Como era de se esperar, a média do tempo em porcentagem seguiu o mesmo padrão de comportamento que a média de tempo em minutos. 
Tabela 13. Média do tempo, em porcentagem, em que os animais permanecem em cada local, dentro da instalação, nos diferentes tratamentos

\begin{tabular}{|c|c|c|}
\hline \multirow[t]{2}{*}{ Atividades } & \multicolumn{2}{|c|}{ Tratamentos } \\
\hline & Aspersão & Nebulização \\
\hline $\mathrm{Na}$ área de cocho & $28,8^{a}$ & $16,5^{\mathrm{b}}$ \\
\hline Na área do bebedouro & $6,0^{\mathrm{a}}$ & $4,0^{\mathrm{a}}$ \\
\hline Cama próxima àclimatização & $41,0^{a}$ & $39,0^{a}$ \\
\hline Cama oposta àclimatização & $7,3^{b}$ & $16,5^{\mathrm{a}}$ \\
\hline Corredor próximo àclimatização & $13,0^{a}$ & $16,8^{a}$ \\
\hline Corredor oposto àclimatização & $4,0^{b}$ & $7,3^{a}$ \\
\hline
\end{tabular}

A Figura 27 mostra a média do tempo, em porcentagem, em que os animais selecionados para a análise comportamental permaneceram em cada local, dentro da instalação, nos diferentes tratamentos.

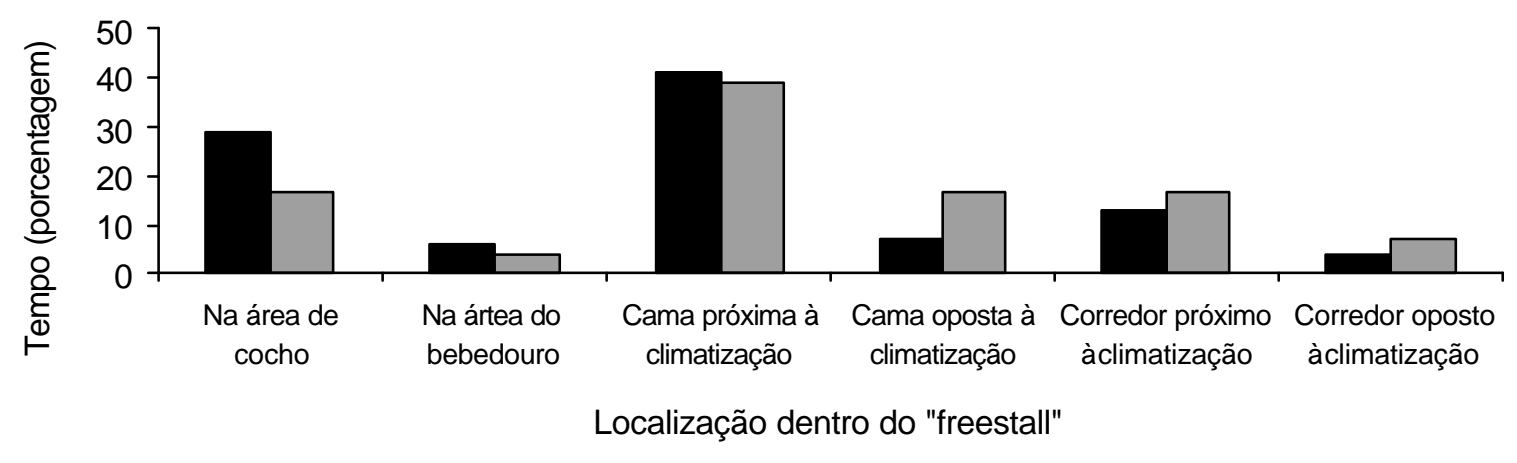

- Tratamento com aspersão $\quad \square$ Tratamento com nebulização

Figura 27 - Porcentagem do tempo em que os animais permanecem em cada local dentro do "freestall", nos tratamentos estudados

Os amimais gastaram 28,8 e 16,5\% do tempo alimentando-se nos tratamentos com aspersão e nebulização, respectivamente, sendo essas porcentagens de tempo significativamente diferentes. 
O tempo de permanência no bebedouro não foi estatisticamente diferente entre os tratamentos, observando $6 \%$ do tempo gasto neste local pelos animais do TA e $4 \%$ gasto pelos animais do TN.

A porcentagem de tempo nos locais próximos à climatização não apresentou diferença significativa entre os tratamentos, com valores de 41,0 e $39,0 \%$ do tempo no corredor com climatização e 13,0 e 16,8\% do tempo na cama com climatização, para os tratamentos com aspersão e nebulização, respectivamente.

Por sua vez, o lado da instalação sem climatização foi significativamente mais visitado pelos animais do TN, com $16,5 \%$ do tempo na cama sem climatização, contra 7,3\% do tempo do TA, e 7,3\% do tempo no corredor sem climatização, em comparação aos $4 \%$ do tempo gastos pelos animais do TA.

\subsubsection{Ingestão de matéria seca}

Para a determinação da ingestão de alimentos pelos animais, registrou-se o consumo diário, por diferença de peso entre o que era fornecido e a sobra, sendo esse valor dividido pelo número de animais do lote, o que possibilitou a obtenção do consumo de alimento diário por animal. Para a determinação dos dados de ingestão de matéria seca (MS) amostrou-se semanalmente o alimento, que foi analisado em laboratório, fornecendo a porcentagem de matéria seca do alimento disponibilizado para os animais, valor este que possibilitou a determinação da média de ingestão de matéria seca pelos animais por dia (Tabela 14).

Tabela 14. Médias de ingestão de matéria seca pelos animais, nos diferentes tratamentos

\begin{tabular}{lc}
\hline Tratamento & Consumo média de MS (kg.d $\left.{ }^{-1}\right)$ \\
\hline Aspersão & $15,0^{a}$ \\
Nebulização & $14,9^{b}$ \\
\hline$a, b$ - Médias seguidas de letras distintas na mesma linha diferem \\
$(p<0,05)$ pelo teste Tukey.
\end{tabular}

Pela análise da Tabela 14, conclui-se que o consumo de alimentos $\left(\mathrm{kg}^{-\mathrm{d}^{-1}}\right)$ dos 
animais confinados em local que dispõe de sistema de dimatização com aspersão associada à ventilação forçada não difere estatisticamente do consumo dos animais confinados em locais com sistema de climatização com nebulização associada à ventilação forçada, sendo essa diferença de apenas $1 \%$, equivalendo, segundo os dados obtidos, a $3 \mathrm{~kg}$ de MS.animal ${ }^{-1}$. $\mathrm{mês}^{-1}$.

Observa-se que mesmo que os animais do TA tenham permanecido aproximadamente $12,2 \%$ a mais do tempo na área de cocho que os animais do TN e que, pela análise comportamental, tenham permanecido $14,5 \%$ a mais do tempo comendo em TA que em TN, em termos de quantidade de alimento consumido, não houve diferença entre os tratamentos. Esse fato sugere que o TA realmente atrai os animais para sua proximidade, faz com que permaneçam mais tempo ao seu redor, porém, isso não reflete em quantidade de alimento ingerido em comparação com o TN.

\subsection{Produção de leite}

Para a determinação da produção de leite em cada sistema de climatização, utilizaram-se os dez animais previamente selecionados, para cada tratamento, de acordo com a produção e estágio de lactação. Os dados foram registrados de acordo com o controle da granja, e os dados médios, durante o período experimental, são apresentados na Tabela 15.

Tabela 15. Médias de produção de leite, nos diferentes tratamentos, durante o período experimental

\begin{tabular}{lc}
\hline Tratamento & Produção de leite média (litros) \\
\hline Aspersão & $20,3^{a}$ \\
Nebulização & $19,7^{a}$ \\
\hline$a, b$ & Médias seguidas de letras distintas na mesma linha diferem \\
$(p<0,05)$ pelo teste Tukey.
\end{tabular}

A análise da Tabela 15 mostra que não houve diferença estatística significativa na produção média de leite entre os animais do TA e os do TN. Mesmo não havendo 
diferença significativa entre os dados de produção média de leite, observa-se que, em TA, a produção foi 0,6 l.animal ${ }^{-1} \cdot$ mês $^{-1}(3 \%)$ maior que em TN. Esse fato a nível econômico é significativo, ocasionando um aumento na receita mensal total de aproximadamente $5,8 \%$ por animal, quando comparado ao sistema de nebulização, o que equivale a cerca de $\mathrm{R} \$ 6,00$.animal ${ }^{-1} \cdot \mathrm{mês}^{-1}$, como será visto na análise econômica.

Os resultados concordam com as pesquisas realizadas por Bucklin \& Bray (1998), Chastain \& Turner (1994), Frazzi et al. (1998) e Lin et al. (1998), entre outros, nos quais o sistema de aspersão promoveu aumentos de até $12,7 \%$ na produção diária de leite, quando comparado a sistemas de produção não climatizados.

A maior produção no TA pode estar relacionada principalmente aos melhores resultados obtidos com este sistema com relação às variáveis fisiológicas, assim como o fato de "molhar" o bovino, corresponder a uma "sensação" de bem-estar que foi evidenciado na análise comportamental dos animais.

\subsection{Indicativo econômico}

A seguir serão apresentados os resultados referentes àanálise econômica dos resultados e as tabelas referentes a essa análise estão sumanizadas no Anexo.

O sistema de climatização com aspersão ficou ligado em média 9,2 h e o com nebulização 9,8 h. De acordo com os resultados obtidos, o consumo de água mensal pelo sistema de aspersão foi cerca de 11 vezes maior em relação ao sistema de nebulização, sendo que se consumiram aproximadamente 8.270 l.animal ${ }^{-1} \cdot \mathrm{mês}^{-1}$, utilizando-se o sistema de aspersão e cerca de 730 I.animal $^{-1}$.mês ${ }^{-1}$ com a utilização do sistema de nebulização. Em experimento realizado por Lin, (1998), o gasto de água do sistema de aspersão foi 10 vezes maior que o sistema de nebulização, valor próximo ao encontrado neste experimento.

Os custos com água referem-se ao valor de bombeamento, que foi cerca de $14,8 \mathrm{~kW} \cdot \mathrm{h}^{-1}$ para bombear 1000 litros do produto. Para o tratamento com aspersão, esse custo foi de $R \$ 2,00 \cdot \mathrm{mês}^{-1}$.animal ${ }^{-1}$, equivalendo a um gasto de 12,3 kW.mês ${ }^{1}$.animal ${ }^{-1}$. Por outro lado, o sistema equipado com nebulizadores gastou $R \$ 0,18$ mês ${ }^{-}$ ${ }^{1}$.animal ${ }^{-1}$, referente a $1,2 \mathrm{~kW} \cdot \mathrm{mês}^{-1} \cdot$ animal $^{-1}$. 
O gasto com energia elétrica para o acionamento dos 10 ventiladores integrantes do sistema de ventilação foi cerca de 1020,1 kW.mês ${ }^{-1}$ (102 kW.mês ${ }^{1}$.ventilador ${ }^{-1}$ ) no TA e cerca de 1089 kW.mês ${ }^{-1}$ (109 kW.mês ${ }^{-1}$.ventilador ${ }^{-1}$ ) no TN, equivalendo a um custo de $R \$ 166,3 \cdot$ mês $^{-1}\left(R \$ 16,6\right.$. ês $^{-1}$.ventilador $\left.{ }^{-1}\right)$ e $R \$ 177,5$.mês 1 (R $\$ 17,7$. mês $^{-1}$.ventilador $\left.{ }^{-1}\right)$, para o $\mathrm{TA}$ e $\mathrm{TN}$, respectivamente. Esses números equivalem a um custo de $\mathrm{R} \$ 2,8 \cdot \mathrm{mês}^{-1}$. animal $^{-1}\left(17,0 \mathrm{~kW} \cdot \mathrm{mês}^{-1}\right.$. animal $\left.^{-1}\right)$ no TA e de aproximadamente $\mathrm{R} \$ 3,0 \cdot \mathrm{mês}^{-1}$. animal $^{-1}\left(18,1 \mathrm{~kW} \cdot \mathrm{mês}^{-1}\right.$. animal $\left.{ }^{-1}\right)$ no TN.

Para o acionamento da bomba do sistema de climatização, gasta-se $R \$$ 1,1. mês $^{-1}$.animal ${ }^{-1}\left(6,8 \mathrm{~kW} \cdot \mathrm{mês}^{-1}\right.$.animal $\left.{ }^{-1}\right)$ e $\mathrm{R} \$$ 0,6. mês $^{-1} \cdot$ animal $^{-1}$ (3,65 kW.mês ${ }^{1}$.animal ${ }^{-1}$ ) no TA e no TN, respectivamente.

O gasto com energia elétrica para funcionamento do sistema climatização (bombeamento de água, acionamento do sistema e ventilação), como conseqüência dos valores citados acima, assim como o consumo de água, foi maior no tratamento com aspersão, com um consumo total de cerca de 2160 kW.mês ${ }^{-1}$ (36 kW.mês ${ }^{1}$.animal ${ }^{-1}$ ) em comparação com aproximadamente 1370 kW.mês ${ }^{-1}$ (22,9 kW.mês ${ }^{1}$. animal $^{-1}$ ) do sistema com nebulização (diferença de 36,5\%). Esses valores equivalem a um custo de cerca de $\mathrm{R} \$ 5,9 . \mathrm{mês}^{-1}$.animal ${ }^{-1}$ e $\mathrm{R} \$ 3,8 . \mathrm{mês}^{-1}$. animal ${ }^{-1}$ no TA e no TN, respectivamente.

O TA possibilitou um incremento em produção de 3\% (18,0 I.mês ${ }^{-1}$.animal $\left.{ }^{-1}\right)$ em relação ao TN, o que não apresentou diferença estatística significativa, porém, esse aumento em produção equivale a um incremento de aproximadamente $R \$ 6,00$ mês ${ }^{1}$.animal ${ }^{-1}$, podendo viabilizar o sistem a de aspersão quando se trabalha em escala de produção. O sistema de aspersão, permitiu conseqüentemente um aumento de 5,8\% na receita total do produtor. 


\section{CONCLUSÕES}

De acordo com os resultados obtidos no presente trabalho, pode-se concluir que:

1. O sistema de resfriamento por nebulização conjugado com ventilação forçada, proporcionou um ambiente mais confortável termicamente que o sistema de resfriamento por aspersão também conjugado com ventilação forçada, porém ambos mantiveram um ambiente com condições temohigrométricas acima das recomendadas pela literatura.

2. Os sistemas de resfriamento estudados não promoveram diferenças significativas na temperatura retal, freqüência respiratória e temperatura do pelame, porém observou-se uma tendência da aspersão melhorar essas variáveis em relação ànebulização.

3. O comportamento dos animais dentro do sistema de confinamento foi significativamente afetado pelos sistemas de climatização estudados. Os animais preferiram permanecerem próximos aos sistemas de resfriamento, porém o sistema de aspersão fez com que os animais permanecessem mais tempo na área de cocho e menos tempo em ócio que o sistema por nebulização.

4. O sistema de resfriamento por aspersão apresentou um consumo de água 11 vezes maior que o sistema de resfriamento por nebulização. A aspersão também obteve um gasto de energia maior que a nebulização.

5. Os sistemas de resfriamento estudados, não promoveram diferenças quanto ao consumo de alimentos, porém o sistema de aspersão promoveu um aumento na produção de leite de 3\% (18,0 litros/animal/mês) ocasionando um aumento na receita mensal total de aproximadamente 5,8\% por animal quando comparado ao sistema de nebulização. 
ANEXO 
Anexo. Consumo médio de água (em litros e em $R \$$ ) e energia elétrica (em kw e em $R \$$ ) e produção de leite (em litros e em $R \$$ ), por animal e para os 60 animais da instalação, nos sistemas de climatização testados

\begin{tabular}{|c|c|c|c|}
\hline Consumo de água na linha de climatização & Aspersão $\mathrm{N}$ & ebulização & \\
\hline Média /dia ligado (horas) & 9,2 & 9,8 & \\
\hline Consumo de água/bico (l/h) & 30 & 2,5 & \\
\hline Consumo de água/bico (l/dia) & 275,7 & 24,5 & \\
\hline Consumo de água/bico (l/mês) & 8271,4 & 735,7 & \\
\hline Número de bicos & 60,0 & 60,0 & \\
\hline Consumo de água/ 60 bicos (l/h) & 1800 & 150 & \\
\hline Consumo de água/ 60 bicos/dia (I) & 16542,9 & 1471,4 & \\
\hline Consumo de água/ 60 bicos/mês (I) & 496285,7 & 44142,9 & \\
\hline Consumo de água/animal/dia (I) & 275,7 & 24,5 & \\
\hline Consumo de água/animal/mês (I) & 8271,4 & 735,7 & \\
\hline Consumo de energia na linha de climá & tização & Aspersão & Nebulização \\
\hline Consumo de energia da bomba (kW/h) & & 1,48 & 0,74 \\
\hline Consumo de energia da bomba na linha/dia & (kW) & 13,6 & 7,3 \\
\hline Preço do kW/h $(\mathrm{R} \$)$ & & 0,163 & 0,163 \\
\hline Gasto com energia pela bomba na linha/anir & nal/dia $(\mathrm{kW})$ & 0,23 & 0,12 \\
\hline Gasto com energia pela bomba na linha/anir & nal/mês (kW) & 6,8 & 3,65 \\
\hline Gasto com energia pela bomba na linha/dia & $\mathrm{R} \$)$ & 2,2 & 1,2 \\
\hline Gasto com energia pela bomba na linha/mês & $(\mathrm{R} \$)$ & 66,5 & 35,5 \\
\hline Gasto com energia pela bomba na linha/anir & nal/dia $(R \$)$ & 0,04 & 0,02 \\
\hline Gasto com energia pela bomba na linha/ani & nal/mês $(R \$)$ & 1,1 & 0,6 \\
\hline
\end{tabular}

\begin{tabular}{lcc}
\hline Consumo de energia p/ bombear a água & Aspersão & Nebulização \\
\hline Gasto p/ bombear 1000 I de água (kW/h) & 14,8 & 14,8 \\
Gasto p/ bombear a água/dia (kW) & 24,5 & 2,2 \\
Gasto p/ bombear a água/mês (kW) & 734,5 & 65,3 \\
Gasto p/ bombear água/animal/dia (kW) & 0,41 & 0,04
\end{tabular}




\begin{tabular}{lcc} 
Gasto $\mathrm{p} /$ bombear água/animal/mês $(\mathrm{kW})$ & 12,3 & 1,2 \\
\hline Gasto $\mathrm{p} /$ bombear água/dia $(\mathrm{R} \$)$ & 4,0 & 0,4 \\
Gasto $\mathrm{p} /$ bombear água/mês $(\mathrm{R} \$)$ & 119,7 & 10,6 \\
Gasto $\mathrm{p} /$ bombear água/animal/dia $(\mathrm{R} \$)$ & 0,07 & 0,01 \\
Gasto $\mathrm{p} /$ bombear água/animal/mês $(\mathrm{R} \$)$ & 2,0 & 0,18 \\
\hline
\end{tabular}

\begin{tabular}{lcc}
\hline Consumo de energia do sistema de ventilação & Aspersão & Nebulização \\
\hline Média /dia ligado (horas) & 9,2 & 9,8 \\
Consumo de energia/ventilador (kW/h) & 0,37 & 0,37 \\
Consumo de energia/10 ventil (kW/h) & 3,7 & 3,7 \\
Consumo de energia/10 ventil (kW/dia) & 34,0 & 36,3 \\
Consumo de energia/10 ventil (kW/mês) & 1020,1 & 1088,9 \\
Gasto de energia com vent/animal (kW/dia) & 0,56 & 0,60 \\
Gasto de energia com vent/animal (kW/mês) & 17,0 & 18,1 \\
Gasto de energia com 10 vent (R\$/dia) & 5,5 & 5,9 \\
Gasto de energia com 10 vent (R\$/mês) & 166,3 & 177,5 \\
Gasto de energia com vent/animal (R\$/dia) & 0,09 & 0,10 \\
Gasto de energia com vent/animal (R\$/mês) & 2,77 & 2,96 \\
\hline
\end{tabular}

\begin{tabular}{lcc}
\hline \multicolumn{1}{c}{ Gasto diário com energia (kW) } & Aspersão & Nebulização \\
\hline Gasto com energia na linha (kW/dia) & 13,6 & 7,30 \\
Gasto com energia p/ bombear água (kW/dia) & 24,5 & 2,20 \\
Gasto com ventilação (kW/dia) & 34,0 & 36,30 \\
Total (kW/dia) & 72,1 & 45,80 \\
Total (kW/dia)/animal & 1,2 & 0,76 \\
\hline \multicolumn{3}{c}{ Gasto mensal com energia (kW) } \\
Gasto com energia na linha (kW/mês) & 408,0 & \\
Gasto com energia p/ bombear água (kW/mês) & 735,0 & Nebulização \\
Gasto com ventilação (kW/mês) & 1020,0 & 1089,0 \\
Total (kW/mês) & 2163,0 & 1374,0 \\
Total (kW/mês)/animal & 36,05 & 22,9 \\
\hline
\end{tabular}




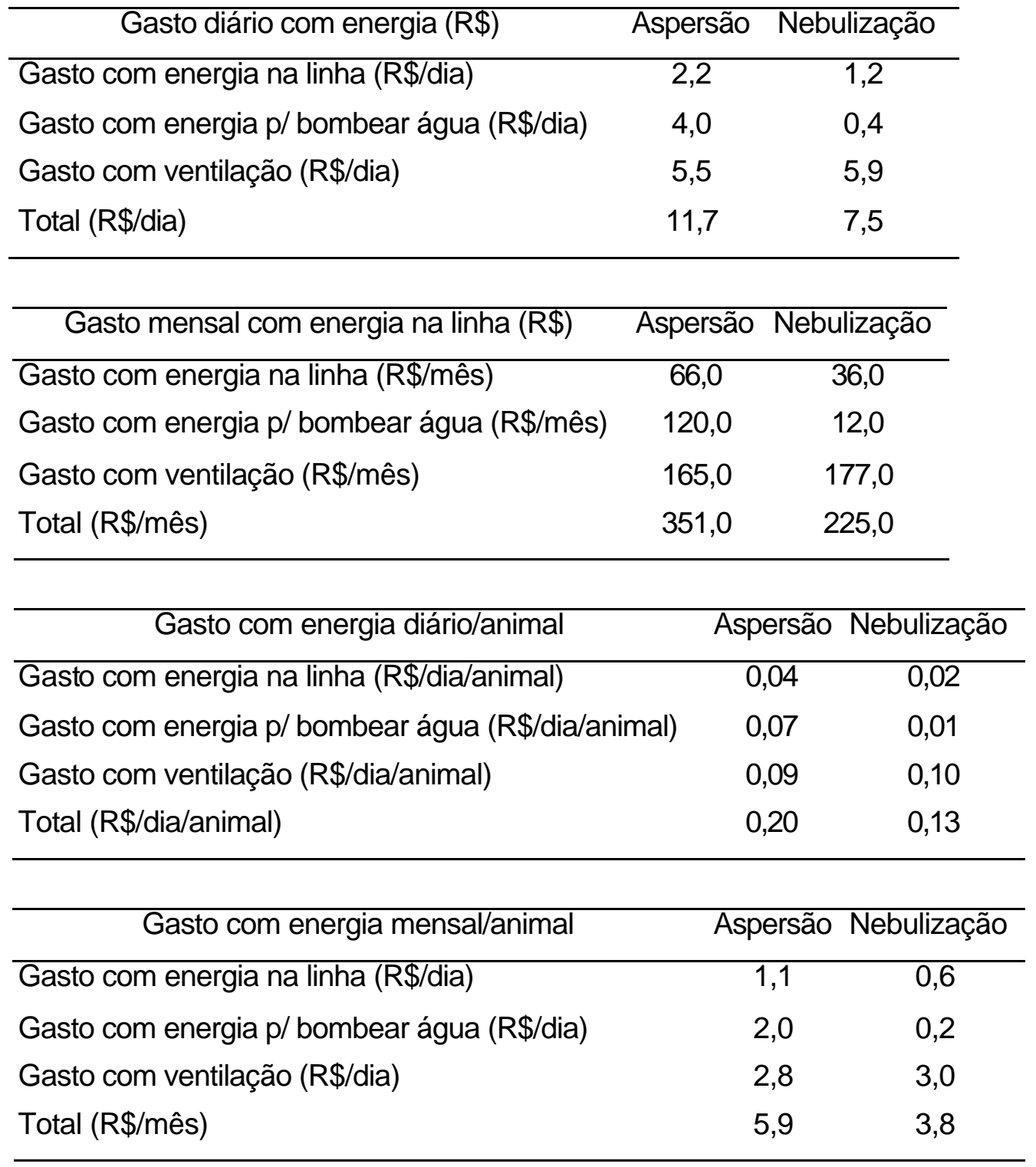

\begin{tabular}{lcc}
\hline \multicolumn{1}{c}{ Produção de leite/animal } & Aspersão & Nebulização \\
\hline Produção média de leite/animal/dia & 20,3 & 19,7 \\
Preço do leite (R $\$ /$ dia) & 0,45 & 0,45 \\
Ganho com o leite (R $\$ /$ dia/animal) & 9,14 & 8,9 \\
Produção média de leite/animal/mês & 609 & 591 \\
Ganho com o leite (R $\$$ /mês/animal) & 274,1 & 266,0 \\
\hline
\end{tabular}




\begin{tabular}{lrc}
\hline \multicolumn{1}{c}{ Produção de leite/60 animais } & Aspersão & Nebulização \\
\hline Produção média de leite/ 60 animais/dia & 1218,0 & 1182,0 \\
Preço do leite ( $\mathrm{R} \$$ dia) & 0,45 & 0,45 \\
Ganho com o leite $(\mathrm{R} \$ / \mathrm{dia} / 60$ animais) & 548,1 & 531,9 \\
Produção média de leite/ 60 animais/mês & 36540,0 & 35460,0 \\
Ganho com o leite (R\$/mês/60 animais) & 16443,0 & 15957,0 \\
\hline
\end{tabular}

\begin{tabular}{lccc}
\hline \multicolumn{1}{c}{ Aspersão X Nebulização (por animal) } & Aspersão & Nebulização & Diferença \\
\hline Produção média de leite/animal/dia & 20,3 & 19,7 & 0,6 \\
Ganho com o leite (R\$/dia/animal) & 9,1 & 8,9 & 0,3 \\
Produção média de leite/animal/mês & 609,0 & 591,0 & 18,0 \\
Ganho com o leite (R\$/mês/animal) & 274,1 & 266,0 & 8,1 \\
Gasto total com o sistema de climat/animal/dia & 0,20 & 0,13 & 0,1 \\
Gasto total com o sistema de climat/animal/mês & 5,9 & 3,8 & 2,1 \\
Ganho/dia/animal - gasto/dia/animal & 8,9 & 8,7 & 0,2 \\
Ganho/mês/animal - gasto/mês/animal & 268,2 & 262,2 & 6,0 \\
\hline
\end{tabular}

\begin{tabular}{lccc}
\hline \multicolumn{1}{c}{ Aspersão X Nebulização (60 animais) } & Aspersão & Nebulização & Diferença \\
\hline Produção média de leite/ 60 animais/dia & 1218,0 & 1182,0 & 36,0 \\
Ganho com o leite (R\$/dia/60 animais) & 548,1 & 531,9 & 16,2 \\
Produção média de leite/ 60 animais/mês & 36540,0 & 35460,0 & 1080,0 \\
Ganho com o leite (R\$/mês/60 animais) & 16443,0 & 15957,0 & 486,0 \\
Gasto total com o sistema de climat/60animais/dia & 11,7 & 7,5 & 4,2 \\
Gasto total com o sistema de climat/60animais/mês & 351,0 & 225,0 & 126,0 \\
Ganho/dia/60animais - gasto/dia/60animais & 536,4 & 524,4 & 12,0 \\
Ganho/mês/60animais - gasto/mês/60animais & 15906,6 & 15432,6 & 474,0 \\
\hline
\end{tabular}

\begin{tabular}{lccc}
\hline \multicolumn{1}{c}{ Custo da alimentação } & Aspersão & Nebulização & Diferença \\
\hline Produção média de leite/animal/dia (l) & 20,3 & 19,7 & 0,6 \\
Consumo médio de matéria seca/animal/dia $(\mathrm{kg})$ & 15,00 & 14,90 & 0,10 \\
Consumo médio de matéria seca/animal/mês $(\mathrm{kg})$ & 450,0 & 447,0 &
\end{tabular}




\begin{tabular}{lccc} 
Conversão alimentar (kg MS cons./kg leite prod.) & 0,74 & 0,76 & $-0,02$ \\
\hline Custo/alimentação MS(kg) (R\$) & 0,37 & 0,37 & \\
Custo/alimentação MS(kg) (R\$)/dia/animal & 5,6 & 5,5 & 0,04 \\
Custo/alimentação MS(kg) (R\$)/mês/animal & 166,5 & 165,4 & 1,11 \\
Custo/alimentação MS(kg) (R\$)/dia/60 animais & 333,0 & 330,8 & 2,22 \\
Custo/alimentação MS(kg) (R\$)/mês/60animais & 9990,0 & 9923,4 & 66,60 \\
\hline
\end{tabular}

\begin{tabular}{|c|c|c|c|}
\hline Aspersão X Nebulização (por animal) & Aspersão $\Lambda$ & Nebulização & Diferença \\
\hline Ganho com o leite ( $\mathrm{R} \$ /$ dia/animal) & 9,1 & 8,9 & 0,3 \\
\hline Ganho com o leite (R\$/mês/animal) & 274,1 & 266,0 & 8,1 \\
\hline Gasto total com o sistema de climat/animal/dia $(R \$)$ & 0,20 & 0,13 & 0,1 \\
\hline Gasto total com o sistema de climat/animal/mês $(R \$)$ & 5,9 & 3,8 & 2,1 \\
\hline Gasto com o alimentação/animal/dia (R\$) & 5,6 & 5,5 & 0,1 \\
\hline Gasto com alimentação/animal/mês (R\$) & 166,5 & 166,4 & 0,1 \\
\hline Ganho/dia/animal - gasto/dia/animal ( $\mathrm{R} \$)$ & 3,3 & 3,2 & 0,1 \\
\hline Ganho/mês/animal - gasto/mês/animal (R\$) & 101,7 & 95,8 & 5,9 \\
\hline Aspersão X Nebulização (por 60 animais) & Aspersão & Nebulização & Diferença \\
\hline Ganho com o leite (R\$/dia/60animais) & 548,1 & 531,9 & 16,2 \\
\hline Ganho com o leite ( $\mathrm{R} \$ /$ mês/60animais) & 16443,0 & 15957,0 & 486,0 \\
\hline Gasto total com o sistema de climat/60animais/dia $(R \$)$ & 11,70 & 7,50 & 4,2 \\
\hline Gasto total com o sistema de climat/60animais/mês $(R \$)$ & 351,0 & 225,0 & 126,0 \\
\hline Gasto com o alimentação/60animais/dia $(\mathrm{R} \$)$ & 336,0 & 330,8 & 5,2 \\
\hline Gasto com o alimentação/60animais/mês ( $\mathrm{R} \$$ ) & 10080,0 & 9923,4 & 156,6 \\
\hline Ganho/dia/60animais - gasto/dia/60animais $(\mathrm{R} \$)$ & 200,4 & 193,6 & 6,8 \\
\hline Ganho/mês/60animais - gasto/mês/60animais $(R \$)$ & 6012,0 & 5808,6 & 203,4 \\
\hline
\end{tabular}

Custo de implantação de cada sistema (R\$) $\quad 6000,0$ 


\section{REFERÊNCIAS BIBLIOGR ÁFICAS}

ABREU, P.G.; ABREU, V.M.N.; MZZUCO, H. Uso do resfriamento evaporativo (adiabático) na criação de frangos de corte. Concórdia: EMBRAPA-CNPSA, 1999. 51p.

AGRODATA VÍDEO. Instalações para vacas leiteiras no sistema Free-Stall (vídeo). Direção geral de J. Chotguis; roteiro de J.F. Telli; coordenação de produção de M.Andrade. Piracicaba, 1998. vídeo, Vídeo Par, 50 min.

ALBRIGHT, L.D. Environment control for animals and plants. St Joseph, Michigan: American Society of Agricultural Engineers Michigan, 1990. (ASAE Textbook, 4), 453p.

AMPÉRES AUTOMATION. Pirômetros. Disponível em: http:// www. amperesautomation.hpg.ig.com.br/ pirometro. html. Acesso em 20 de ago. de 2003.

APPLEY, S.J., WEARY, A.D. Pre-farrowing behavior distinguishes piglet-savaging gilts form non-piglet-savaging gilts. In: INTERNATIONAL CONGRESS FOR APPLIED ETHOLOGY. Florianópolis, 2000. Proceedings. Florianópolis: ISAE, 2000. p.17-20.

ARMSTRONG, D.W.; WELCHERT, W.T. Dairy cattle housing to reduces stress in a hot-arid climate. In: INTERNATIONAL DAIRY HOUSING CONFERENCE, Orlando, Flórida, 1994, Dairy systems for the $21^{\text {st }}$ century. Orlando: ASAE, 1994. p.598 604.

BACCARI JUNIOR, F. Adaptação de sistemas de manejo na produção de leite em clima quente. In: SIMPÓSIO BRASILEIRO DE AMBIÊNCIA NA PRODUÇÃO DE LEITE, Piracicaba, 1998. Anais. Piracicaba: FEALQ, 1998. p.24 - 67. 
BACCARI JUNIOR, F. Manejo ambiental da vaca leiteira em climas quentes. Londrina: Universidade Estadual de Londrina, 2001. 142p.

BAÊTA, F.C.; SOUZA, C.F. Ambiência em edificações rurais - conforto animal. Viçosa: Universidade Federal de Viçosa, 1997. 246p.

BARNETT, J.L. E HEMSWORTH, P.H. The validity of physiological and behavioural measures of animal welfare. Applied Animal Behaviour Science. v.1, p.177-187, 1990.

BRAY, D.R. BUCKLIN, R.A., MONTOYA, R., GIESY, R. Means to reduce environmental stress on dairy cows in hot, humid climates. In: INTERNATIONAL DAIRY HOUSING CONFERENCE, Orlando, Flórida, 1994, Dairy systems for the $21^{\text {st }}$ century. Orlando: ASAE, 1994. p.589- 597.

BROOM, D. M. Animal welfare: concepts and measurement. Journal Animal Science, v.69, n.10. p.4167-4175, Oct. 1991.

BUCKLIN, R.A; BRAY D.R. The american experience in dairy management in warm and hot climates. In: SIMPÓSIO BRASILEIRO DE AMBIÊMCIA NA PRODUÇÃO DE LEITE. Piracicaba, 1998. Anais. Piracicaba: FEALQ, 1998. p.56 - 174.

BUFFINGTON, D.E.; COLLAZO-AROCHO, A.; CANTON, G. H. Black globe-humidity comfort index $(\mathrm{BGHI})$ as comfort equation for dairy cows. Transactions of the ASAE, v.24, n.4, p.711-714, 1981.

CAMARGO, A.C. de. Confinamento em "free-stall". In: CONFINAMENTO DE BOVINOS LEITEIROS, Piracicaba, 1991. Anais. Piracicaba: FEALQ, 1991. p.1-28.

CAMPOS A. T. A importância da água para o gado de leite. Embrapa Gado de Leite. Disponível em: http://www.sbz.org.br . Acesso em 20 de mar. de 2003.

CHASTAIN, J.P.; TURNER, L.W. Practical results of a model of direct evaporative cooling of dairy cows. In: INTERNATIONAL DAIRY HOUSING CONFERENCE, Orlando, Flórida, 1994, Dairy systems for the $21^{\text {st }}$ century. Orlando: ASAE, 1994. p.337 - 352. 
DEGASPARI, S.A.R.; PIEKARSKI, P.R.B. Bovinocultura leiteira: Planejamento, Manejo e Instalações. 1998. 429p.

ESMAY, M.L. Principles of animal environment. West Port CT: ABI, 1982. 325p.

FRASER, D., RITCHIE, J.S.D. E FRASER, A.F. The term "stress" in a veterinary context. British Veterinary Journal, v.13, n.1, p.653-662, 1975.

FRAZZI, E.; CALAMARI, L.; CALEGARI, F.; STEFANINI, L. Behavior of dairy cows in response to different barn cooling systems. In: INTERNATIONAL DAIRY HOUSING CONFERENCE, 4. St. Louis, Missouri, 1998. St. Louis: ASAE, 1998. p.387-394.

FURLAN, R.A. Avaliação da nebulização e abertura de cortinas na redução da temperatura do ar em ambiente protegido. Piracicaba, 2001. 146 p. Tese (Doutorado) Escola Superior de Agricultura "Luiz de Queiroz", Universidade de São Paulo.

HAHN, G. L. Compensatory performance in livestock: influence on environmental criteria. In: Livestock Environment, 2, 1982. PROCEEDINGS OF THE SECOND INTERNATIONAL LIVESTOCK ENVIRONMENT SYMPOSIUM. lowa State University, St. Joseph, Michigan: ASAE, 1982. P.285-294.

HEAD, H. H. The strategic use of the physiologic potencial of the dairy cows. In: SIMPÓSIO DE LEITE NOS TRÓPICOS: NOVAS ESTRATÉGIAS DE PRODUÇÃO. Botucatu, 1989. Anais. Botucatu, 1989. p.38-89.

HEAD, H. H. Management of dairy cattle in tropical and subtropical environments. In: CONGRESSO BRASILEIRO DE BIOMETEOROLOGIA, Anais. Jaboticabal: SBBiomet, 1995. p.26-68.

HUBER, J. T. Alimentação de vacas de alta produção sob condições de estresse térmico. In: Bovinocultura leiteira Piracicaba: FEALQ. 1990. p.33-48.

HURNIK, J. F. Behaviour. In: PHILLIPS, C.; PIGGINS, D. (Ed.). Farm animals and the environment. Wallingford: CAB International, 1992, cap.13 p.235-244. 
JOHNSON, H. D. Bioclimatology and adaptation of livestock. Amsterdam: Elsevier, 1987. 279p.

LIN, J.C.; MOSS, B.R.; KOON, J.L.; FLOOD, C.A; SMITH III, R.C.; CUMMINS, K.A; COLEMAN, D.A. Comparasion of various fan, sprinkler, and mister systens in reducing heat stress in dairy cows. American society of agricultural engineers, v.14, n.2, p.177 - 182, 1998.

MACHADO, P.F. Efeitos da alta temperatura sobre a produção, reprodução e sanidade de bovinos leiteiros. In: SIMPÓSIO BRASILEIRO DE AMBIÊMCIA NA PRODUÇÃO DE LEITE. Piracicaba, 1998. Anais. Piracicaba: FEALQ, 1998. p.179 - 201.

MARQUES, D. Calor: conhecimentos e cuidados para minimizar seus efeitos sobre os frangos. Amparo: CASP, 1992. 11p.

MARTELLO, L. S. Diferentes recursos de climatização e sua influência na produção de leite, na termorregulação dos animais e no investimento das instalações. Pirassununga, 2002. Dissertação (Mestrado) - Faculdade de Zootecnia e Engenharia de Alimentos, Universidade de São Paulo.

MARTINELLI JUNIOR, L. C. Refrigeração e Ar-Condicionado. Parte IV - Psicrometria. DeTEC. Disponível em: http://www.unijui.tche.br/ martinelli/curriculo.htm. Acesso em 21 de mar. de 2003.

NÄÄS, I.A. Tipologia ce instalações em clima quente. In: SIMPÓSIO BRASILEIRO DE AMBIÊMCIA NA PRODUÇÃO DE LEITE. Piracicaba, 1998. Anais. Piracicaba: FEALQ, 1998. p. $146-155$.

PIRES, M. F. A.; SATURNinO, H. M.; VERNEQUE, A. M.; FERREIRA, A. M. Efeito da estação do ano sobre a temperatura retal e freqüência respiratória da vacas da raça holandesa confinadas em frescal. Arquivo Brasileiro de Medicina Veterinária e Zootecnia, v. 50, n.6, p.747-752, 1998 a. 
PIRES, M. F. A.; VILELA, D.; VERNEQUE, R. S.; TEODORO, R. L. Reflexos do estresse térmico no comportamento das vacas em lactação. In: SIMPÓsIO BRASILEIRO DE AMBIÊMCIA NA PRODUÇÃO DE LEITE. Piracicaba, 1998 b. Anais. . Piracicaba: FEALQ, 1998 b. p. $68-102$.

SARTOR, V. Efeito do resfriamento evaporativo e da ventilação forçada no conforto térmico ambiental de verão, em maternidades de suínos. Viçosa, 1997. Dissertação (Mestrado) - Universidade Federal de Viçosa.

SAS INSTITUTE, Statistical Analysis System: release 6.08, (software). Cary, 1992. 620p.

SILVA, I.J.O. Climatização das instalações para bovino leiteiro. In: SIMPÓSIO BRASILEIRO DE AMBIÊMCIA NA PRODUÇÃO DE LEITE, Piracicaba, 1998. Anais. Piracicaba: FEALQ, 1998. p.114-145.

SILVA, I.J.O. Vacas produzem mais e melhor em ambientes adequados. Balde Branco, v.35, p.20-27. Mar 1999.

SILVA, I.J.O. RASTREABILIDADE NA PRODUÇÃO ANIMAL, 2. Piracicaba, 2003. Compact disc. Piracicaba: FEALQ, 2003.

SILVA, R. G. da , SCALA JUNIOR, N. L.; POCAY, P. L. B. Transmissão de Radiação Ultravioleta Através do Pelame e da Epiderme de Bovinos. Revista Brasileira de Zootecnia, v.30, n.6. p.1939-1947, 2001.

TITTO, E. A. L.; PEREIRA, A. M. F.; PASSINI, R.; BALIEIRO NETO, G.; FAGUNDES, A. C. A.; LIMA, C. G. Estudo da tolerância ao calor em tourinhos das raças Marchigiana, Nelore e Simental. In: CONGRESSO BRASILEIRO DE BIOMETEOROLOGIA. Goiânia, 1998. Anais. Goiânia: SBBiomet, 1998. p.361-366.

VAN BORELL, E. Neuroendocrine integration of stress and significance of stress for the performance of farm animals. Applied Animal Behaviour Science . v.44, p.219-227, 1995. 
WARRISS, P. D. Meat Science: an introductory text. (Chapters 1 and 10). Wallingford: CABI Publishing, 2000, cap.1-10. 310p. 


\section{APÊNDICES}


Apêndice 1. Dados das variáveis fisiológicas dos animais obtidos no dia 08/11/2003

\begin{tabular}{|c|c|c|c|c|c|c|c|c|c|}
\hline \multicolumn{5}{|c|}{ Ventilação/Aspersão cocho+ Ventilação cama } & \multicolumn{5}{|c|}{ Ventilação/Nebulização cocho+ Ventilação cama } \\
\hline Número do brinco & Hora & TR FR & Negra & Branca & Número do brinco & Hora & TR FR & Negra & Branca \\
\hline 1853 & 9 & 38 & 33,2 & 41,8 & 994 & 9 & 38,4 & 32,4 & 34,7 \\
\hline 1853 & 11 & 38,3 & 31,4 & 34,3 & 994 & 11 & 38,1 & 32,4 & 40,3 \\
\hline 1853 & 13 & 38,3 & 28,8 & 40 & 994 & 13 & 38,6 & 33,9 & 34 \\
\hline 1853 & 15 & 38,2 & 28,7 & 27,1 & 994 & 15 & 38,7 & 33,3 & 35,5 \\
\hline 1853 & 17 & 38,5 & 34,8 & 32,3 & 994 & 17 & 38,6 & 32,3 & 31,4 \\
\hline 898 & 9 & 37,9 & 29,8 & 36,1 & 685 & 9 & 38,1 & 31,8 & 37,7 \\
\hline 898 & 11 & 37,9 & 27,3 & 29,3 & 685 & 11 & 38 & 32,4 & 37,4 \\
\hline 898 & 13 & 38,4 & 31,5 & 40 & 685 & 13 & 38 & 28,9 & 34,2 \\
\hline 898 & 15 & 38,3 & 28,8 & 29,1 & 685 & 15 & 38 & 29,8 & 34,9 \\
\hline 898 & 17 & 38,1 & 35,1 & 37,4 & 685 & 17 & 38,3 & 28,5 & 32,4 \\
\hline 755 & 9 & 37,8 & 32,2 & 38,3 & 478 & 9 & 38,3 & 33,5 & 39,4 \\
\hline 755 & 11 & 37,8 & 27,8 & 30,2 & 478 & 11 & 38,2 & 33,7 & 41,2 \\
\hline 755 & 13 & 38,6 & 27,1 & 38,6 & 478 & 13 & 38,5 & 29,9 & 32,6 \\
\hline 755 & 15 & 37,8 & 26,5 & 25,7 & 478 & 15 & 38,4 & 28,3 & 31,1 \\
\hline 755 & 17 & 38 & 26,7 & 26,3 & 478 & 17 & 38,8 & 28,3 & 27,4 \\
\hline 890 & 9 & 38 & 32,8 & 41,8 & 1282 & 9 & 37,7 & 31,7 & 38,4 \\
\hline 890 & 11 & 38,1 & 31,8 & 32,4 & 1282 & 11 & 38,1 & 30,4 & 34,6 \\
\hline 890 & 13 & 38,7 & 32,8 & 40,2 & 1282 & 13 & 38 & 28,6 & 31,8 \\
\hline 890 & 15 & 38,6 & 28,9 & 38,4 & 1282 & 15 & 38,1 & 27,1 & 33,6 \\
\hline 890 & 17 & 38,4 & 34,2 & 38,7 & 1282 & 17 & 38,3 & 26,8 & 33 \\
\hline 1085 & 9 & 38,6 & 33,8 & 39,4 & 1077 & 9 & 38,3 & 31,9 & 38,1 \\
\hline 1085 & 11 & 38,3 & 28,1 & 30,3 & 1077 & 11 & 38 & 28,9 & 38,4 \\
\hline 1085 & 13 & 38,3 & 28,4 & 40,9 & 1077 & 13 & 38,6 & 28,9 & 34,2 \\
\hline 1085 & 15 & 38,3 & 27,1 & 28,5 & 1077 & 15 & 38,3 & 31,9 & 36 \\
\hline 1085 & 17 & 38,3 & 29,3 & 37,1 & 1077 & 17 & 38,6 & 27,8 & 28,1 \\
\hline
\end{tabular}


Apêndice 2. Dados das variáveis fisiológicas dos animais obtidos no dia 09/11/2003

\begin{tabular}{cccccccccccc}
\hline \multicolumn{3}{c}{ Ventilação/Aspersão cocho+ Ventilação cama } & \multicolumn{3}{c}{ Ventilação/Nebulização cocho+ Ventilação cama } \\
\hline Número do brinco & Hora & TR & FR & Negra & Branca & Número do brinco & Hora & TR & FR & Negra & Branca \\
1853 & 9 & 38 & 10 & 34,7 & 40,1 & 994 & 9 & 38,4 & 12 & 33,2 & 35,8 \\
1853 & 11 & 38,1 & 15 & 30,3 & 38,1 & 994 & 11 & 38,6 & 12 & 30,9 & 28,7 \\
1853 & 13 & 37,9 & 11 & 28,2 & 31,4 & 994 & 13 & 39,2 & 14 & 34,3 & 38,7 \\
1853 & 15 & 37,6 & 12 & 30,4 & 24,1 & 994 & 15 & 38,9 & 13 & 32,1 & 36 \\
1853 & 17 & 38,1 & 9 & 25,9 & 23,2 & 994 & 17 & 38,7 & 13 & 31,8 & 31,6 \\
898 & 9 & 37,7 & 17 & 32,9 & 39,6 & 685 & 9 & 38 & 12 & 31,8 & 38,9 \\
898 & 11 & 37,6 & 17 & 30,1 & 34,2 & 685 & 11 & 37,9 & 11 & 33,8 & 34,1 \\
898 & 13 & 37,8 & 17 & 26,8 & 31,8 & 685 & 13 & 38,7 & 12 & 30,8 & 36 \\
898 & 15 & 37,8 & 14 & 24,4 & 26,5 & 685 & 15 & 37,5 & 10 & 27,1 & 32,6 \\
898 & 17 & 38,1 & 12 & 28,1 & 26,4 & 685 & 17 & 38 & 13 & 30,4 & 33,6 \\
755 & 9 & 38,1 & 9 & 31,1 & 36,7 & 478 & 9 & 38,6 & 19 & 33,6 & 42 \\
755 & 11 & 37,7 & 10 & 26,1 & 26,5 & 478 & 11 & 38,9 & 14 & 33,4 & 32,6 \\
755 & 13 & 38,5 & 16 & 29,4 & 39,5 & 478 & 13 & 39,4 & 18 & 34,9 & 36,9 \\
755 & 15 & 38,1 & 14 & 34,2 & 36,6 & 478 & 15 & 39,4 & 15 & 34,4 & 39,3 \\
755 & 17 & 38,3 & 10 & 27,8 & 25,9 & 478 & 17 & 39,2 & 19 & 34,8 & 35,3 \\
890 & 9 & 38 & 12 & 33 & 36,9 & 1282 & 9 & 38 & 10 & 31,8 & 39,7 \\
890 & 11 & 37,7 & 11 & 29,9 & 29,2 & 1282 & 11 & 37,7 & 10 & 32,9 & 32,5 \\
890 & 13 & 38,2 & 13 & 27,7 & 39,8 & 1282 & 13 & 38,4 & 9 & 34,6 & 37,8 \\
890 & 15 & 38,1 & 16 & 33,4 & 37,3 & 1282 & 15 & 37,8 & 11 & 31,8 & 30,4 \\
890 & 17 & 37,6 & 13 & 27,8 & 27,7 & 1282 & 17 & 38,3 & 11 & 30,1 & 35,2 \\
1085 & 9 & 38,3 & 13 & 34,1 & 39,9 & 1077 & 9 & 38,6 & 14 & 32,4 & 40,2 \\
1085 & 11 & 38,1 & 12 & 30,4 & 36,7 & 1077 & 11 & 38,4 & 14 & 33,9 & 31,6 \\
1085 & 13 & 38,6 & 21 & 32,8 & 38,7 & 1077 & 13 & 39 & 15 & 33,1 & 31,5 \\
1085 & 15 & 38,6 & 15 & 25,7 & 37,4 & 1077 & 15 & 38,6 & 14 & 28,9 & 32,2 \\
1085 & 17 & 38,1 & 10 & 28,1 & 24,4 & 1077 & 17 & 38,6 & 15 & 30,5 & 33,6 \\
\hline
\end{tabular}


Apêndice 3. Dados das variáveis fisiológicas dos animais obtidos no dia 10/11/2003

\begin{tabular}{cccccccccccc}
\hline \multicolumn{3}{c}{ Ventilação/Aspersão cocho+ Ventilação cama } & \multicolumn{3}{c}{ Ventilação/Nebulização cocho+ Ventilação cama } \\
\hline Número do brinco & Hora & TR & FR & Negra & Branca & Número do brinco & Hora & TR & FR & Negra & Branca \\
1853 & 9 & 37,9 & 8 & 29,3 & 31,8 & 994 & 9 & 38,2 & 12 & 30,8 & 33,7 \\
1853 & 11 & 38,2 & 12 & 34,3 & 33 & 994 & 11 & 38,7 & 14 & 33,2 & \\
1853 & 13 & 38,4 & 9 & 30,3 & 29,9 & 994 & 13 & 39,1 & 13 & 33,2 & \\
1853 & 15 & 38,4 & 8 & 35,4 & 32,4 & 994 & 15 & 39,2 & 13 & 33,9 & \\
1853 & 17 & 38,3 & 11 & 35,7 & 31,4 & 994 & 17 & 39,1 & 11 & 33,4 & \\
898 & 9 & 37,7 & 15 & 28,7 & 35,7 & 685 & 9 & 38,1 & 13 & 27,9 & 36,2 \\
898 & 11 & 38,3 & 11 & 30,3 & 28,7 & 685 & 11 & 38,3 & 13 & 32,9 & 38,4 \\
898 & 13 & 38,1 & 15 & 30,3 & 33,2 & 685 & 13 & 38,3 & 13 & 34,3 & 36,7 \\
898 & 15 & 38 & 12 & 30,4 & 38,5 & 685 & 15 & 38,3 & 15 & 32,6 & 36,4 \\
898 & 17 & & 10 & 35,3 & 29,1 & 685 & 17 & 38,3 & 15 & 33,2 & 31,8 \\
755 & 9 & 38 & 12 & 31,4 & 27,8 & 478 & 9 & 38,4 & 13 & 23,6 & 31,8 \\
755 & 11 & 38,1 & 12 & 26,1 & 25,1 & 478 & 11 & 38,2 & 12 & 31,6 & 36,4 \\
755 & 13 & 38,1 & 11 & 29,2 & 30,8 & 478 & 13 & 38,7 & 19 & 35,6 & 38,6 \\
755 & 15 & 38,2 & 16 & 32,6 & 33,8 & 478 & 15 & 38,8 & 17 & 34,6 & 36,6 \\
755 & 17 & 38,5 & 11 & 34,9 & 30,1 & 478 & 17 & 38,2 & 15 & 33,9 & 33,4 \\
890 & 9 & 38,1 & 11 & 29,4 & 29,3 & 1282 & 9 & 38,2 & 10 & 32,4 & 36,8 \\
890 & 11 & 38,2 & 12 & 27,8 & 27,7 & 1282 & 11 & 38,2 & 13 & 33,9 & 39,7 \\
890 & 13 & 38 & 9 & 30,7 & 31,1 & 1282 & 13 & 38,8 & 12 & 34,8 & 38,3 \\
890 & 15 & 38,3 & 11 & 34,2 & 36,7 & 1282 & 15 & 38,6 & 9 & 34,7 & 37,7 \\
890 & 17 & 38,5 & 8 & 35,1 & 32,7 & 1282 & 17 & 38,7 & 11 & 35 & 32,2 \\
1085 & 9 & 38 & 11 & 30,1 & 28,8 & 1077 & 9 & 38,5 & 15 & 33,2 & 36,6 \\
1085 & 11 & 38,2 & 13 & 29,2 & 26,9 & 1077 & 11 & 38,3 & 19 & 32,8 & 38,4 \\
1085 & 13 & 38,3 & 14 & 32,8 & 36,4 & 1077 & 13 & 38,8 & 15 & 31,8 & 36,8 \\
1085 & 15 & 38,3 & 15 & 30,7 & 37,3 & 1077 & 15 & 38,6 & 19 & 31,9 & 35,7 \\
1085 & 17 & 38,5 & 15 & 35 & 36,4 & 1077 & 17 & 38,6 & 16 & 32,2 & 30,3 \\
\hline
\end{tabular}


Apêndice 4. Dados das variáveis fisiológicas dos animais obtidos no dia 11/11/2003

\begin{tabular}{|c|c|c|c|c|c|c|c|c|c|c|c|}
\hline \multicolumn{6}{|c|}{ Ventilação/Aspersão cocho+ Ventilação cama } & \multicolumn{6}{|c|}{ Ventilação/Nebulização cocho+ Ventilação cama } \\
\hline Número do brinco & Hora & TR & FR & Negra & Branca & Número do brinco & Hora & TR & FR & Negra & Branca \\
\hline 1853 & 9 & 38,2 & 13 & 30,3 & 35,2 & 994 & 9 & 38,7 & 11 & 35,8 & \\
\hline 1853 & 11 & 38,3 & 10 & 33,4 & 33,4 & 994 & 11 & & & & \\
\hline 1853 & 13 & & & & & 994 & 13 & 39,2 & 14 & 35,6 & \\
\hline 1853 & 15 & 38,6 & 10 & 29,7 & 29,9 & 994 & 15 & 39,5 & 16 & 35,9 & \\
\hline 1853 & 17 & 38,4 & 12 & 29,9 & 27,3 & 994 & 17 & 39,3 & 14 & 35,9 & \\
\hline 898 & 9 & 38 & 12 & 29,3 & 33,8 & 685 & 9 & 38,2 & 11 & 33,6 & 40,3 \\
\hline 898 & 11 & 38,5 & 20 & 32,3 & 36,2 & 685 & 11 & & & & \\
\hline 898 & 13 & & & & & 685 & 13 & 38,7 & 16 & 32,6 & 38,7 \\
\hline 898 & 15 & 38,5 & 14 & 29,9 & 23,3 & 685 & 15 & 38,5 & 16 & 34,2 & 35,3 \\
\hline 898 & 17 & 38,5 & 12 & 30,7 & 31,8 & 685 & 17 & 37,9 & 16 & 31,8 & 32,7 \\
\hline 755 & 9 & 38,2 & 11 & 31,6 & 33,4 & 478 & 9 & 38,4 & 11 & 38 & 40,1 \\
\hline 755 & 11 & 38,6 & 16 & 31,6 & 33,2 & 478 & 11 & & & & \\
\hline 755 & 13 & & & & & 478 & 13 & 38,8 & 16 & 33,3 & 34,2 \\
\hline 755 & 15 & 38,4 & 16 & 30,4 & 28,7 & 478 & 15 & 38,8 & 14 & 35,1 & 38,6 \\
\hline 755 & 17 & 38,3 & 13 & 28,5 & 26,5 & 478 & 17 & 38,6 & 15 & 36 & 34,9 \\
\hline 890 & 9 & 38,3 & 8 & 29,1 & 31,6 & 1282 & 9 & 38,2 & 15 & 36,9 & 38,5 \\
\hline 890 & 11 & 38 & 10 & 33,6 & 38,9 & 1282 & 11 & & & & \\
\hline 890 & 13 & & & & & 1282 & 13 & 38,9 & 15 & 35,2 & 32,2 \\
\hline 890 & 15 & 38,5 & 10 & 27,7 & 25,3 & 1282 & 15 & 38,7 & 13 & 34,7 & 35,7 \\
\hline 890 & 17 & 38,4 & 11 & 26,6 & 26,1 & 1282 & 17 & 38,8 & 13 & 34,6 & 30,8 \\
\hline 1085 & 9 & 38 & 16 & 27,6 & 30,8 & 1077 & 9 & 38,4 & 16 & 32,6 & 46,9 \\
\hline 1085 & 11 & 38,6 & 13 & 29,8 & 39 & 1077 & 11 & & & & \\
\hline 1085 & 13 & & & & & 1077 & 13 & 38,9 & 21 & 30,7 & 36,1 \\
\hline 1085 & 15 & 38,9 & 14 & 31,8 & 35,8 & 1077 & 15 & 38,6 & 18 & 33,3 & 28,9 \\
\hline 1085 & 17 & 38,9 & 18 & 29,5 & 34,6 & 1077 & 17 & 38,6 & 15 & 30,3 & 33,4 \\
\hline
\end{tabular}


Apêndice 5. Dados das variáveis fisiológicas dos animais obtidos no dia 12/11/2003

\begin{tabular}{cccccccccccc}
\hline \multicolumn{3}{c}{ Ventilação/Aspersão cocho+ Ventilação cama } & \multicolumn{3}{c}{ Ventilação/Nebulização cocho+ Ventilação cama } \\
\hline Número do brinco & Hora & TR & FR & Negra & Branca & Número do brinco & Hora & TR & FR & Negra & Branca \\
1853 & 9 & 38,6 & 13 & 33,9 & 40,1 & 994 & 9 & 38,9 & 12 & 34,9 & \\
1853 & 11 & 38,6 & 15 & 34,5 & 38,4 & 994 & 11 & 38,9 & 13 & 33,7 \\
1853 & 13 & 38,6 & 16 & 35,3 & 37,8 & 994 & 13 & 39,1 & 16 & 34,4 \\
1853 & 15 & 38,6 & 12 & 35,6 & 39,6 & 994 & 15 & 39,1 & 16 & 34,8 \\
1853 & 17 & 38,3 & 17 & 32,8 & 28,9 & 994 & 17 & 39,3 & 18 & 32,6 & \\
898 & 9 & 38,6 & 20 & 31,9 & 36,6 & 685 & 9 & 37,8 & 11 & 34,2 & 33,3 \\
898 & 11 & 38 & 15 & 29,4 & 36,2 & 685 & 11 & 38,3 & 15 & 32,4 & 33,4 \\
898 & 13 & 38,1 & 14 & 32,2 & 26,9 & 685 & 13 & 38,2 & 13 & 34,7 & 37,8 \\
898 & 15 & 38,1 & 15 & 32,6 & 29,3 & 685 & 15 & 38,5 & 17 & 34,3 & 36,2 \\
898 & 17 & 38,1 & 13 & 34,2 & 38,2 & 685 & 17 & 38,4 & 18 & 36,2 & 36,5 \\
755 & 9 & 38,4 & 15 & 32,9 & 38,4 & 478 & 9 & 37,8 & 14 & 32,7 & 35,9 \\
755 & 11 & 39 & 15 & 34,3 & 37,5 & 478 & 11 & 38,2 & 20 & 36,5 & 33,4 \\
755 & 13 & 38,6 & 15 & 33,9 & 35,8 & 478 & 13 & 38,7 & 17 & 33,4 & 33,2 \\
755 & 15 & 38,8 & 21 & 34,8 & 31,8 & 478 & 15 & 38,9 & 22 & 35,4 & 36,6 \\
755 & 17 & 38,8 & 12 & 28,8 & 35,7 & 478 & 17 & 38,9 & 18 & 33,2 & 34,3 \\
890 & 9 & 38,1 & 12 & 30,4 & 27,6 & 1282 & 9 & 38,3 & 13 & 34,2 & 38,2 \\
890 & 11 & 38,1 & 14 & 32,8 & 36,3 & 1282 & 11 & 38,8 & 16 & 33,6 & 35,3 \\
890 & 13 & 38,4 & 15 & 34,8 & 34,8 & 1282 & 13 & 39,5 & 20 & 36 & 37,7 \\
890 & 15 & 38,4 & 11 & 24,4 & 31,2 & 1282 & 15 & 39 & 15 & 35,1 & 29,1 \\
890 & 17 & 38,2 & 16 & 32,6 & 32,2 & 1282 & 17 & 38,5 & 14 & 32,6 & 30,5 \\
1085 & 9 & 38,8 & 14 & 33,8 & 37,3 & 1077 & 9 & 38,2 & 13 & 33,9 & 34,2 \\
1085 & 11 & 39,2 & 16 & 33,6 & 31,5 & 1077 & 11 & 38,7 & 17 & 34,7 & 34,3 \\
1085 & 13 & 39,4 & 18 & 35,1 & 36,8 & 1077 & 13 & 38,8 & 17 & 35,3 & 37,5 \\
1085 & 15 & 39,4 & 17 & 30,7 & 36,9 & 1077 & 15 & 38,8 & 19 & 34,3 & 35,7 \\
1085 & 17 & 38,8 & 16 & 31,9 & 32,8 & 1077 & 17 & 38,7 & 15 & 32,8 & 27,5 \\
\hline
\end{tabular}


Apêndice 6. Dados das variáveis fisiológicas dos animais obtidos no dia 15/11/2003

\begin{tabular}{|c|c|c|c|c|c|c|c|c|c|c|c|}
\hline \multicolumn{6}{|c|}{ Ventilação/Aspersão cocho+ Ventilação cama } & \multicolumn{6}{|c|}{ Ventilação/Nebulização cocho+ Ventilação cama } \\
\hline Número do brinco & Hora & TR & FR & Negra & Branca & Número do brinco & Hora & TR & FR & Negra & Branca \\
\hline 1853 & 9 & 38,4 & 9 & 32,9 & 40,2 & 994 & 9 & 38,4 & 10 & 33,1 & \\
\hline 1853 & 11 & 38,6 & 12 & 32,7 & 36,7 & 994 & 11 & 38,6 & 9 & 33,4 & \\
\hline 1853 & 13 & 38,6 & 15 & 35,8 & 39,9 & 994 & 13 & 38,8 & 14 & 30,5 & \\
\hline 1853 & 15 & 39,1 & 15 & 31,6 & 33,2 & 994 & 15 & 39 & 13 & 33 & \\
\hline 1853 & 17 & 38,7 & 12 & 33 & 37,8 & 994 & 17 & 39 & 10 & 38,2 & \\
\hline 898 & 9 & 38,3 & 17 & 31,6 & 38,9 & 685 & 9 & 38 & 10 & 30,8 & 39,7 \\
\hline 898 & 11 & 38,6 & 22 & 33,7 & 34,2 & 685 & 11 & 38,1 & 13 & 36 & 32,7 \\
\hline 898 & 13 & 38,3 & 20 & 33,9 & 37 & 685 & 13 & 38,7 & 17 & 34,9 & 38,9 \\
\hline 898 & 15 & 37,8 & 15 & 33,8 & 24,9 & 685 & 15 & 38,6 & 14 & 35,1 & 34,2 \\
\hline 898 & 17 & 38,6 & 18 & 33,9 & 36,6 & 685 & 17 & 38,6 & 13 & 31,8 & 34,3 \\
\hline 755 & 9 & 38,9 & 15 & 31,4 & 38,6 & 478 & 9 & 38,3 & 16 & 31,8 & 39,5 \\
\hline 755 & 11 & 39,1 & 14 & 31,4 & 34,6 & 478 & 11 & 38,5 & 13 & 31,8 & 37,3 \\
\hline 755 & 13 & 38,8 & 15 & 33,2 & 38,2 & 478 & 13 & 38,8 & 14 & 29,6 & 34,9 \\
\hline 755 & 15 & 39,1 & 14 & 33,4 & 35,8 & 478 & 15 & 38,7 & 15 & 30,4 & 33,2 \\
\hline 755 & 17 & 39,1 & 17 & 35,1 & 33,7 & 478 & 17 & 38,8 & 9 & 30,1 & 35,3 \\
\hline 890 & 9 & 38,1 & 13 & 33,2 & 40,6 & 1282 & 9 & 38,4 & 8 & 32,8 & 40,7 \\
\hline 890 & 11 & 38,2 & 11 & 33,6 & 37,1 & 1282 & 11 & 38,1 & 8 & 33,4 & 41,5 \\
\hline 890 & 13 & 38,8 & 14 & 33,8 & 34,9 & 1282 & 13 & 38,7 & 12 & 35,3 & 38,9 \\
\hline 890 & 15 & 39,2 & 15 & 33,8 & 32,3 & 1282 & 15 & 38,2 & 12 & 34,2 & 33 \\
\hline 890 & 17 & 38,6 & 12 & 31,8 & 32,7 & 1282 & 17 & 38,2 & 13 & 33,7 & 32,8 \\
\hline 1085 & 9 & 38,4 & 10 & 31,2 & 40,7 & 1077 & 9 & 37,9 & 12 & 32,4 & 39,8 \\
\hline 1085 & 11 & 38,9 & 12 & 31,2 & 35,7 & 1077 & 11 & 38,3 & 10 & 33,9 & 38 \\
\hline 1085 & 13 & 39,2 & 16 & 38,5 & 35,3 & 1077 & 13 & 38,7 & 16 & 31,4 & 35,4 \\
\hline 1085 & 15 & 39,5 & 17 & 34,8 & 35,3 & 1077 & 15 & 38 & 13 & 31,1 & 33 \\
\hline 1085 & 17 & 39,5 & 18 & 30,3 & 34,2 & 1077 & 17 & 38,1 & 14 & 29,7 & 29,2 \\
\hline
\end{tabular}


Apêndice 7. Dados das variáveis fisiológicas dos animais obtidos no dia 20/11/2003

\begin{tabular}{cccccccccccc}
\hline \multicolumn{3}{c}{ Ventilação/Aspersão cocho+ Ventilação cama } & \multicolumn{3}{c}{ Ventilação/Nebulização cocho+ Ventilação cama } \\
\hline Número do brinco & Hora & TR & FR & Negra & Branca & Número do brinco & Hora & TR & FR & Negra & Branca \\
1853 & 9 & 38,7 & 10 & 32,2 & 37,3 & 994 & 9 & 38,4 & 12 & 34,3 & \\
1853 & 11 & 38,2 & 10 & 31,8 & 35,4 & 994 & 11 & 38,9 & 11 & 31,9 \\
1853 & 13 & 38 & 11 & 34,2 & 38,8 & 994 & 13 & 38,9 & 11 & 34,8 & \\
1853 & 15 & 38,6 & 16 & 35 & 39,4 & 994 & 15 & 38,9 & 14 & 32,6 & \\
1853 & 17 & 38,3 & 11 & 35,3 & 38,2 & 994 & 17 & 38,9 & 11 & 34 & \\
898 & 9 & 38,4 & 15 & 33,4 & 39,2 & 685 & 9 & 38,1 & 13 & 32,9 & 35,2 \\
898 & 11 & 37 & 11 & 28,6 & 29,6 & 685 & 11 & 38,2 & 15 & 33 & 37,1 \\
898 & 13 & 38,3 & 17 & 34,5 & 39,3 & 685 & 13 & 38,5 & 14 & 31,8 & 37,3 \\
898 & 15 & 38,2 & 18 & 34,6 & 37,3 & 685 & 15 & 38,2 & 12 & 28,4 & 31,2 \\
898 & 17 & 38,8 & 17 & 26,3 & 26,5 & 685 & 17 & 38,3 & 15 & 32,4 & 32,3 \\
755 & 9 & 38,7 & 16 & 34,1 & 38,3 & 478 & 9 & 38 & 14 & 31,5 & 37,5 \\
755 & 11 & 38,9 & 16 & 33,2 & 38,6 & 478 & 11 & 38,7 & 15 & 33,4 & 31,2 \\
755 & 13 & 38,3 & 12 & 24,1 & 24,3 & 478 & 13 & 38,8 & 15 & 24,9 & 31,2 \\
755 & 15 & 38,7 & 19 & 33,6 & 36,9 & 478 & 15 & 37,8 & 18 & 33,5 & 38 \\
755 & 17 & 38,3 & 15 & 27,6 & 24,3 & 478 & 17 & 38,5 & 13 & 33,1 & 32,8 \\
890 & 9 & 38,3 & 13 & 32,1 & 30,4 & 1282 & 9 & 37,7 & 8 & 34,3 & 40,2 \\
890 & 11 & 38,3 & 13 & 31,9 & 34,8 & 1282 & 11 & 38,4 & 11 & 34,7 & 40 \\
890 & 13 & 38,4 & 14 & 33,1 & 37,6 & 1282 & 13 & 38,6 & 14 & 33,2 & 34,6 \\
890 & 15 & 38,3 & 13 & 33 & 32,6 & 1282 & 15 & 38,7 & 16 & 31,6 & 37,6 \\
890 & 17 & 38,8 & 12 & 32,7 & 32,6 & 1282 & 17 & 38,4 & 11 & 33,4 & 34,4 \\
1085 & 9 & 38,8 & 14 & 32,5 & 35,6 & 1077 & 9 & 38 & 14 & 32,4 & 35,9 \\
1085 & 11 & 39,4 & 17 & 30,8 & 36 & 1077 & 11 & 38,1 & 13 & 24,3 & 24,1 \\
1085 & 13 & 38,5 & 13 & 31,5 & 36,8 & 1077 & 13 & 39 & 16 & 33,2 & 38,4 \\
1085 & 15 & 38,6 & 19 & 33,8 & 38,4 & 1077 & 15 & 38,5 & 18 & 35,1 & 38,3 \\
1085 & 17 & 38,1 & 13 & 27,2 & 31,4 & 1077 & 17 & 38,7 & 12 & 27,6 & 24,7 \\
\hline
\end{tabular}


Apêndice 8. Dados das variáveis fisiológicas dos animais obtidos no dia 16/11/2003

\begin{tabular}{|c|c|c|c|c|c|c|c|c|c|c|c|}
\hline \multicolumn{6}{|c|}{ Ventilação/Aspersão cocho+ Ventilação cama } & \multicolumn{6}{|c|}{ Ventilação/Nebulização cocho+ Ventilação cama } \\
\hline Número do brinco & Hora & $\mathrm{TR}$ & FR & Negra & Branca & Número do brinco & Hora & TR & FR & Negra & Branca \\
\hline 1853 & 9 & 38,4 & 12 & 32,4 & 35,2 & 994 & 9 & 38,5 & 10 & 34,2 & \\
\hline 1853 & 11 & 38,6 & 14 & 32,6 & 35,7 & 994 & 11 & 38,4 & 12 & 35 & \\
\hline 1853 & 13 & 39 & 16 & 35,6 & 37,3 & 994 & 13 & 38,5 & 14 & 32,8 & \\
\hline 1853 & 15 & 39,1 & 15 & 32,4 & 31,1 & 994 & 15 & 39 & 17 & 32,6 & \\
\hline 1853 & 17 & 38,9 & 12 & 33,4 & 37,4 & 994 & 17 & 39,3 & 10 & 33,9 & \\
\hline 898 & 9 & 38,2 & 12 & 33,9 & 38,4 & 685 & 9 & 38 & 14 & 33 & 37,3 \\
\hline 898 & 11 & 38,4 & 17 & 34,2 & 37,8 & 685 & 11 & 38 & 13 & 32,4 & 36,7 \\
\hline 898 & 13 & 38,8 & 21 & 35,6 & 39,1 & 685 & 13 & 38,2 & 13 & 34,4 & 34,3 \\
\hline 898 & 15 & 38,8 & 22 & 31,8 & 31,4 & 685 & 15 & 38,5 & 14 & 34,9 & 37,7 \\
\hline 898 & 17 & 38,7 & 16 & 33,8 & 29,3 & 685 & 17 & 38,6 & 12 & 36 & 34,3 \\
\hline 755 & 9 & 38,6 & 16 & 33,9 & 39,2 & 478 & 9 & 38,4 & 11 & 29,5 & 31,1 \\
\hline 755 & 11 & 38,8 & 18 & 32,7 & 39,6 & 478 & 11 & 38,4 & 11 & 30,4 & 32,1 \\
\hline 755 & 13 & 39 & 23 & 34,3 & 37,7 & 478 & 13 & 38,3 & 12 & 34,1 & 38,4 \\
\hline 755 & 15 & 38,6 & 17 & 35,4 & 37,3 & 478 & 15 & 38,3 & 18 & 34,1 & 33,3 \\
\hline 755 & 17 & 38,6 & 17 & 34,2 & 31,2 & 478 & 17 & 38 & 8 & 30,1 & 34,3 \\
\hline 890 & 9 & 38,3 & 10 & 30,3 & 30,7 & 1282 & 9 & 38,7 & 10 & 34,4 & 36,4 \\
\hline 890 & 11 & 39 & 13 & 32,4 & 30,6 & 1282 & 11 & 38,6 & 12 & 32,9 & 35,8 \\
\hline 890 & 13 & 39 & 15 & 34,7 & 36,6 & 1282 & 13 & 38,4 & 13 & 34,2 & 38,5 \\
\hline 890 & 15 & 39 & 18 & 32,2 & 37,7 & 1282 & 15 & 38,6 & 11 & 35,7 & 37,7 \\
\hline 890 & 17 & 38,8 & 15 & 33,4 & & 1282 & 17 & 38,7 & 8 & 33,1 & 37,2 \\
\hline 1085 & 9 & 38,7 & 18 & 30,4 & 35,3 & 1077 & 9 & 38,1 & 13 & 28,5 & 29,2 \\
\hline 1085 & 11 & 39 & 15 & 30,9 & 35,4 & 1077 & 11 & 38,2 & 13 & 29,8 & 30,7 \\
\hline 1085 & 13 & 39,3 & 13 & 30,8 & 32,1 & 1077 & 13 & 38,4 & 13 & 33,6 & 37,3 \\
\hline 1085 & 15 & 39,1 & 16 & 36 & 29,1 & 1077 & 15 & 38,3 & 19 & 36,2 & 37,3 \\
\hline 1085 & 17 & 39,7 & 16 & 30,1 & 28,9 & 1077 & 17 & 38,9 & 12 & 33,4 & 33,8 \\
\hline
\end{tabular}


Apêndice 9. Dados das variáveis fisiológicas dos animais obtidos no dia 21/11/2003

\begin{tabular}{|c|c|c|c|c|c|c|c|c|c|c|c|}
\hline \multicolumn{6}{|c|}{ Ventilação/Aspersão cocho+ Ventilação cama } & \multicolumn{6}{|c|}{ Ventilação/Nebulização cocho+ Ventilação cama } \\
\hline Número do brinco & Hora & TR & FR & Negra & Branca & Número do brinco & Hora & TR & FR & Negra & Branca \\
\hline 1853 & 9 & 38,1 & 11 & 31,4 & 38,6 & 994 & 9 & 39,4 & 15 & 31,7 & \\
\hline 1853 & 11 & 38,3 & 11 & 31,2 & 41,6 & 994 & 11 & 39,1 & 13 & 32,2 & \\
\hline 1853 & 13 & 38,3 & 9 & 32,6 & 36,7 & 994 & 13 & 39,4 & 16 & 32,5 & \\
\hline 1853 & 15 & 38 & 11 & 27,8 & 32,6 & 994 & 15 & 39,5 & 15 & 31,7 & \\
\hline 1853 & 17 & 38,2 & 10 & 33,7 & 38,7 & 994 & 17 & 39,3 & 13 & 32,4 & \\
\hline 898 & 9 & 37,8 & 10 & 31,9 & 38,2 & 685 & 9 & 38,1 & 12 & 30,1 & 38,7 \\
\hline 898 & 11 & 38,3 & 15 & 30,6 & 35 & 685 & 11 & 38,2 & 13 & 30,9 & 37,4 \\
\hline 898 & 13 & 38,4 & 15 & 31,4 & 36,6 & 685 & 13 & 38,6 & 12 & 31,9 & 35,9 \\
\hline 898 & 15 & 38,1 & 10 & 29,3 & 25,8 & 685 & 15 & 38,3 & 13 & 30,8 & 34,9 \\
\hline 898 & 17 & 38,4 & 14 & 32,8 & 36 & 685 & 17 & 38,1 & 12 & 33,2 & 36,7 \\
\hline 755 & 9 & 38,4 & 10 & 30,6 & 38,1 & 478 & 9 & 38,5 & 14 & 31,1 & 37,7 \\
\hline 755 & 11 & 38,4 & 12 & 31,4 & 36,1 & 478 & 11 & 38,6 & 18 & 29,4 & 36,4 \\
\hline 755 & 13 & 38,3 & 13 & 29,9 & 27,8 & 478 & 13 & 38,7 & 18 & 33 & 39,6 \\
\hline 755 & 15 & 38,8 & 14 & 33,3 & 36,9 & 478 & 15 & 38,6 & 16 & 34,6 & 37,3 \\
\hline 755 & 17 & 38,8 & 18 & 30,5 & 33,4 & 478 & 17 & 38,8 & 14 & 31,5 & 38 \\
\hline 890 & 9 & 38,2 & 10 & 30,1 & 35,9 & 1282 & 9 & 38,4 & 12 & 30,3 & 41,2 \\
\hline 890 & 11 & 38,3 & 14 & 31,4 & 37,1 & 1282 & 11 & 38,7 & 14 & 32,7 & 35,8 \\
\hline 890 & 13 & 38,6 & 13 & 32,7 & 38,1 & 1282 & 13 & 38,4 & 12 & 32,4 & 38,7 \\
\hline 890 & 15 & 38,3 & 9 & 26,9 & 29,3 & 1282 & 15 & 38,5 & 14 & 30,7 & 37,2 \\
\hline 890 & 17 & 38,4 & 12 & 29,2 & 31,7 & 1282 & 17 & 38,4 & 13 & 31,6 & 35,7 \\
\hline 1085 & 9 & 38,2 & 11 & 29,7 & 32,4 & 1077 & 9 & 39,1 & 15 & 31,9 & 39,2 \\
\hline 1085 & 11 & 38,3 & 12 & 29,9 & 34,6 & 1077 & 11 & 38,5 & 13 & 27,7 & 34,1 \\
\hline 1085 & 13 & 38,1 & 10 & 25,1 & 27,9 & 1077 & 13 & 38,7 & 14 & 31,7 & 37,6 \\
\hline 1085 & 15 & 38,3 & 11 & 32,3 & 32,6 & 1077 & 15 & 39,2 & 16 & 32,3 & 29,4 \\
\hline 1085 & 17 & 38,6 & 13 & 28,9 & 35,6 & 1077 & 17 & 38,9 & 17 & 29,3 & 34,2 \\
\hline
\end{tabular}


Apêndice 10. Definição dos grupos de comportamento para a avaliação comportamental dos animais

GRUPO A (localização):

1 - Na área de cocho

2 - Na área de bebedouro

3 - Na cama próxi ma àclimatização

4 - Na cama oposta àclimatização

5 - No corredor próximo àclimatização

6 - No corredor oposto à climatização

GRUPO B (atividades):

1 - Em pé ruminando

2 - Em pé em ócio

3 - Em pé comendo

4 - Em pé bebendo

5 - Deitado ruminando

6 - Deitado em ócio 
Apêndice 11. Dados das variáveis comportamentais dos animais, no tratamento com aspersão, no dia 22/11/2003

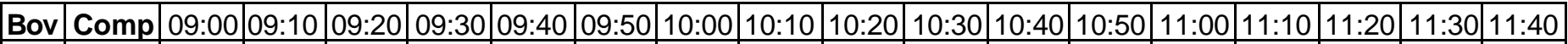

\begin{tabular}{|c|c|c|c|c|c|c|c|c|c|c|c|c|c|c|c|c|c|c|}
\hline \multirow{3}{*}{1} & & & & & & & & & & & & & & & & & & \\
\hline & A & 3 & 3 & 5 & 2 & 6 & 1 & 1 & 3 & 3 & 3 & 3 & 3 & 3 & 3 & 3 & 3 & 3 \\
\hline & B & 6 & 6 & 2 & 4 & 2 & 3 & 3 & 5 & 5 & 5 & 5 & 5 & 5 & 6 & 6 & 6 & 6 \\
\hline \multirow[t]{2}{*}{2} & $A$ & & & 5 & 2 & 6 & 1 & 1 & 3 & 3 & 3 & 3 & 3 & 3 & 3 & 3 & 3 & 3 \\
\hline & B & & & 2 & 4 & 2 & 3 & 3 & 5 & 5 & 5 & 5 & 5 & 5 & 5 & 6 & 6 & 6 \\
\hline \multirow[t]{2}{*}{3} & A & & & 5 & 1 & 5 & 2 & 1 & 1 & 1 & 3 & 3 & 3 & 3 & 3 & 3 & 3 & 3 \\
\hline & B & & & 2 & 3 & 1 & 4 & 3 & 3 & 3 & 5 & 5 & 6 & 6 & 6 & 6 & 6 & 6 \\
\hline \multirow[t]{2}{*}{4} & $A$ & 4 & 4 & 5 & 3 & 3 & 3 & 3 & 3 & 3 & 3 & 3 & 3 & 3 & 3 & 2 & 1 & 1 \\
\hline & B & 6 & 6 & 2 & 2 & 2 & 2 & 6 & 6 & 5 & 5 & 5 & 6 & 6 & 2 & 4 & 3 & 3 \\
\hline \multirow[t]{2}{*}{5} & $\mathbf{A}$ & 3 & 3 & 5 & 5 & 3 & 3 & 3 & 3 & 3 & 3 & 3 & 3 & 3 & 3 & 3 & 3 & 3 \\
\hline & B & 6 & 6 & 2 & 2 & 5 & 5 & 5 & 6 & 6 & 6 & 6 & 6 & 6 & 6 & 6 & 5 & 5 \\
\hline
\end{tabular}

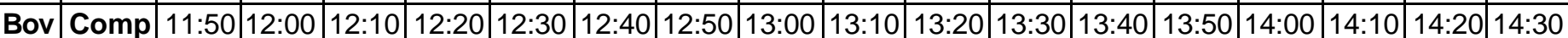

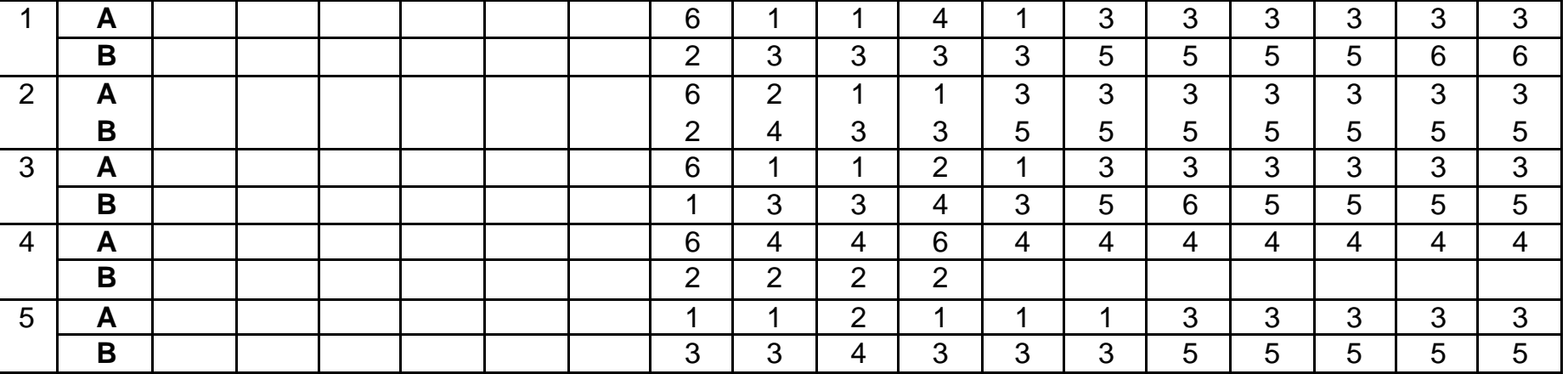

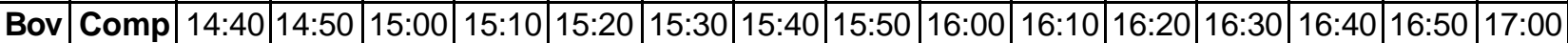

\begin{tabular}{|c|c|c|c|c|c|c|c|c|c|c|c|c|c|c|c|c|}
\hline \multirow[t]{2}{*}{1} & A & 3 & 3 & 3 & 1 & 1 & 2 & 4 & 4 & 4 & 4 & 4 & 4 & 4 & 4 & 2 \\
\hline & B & 6 & 6 & 2 & 3 & 3 & 4 & 2 & 6 & 6 & 6 & 2 & 6 & 6 & 6 & 4 \\
\hline \multirow[t]{2}{*}{2} & $A$ & 3 & 3 & 1 & 4 & 1 & 2 & 1 & 3 & 5 & 5 & 3 & 3 & 3 & 3 & 5 \\
\hline & B & 5 & 6 & 3 & 3 & 3 & 4 & 3 & 2 & 2 & 2 & 6 & 6 & 6 & 6 & 2 \\
\hline \multirow[t]{2}{*}{3} & $A$ & 1 & 1 & 1 & 2 & 1 & 1 & 1 & 1 & 5 & 5 & 6 & 4 & 4 & 4 & 1 \\
\hline & B & 3 & 3 & 3 & 4 & 3 & 3 & 3 & 3 & 1 & 1 & 2 & 6 & 6 & 6 & 3 \\
\hline \multirow[t]{2}{*}{4} & $\mathrm{~A}$ & 4 & 2 & 1 & 6 & 6 & 1 & 4 & 1 & 5 & 1 & 3 & 3 & 3 & 1 & 1 \\
\hline & B & & 4 & 3 & 2 & 2 & 3 & 3 & 3 & 2 & 3 & 6 & 6 & 6 & 3 & 3 \\
\hline \multirow[t]{2}{*}{5} & $A$ & 3 & 3 & 1 & 2 & 1 & 1 & 1 & 1 & 1 & 1 & 5 & 3 & 3 & 5 & 1 \\
\hline & B & 6 & 6 & 3 & 4 & 3 & 3 & 3 & 3 & 3 & 3 & 2 & 6 & 6 & 1 & 3 \\
\hline
\end{tabular}


Apêndice 12. Dados das variáveis comportamentais dos animais, no tratamento com nebulização, no dia 22/11/2003 \begin{tabular}{|c|c|c|c|c|c|c|c|c|c|c|c|c|c|c|c|c|c|c|}
\hline Bov & Comp & 09:00 & $09: 10$ & $09: 20$ & $09: 30$ & $09: 40$ & $09: 50$ & $10: 00$ & $10: 10$ & $10: 20$ & $10: 30$ & $10: 40$ & $10: 50$ & $11: 00$ & $11: 10$ & $11: 20$ & $11: 30$ & $11: 40$ \\
\hline
\end{tabular}

\begin{tabular}{|c|c|c|c|c|c|c|c|c|c|c|c|c|c|c|c|c|c|c|}
\hline & & & & & & & & & 0.10 & 20 & U:30 & 40 & $0: 50$ & 1.00 & 1.10 & $1: 20$ & $1: 30$ & |11:40 \\
\hline \multirow{2}{*}{1} & $\mathbf{A}$ & 5 & 5 & 1 & 5 & 1 & 1 & 5 & 5 & 5 & 3 & 3 & 3 & 3 & 3 & 3 & 3 & 3 \\
\hline & B & 1 & 1 & 5 & 2 & 3 & 2 & 2 & 1 & 2 & 6 & 6 & 6 & 6 & 6 & 6 & 6 & 5 \\
\hline \multirow[t]{2}{*}{2} & $\mathbf{A}$ & 3 & 3 & 3 & 5 & 1 & 1 & 2 & 4 & 4 & 4 & 4 & 4 & 4 & 4 & 4 & 4 & 4 \\
\hline & B & 6 & 5 & 5 & 2 & 3 & 3 & 4 & 6 & 6 & 6 & 5 & 5 & 5 & 6 & 6 & 6 & 5 \\
\hline \multirow[t]{2}{*}{3} & A & 4 & 4 & 4 & 5 & 1 & 1 & 2 & 1 & 1 & 1 & 3 & 3 & 3 & 3 & 3 & 3 & 3 \\
\hline & B & 5 & 5 & 2 & 2 & 3 & 3 & 4 & 3 & 3 & 3 & 5 & 5 & 5 & 5 & 6 & 6 & 6 \\
\hline \multirow[t]{2}{*}{4} & A & & & & & & & & & & & & & & & & & \\
\hline & B & & & & & & & & & & & & & & & & & \\
\hline \multirow[t]{2}{*}{5} & A & & & & & & & & & & & & & & & & & \\
\hline & B & & & & & & & & & & & & & & & & & \\
\hline
\end{tabular}

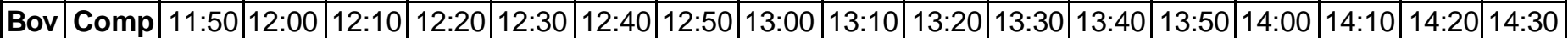

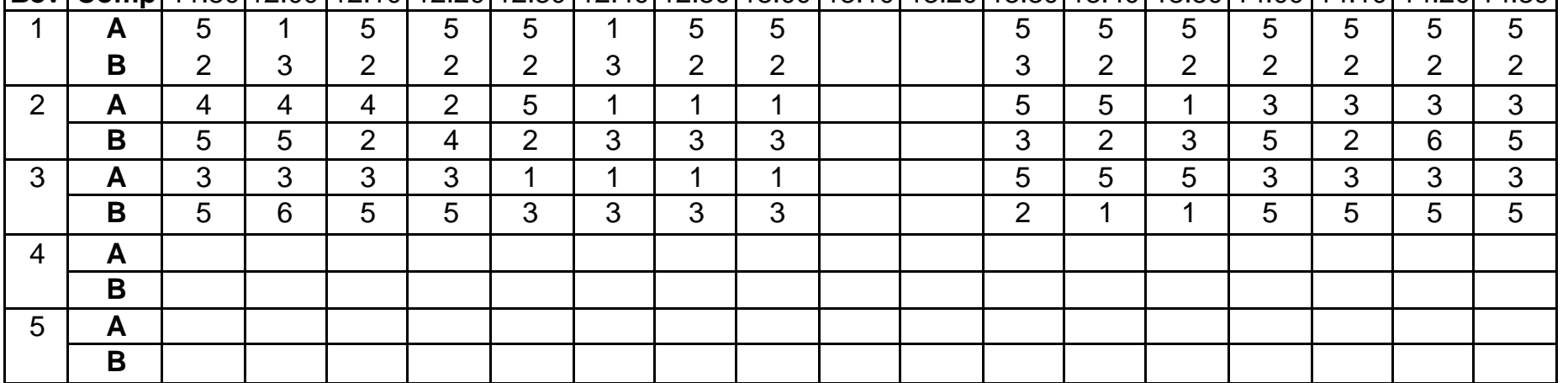

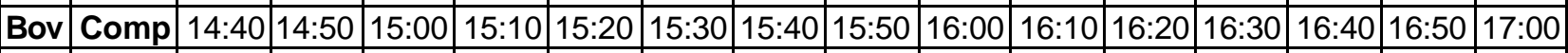

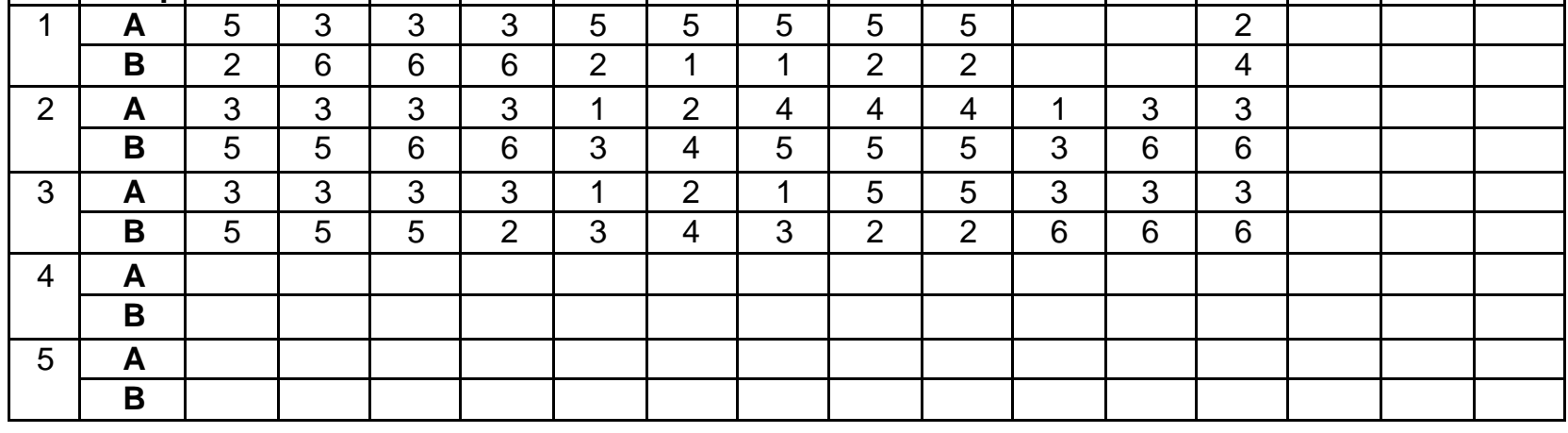


Apêndice 13. Dados das variáveis comportamentais dos animais, no tratamento com aspersão, no dia 23/11/2003

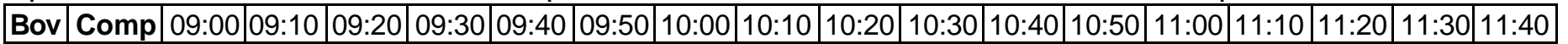

\begin{tabular}{|c|c|c|c|c|c|c|c|c|c|c|c|c|c|c|c|c|c|c|}
\hline & Uc & | & (1) & J.5. & 0.30 & | & | & & & & & & & & & & 30 & 111.40 \\
\hline \multirow[t]{2}{*}{1} & A & 1 & 1 & 5 & & 1 & 3 & 3 & 3 & 3 & 3 & 3 & 3 & 3 & 3 & 3 & 3 & 3 \\
\hline & B & 3 & 3 & 1 & & 4 & 5 & 5 & 5 & 5 & 5 & 5 & 5 & 6 & 5 & 6 & 6 & 6 \\
\hline \multirow[t]{2}{*}{2} & A & & & & & 5 & 5 & 5 & 5 & 1 & 1 & 3 & 3 & 3 & 3 & 3 & 3 & 3 \\
\hline & B & & & & & 2 & 2 & 1 & 1 & 3 & 3 & 5 & 6 & 6 & 5 & 5 & 5 & 5 \\
\hline \multirow[t]{2}{*}{3} & A & 3 & 3 & 3 & 3 & 5 & 5 & 3 & 3 & 3 & 3 & 3 & 3 & 3 & 3 & 3 & 3 & 3 \\
\hline & B & & & & & 2 & 2 & 5 & 5 & 6 & 6 & 6 & 6 & 6 & 5 & 5 & 5 & 1 \\
\hline \multirow[t]{2}{*}{4} & A & & & & & 5 & 1 & 1 & 1 & 3 & 3 & 3 & 3 & 3 & 3 & 3 & 3 & 3 \\
\hline & B & & & & & 2 & 3 & 3 & 3 & 6 & 5 & 5 & 5 & 5 & 5 & 6 & 6 & 6 \\
\hline \multirow[t]{2}{*}{5} & A & 4 & 4 & 4 & 4 & 5 & 5 & 5 & 5 & 1 & 1 & 1 & 1 & 2 & 3 & 3 & 3 & 3 \\
\hline & B & 6 & 6 & 6 & 6 & 2 & 2 & 2 & 2 & 3 & 3 & 3 & 3 & 4 & 5 & 5 & 5 & 5 \\
\hline
\end{tabular}

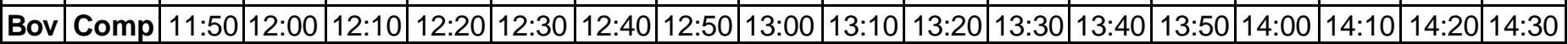

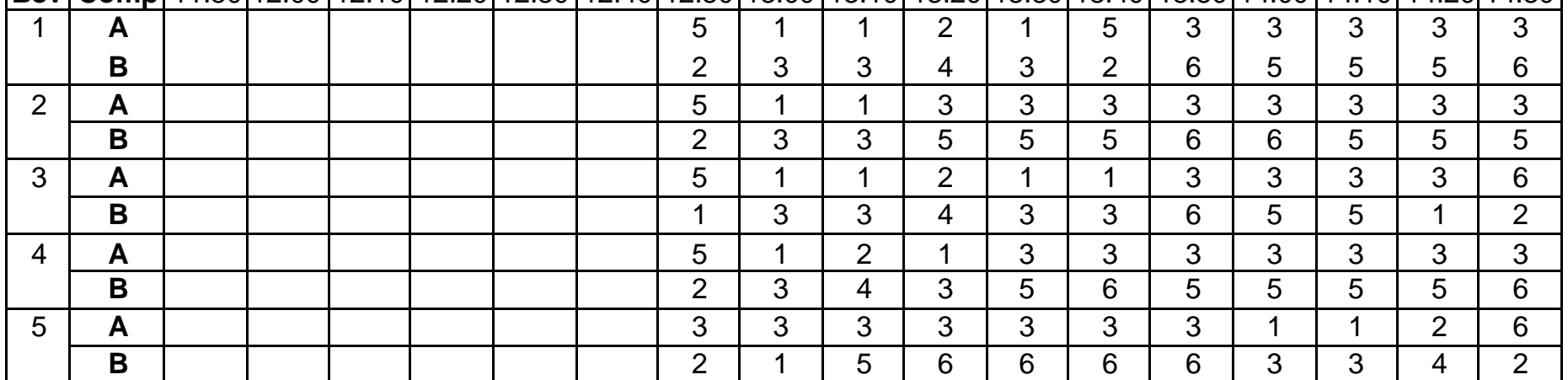

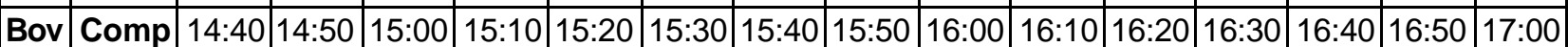

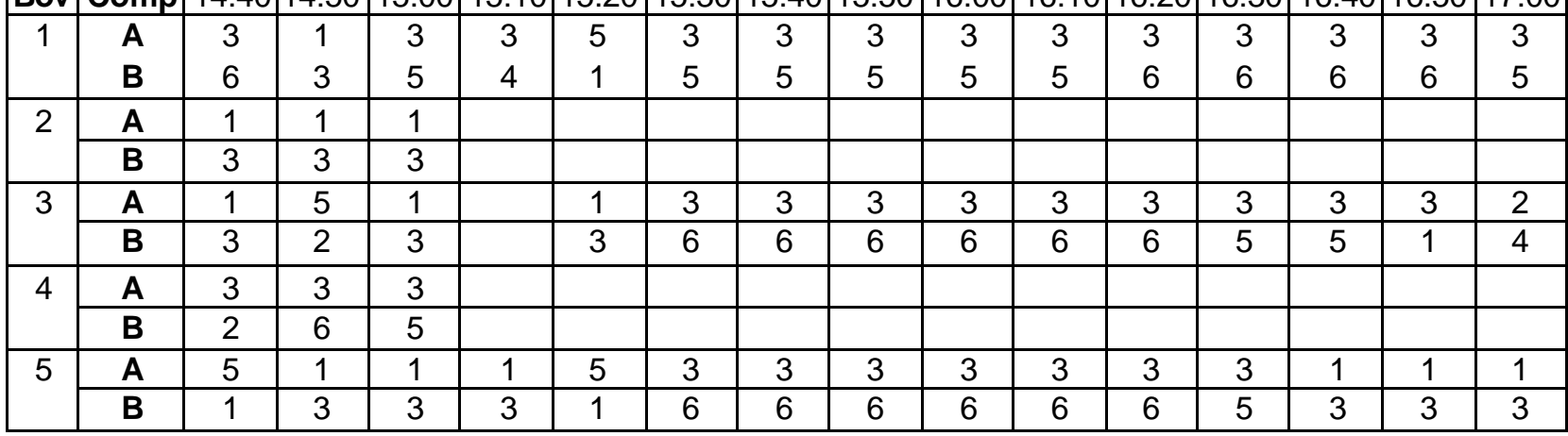


Apêndice 14. Dados das variáveis comportamentais dos animais, no tratamento com nebulização, no dia 23/11/2003

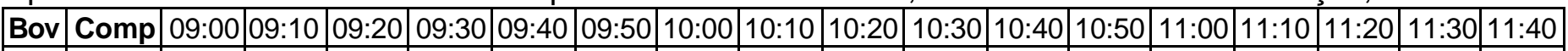

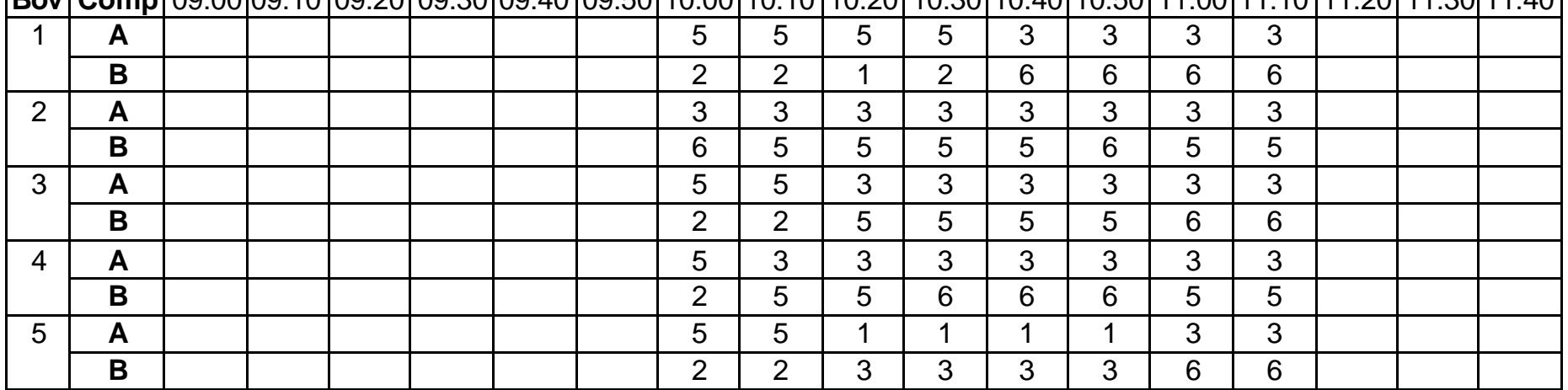

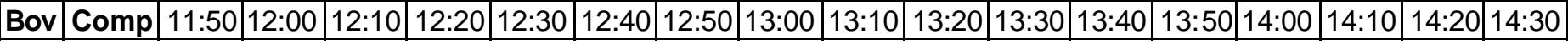

\begin{tabular}{|c|c|c|c|c|c|c|c|c|c|c|c|c|c|c|c|c|c|c|}
\hline \multirow[t]{2}{*}{1} & $\mathbf{A}$ & 3 & 5 & 5 & 5 & 1 & 5 & 5 & 5 & 5 & 5 & 6 & 6 & 2 & 1 & 3 & 3 & 3 \\
\hline & B & 2 & 1 & 2 & 1 & 3 & 2 & 2 & 2 & 2 & 2 & 2 & 2 & 4 & 3 & 6 & 6 & 6 \\
\hline \multirow[t]{2}{*}{2} & $\mathbf{A}$ & 3 & 3 & 3 & 3 & 3 & 5 & 1 & 1 & 5 & 5 & 6 & 6 & 2 & 1 & 3 & 3 & 3 \\
\hline & B & 1 & 5 & 5 & 6 & 6 & 2 & 3 & 3 & 2 & 2 & 2 & 1 & 4 & 3 & 6 & 5 & 6 \\
\hline \multirow[t]{2}{*}{3} & $\mathbf{A}$ & 3 & 3 & 2 & 1 & 1 & 5 & 1 & 1 & 1 & 5 & 6 & 6 & 1 & 1 & 3 & 3 & 3 \\
\hline & B & 6 & 6 & 4 & 3 & 3 & 2 & 3 & 3 & 3 & 2 & 1 & 1 & 3 & 3 & 6 & 5 & 6 \\
\hline \multirow[t]{2}{*}{4} & $\mathbf{A}$ & 5 & 1 & 2 & 1 & 3 & 3 & 3 & 3 & 3 & 5 & 6 & 6 & 1 & 1 & 5 & 3 & 3 \\
\hline & B & 2 & 3 & 4 & 3 & 6 & 6 & 6 & 6 & 6 & 2 & 2 & 2 & 3 & 3 & 2 & 5 & 6 \\
\hline \multirow[t]{2}{*}{5} & $\mathbf{A}$ & 3 & 3 & 3 & 3 & 3 & 1 & 5 & 1 & 2 & 5 & 6 & 6 & 6 & 1 & 3 & 3 & 3 \\
\hline & B & 6 & 6 & 6 & 5 & 6 & 3 & 2 & 3 & 4 & 2 & 1 & 2 & 2 & 3 & 6 & 5 & 5 \\
\hline
\end{tabular}

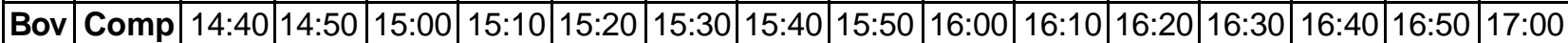

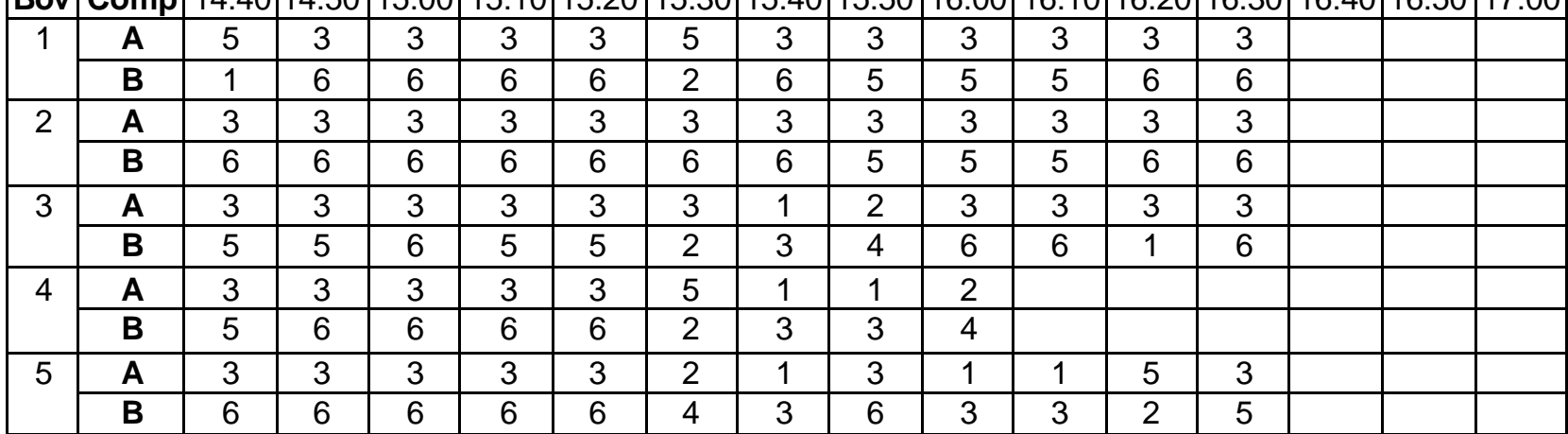


Apêndice 15. Dados das variáveis comportamentais dos animais, no tratamento com aspersão, no dia 24/11/2003

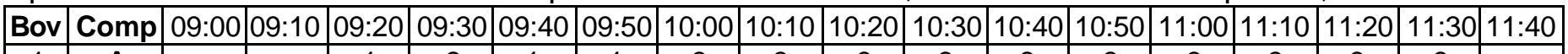

\begin{tabular}{|c|c|c|c|c|c|c|c|c|c|c|c|c|c|c|c|c|c|c|}
\hline \multirow{3}{*}{1} & $\Delta$ & & & & & & & & & & & & & & & & & \\
\hline & & & & & & & & & & & & & & & & & & \\
\hline & B & & & 3 & 4 & 3 & 3 & 5 & 5 & 5 & 5 & 5 & 5 & 6 & 6 & 6 & 6 & \\
\hline \multirow[t]{2}{*}{2} & $\mathbf{A}$ & 5 & 5 & 5 & 3 & 3 & 3 & 3 & 3 & 3 & 3 & 3 & 3 & 3 & 3 & 3 & 3 & \\
\hline & B & 2 & 2 & 2 & 5 & 6 & 6 & 6 & 2 & 6 & 5 & 5 & 5 & 5 & 5 & 6 & 6 & \\
\hline \multirow[t]{2}{*}{3} & $\mathbf{A}$ & & & 5 & 5 & 5 & 3 & 3 & 1 & 1 & 1 & 5 & 1 & 5 & 3 & 3 & 5 & \\
\hline & B & & & 2 & 1 & 1 & 5 & 5 & 3 & 3 & 3 & 1 & 3 & 2 & 6 & 6 & 1 & \\
\hline \multirow[t]{2}{*}{4} & $\bar{A}$ & & & 5 & 3 & 3 & 3 & 3 & 3 & 3 & 3 & 3 & 3 & 3 & 3 & 3 & 3 & \\
\hline & B & & & 2 & 6 & 5 & 5 & 5 & 2 & 6 & 6 & 5 & 5 & 6 & 6 & 6 & 6 & \\
\hline \multirow[t]{2}{*}{5} & $\mathbf{A}$ & & & 5 & 3 & 3 & 3 & 3 & 3 & 3 & 1 & 3 & 3 & 3 & 3 & 3 & 3 & \\
\hline & B & & & 2 & 6 & 6 & 5 & 5 & 5 & 6 & 3 & 2 & 6 & 5 & 6 & 6 & 6 & \\
\hline
\end{tabular}

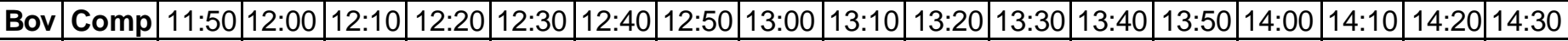

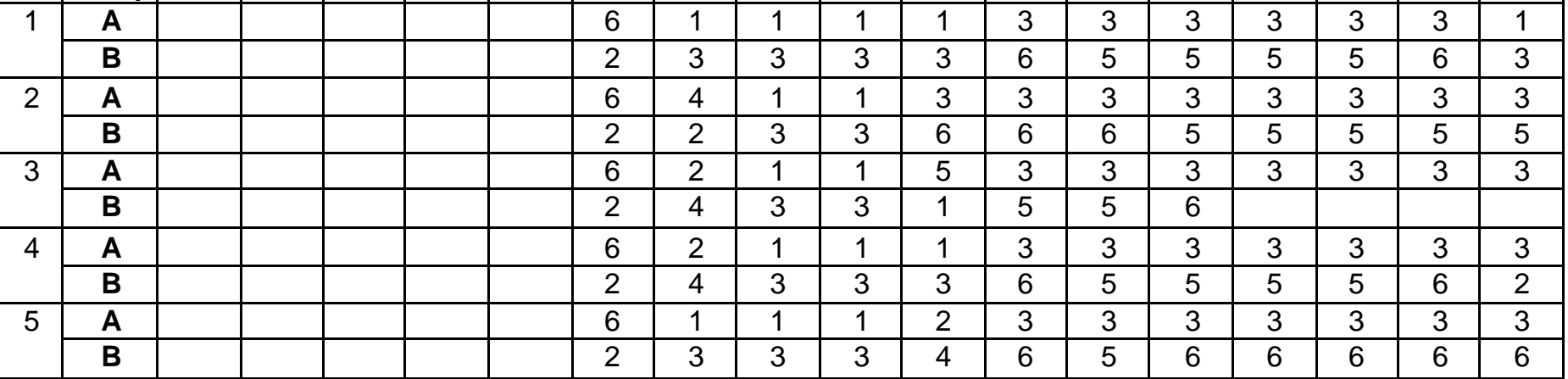

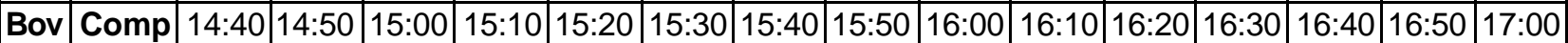

\begin{tabular}{|c|c|c|c|c|c|c|c|c|c|c|c|c|c|c|c|c|}
\hline \multirow[t]{2}{*}{1} & A & 1 & 3 & 3 & 3 & 3 & 3 & 3 & 3 & 1 & 6 & 5 & 1 & 1 & $\frac{4}{2}$ & 6 \\
\hline & B & 3 & 6 & 6 & 6 & 5 & 5 & 6 & 6 & 3 & 2 & 2 & 3 & 3 & 4 & 2 \\
\hline \multirow[t]{2}{*}{2} & A & 3 & 3 & 1 & 1 & 3 & 3 & 3 & 3 & 3 & 3 & 3 & 3 & 3 & 3 & 3 \\
\hline & B & 6 & 6 & 3 & 3 & 1 & 5 & 6 & 2 & 6 & 2 & 1 & 1 & 6 & 6 & 6 \\
\hline \multirow[t]{2}{*}{3} & A & 3 & 3 & 1 & 5 & 1 & 1 & 3 & 3 & 3 & 3 & 3 & 3 & 3 & 3 & 3 \\
\hline & B & & & 3 & & 3 & 3 & 6 & 6 & 2 & 5 & 5 & 5 & 5 & 5 & 5 \\
\hline \multirow[t]{2}{*}{4} & A & 3 & 3 & 3 & 3 & 3 & 3 & 3 & 1 & 1 & 3 & 3 & 3 & 3 & 3 & 3 \\
\hline & B & 6 & 5 & 5 & 6 & 5 & 6 & 2 & 3 & 3 & 2 & 6 & 5 & 5 & 5 & 5 \\
\hline \multirow[t]{2}{*}{5} & A & 1 & 1 & 1 & 5 & 1 & 1 & 1 & 2 & 1 & 3 & 3 & 3 & 3 & 3 & 3 \\
\hline & B & 3 & 3 & 3 & 2 & 3 & 3 & 3 & 4 & 3 & 5 & 5 & 2 & 1 & 1 & 2 \\
\hline
\end{tabular}


Apêndice 16. Dados das variáveis comportamentais dos animais, no tratamento com nebulização, no dia 24/11/2003



\begin{tabular}{|c|c|c|c|c|c|c|c|c|c|c|c|c|c|c|c|c|c|}
\hline & C & $J$ & 9 & U. U. U. & & & & & & & & & & & & 30 & $11: 40$ \\
\hline \multirow[t]{2}{*}{1} & A & & & 2 & 6 & 6 & 5 & 5 & 3 & 3 & 3 & 3 & 3 & 3 & 3 & 3 & 5 \\
\hline & B & & & 4 & 2 & 2 & 2 & 2 & 1 & 1 & 6 & 6 & 6 & 6 & 6 & 6 & 1 \\
\hline \multirow[t]{2}{*}{2} & $\mathbf{A}$ & & & 2 & 1 & 1 & 1 & 1 & 3 & 3 & 3 & 3 & 3 & 3 & 3 & 3 & 3 \\
\hline & B & & & 4 & 3 & 3 & 3 & 3 & 5 & 6 & 5 & 5 & 5 & 5 & 6 & 6 & 6 \\
\hline \multirow[t]{2}{*}{3} & $\overline{\mathbf{A}}$ & & & 3 & 3 & 3 & 3 & 3 & 3 & 3 & 5 & 1 & 1 & 2 & 2 & 1 & 1 \\
\hline & B & & & 5 & 5 & 5 & 5 & 5 & 5 & 5 & 2 & 3 & 3 & 4 & 4 & 3 & 3 \\
\hline \multirow[t]{2}{*}{4} & A & & & 1 & 2 & 6 & 4 & 4 & 6 & 1 & 3 & 3 & 3 & 3 & 3 & 3 & 3 \\
\hline & B & & & 3 & 4 & 2 & 2 & 2 & 2 & 3 & 2 & 5 & 6 & 6 & 5 & 5 & 5 \\
\hline \multirow[t]{2}{*}{5} & A & & & 4 & 4 & 4 & 4 & 4 & 4 & 4 & 1 & 5 & 1 & 5 & 1 & 1 & 5 \\
\hline & B & & & 5 & 5 & 5 & 5 & 5 & 5 & 2 & 3 & 2 & 3 & 2 & 3 & 3 & 1 \\
\hline
\end{tabular}

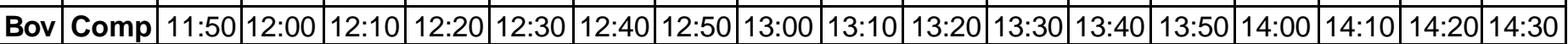

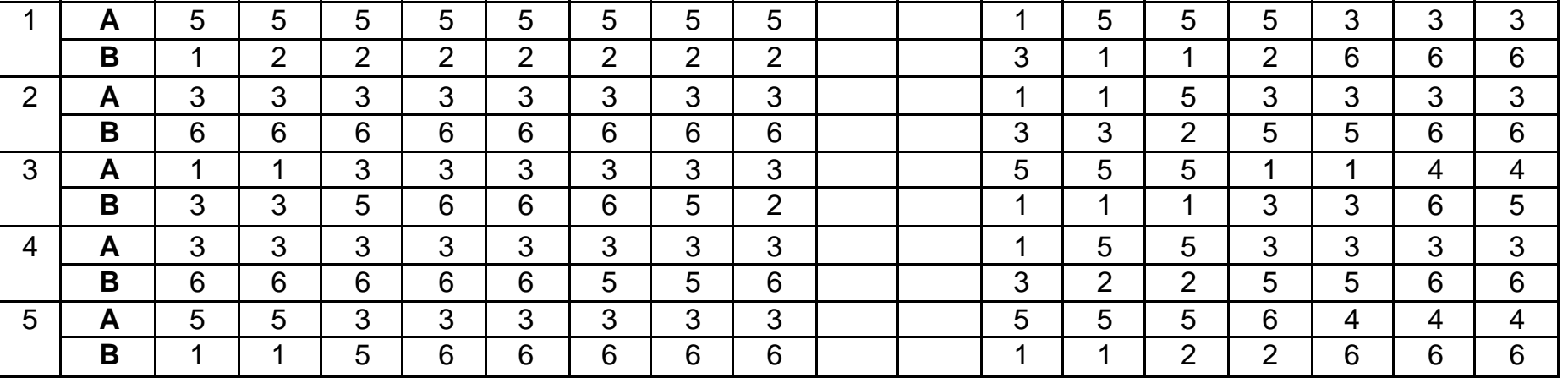

\begin{tabular}{|l|r|r|r|r|r|r|r|r|r|r|r|r|r|r|r|}
\hline Bov Comp & $14: 40$ & $14: 50$ & $15: 00$ & $15: 10$ & $15: 20$ & $15: 30$ & $15: 40$ & $15: 50$ & $16: 00$ & $16: 10$ & $16: 20$ & $16: 30$ & $16: 40$ & $16: 50$ & $17: 00$ \\
\hline
\end{tabular}

\begin{tabular}{|c|c|c|c|c|c|c|c|c|c|c|c|c|c|c|c|c|}
\hline \multirow{3}{*}{1} & & & & & & & & & & & & & & & & \\
\hline & $\mathbf{A}$ & 3 & 3 & 3 & 3 & 3 & 3 & 3 & 3 & 5 & 3 & 3 & & & & \\
\hline & B & 5 & 6 & 6 & 6 & 6 & 5 & 5 & 5 & 2 & 6 & 6 & & & & \\
\hline \multirow[t]{2}{*}{2} & A & 3 & 3 & 3 & 3 & 3 & 3 & 3 & 3 & 3 & 3 & 3 & & & & \\
\hline & B & 6 & 6 & 5 & 6 & 6 & 6 & 6 & 6 & 6 & 5 & 5 & & & & \\
\hline \multirow[t]{2}{*}{3} & $\mathbf{A}$ & 4 & 4 & 4 & 4 & 4 & 4 & 4 & 4 & 1 & 1 & 1 & & & & \\
\hline & B & 5 & 5 & 5 & 5 & 5 & 5 & 5 & 5 & 3 & 3 & 3 & & & & \\
\hline \multirow[t]{2}{*}{4} & A & 3 & 3 & 3 & 3 & 2 & 1 & 5 & 5 & 6 & 5 & 5 & & & & \\
\hline & B & 6 & 6 & 5 & 6 & 4 & 3 & 2 & 2 & 2 & 2 & 2 & & & & \\
\hline \multirow[t]{2}{*}{5} & A & 4 & 4 & 4 & 4 & 4 & 4 & 4 & 4 & 4 & 4 & 4 & & & & \\
\hline & B & 6 & 6 & 6 & 6 & 5 & 5 & 5 & 5 & 6 & 6 & 6 & & & & \\
\hline
\end{tabular}


Apêndice 17. Dados das variáveis comportamentais dos animais, no tratamento com aspersão, no dia 25/11/2003

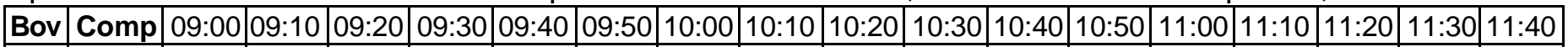

\begin{tabular}{|c|c|c|c|c|c|c|c|c|c|c|c|c|c|c|c|c|c|c|}
\hline \multirow{3}{*}{1} & $\Delta$ & & 3 & & & & & & & & & & & & & & & \\
\hline & & & & & & & & & & & & & & & & & & \\
\hline & B & & & & & 3 & 3 & 3 & 2 & & & 1 & 5 & 5 & 6 & 3 & 2 & \\
\hline \multirow[t]{2}{*}{2} & $\mathbf{A}$ & 1 & 1 & 5 & 4 & 4 & 4 & 1 & 3 & 3 & 3 & 3 & 3 & 3 & 3 & 1 & 5 & \\
\hline & B & 3 & 3 & 2 & 2 & 2 & 2 & 3 & & & 5 & 5 & 5 & 5 & 5 & 3 & 2 & \\
\hline \multirow[t]{2}{*}{3} & $\mathbf{A}$ & & & & & 5 & 1 & 1 & 2 & & & 5 & 5 & 3 & 5 & 1 & 1 & \\
\hline & B & & & & & 2 & 3 & 3 & 4 & & & 1 & 1 & 1 & 1 & 3 & 3 & \\
\hline \multirow[t]{2}{*}{4} & $\bar{A}$ & & & & & 2 & 1 & 1 & 1 & & & 3 & 3 & 3 & 1 & 5 & 3 & \\
\hline & B & & & & & 4 & 3 & 3 & 3 & & & 1 & 1 & 5 & 3 & 2 & 2 & \\
\hline \multirow[t]{2}{*}{5} & $\mathbf{A}$ & 4 & 4 & 4 & 4 & 4 & 2 & 1 & 1 & & & 1 & 1 & 2 & 2 & 5 & 5 & \\
\hline & B & & & & & & 4 & 3 & 3 & & & 3 & 3 & 4 & 4 & 2 & 2 & \\
\hline
\end{tabular}

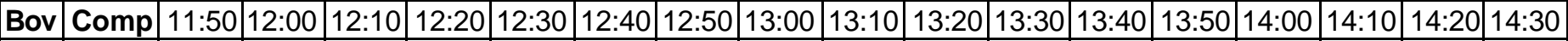

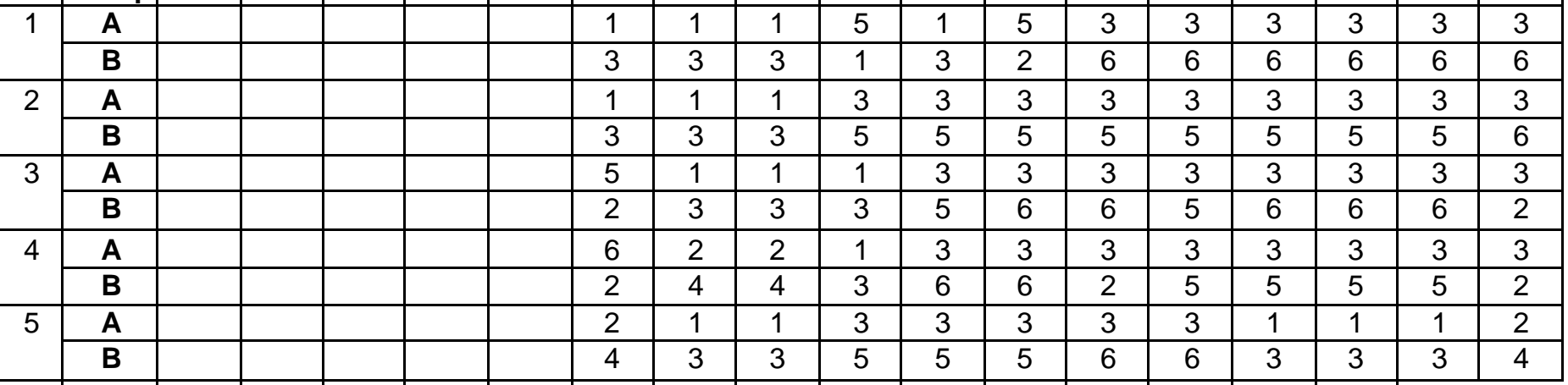

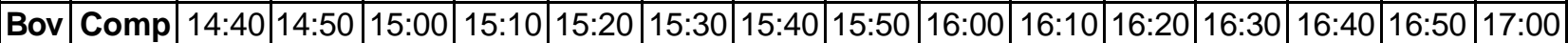

\begin{tabular}{|c|c|c|c|c|c|c|c|c|c|c|c|c|c|c|c|c|}
\hline \multirow{3}{*}{1} & $A$ & 1 & 1 & & & & & & & & & & & & & \\
\hline & & & & & & & & & & & & & & & & \\
\hline & B & 3 & 3 & 1 & 1 & 3 & 3 & 2 & 3 & 6 & 2 & 2 & 1 & 1 & 3 & 3 \\
\hline \multirow[t]{2}{*}{2} & A & 1 & 1 & 2 & 1 & 1 & 1 & 1 & 1 & 3 & 5 & 1 & 1 & 1 & 5 & 1 \\
\hline & B & 3 & 3 & 4 & 3 & 3 & 3 & 3 & 3 & 6 & 2 & 3 & 3 & 3 & 1 & 3 \\
\hline \multirow[t]{2}{*}{3} & $\mathbf{A}$ & 1 & 5 & 5 & 1 & 1 & 1 & 1 & 1 & 1 & 6 & 1 & 1 & 1 & 1 & 1 \\
\hline & B & 3 & 2 & 2 & 3 & 3 & 3 & 3 & 3 & 3 & 2 & 3 & 3 & 3 & 3 & 3 \\
\hline \multirow[t]{2}{*}{4} & A & 5 & 2 & 6 & 1 & 1 & 1 & 1 & 1 & 5 & 1 & 1 & 1 & 2 & 1 & 1 \\
\hline & B & 2 & 4 & 2 & 3 & 3 & 3 & 3 & 3 & 2 & 3 & 3 & 3 & 4 & 3 & 3 \\
\hline \multirow[t]{2}{*}{5} & $\mathbf{A}$ & 5 & 1 & 2 & 5 & 1 & 1 & 1 & 1 & 1 & 2 & 1 & 1 & 1 & 1 & 1 \\
\hline & B & 2 & 3 & 4 & & 3 & 3 & 3 & 3 & 3 & 4 & 3 & 3 & 3 & 3 & 3 \\
\hline
\end{tabular}


Apêndice 18. Dados das variáveis comportam entais dos animais, no tratamento com nebulização, no dia 25/11/2003

\begin{tabular}{|l|c|c|c|c|c|c|c|c|c|c|c|c|c|c|c|c|c|c|}
\hline Bov & Comp & $09: 00$ & $09: 10$ & $09: 20$ & $09: 30$ & $09: 40$ & $09: 50$ & $10: 00$ & $10: 10$ & $10: 20$ & $10: 30$ & $10: 40$ & $10: 50$ & $11: 00$ & $11: 10$ & $11: 20$ & $11: 30$ & $11: 40$ \\
\hline
\end{tabular}

\begin{tabular}{|c|c|c|c|c|c|c|c|c|c|c|c|c|c|c|c|c|c|c|}
\hline \multirow{3}{*}{1} & & & & & & & & & & & & & & & & & & \\
\hline & & & & 2 & 6 & 6 & 6 & 6 & 4 & 4 & 4 & 4 & 4 & 4 & 6 & 4 & 4 & 4 \\
\hline & B & & & 4 & 2 & 2 & 2 & 2 & 6 & 6 & 6 & 6 & 6 & 6 & 2 & 5 & 5 & 5 \\
\hline \multirow[t]{2}{*}{2} & A & & & 4 & 4 & 4 & 4 & 4 & 1 & 3 & 3 & 3 & 3 & 3 & 3 & 3 & 3 & 3 \\
\hline & B & & & 2 & 5 & 5 & 5 & 2 & 3 & 6 & 5 & 5 & 5 & 6 & 5 & 5 & 6 & 1 \\
\hline \multirow[t]{2}{*}{3} & $\mathbf{A}$ & & & 3 & 3 & 3 & 3 & 3 & 3 & 3 & 3 & 3 & 3 & 3 & 3 & 3 & 3 & 3 \\
\hline & B & & & 5 & 2 & 5 & 5 & 5 & 5 & 2 & 2 & 6 & 6 & 6 & 6 & 6 & 6 & 6 \\
\hline \multirow[t]{2}{*}{4} & A & & & 6 & 1 & 5 & 1 & 3 & 3 & 3 & 3 & 3 & 3 & 3 & 3 & 3 & 3 & 1 \\
\hline & B & & & 2 & 3 & 2 & 3 & 2 & 5 & 5 & 5 & 5 & 5 & 6 & 6 & 6 & 6 & 3 \\
\hline \multirow[t]{2}{*}{5} & $\mathbf{A}$ & & & 4 & 2 & 6 & 6 & 6 & 6 & 4 & 4 & 4 & 4 & 4 & 4 & 4 & 4 & 4 \\
\hline & B & & & 2 & 4 & 2 & 2 & 2 & 2 & 5 & 5 & 5 & 6 & 6 & 6 & 6 & 6 & 6 \\
\hline
\end{tabular}

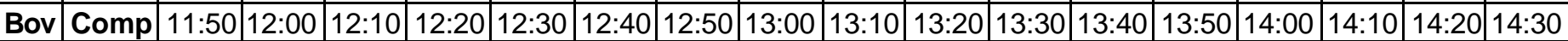

\begin{tabular}{|c|c|c|c|c|c|c|c|c|c|c|c|c|c|c|c|c|c|c|}
\hline \multirow[t]{2}{*}{1} & $\mathbf{A}$ & 4 & 4 & 4 & 2 & 1 & 1 & 5 & 3 & 5 & & & 6 & 6 & 6 & 5 & 5 & 5 \\
\hline & B & 5 & 5 & 2 & 4 & 3 & 3 & 2 & 5 & 2 & & & 1 & 1 & 2 & 5 & 5 & 5 \\
\hline \multirow[t]{2}{*}{2} & A & 1 & 2 & 4 & 4 & 4 & 6 & 6 & 6 & 1 & & & 4 & 4 & 4 & 4 & 4 & 4 \\
\hline & B & 3 & 4 & 6 & 5 & 5 & 2 & 2 & 2 & 3 & & & 5 & 5 & 5 & 5 & 5 & 5 \\
\hline \multirow[t]{2}{*}{3} & A & 3 & 3 & 3 & 3 & 3 & 3 & 3 & 3 & 3 & & & 4 & 4 & 4 & 4 & 4 & 4 \\
\hline & B & 6 & 6 & 5 & 5 & 5 & 5 & 2 & 6 & 2 & & & 6 & 6 & 5 & 5 & 5 & 5 \\
\hline \multirow[t]{2}{*}{4} & A & 2 & 1 & 1 & 3 & 3 & 3 & 3 & 3 & 3 & & & 4 & 2 & 1 & 3 & 3 & 3 \\
\hline & B & 4 & 3 & 3 & 6 & 6 & 6 & 5 & 5 & 6 & & & 2 & 4 & 3 & 6 & 6 & 6 \\
\hline \multirow[t]{2}{*}{5} & A & 4 & 4 & 1 & 1 & 5 & 5 & 5 & 5 & 5 & & & 4 & 4 & 4 & 4 & 4 & 2 \\
\hline & B & 1 & 1 & 3 & 3 & 2 & 2 & 1 & 1 & 1 & & & 6 & 6 & 6 & 6 & 6 & 4 \\
\hline
\end{tabular}

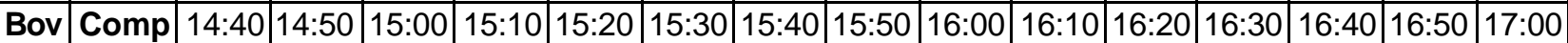

\begin{tabular}{|c|c|c|c|c|c|c|c|c|c|c|c|c|c|c|c|c|}
\hline \multirow{3}{*}{1} & $\mathbf{A}$ & 4 & 4 & 4 & & & & & & & & & & & & \\
\hline & & & & & & & & & & & & & & & & \\
\hline & B & 5 & 5 & 6 & 6 & 2 & 4 & 2 & 2 & 2 & 3 & 2 & 3 & 5 & & \\
\hline \multirow[t]{2}{*}{2} & A & 4 & 4 & 4 & 4 & 4 & 4 & 4 & 4 & 4 & 2 & 1 & 1 & 3 & & \\
\hline & B & 6 & 6 & 6 & 6 & 6 & 6 & 6 & 5 & 5 & 4 & 3 & 3 & 6 & & \\
\hline \multirow[t]{2}{*}{3} & $\mathbf{A}$ & 4 & 1 & 1 & 5 & 5 & 5 & 1 & 5 & 5 & 3 & 3 & 3 & 3 & & \\
\hline & B & 2 & 3 & 3 & 2 & 2 & 2 & 3 & 2 & 2 & 6 & 6 & 6 & 6 & & \\
\hline \multirow[t]{2}{*}{4} & A & 3 & 3 & 3 & 3 & 3 & 3 & 1 & 1 & 1 & 1 & 5 & 1 & 5 & & \\
\hline & B & 5 & 5 & 5 & 6 & 6 & 2 & 3 & 3 & 3 & 3 & 2 & 3 & 2 & & \\
\hline \multirow[t]{2}{*}{5} & $\mathbf{A}$ & 1 & 5 & 5 & 3 & 3 & 3 & 5 & 5 & 5 & 1 & 1 & 1 & 3 & & \\
\hline & B & 3 & 2 & 2 & 6 & 6 & 2 & 1 & 1 & 1 & 3 & 3 & 3 & 6 & & \\
\hline
\end{tabular}


Apêndice 19. Dados das variáveis comportamentais dos animais, no tratamento com aspersão, no dia 26/11/2003

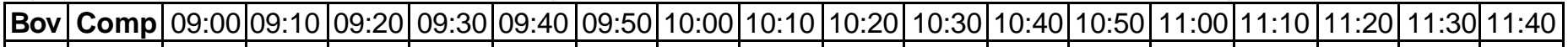

\begin{tabular}{|c|c|c|c|c|c|c|c|c|c|c|c|c|c|c|c|c|c|c|}
\hline \multirow{3}{*}{1} & $\Delta$ & & & & & & & & & & & & & & & & & \\
\hline & & & & & & & & & & & & & & & & & & \\
\hline & B & 1 & 3 & 3 & 2 & 4 & 2 & 5 & 5 & 5 & 5 & 6 & 6 & 6 & 3 & 3 & 1 & \\
\hline \multirow[t]{2}{*}{2} & A & & & & & 1 & 6 & 4 & 4 & 4 & 4 & 4 & 4 & 4 & 4 & 1 & 1 & \\
\hline & B & & & & & 3 & 1 & 2 & 6 & & & & & & 2 & 3 & 3 & \\
\hline \multirow[t]{2}{*}{3} & $\mathbf{A}$ & 4 & 1 & 3 & 3 & 5 & 5 & 3 & 3 & 3 & 3 & 3 & 3 & 3 & 1 & 1 & 2 & \\
\hline & B & & 3 & 6 & 6 & 1 & 1 & 5 & 5 & 5 & 2 & 6 & 6 & 6 & 3 & 3 & 4 & \\
\hline \multirow[t]{2}{*}{4} & $\bar{A}$ & 2 & 1 & 1 & 1 & 3 & 3 & 3 & 3 & 3 & 3 & 3 & 3 & 3 & 3 & 3 & 1 & \\
\hline & B & 4 & 3 & 3 & 3 & 2 & 2 & 5 & 5 & 5 & 6 & 6 & 6 & 6 & 5 & 2 & 3 & \\
\hline \multirow[t]{2}{*}{5} & $\mathbf{A}$ & 1 & 1 & 1 & 1 & 1 & 6 & 3 & 3 & 3 & 3 & 3 & 3 & 3 & 1 & 1 & 5 & \\
\hline & B & 3 & 3 & 3 & 3 & 3 & & 5 & 5 & 5 & 5 & 5 & 6 & 6 & 3 & 3 & 2 & \\
\hline
\end{tabular}

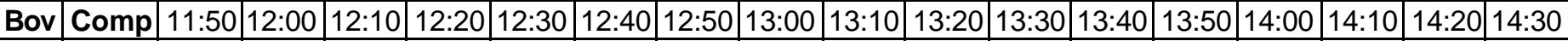

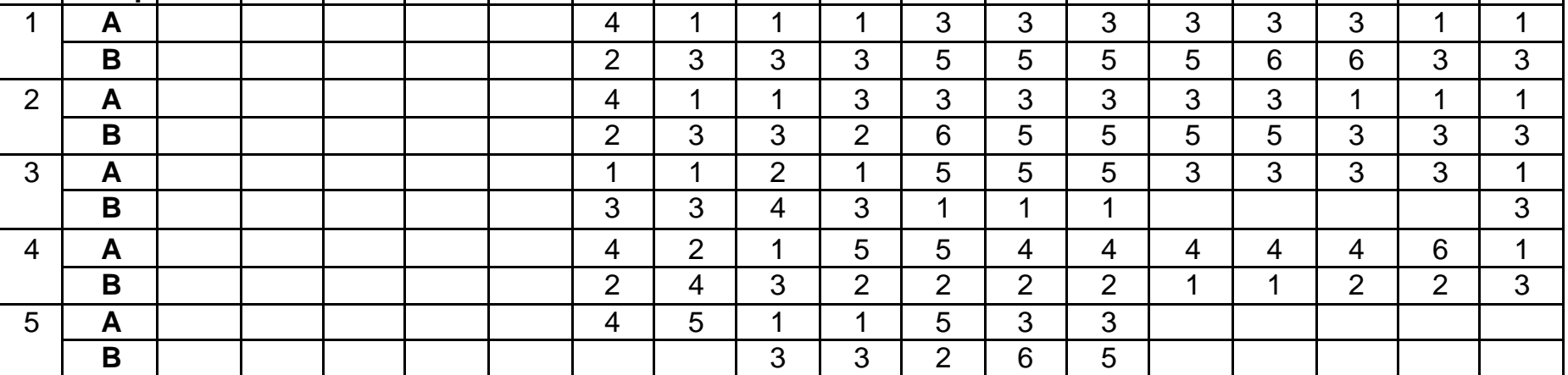

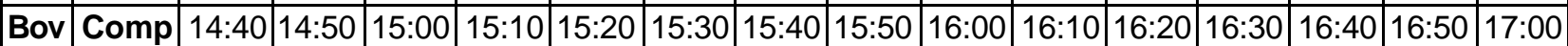

\begin{tabular}{|c|c|c|c|c|c|c|c|c|c|c|c|c|c|c|c|c|}
\hline \multirow[t]{2}{*}{1} & A & 2 & 5 & 1 & 1 & 1 & 1 & 3 & 3 & 3 & 3 & 3 & 3 & 3 & 3 & 1 \\
\hline & B & 4 & 2 & 3 & 3 & 3 & 3 & 2 & 6 & 6 & 6 & 6 & 6 & 6 & 1 & 3 \\
\hline \multirow[t]{2}{*}{2} & $A$ & 2 & 5 & 1 & 1 & & & & & & & & & & & \\
\hline & B & 4 & 2 & 3 & 3 & & & & & & & & & & & \\
\hline \multirow[t]{2}{*}{3} & A & 2 & 1 & 1 & 1 & 1 & 5 & 5 & 5 & 2 & 5 & 5 & 5 & 5 & 5 & 5 \\
\hline & B & 4 & 3 & 3 & 3 & 3 & 1 & 1 & 1 & 4 & 1 & 1 & 1 & 1 & 1 & 1 \\
\hline \multirow[t]{2}{*}{4} & A & 1 & 5 & 6 & & & & & & & & & & & & \\
\hline & B & 3 & 2 & & & & & & & & & & & & & \\
\hline \multirow[t]{2}{*}{5} & A & 1 & 5 & & & & 6 & 4 & 6 & & 6 & 6 & 6 & 6 & 5 & \\
\hline & B & 3 & 2 & & & & 2 & 6 & 2 & & 1 & 2 & 1 & 1 & 2 & \\
\hline
\end{tabular}


Apêndice 20. Dados das variáveis comportamentais dos animais, no tratamento com nebulização, no dia 26/11/2003

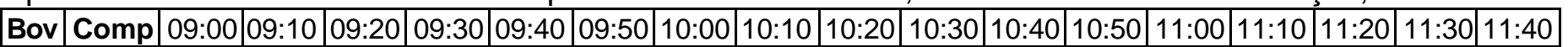

\begin{tabular}{|c|c|c|c|c|c|c|c|c|c|c|c|c|c|c|c|c|c|c|}
\hline \multirow{3}{*}{1} & $\Delta$ & & & & & & & & & & & & & & & & & \\
\hline & & & & & & & & & & & & & & & & & & 6 \\
\hline & B & & & 3 & 3 & 3 & 2 & 2 & 1 & 1 & 5 & 5 & 6 & 6 & 6 & 4 & 2 & 1 \\
\hline \multirow[t]{2}{*}{2} & A & & & 1 & 1 & 3 & 3 & 3 & 3 & 3 & 3 & 3 & 3 & 3 & 3 & 3 & 3 & 3 \\
\hline & B & & & 3 & 3 & 6 & 6 & 6 & 6 & 6 & 6 & 5 & 5 & 5 & 5 & 5 & 6 & 6 \\
\hline \multirow[t]{2}{*}{3} & A & & & 1 & 1 & 3 & 3 & 3 & 3 & 3 & 3 & 3 & 3 & 3 & 3 & 3 & 3 & 3 \\
\hline & B & & & 3 & 3 & 2 & 5 & 5 & 5 & 6 & 6 & 6 & 6 & 6 & 6 & 5 & 5 & 5 \\
\hline \multirow[t]{2}{*}{4} & A & & & 1 & 5 & 5 & 3 & 3 & 3 & 3 & 3 & 3 & 3 & 1 & 1 & 1 & 3 & 3 \\
\hline & B & & & 3 & 2 & 2 & 5 & 5 & 5 & 5 & 5 & 6 & 6 & 3 & 3 & 3 & 6 & 6 \\
\hline \multirow[t]{2}{*}{5} & $\mathbf{A}$ & & & 1 & 6 & 6 & 6 & 6 & 4 & 4 & 4 & 4 & 4 & 4 & 4 & 4 & 1 & 1 \\
\hline & B & & & 3 & 2 & 1 & 1 & 1 & 5 & 5 & 5 & 6 & 6 & 6 & 6 & 2 & 3 & 3 \\
\hline
\end{tabular}

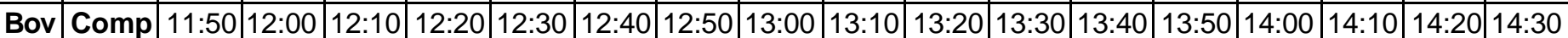

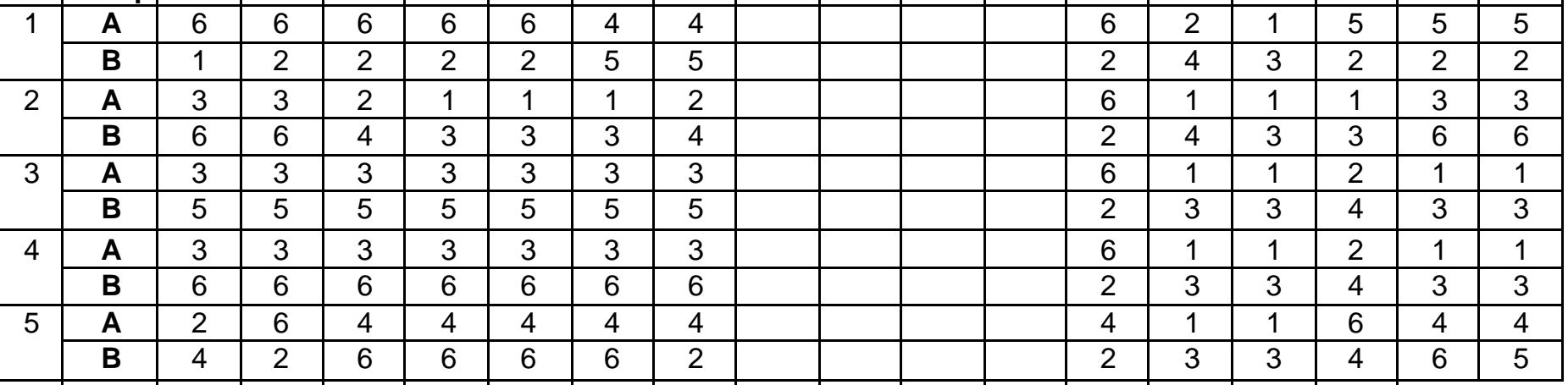

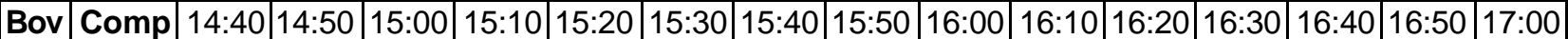

\begin{tabular}{|c|c|c|c|c|c|c|c|c|c|c|c|c|c|c|c|c|}
\hline \multirow[t]{2}{*}{1} & A & 3 & 3 & 3 & 3 & 3 & 5 & 2 & 1 & 1 & 1 & 5 & 3 & 3 & 3 & 1 \\
\hline & B & 6 & 6 & 6 & 6 & 2 & 2 & 4 & 3 & 3 & 3 & 2 & 6 & 5 & 5 & 3 \\
\hline \multirow[t]{2}{*}{2} & A & 3 & 3 & 3 & 3 & 3 & 3 & 5 & 2 & 3 & 3 & 1 & 1 & 3 & 3 & 3 \\
\hline & B & 6 & 6 & 6 & 6 & 5 & 5 & 2 & 4 & 6 & 6 & 3 & 3 & 5 & 5 & 5 \\
\hline \multirow[t]{2}{*}{3} & $\mathbf{A}$ & 1 & 4 & 4 & 4 & 4 & 4 & 4 & 4 & 4 & 1 & 1 & 1 & 2 & 2 & 1 \\
\hline & B & 3 & 6 & 6 & 6 & 5 & 5 & 5 & 5 & 5 & 3 & 3 & 3 & 4 & 4 & 3 \\
\hline \multirow[t]{2}{*}{4} & $\mathbf{A}$ & 3 & 3 & 3 & 3 & 3 & 3 & & & & & & & & & \\
\hline & B & 6 & 6 & 5 & 5 & 5 & 2 & & & & & & & & & \\
\hline \multirow[t]{2}{*}{5} & $\mathbf{A}$ & 4 & 4 & 4 & 4 & 4 & 2 & 1 & & & & & & & & \\
\hline & B & 6 & 6 & 6 & 6 & 6 & 4 & 3 & & & & & & & & \\
\hline
\end{tabular}


Apêndice 21. Dados das variáveis comportamentais dos animais, no tratamento com aspersão, no dia 27/11/2003

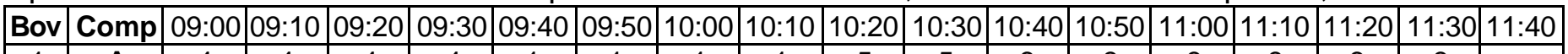

\begin{tabular}{|c|c|c|c|c|c|c|c|c|c|c|c|c|c|c|c|c|c|c|}
\hline \multirow{3}{*}{1} & & & & & & & & & & & & & & & & & & \\
\hline & A & 4 & 4 & 4 & 4 & 1 & 1 & 1 & 1 & 5 & 5 & 3 & 3 & 3 & 3 & 3 & 3 & \\
\hline & B & 5 & 5 & 6 & 2 & 3 & 3 & 3 & 3 & 2 & 1 & 5 & 5 & 5 & 5 & 6 & 6 & \\
\hline \multirow[t]{2}{*}{2} & A & 3 & 3 & 3 & 3 & 1 & 2 & 1 & 1 & 1 & 1 & 3 & 3 & 3 & 3 & 3 & 3 & \\
\hline & B & & & 6 & 6 & 3 & 4 & 3 & 3 & 3 & 3 & 6 & 6 & 6 & 6 & 5 & 5 & \\
\hline \multirow[t]{2}{*}{3} & A & & & & & 1 & 1 & 1 & 5 & 5 & 5 & 5 & 3 & 3 & 3 & 3 & 3 & \\
\hline & B & & & & & 3 & 3 & 3 & 1 & 1 & 1 & 1 & 5 & 5 & 6 & 6 & 6 & \\
\hline \multirow[t]{2}{*}{4} & $\mathbf{A}$ & 3 & 3 & 3 & 3 & 1 & 1 & 2 & 1 & 1 & 1 & 3 & 3 & 3 & 3 & 3 & 2 & \\
\hline & B & 6 & 5 & 5 & 6 & 3 & 3 & 4 & 3 & 3 & 3 & 6 & 6 & 6 & 6 & 2 & 4 & \\
\hline \multirow[t]{2}{*}{5} & $\mathbf{A}$ & & & & & 1 & 1 & 2 & 1 & 1 & 5 & 3 & 3 & 3 & 3 & 3 & 2 & \\
\hline & B & & & & & 3 & 3 & 4 & 3 & 3 & 1 & 5 & 5 & 5 & 5 & 5 & 4 & \\
\hline
\end{tabular}

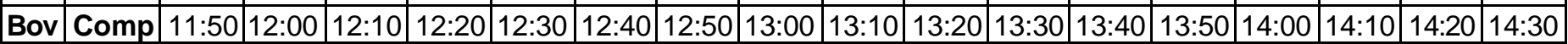

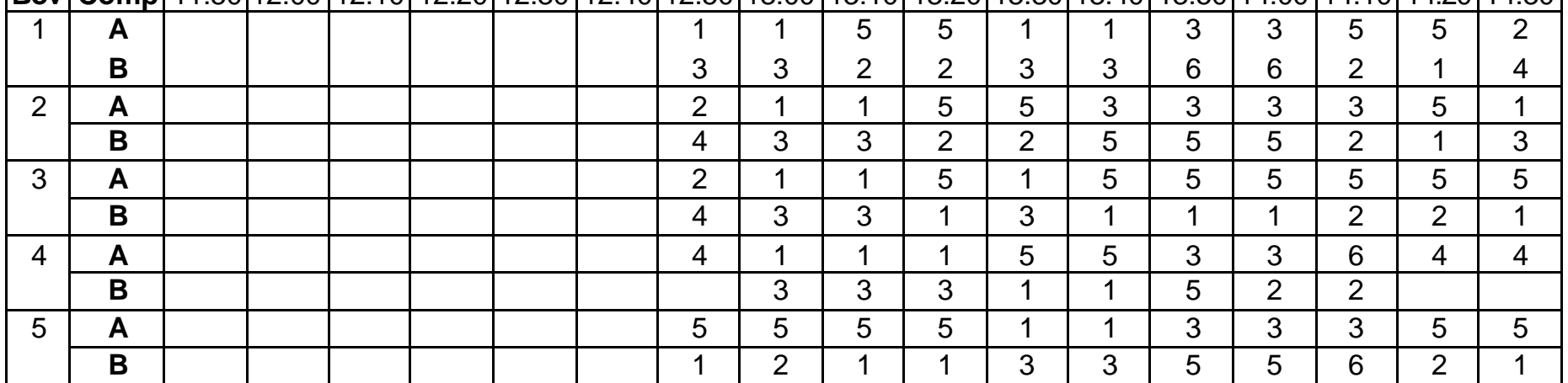

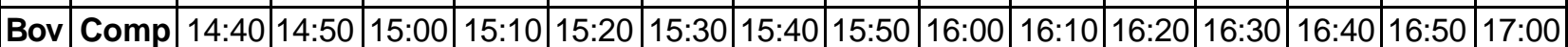

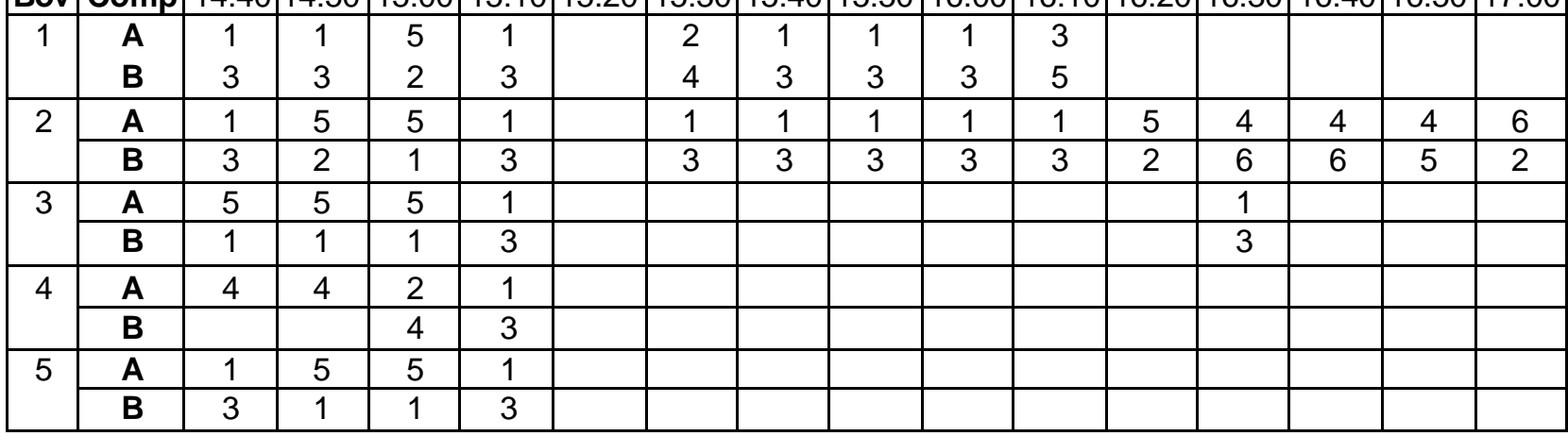


Apêndice 22. Dados das variáveis comportamentais dos animais, no tratamento com nebulização, no dia 27/11/2003

\begin{tabular}{|c|c|c|c|c|c|c|c|c|c|c|c|c|c|c|c|c|c|c|}
\hline Bov & Comp & 09:00 & $09: 10$ & $09: 20$ & $09: 30$ & $09: 40$ & $09: 50$ & $10: 00$ & $10: 10$ & $10: 20$ & $10: 30$ & $10: 40$ & $10: 50$ & $11: 00$ & $11: 10$ & $11: 20$ & $11: 30$ & $11: 40$ \\
\hline
\end{tabular}

\begin{tabular}{|c|c|c|c|c|c|c|c|c|c|c|c|c|c|c|c|c|c|c|}
\hline \multirow{2}{*}{1} & $\Delta$ & & & & & & & & & & & & & & & & & \\
\hline & & & & & & & & & & & & & & & & & & \\
\hline & B & 1 & 1 & 3 & 2 & & 3 & 1 & 1 & & & 2 & 4 & & & 5 & 5 & 5 \\
\hline \multirow[t]{2}{*}{2} & A & 3 & 3 & 3 & 3 & 1 & 1 & 2 & 1 & 3 & 3 & 3 & 3 & 3 & 3 & 3 & 3 & 3 \\
\hline & B & & & & & 3 & 3 & 4 & 3 & 6 & 6 & 6 & 6 & 6 & 6 & 6 & 6 & 6 \\
\hline \multirow[t]{2}{*}{3} & A & 4 & 4 & 4 & 4 & 4 & 1 & 1 & 1 & 1 & 2 & 4 & 4 & 4 & 4 & 4 & 4 & 4 \\
\hline & B & 6 & 6 & 6 & 6 & 6 & 3 & 3 & 3 & 3 & 4 & 6 & 6 & 6 & 6 & 6 & 6 & 6 \\
\hline \multirow[t]{2}{*}{4} & $\mathbf{A}$ & 3 & 3 & 1 & 5 & & 1 & 1 & 2 & 4 & 4 & 4 & 4 & 4 & 4 & 4 & 6 & 6 \\
\hline & B & 2 & 2 & 3 & 1 & & 3 & 3 & 4 & 1 & 1 & 2 & 6 & 6 & 6 & 2 & & \\
\hline \multirow[t]{2}{*}{5} & $\bar{A}$ & & & & & & 1 & 1 & 1 & 1 & 2 & 6 & & & & & & \\
\hline & B & & & & & & 3 & 3 & 3 & 3 & 4 & 2 & & & & & & \\
\hline
\end{tabular}

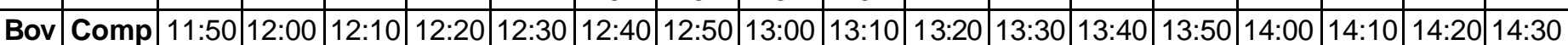

\begin{tabular}{|c|c|c|c|c|c|c|c|c|c|c|c|c|c|c|c|c|c|c|}
\hline \multirow[t]{2}{*}{1} & $\mathbf{A}$ & 4 & 4 & 4 & 4 & 4 & 4 & 6 & 6 & 5 & 1 & 5 & & & 5 & 5 & 1 & 5 \\
\hline & B & 6 & 6 & 6 & 6 & 6 & 2 & & & 2 & 3 & 2 & & & 1 & 1 & 3 & \\
\hline \multirow[t]{2}{*}{2} & $\mathbf{A}$ & 2 & 1 & 5 & 3 & 3 & 5 & 5 & 5 & 5 & 5 & 5 & & & 5 & 5 & 3 & 3 \\
\hline & B & 4 & 3 & 2 & & & 6 & 2 & 2 & 2 & 2 & 2 & & & 2 & 2 & 2 & 5 \\
\hline \multirow[t]{2}{*}{3} & $\mathbf{A}$ & 4 & 4 & 4 & 1 & 5 & 1 & 1 & 1 & 1 & 6 & 6 & & & 5 & 3 & 3 & 3 \\
\hline & B & 6 & 6 & 6 & 3 & 2 & 3 & 3 & 3 & 3 & 2 & 2 & & & 2 & 6 & 6 & 6 \\
\hline \multirow[t]{2}{*}{4} & $\mathbf{A}$ & 4 & 4 & 1 & 1 & 3 & 3 & 3 & 3 & 5 & 5 & 6 & & & 1 & 1 & 1 & 1 \\
\hline & B & 1 & 2 & 3 & 3 & 6 & 6 & 6 & 6 & 2 & 1 & 2 & & & 3 & 3 & 3 & 3 \\
\hline \multirow[t]{2}{*}{5} & $\mathbf{A}$ & & & & & & 2 & 1 & 5 & 5 & 5 & 5 & & & 3 & 3 & 3 & 3 \\
\hline & B & & & & & & 4 & 3 & 2 & 1 & & & & & 5 & 6 & 6 & 6 \\
\hline
\end{tabular}

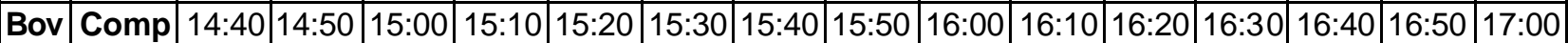

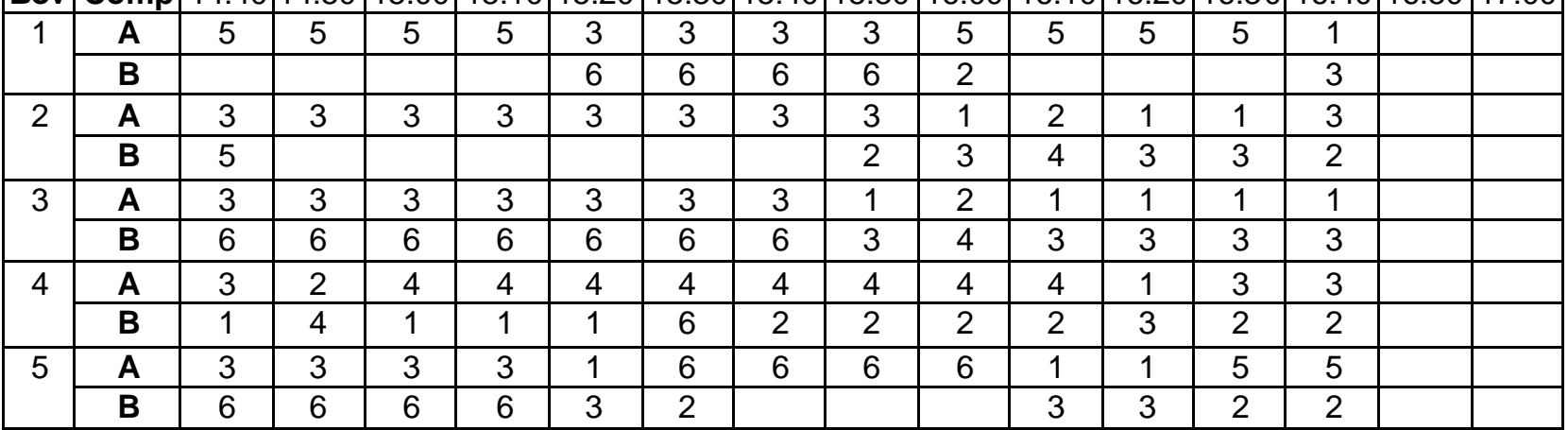


Apêndice 23. Dados da produção de leite diária dos animais, do tratamento com aspersão, durante o período experimental

\begin{tabular}{|c|cccccccccccc|}
\hline Animal/Dia & 7 & 8 & 9 & 10 & 11 & 12 & 13 & 14 & 15 & 16 & 17 & 18 \\
\hline 1 & 19,8 & 23,7 & 19,2 & 20,2 & 20,5 & 20,1 & 20,2 & 19,8 & 20,3 & 18,5 & 19,3 & 18,8 \\
2 & 18,7 & 20,5 & 17,9 & 18,1 & 17,7 & 17,5 & 19,0 & 17,3 & 17,6 & 16,2 & 16,5 & 17,2 \\
3 & 14,4 & 14,6 & 14,2 & 14,8 & 13,3 & 14,8 & 14,0 & 12,8 & 13,5 & 11,3 & 14,7 & 12,6 \\
4 & 19,7 & 23,8 & 24,9 & 21,1 & 22,8 & 23,3 & 20,5 & 19,8 & 20,1 & 16,4 & 19,7 & 19,3 \\
5 & 24,9 & 29,8 & 27,1 & 25,7 & 26,4 & 27,0 & 23,0 & 27,6 & 24,5 & 27,1 & 24,8 & 24,5 \\
6 & 20,4 & 20,3 & 19,7 & 19,7 & 22,8 & 20,7 & 18,9 & 20,7 & 17,3 & 19,5 & 15,1 & 21,3 \\
7 & 24,6 & 24,0 & 23,3 & 23,1 & 22,8 & 23,6 & 22,7 & 22,8 & 22,6 & 23,1 & 17,2 & 23,6 \\
8 & 23,2 & 21,2 & 20,7 & 22,5 & 21,8 & 22,3 & 22,9 & 21,9 & 23,0 & 22,6 & 21,6 & 21,6 \\
9 & 22,1 & 21,6 & 23,5 & 20,9 & 21,3 & 23,4 & 20,7 & 22,1 & 18,8 & 20,7 & 19,5 & 20,6 \\
10 & 22,0 & 21,5 & 22,4 & 22,9 & 22,0 & 21,5 & 21,4 & 21,2 & 22,4 & 20,5 & 21,2 & 17,7 \\
\hline Média & 21,0 & 22,1 & 21,3 & 20,9 & 21,1 & 21,4 & 20,3 & 20,6 & 20,0 & 19,6 & 19,0 & 19,7 \\
\hline
\end{tabular}

\begin{tabular}{|c|cccccccccc|c|}
\hline Animal/Dia & 19 & 20 & 21 & 22 & 23 & 24 & 25 & 26 & 27 & 28 & Média \\
\hline 1 & 21,1 & 19,0 & 20,3 & 19,4 & 19,4 & 19,3 & 19,3 & 17,2 & 14,0 & 13,8 & 19,2 \\
2 & 16,2 & 15,7 & 16,7 & 16,2 & 16,4 & 15,7 & 17,0 & 18,8 & 16,5 & 19,1 & 17,4 \\
3 & 12,9 & 13,1 & 13,0 & 13,5 & 12,3 & 13,2 & 14,1 & 12,0 & 9,4 & 11,3 & 13,2 \\
4 & 17,9 & 18,5 & 19,2 & 19,0 & 16,2 & 20,9 & 13,8 & 21,2 & 19,8 & 20,3 & 19,9 \\
5 & 27,0 & 28,1 & 26,5 & 23,8 & 26,4 & 28,2 & 27,0 & 28,1 & 26,7 & 28,2 & 26,5 \\
6 & 17,8 & 18,7 & 18,4 & 20,3 & 20,1 & 20,3 & 17,7 & 20,5 & 17,5 & 19,2 & 19,4 \\
7 & 20,7 & 23,0 & 22,8 & 22,9 & 23,4 & 23,9 & 24,3 & 23,7 & 19,6 & 21,8 & 22,7 \\
8 & 22,2 & 22,4 & 23,1 & 21,9 & 21,8 & 22,5 & 22,5 & 21,3 & 20,7 & 20,4 & 22,0 \\
9 & 23,5 & 21,2 & 22,5 & 24,3 & 21,6 & 22,8 & 21,5 & 19,6 & 20,1 & 20,8 & 21,5 \\
10 & 20,7 & 20,8 & 19,8 & 21,0 & 14,4 & 22,2 & 20,1 & 20,6 & 21,5 & 20,6 & 20,8 \\
\hline Média & 20,0 & 20,1 & 20,2 & 20,2 & 19,2 & 20,9 & 19,7 & 20,3 & 18,6 & 19,6 & 20,3 \\
\hline
\end{tabular}


Apêndice 24. Dados da produção de leite diária dos animais, do tratamento com nebulização, durante o período experimental

\begin{tabular}{|c|cccccccccccc|}
\hline Animal/Dia & 7 & 8 & 9 & 10 & 11 & 12 & 13 & 14 & 15 & 16 & 17 & 18 \\
\hline 1 & 18,5 & 19,6 & 16,4 & 16,8 & 17,1 & 18,7 & 16,5 & 18,0 & 17,7 & 16,2 & 17,4 & 17,7 \\
2 & 20,8 & 19,7 & 17,9 & 19,1 & 20,6 & 21,0 & 20,3 & 18,2 & 18,4 & 19,3 & 20,4 & 19,0 \\
3 & 18,5 & 18,4 & 20,8 & 20,3 & 19,6 & 19,5 & 19,4 & 18,8 & 20,2 & 17,8 & 18,4 & 20,6 \\
4 & 32,0 & 27,6 & 28,5 & 25,1 & 17,6 & 28,0 & 24,4 & 31,7 & 31,6 & 26,9 & 38,1 & 28,3 \\
5 & 23,0 & 26,2 & 23,5 & 16,7 & 23,6 & 23,4 & 24,2 & 23,2 & 22,6 & 22,8 & 20,9 & 21,6 \\
6 & 23,1 & 21,1 & 19,3 & 22,3 & 22,8 & 23,7 & 21,5 & 21,2 & 22,7 & 23,2 & 14,7 & 21,1 \\
7 & 18,4 & 19,9 & 21,1 & 21,7 & 22,0 & 21,7 & 20,4 & 21,3 & 20,6 & 21,6 & 20,5 & 22,9 \\
8 & 15,1 & 14,3 & 14,9 & 14,2 & 13,4 & 13,3 & 13,5 & 13,3 & 13,2 & 12,8 & 15,8 & 13,4 \\
9 & 21,9 & 16,1 & 11,7 & 15,3 & 18,6 & 17,6 & 13,8 & 10,1 & 16,6 & 18,3 & 19,3 & 18,1 \\
10 & 21,4 & 19,6 & 20,2 & 20,8 & 8,9 & 20,1 & 17,3 & 19,5 & 20,1 & 17,7 & 20,2 & 20,1 \\
\hline Média & 21,3 & 20,3 & 19,4 & 19,2 & 18,4 & 20,7 & 19,1 & 19,5 & 20,4 & 19,7 & 20,6 & 20,3 \\
\hline
\end{tabular}

\begin{tabular}{|c|cccccccccc|c|}
\hline Animal/Dia & 19 & 20 & 21 & 22 & 23 & 24 & 25 & 26 & 27 & 28 & Média \\
\hline 1 & 15,8 & 17,3 & 15,9 & 15,5 & 16,5 & 15,9 & 17,1 & 20,8 & 14,3 & 16,1 & 17,1 \\
2 & 18,5 & 19,6 & 20,4 & 18,6 & 19,6 & 19,2 & 16,8 & 23,9 & 16,4 & 17,1 & 19,3 \\
3 & 18,7 & 20,2 & 18,8 & 21,7 & 13,4 & 20,7 & 21,6 & 25,2 & 19,5 & 18,3 & 19,6 \\
4 & 28,9 & 32,2 & 25,4 & 32,7 & 26,1 & 13,9 & 26,4 & 27,0 & 25,5 & 26,7 & 27,5 \\
5 & 22,2 & 23,3 & 23,8 & 13,1 & 21,2 & 24,2 & 22,4 & 22,5 & 22,4 & 21,2 & 22,2 \\
6 & 21,5 & 21,0 & 19,9 & 21,7 & 21,4 & 22,8 & 21,7 & 25,6 & 21,1 & 20,9 & 21,6 \\
7 & 20,9 & 20,6 & 20,8 & 21,1 & 20,9 & 21,4 & 21,6 & 23,0 & 16,0 & 19,9 & 20,8 \\
8 & 13,0 & 14,1 & 12,2 & 13,2 & 12,9 & 12,9 & 11,5 & 9,1 & 8,8 & 9,1 & 12,9 \\
9 & 18,8 & 19,0 & 18,9 & 19,6 & 19,2 & 18,7 & 20,3 & 21,8 & 17,8 & 17,9 & 17,7 \\
10 & 19,2 & 19,6 & 20,0 & 19,4 & 19,8 & 18,6 & 20,0 & 24,1 & 13,2 & 10,4 & 18,6 \\
Média & 19,8 & 20,7 & 19,6 & 19,7 & 19,1 & 18,8 & 19,9 & 22,3 & 17,5 & 17,8 & 19,7 \\
\hline
\end{tabular}


Apêndice 25. Dados diários de temperatura de bulbo seco no período das 9 - $17 \mathrm{~h}$, no tratamento com aspersão, durante o período experimental

\begin{tabular}{|c|c|c|c|c|c|c|c|c|c|c|}
\hline \multicolumn{10}{|c|}{ TRATAMENTO COM ASPERSÃO - TbS } & \multirow{2}{*}{$\begin{array}{l}\text { Média } \\
\text { Diária }\end{array}$} \\
\hline Dia/hora & 9 & 10 & 11 & 12 & 13 & 14 & 15 & 16 & 17 & \\
\hline 7 & 24,8 & 25,2 & 25,9 & 27,6 & 27,9 & 28,0 & 28,2 & 26,1 & 23,0 & 26,3 \\
\hline 8 & 22,2 & 24,1 & 26,0 & 27,7 & 28,2 & 29,2 & 30,7 & 30,0 & 29,0 & 27,5 \\
\hline 9 & 24,6 & 26,7 & 28,6 & 30,1 & 30,9 & 31,1 & 31,5 & 30,7 & 30,0 & 29,4 \\
\hline 10 & 27,5 & 29,3 & 30,5 & 31,3 & 31,9 & 32,4 & 33,6 & 31,9 & 31,2 & 31,1 \\
\hline 11 & 25,5 & 27,8 & 30,7 & 33,1 & 34,1 & 34,3 & 34,1 & 31,2 & 29,5 & 31,1 \\
\hline 12 & 30,2 & 30,4 & 31,0 & 31,9 & 32,2 & 32,8 & 33,2 & 31,6 & 30,6 & 31,6 \\
\hline 13 & 23,2 & 22,6 & 22,5 & 23,8 & 25,6 & 25,6 & 25,6 & 25,1 & 24,7 & 24,3 \\
\hline 14 & 21,3 & 22,6 & 23,9 & 25,1 & 26,2 & 26,4 & 27,3 & 26,6 & 26,0 & 25,1 \\
\hline 15 & 23,0 & 24,5 & 26,2 & 28,4 & 29,4 & 29,2 & 29,0 & 29,4 & 29,3 & 27,6 \\
\hline 16 & 28,4 & 28,9 & 28,8 & 30,0 & 30,2 & 31,5 & 32,0 & 30,6 & 29,3 & 30,0 \\
\hline 17 & 26,5 & 27,7 & 28,8 & 25,6 & 23,2 & 22,5 & 23,1 & 22,9 & 22,6 & 24,8 \\
\hline 18 & 24,8 & 25,7 & 26,3 & 26,4 & 28,2 & 29,3 & 29,6 & 28,5 & 28,0 & 27,4 \\
\hline 19 & 22,0 & 22,9 & 23,1 & 23,8 & 23,5 & 25,7 & 26,0 & 25,4 & 24,7 & 24,1 \\
\hline 20 & 25,0 & 25,7 & 26,4 & 27,7 & 28,1 & 28,6 & 29,2 & 28,6 & 27,9 & 27,5 \\
\hline 21 & 21,4 & 22,9 & 23,8 & 25,1 & 25,4 & 25,8 & 26,1 & 26,0 & 25,0 & 24,6 \\
\hline 22 & 21,1 & 23,5 & 24,8 & 25,9 & 27,5 & 28,5 & 28,9 & 29,6 & 28,9 & 26,5 \\
\hline 23 & 22,3 & 23,7 & 25,2 & 26,1 & 28,2 & 25,6 & 24,3 & 25,7 & 25,6 & 25,2 \\
\hline 24 & 22,4 & 23,3 & 25,0 & 26,4 & 27,4 & 26,9 & 23,9 & 21,5 & 22,3 & 24,4 \\
\hline 25 & 25,6 & 26,4 & 28,2 & 29,0 & 29,9 & 30,6 & 30,6 & 31,3 & 30,8 & 29,2 \\
\hline 26 & 22,6 & 22,5 & 23,7 & 25,6 & 27,7 & 28,4 & 26,2 & 24,8 & 25,5 & 25,2 \\
\hline 27 & 26,5 & 27,4 & 29,3 & 29,9 & 30,3 & 29,1 & 29,0 & 27,3 & 27,1 & 28,4 \\
\hline 28 & 24,0 & 23,9 & 20,9 & 21,5 & 22,1 & 22,4 & 22,5 & 22,1 & 22,1 & 22,4 \\
\hline Média horária & 24,3 & 25,3 & 26,3 & 27,4 & 28,1 & 28,4 & 28,4 & 27,6 & 27,0 & 27,0 \\
\hline
\end{tabular}


Apêndice 26. Dados diários de umidade relativa no período das 9 - 17 h, no tratamento com aspersão, durante o período experimental

\begin{tabular}{|c|ccccccccc|c|}
\hline \multicolumn{10}{|c|}{ TRATAMENTO COM ASPERSÃO- UR } & Média \\
\cline { 1 - 8 } Dia/hora & 9 & 10 & 11 & 12 & 13 & 14 & 15 & 16 & 17 & Diária \\
\hline 7 & 69,8 & 68,5 & 62,3 & 54,7 & 52,2 & 47,9 & 44,9 & 49,1 & 58,8 & 56,4 \\
8 & 71,3 & 66,5 & 61,7 & 54,0 & 50,1 & 44,8 & 38,5 & 39,0 & 43,2 & 52,1 \\
9 & 67,4 & 57,5 & 46,2 & 37,7 & 31,6 & 30,1 & 30,3 & 31,2 & 35,3 & 40,8 \\
10 & 49,9 & 40,9 & 35,6 & 30,7 & 27,5 & 27,7 & 26,2 & 26,0 & 28,9 & 32,6 \\
11 & 57,4 & 51,8 & 46,4 & 40,1 & 33,2 & 34,3 & 34,3 & 54,9 & 62,2 & 46,0 \\
12 & 47,2 & 47,1 & 46,8 & 46,9 & 44,4 & 44,6 & 41,9 & 46,0 & 53,9 & 46,5 \\
13 & 84,6 & 89,4 & 89,4 & 82,0 & 73,7 & 71,3 & 70,4 & 68,2 & 70,2 & 77,7 \\
14 & 76,8 & 71,5 & 66,7 & 61,4 & 57,7 & 55,3 & 54,1 & 52,3 & 53,8 & 61,1 \\
15 & 71,3 & 67,4 & 63,2 & 57,4 & 55,7 & 56,9 & 56,6 & 54,5 & 52,5 & 59,5 \\
16 & 58,5 & 55,2 & 54,0 & 51,8 & 49,3 & 44,6 & 44,8 & 48,7 & 52,3 & 51,0 \\
17 & 75,8 & 69,0 & 64,0 & 77,3 & 85,8 & 87,8 & 82,7 & 83,5 & 83,1 & 78,8 \\
18 & 67,5 & 66,5 & 67,0 & 71,8 & 62,5 & 57,6 & 53,6 & 55,5 & 58,8 & 62,3 \\
19 & 72,5 & 70,6 & 70,2 & 64,7 & 64,6 & 57,9 & 58,0 & 59,5 & 64,7 & 64,7 \\
20 & 52,1 & 44,9 & 41,8 & 37,7 & 35,7 & 35,4 & 32,6 & 35,1 & 33,9 & 38,8 \\
21 & 72,3 & 67,9 & 63,0 & 59,3 & 57,8 & 56,3 & 56,3 & 57,2 & 59,5 & 61,1 \\
22 & 76,0 & 68,0 & 64,9 & 62,0 & 56,9 & 53,4 & 50,9 & 48,6 & 48,4 & 58,8 \\
23 & 80,6 & 76,6 & 71,7 & 69,7 & 62,5 & 72,1 & 71,1 & 71,1 & 75,5 & 72,3 \\
24 & 81,9 & 76,9 & 72,7 & 66,6 & 62,3 & 61,7 & 75,7 & 85,0 & 81,0 & 73,7 \\
25 & 72,9 & 67,1 & 62,9 & 58,8 & 54,6 & 51,8 & 51,2 & 50,6 & 54,4 & 58,2 \\
26 & 87,8 & 89,2 & 84,4 & 76,8 & 69,0 & 66,1 & 68,5 & 74,4 & 72,8 & 76,5 \\
27 & 71,3 & 68,1 & 63,5 & 60,7 & 60,5 & 70,0 & 68,5 & 68,9 & 71,8 & 67,0 \\
28 & 76,1 & 77,3 & 86,2 & 83,3 & 77,4 & 77,1 & 77,7 & 80,6 & 81,3 & 79,7 \\
\hline Média horária & 70,0 & 66,2 & 62,9 & 59,3 & 55,7 & 54,7 & 54,0 & 56,4 & 58,9 & 59,8 \\
\hline
\end{tabular}


Apêndice 27. Dados diários de temperatura de globo negro no período das 9 - 17 h, no tratamento com aspersão, durante o período experimental

\begin{tabular}{|c|c|c|c|c|c|c|c|c|c|c|}
\hline \multicolumn{10}{|c|}{ TRATAMENTO COM AS PERSÃO - TG } & \multirow{2}{*}{$\begin{array}{l}\text { Média } \\
\text { Diária }\end{array}$} \\
\hline Dia/hora & 9 & 10 & 11 & 12 & 13 & 14 & 15 & 16 & 17 & \\
\hline 7 & 25,7 & 25,8 & 26,7 & 28,6 & 28,6 & 29,2 & 29,6 & 26,4 & 23,1 & 27,1 \\
\hline 8 & 22,9 & 24,6 & 26,7 & 28,6 & 28,8 & 30,3 & 32,9 & 30,5 & 29,3 & 28,3 \\
\hline 9 & 25,3 & 27,5 & 29,4 & 30,9 & 31,7 & 31,9 & 33,3 & 31,1 & 30,2 & 30,2 \\
\hline 10 & 28,3 & 30,0 & 31,1 & 32,2 & 32,8 & 33,2 & 36,2 & 32,4 & 31,2 & 31,9 \\
\hline 11 & 26,0 & 28,6 & 31,5 & 34,1 & 35,1 & 35,1 & 35,9 & 30,9 & 29,5 & 31,8 \\
\hline 12 & 30,6 & 30,8 & 31,6 & 32,3 & 33,0 & 33,5 & 34,2 & 31,8 & 30,7 & 32,1 \\
\hline 13 & 23,3 & 22,6 & 22,6 & 24,0 & 26,0 & 25,7 & 26,0 & 25,2 & 24,9 & 24,5 \\
\hline 14 & 21,8 & 23,1 & 24,7 & 25,8 & 27,0 & 27,2 & 29,0 & 27,0 & 26,2 & 25,8 \\
\hline 15 & 23,6 & 25,0 & 26,9 & 29,4 & 30,2 & 29,7 & 29,4 & 29,9 & 29,7 & 28,2 \\
\hline 16 & 29,0 & 29,5 & 29,2 & 30,7 & 31,0 & 32,6 & 34,1 & 30,9 & 29,4 & 30,7 \\
\hline 17 & 26,8 & 28,4 & 29,5 & 25,6 & 22,9 & 22,4 & 23,2 & 23,1 & 22,6 & 24,9 \\
\hline 18 & 25,2 & 26,1 & 26,7 & 26,8 & 29,0 & 30,1 & 31,0 & 28,8 & 28,2 & 28,0 \\
\hline 19 & 22,4 & 23,2 & 23,3 & 24,3 & 23,8 & 26,6 & 26,8 & 25,6 & 24,7 & 24,5 \\
\hline 20 & 25,6 & 26,4 & 27,2 & 28,5 & 28,8 & 29,2 & 31,5 & 29,0 & 28,3 & 28,3 \\
\hline 21 & 21,7 & 23,2 & 24,2 & 25,6 & 25,9 & 26,2 & 26,7 & 26,3 & 25,2 & 25,0 \\
\hline 22 & 21,9 & 24,3 & 25,4 & 26,7 & 28,4 & 29,3 & 29,6 & 31,4 & 29,2 & 27,4 \\
\hline 23 & 22,8 & 24,1 & 25,7 & 26,7 & 28,9 & 25,6 & 24,5 & 26,1 & 25,7 & 25,6 \\
\hline 24 & 22,7 & 23,9 & 25,7 & 27,1 & 28,2 & 27,3 & 23,9 & 21,4 & 22,3 & 24,7 \\
\hline 25 & 26,0 & 27,0 & 29,0 & 29,5 & 30,8 & 31,4 & 31,4 & 33,7 & 31,1 & 30,0 \\
\hline 26 & 22,5 & 22,7 & 24,1 & 26,2 & 28,6 & 29,2 & 26,3 & 25,1 & 26,0 & 25,6 \\
\hline 27 & 26,9 & 28,0 & 29,9 & 30,6 & 31,0 & 29,1 & 29,5 & 27,4 & 27,4 & 28,9 \\
\hline 28 & 24,3 & 24,1 & 20,9 & 21,8 & 22,5 & 22,7 & 22,6 & 22,2 & 22,3 & 22,6 \\
\hline Média horária & 24,8 & 25,9 & 26,9 & 28,0 & 28,8 & 29,0 & 29,4 & 28,0 & 27,1 & 27,5 \\
\hline
\end{tabular}


Apêndice 28. Dados diários do índice de temperatura e umidade no período das 9 - $17 \mathrm{~h}$, no tratamento com aspersão, durante o período experimental

\begin{tabular}{|c|c|c|c|c|c|c|c|c|c|c|}
\hline \multicolumn{10}{|c|}{ TRATAMENTO COM ASPERSÃO - THI } & \multirow{2}{*}{$\begin{array}{l}\text { Média } \\
\text { Diária }\end{array}$} \\
\hline Dia/hora & 9 & 10 & 11 & 12 & 13 & 14 & 15 & 16 & 17 & \\
\hline 7 & 73,3 & 73,7 & 74,1 & 75,7 & 75,8 & 75,4 & 75,3 & 73,0 & 69,9 & 74,0 \\
\hline 8 & 69,9 & 72,1 & 74,3 & 75,7 & 76,0 & 76,7 & 77,8 & 76,9 & 76,2 & 75,1 \\
\hline 9 & 72,8 & 74,8 & 76,0 & 76,9 & 77,0 & 77,0 & 77,5 & 76,6 & 76,4 & 76,1 \\
\hline 10 & 75,0 & 76,3 & 77,1 & 77,4 & 77,6 & 78,3 & 79,5 & 77,2 & 76,9 & 77,2 \\
\hline 11 & 73,1 & 75,6 & 78,9 & 81,1 & 81,4 & 81,9 & 81,6 & 80,5 & 78,9 & 79,2 \\
\hline 12 & 78,3 & 78,5 & 79,3 & 80,5 & 80,6 & 81,3 & 81,5 & 80,0 & 79,6 & 80,0 \\
\hline 13 & 72,3 & 71,7 & 71,6 & 72,9 & 74,6 & 74,4 & 74,4 & 73,5 & 73,2 & 73,2 \\
\hline 14 & 69,2 & 70,5 & 71,9 & 72,9 & 74,1 & 74,2 & 75,2 & 74,1 & 73,5 & 72,8 \\
\hline 15 & 71,0 & 72,7 & 74,7 & 77,0 & 78,2 & 78,0 & 77,7 & 78,0 & 77,7 & 76,1 \\
\hline 16 & 77,1 & 77,4 & 77,2 & 78,5 & 78,5 & 79,7 & 80,4 & 79,0 & 77,7 & 78,4 \\
\hline 17 & 76,1 & 77,2 & 78,2 & 74,9 & 72,4 & 71,5 & 72,1 & 71,7 & 71,3 & 73,9 \\
\hline 18 & 73,1 & 74,2 & 75,1 & 75,7 & 77,2 & 78,2 & 78,2 & 76,9 & 76,6 & 76,1 \\
\hline 19 & 69,8 & 70,8 & 71,0 & 71,6 & 71,2 & 73,4 & 73,8 & 73,2 & 72,7 & 71,9 \\
\hline 20 & 71,9 & 72,0 & 72,6 & 73,7 & 74,0 & 74,6 & 74,9 & 74,5 & 73,4 & 73,5 \\
\hline 21 & 69,0 & 70,5 & 71,4 & 72,7 & 73,1 & 73,4 & 73,9 & 73,7 & 72,6 & 72,3 \\
\hline 22 & 68,9 & 71,4 & 72,9 & 74,0 & 75,8 & 76,7 & 77,0 & 77,6 & 76,7 & 74,6 \\
\hline 23 & 70,7 & 72,4 & 74,0 & 75,1 & 77,2 & 74,5 & 72,7 & 74,6 & 74,8 & 74,0 \\
\hline 24 & 71,0 & 71,9 & 73,8 & 75,2 & 76,2 & 75,4 & 72,6 & 70,0 & 70,8 & 73,0 \\
\hline 25 & 74,6 & 75,3 & 77,3 & 77,9 & 78,7 & 79,4 & 79,3 & 80,2 & 79,9 & 78,1 \\
\hline 26 & 71,6 & 71,6 & 73,0 & 74,9 & 77,2 & 77,8 & 75,0 & 73,7 & 74,4 & 74,4 \\
\hline 27 & 75,8 & 76,7 & 78,8 & 79,3 & 79,9 & 79,1 & 78,8 & 76,6 & 76,6 & 78,0 \\
\hline 28 & 72,7 & 72,7 & 69,2 & 69,9 & 70,3 & 70,6 & 70,8 & 70,5 & 70,5 & 70,8 \\
\hline Média horária & 72,6 & 73,6 & 74,6 & 75,6 & 76,2 & 76,4 & 76,4 & 75,6 & 75,0 & 75,1 \\
\hline
\end{tabular}


Apêndice 29. Dados diários do índice do globo negro e umidade no período das 9 - $17 \mathrm{~h}$, no tratamento com aspersão, durante o período experimental

\begin{tabular}{|c|c|c|c|c|c|c|c|c|c|c|}
\hline \multicolumn{10}{|c|}{ TRATAMENTO COM ASPERSÃO - BGHI } & \multirow{2}{*}{ Média } \\
\hline Dia/hora & 9 & 10 & 11 & 12 & 13 & 14 & 15 & 16 & 17 & \\
\hline 7 & 74,0 & 74,1 & 74,7 & 76,5 & 76,3 & 76,4 & 76,6 & 73,1 & 69,8 & $\overline{74,6}$ \\
\hline 8 & 70,4 & 72,4 & 74,8 & 76,4 & 76,4 & 77,6 & 79,8 & 77,2 & 76,3 & 75,7 \\
\hline 9 & 73,3 & 75,4 & 76,6 & 77,5 & 77,6 & 77,6 & 79,1 & 76,8 & 76,4 & 76,7 \\
\hline 10 & 75,6 & 76,8 & 77,5 & 78,1 & 78,2 & 78,8 & 81,8 & 77,6 & 76,7 & 77,9 \\
\hline 11 & 73,4 & 76,2 & 79,5 & 82,0 & 82,2 & 82,4 & 83,2 & 80,0 & 78,7 & 79,7 \\
\hline 12 & 78,5 & 78,7 & 79,7 & 80,7 & 81,1 & 81,9 & 82,4 & 80,0 & 79,5 & 80,3 \\
\hline 13 & 72,2 & 71,5 & 71,5 & 72,9 & 74,9 & 74,3 & 74,6 & 73,4 & 73,2 & 73,2 \\
\hline 14 & 69,5 & 70,8 & 72,4 & 73,4 & 74,7 & 74,7 & 76,7 & 74,3 & 73,5 & 73,3 \\
\hline 15 & 71,4 & 73,0 & 75,2 & 77,8 & 78,8 & 78,3 & 77,9 & 78,3 & 77,9 & 76,5 \\
\hline 16 & 77,5 & 77,8 & 77,4 & 79,0 & 79,1 & 80,5 & 82,3 & 79,1 & 77,6 & 78,9 \\
\hline 17 & 76,2 & 77,6 & 78,7 & 74,7 & 71,8 & 71,2 & 72,0 & 71,7 & 71,1 & 73,9 \\
\hline 18 & 73,3 & 74,5 & 75,3 & 75,9 & 77,8 & 78,8 & 79,4 & 77,0 & 76,6 & 76,5 \\
\hline 19 & 69,9 & 70,9 & 71,1 & 71,8 & 71,3 & 74,2 & 74,5 & 73,1 & 72,5 & 72,1 \\
\hline 20 & 72,3 & 72,6 & 73,2 & 74,3 & 74,4 & 75,0 & 77,0 & 74,7 & 73,6 & 74,1 \\
\hline 21 & 69,1 & 70,7 & 71,6 & 73,0 & 73,3 & 73,6 & 74,3 & 73,9 & 72,6 & 72,5 \\
\hline 22 & 69,4 & 72,0 & 73,2 & 74,7 & 76,5 & 77,3 & 77,5 & 79,3 & 76,8 & 75,2 \\
\hline 23 & 71,0 & 72,6 & 74,2 & 75,5 & 77,7 & 74,3 & 72,7 & 74,9 & 74,7 & 74,2 \\
\hline 24 & 71,1 & 72,3 & 74,3 & 75,7 & 76,8 & 75,6 & 72,4 & 69,7 & 70,6 & 73,2 \\
\hline 25 & 74,9 & 75,7 & 77,9 & 78,2 & 79,4 & 80,0 & 79,9 & 82,4 & 80,0 & 78,7 \\
\hline 26 & 71,3 & 71,6 & 73,1 & 75,4 & 77,8 & 78,4 & 74,9 & 73,8 & 74,7 & 74,6 \\
\hline 27 & 76,0 & 77,1 & 79,2 & 79,8 & 80,4 & 78,9 & 79,1 & 76,5 & 76,7 & 78,2 \\
\hline 28 & 72,8 & 72,7 & 69,0 & 70,0 & 70,4 & 70,7 & 70,7 & 70,4 & 70,5 & 70,8 \\
\hline Média horária & 72,9 & 74,0 & 75,0 & 76,1 & 76,7 & 76,8 & 77,2 & 75,8 & 75,0 & 75,5 \\
\hline
\end{tabular}


Apêndice 30. Dados diários da entalpia no período das $9-17 \mathrm{~h}$, no tratamento com aspersão, durante o período experimental

\begin{tabular}{|c|c|c|c|c|c|c|c|c|c|c|}
\hline \multicolumn{10}{|c|}{ TRATAMENTO COM ASPERSÃO - H (KJ/kg ar seco) } & \multirow{2}{*}{$\begin{array}{l}\text { Média } \\
\text { Diária }\end{array}$} \\
\hline Dia/hora & 9 & 10 & 11 & 12 & 13 & 14 & 15 & 16 & 17 & \\
\hline 7 & 77,1 & 77,6 & 76,6 & 77,5 & 76,9 & 74,7 & 73,5 & 70,4 & 67,1 & 74,6 \\
\hline 8 & 70,3 & 73,6 & 76,8 & 77,4 & 76,5 & 76,0 & 75,8 & 74,4 & 74,5 & 75,0 \\
\hline 9 & 75,4 & 76,6 & 75,3 & 73,8 & 71,6 & 71,1 & 72,1 & 70,9 & 72,0 & 73,2 \\
\hline 10 & 74,6 & 73,8 & 73,4 & 72,0 & 71,0 & 72,2 & 73,6 & 69,9 & 70,5 & 72,3 \\
\hline 11 & 73,0 & 76,4 & 81,1 & 83,1 & 80,4 & 81,8 & 81,3 & 88,4 & 87,7 & 81,5 \\
\hline 12 & 80,2 & 80,7 & 82,2 & 84,9 & 84,0 & 85,7 & 84,8 & 83,4 & 85,8 & 83,5 \\
\hline 13 & 79,0 & 78,9 & 78,6 & 79,7 & 81,4 & 80,2 & 79,7 & 77,2 & 77,0 & 79,1 \\
\hline 14 & 70,1 & 71,4 & 73,1 & 73,9 & 75,3 & 74,6 & 76,4 & 73,6 & 72,8 & 73,5 \\
\hline 15 & 72,4 & 75,1 & 78,1 & 81,4 & 83,3 & 83,4 & 82,7 & 82,6 & 81,0 & 80,0 \\
\hline 16 & 82,0 & 81,5 & 80,5 & 82,6 & 81,6 & 82,1 & 83,7 & 82,4 & 80,9 & 81,9 \\
\hline 17 & 85,7 & 85,9 & 86,5 & 83,2 & 79,5 & 77,9 & 77,9 & 77,3 & 76,3 & 81,1 \\
\hline 18 & 76,0 & 78,1 & 80,4 & 83,2 & 83,7 & 84,2 & 82,6 & 80,5 & 81,0 & 81,1 \\
\hline 19 & 70,2 & 71,9 & 72,2 & 72,0 & 71,1 & 73,8 & 74,6 & 73,8 & 74,4 & 72,7 \\
\hline 20 & 69,2 & 67,3 & 67,5 & 68,2 & 68,0 & 68,9 & 68,5 & 68,7 & 66,5 & 68,1 \\
\hline 21 & 68,6 & 70,7 & 71,2 & 72,9 & 73,1 & 73,2 & 74,3 & 74,3 & 72,8 & 72,3 \\
\hline 22 & 69,2 & 72,6 & 74,8 & 76,4 & 78,5 & 79,3 & 78,9 & 79,5 & 77,4 & 76,3 \\
\hline 23 & 74,3 & 77,0 & 79,2 & 81,2 & 83,8 & 80,6 & 76,3 & 80,4 & 82,3 & 79,5 \\
\hline 24 & 75,2 & 76,0 & 79,1 & 80,5 & 81,2 & 79,4 & 77,2 & 73,8 & 74,5 & 77,4 \\
\hline 25 & 81,0 & 80,8 & 84,0 & 84,0 & 84,1 & 84,4 & 84,0 & 85,8 & 86,8 & 83,9 \\
\hline 26 & 78,2 & 78,5 & 80,5 & 82,9 & 85,9 & 86,5 & 80,6 & 79,3 & 80,6 & 81,4 \\
\hline 27 & 83,3 & 84,4 & 87,8 & 88,0 & 89,2 & 91,2 & 89,9 & 84,5 & 85,5 & 87,1 \\
\hline 28 & 77,6 & 77,9 & 72,2 & 73,1 & 72,5 & 73,2 & 73,7 & 73,8 & 74,0 & 74,2 \\
\hline Média horária & 75,6 & 76,7 & 77,8 & 78,7 & 78,8 & 78,8 & 78,3 & 77,5 & 77,3 & 77,7 \\
\hline
\end{tabular}


Apêndice 31. Dados diários de temperatura de bulbo seco no período das 9 - 17 h, no tratamento com nebulização, durante o período experimental

\begin{tabular}{|c|ccccccccc|c|}
\hline \multicolumn{10}{|c|}{ TRATAMENTO COM NEBULIZAÇÃO - Tbs } & Média \\
\cline { 1 - 6 } Dia/hora & 9 & 10 & 11 & 12 & 13 & 14 & 15 & 16 & 17 & Diária \\
\hline 7 & 23,7 & 24,1 & 26,0 & 27,1 & 27,2 & 27,9 & 27,2 & 25,5 & 23,0 & 25,7 \\
8 & 22,6 & 24,4 & 25,7 & 27,4 & 28,1 & 29,4 & 29,5 & 29,6 & 28,2 & 27,2 \\
9 & 24,8 & 26,6 & 28,5 & 30,0 & 31,0 & 31,1 & 31,0 & 30,8 & 29,6 & 29,3 \\
10 & 27,7 & 29,2 & 30,3 & 31,3 & 31,7 & 32,0 & 32,3 & 31,7 & 30,4 & 30,8 \\
11 & 25,9 & 28,2 & 30,8 & 33,3 & 33,8 & 33,8 & 33,1 & 30,4 & 29,0 & 30,9 \\
12 & 30,5 & 30,4 & 31,2 & 31,7 & 32,3 & 32,5 & 32,4 & 31,4 & 30,0 & 31,4 \\
13 & 23,0 & 22,6 & 23,1 & 23,5 & 25,2 & 25,2 & 25,3 & 25,0 & 24,5 & 24,1 \\
14 & 21,2 & 22,7 & 24,1 & 24,9 & 26,0 & 25,8 & 26,2 & 25,3 & 24,8 & 24,5 \\
15 & 23,1 & 24,3 & 26,5 & 28,2 & 28,5 & 28,7 & 28,6 & 29,3 & 28,7 & 27,3 \\
16 & 28,1 & 28,5 & 29,1 & 30,1 & 30,4 & 31,3 & 31,1 & 30,2 & 28,9 & 29,8 \\
17 & 25,9 & 27,0 & 28,2 & 24,4 & 22,7 & 22,2 & 22,5 & 22,3 & 22,2 & 24,1 \\
18 & 24,5 & 25,6 & 26,0 & 26,0 & 27,9 & 28,5 & 28,3 & 27,7 & 27,2 & 26,9 \\
19 & 22,1 & 22,6 & 23,1 & 23,5 & 23,2 & 25,2 & 24,9 & 24,9 & 23,8 & 23,7 \\
20 & 25,3 & 25,7 & 26,6 & 27,5 & 28,1 & 28,6 & 28,6 & 28,4 & 27,6 & 27,4 \\
21 & 21,2 & 23,1 & 24,3 & 25,4 & 25,95 & 25,5 & 25,7 & 25,3 & 24,3 & 24,5 \\
22 & 21,0 & 23,6 & 24,3 & 25,8 & 27,1 & 28,2 & 28,4 & 28,7 & 28,3 & 26,2 \\
23 & 22,3 & 23,8 & 24,9 & 26,1 & 27,6 & 24,7 & 23,9 & 25,2 & 25,5 & 24,9 \\
24 & 22,1 & 23,6 & 25,4 & 26,5 & 26,9 & 25,9 & 23,1 & 21,1 & 22,1 & 24,1 \\
25 & 25,0 & 26,0 & 27,7 & 28,8 & 29,7 & 30,3 & 30,4 & 30,4 & 25,5 & 28,2 \\
26 & 22,3 & 22,8 & 23,9 & 25,8 & 27,1 & 27,9 & 24,7 & 24,1 & 25,5 & 24,9 \\
27 & 26,0 & 27,1 & 28,9 & 29,7 & 30,2 & 28,9 & 28,8 & 26,5 & 26,7 & 28,1 \\
28 & 23,6 & 23,6 & 21,0 & 21,6 & 22,1 & 22,4 & 22,4 & 22,1 & 22,4 & 22,4 \\
\hline Média horária & 24,2 & 25,3 & 26,3 & 27,2 & 27,9 & 28,0 & 27,7 & 27,1 & 26,3 & 26,7 \\
\hline
\end{tabular}


Apêndice 32. Dados diários de umidade relativa no período das 9-17 h, no tratamento com nebulização, durante o período experimental

\begin{tabular}{|c|c|c|c|c|c|c|c|c|c|c|}
\hline \multicolumn{10}{|c|}{ TRATAMENTO COM NEBULIZAÇÃO - UR } & \multirow{2}{*}{$\begin{array}{l}\text { Média } \\
\text { Diária }\end{array}$} \\
\hline Dia/hora & 9 & 10 & 11 & 12 & 13 & 14 & 15 & 16 & 17 & \\
\hline 7 & 70,9 & 68,5 & 62,8 & 54,1 & 52,6 & 43,3 & 43,1 & 49,6 & 59,4 & 56,0 \\
\hline 8 & 70,0 & 67,4 & 65,4 & 54,7 & 50,1 & 43,2 & 40,8 & 38,5 & 44,3 & 52,7 \\
\hline 9 & 68,5 & 57,7 & 45,5 & 38,0 & 30,3 & 30,5 & 29,9 & 32,2 & 35,8 & 40,9 \\
\hline 10 & 49,9 & 40,0 & 35,5 & 28,1 & 26,7 & 27,0 & 26,3 & 25,9 & 31,0 & 32,3 \\
\hline 11 & 58,9 & 52,6 & 45,9 & 37,2 & 33,4 & 33,9 & 36,0 & 55,6 & 58,2 & 45,7 \\
\hline 12 & 43,3 & 44,8 & 44,1 & 42,6 & 40,6 & 41,4 & 38,0 & 41,6 & 51,9 & 43,1 \\
\hline 13 & 87,4 & 91,4 & 88,9 & 82,7 & 74,5 & 72,3 & 68,9 & 68,2 & 70,3 & 78,3 \\
\hline 14 & 77,8 & 72,3 & 66,2 & 62,6 & 56,7 & 61,7 & 57,1 & 65,3 & 63,4 & 64,8 \\
\hline 15 & 70,4 & 68,1 & 61,3 & 58,9 & 60,1 & 60,1 & 57,7 & 54,9 & 55,6 & 60,8 \\
\hline 16 & 58,2 & 53,9 & 50,2 & 46,2 & 46,8 & 41,9 & 41,3 & 46,8 & 51,7 & 48,6 \\
\hline 17 & 75,2 & 68,6 & 64,1 & 81,3 & 90,2 & 90,2 & 84,4 & 85,8 & 85,3 & 80,5 \\
\hline 18 & 66,9 & 66,1 & 66,5 & 71,9 & 61,2 & 56,4 & 54,5 & 54,6 & 58,1 & 61,8 \\
\hline 19 & 73,5 & 70,5 & 71,1 & 63,9 & 63,8 & 56,4 & 58,8 & 59,5 & 64,6 & 64,7 \\
\hline 20 & 48,4 & 45,0 & 41,0 & 36,8 & 36,8 & 34,6 & 33,8 & 34,1 & 32,7 & 38,1 \\
\hline 21 & 74,8 & 65,4 & 61,2 & 61,2 & 57,5 & 60,0 & 59,3 & 58,8 & 67,3 & 62,8 \\
\hline 22 & 76,4 & 68,8 & 67,2 & 69,6 & 59,7 & 59,6 & 52,3 & 50,2 & 51,7 & 61,7 \\
\hline 23 & 82,8 & 76,8 & 73,5 & 72,6 & 67,4 & 78,6 & 75,1 & 75,1 & 77,2 & 75,5 \\
\hline 24 & 84,0 & 77,3 & 72,7 & 66,2 & 63,5 & 66,6 & 81,8 & 82,7 & 83,9 & 75,4 \\
\hline 25 & 73,9 & 66,9 & 64,2 & 56,5 & 52,6 & 50,3 & 48,9 & 50,6 & 72,6 & 59,6 \\
\hline 26 & 90,8 & 89,2 & 84,8 & 76,3 & 68,9 & 67,3 & 69,3 & 78,0 & 72,6 & 77,5 \\
\hline 27 & 72,6 & 67,4 & 60,8 & 59,5 & 58,3 & 69,7 & 65,2 & 71,6 & 72,7 & 66,4 \\
\hline 28 & 78,1 & 78,8 & 86,6 & 83,3 & 77,7 & 76,6 & 78,8 & 80,6 & 81,6 & 80,2 \\
\hline Média horária & 70,6 & 66,2 & 62,7 & 59,3 & 55,9 & 55,5 & 54,6 & 57,3 & 61,0 & 60,3 \\
\hline
\end{tabular}


Apêndice 33. Dados diários de temperatura de globo negro no período das $9-17 \mathrm{~h}$, no tratamento com nebulização, durante o período experimental

\begin{tabular}{|c|c|c|c|c|c|c|c|c|c|c|}
\hline \multicolumn{10}{|c|}{ TRATAMENTO COM NEBULIZACCÃO - TG } & \multirow{2}{*}{$\begin{array}{l}\text { Média } \\
\text { Diária }\end{array}$} \\
\hline Dia/hora & 9 & 10 & 11 & 12 & 13 & 14 & 15 & 16 & 17 & \\
\hline 7 & 24,5 & 24,7 & 26,6 & 28,0 & 27,8 & 28,6 & 27,7 & 26,1 & 23,1 & 26,3 \\
\hline 8 & 24,9 & 25,3 & 26,3 & 27,7 & 28,3 & 30,1 & 30,1 & 30,1 & 28,5 & 27,9 \\
\hline 9 & 27,0 & 27,3 & 29,3 & 30,8 & 31,8 & 31,9 & 31,4 & 31,2 & 29,8 & 30,1 \\
\hline 10 & 29,5 & 29,8 & 30,9 & 32,1 & 32,6 & 32,9 & 33,0 & 32,0 & 30,7 & 31,5 \\
\hline 11 & 27,6 & 28,6 & 31,6 & 34,1 & 34,5 & 34,3 & 33,2 & 30,3 & 29,0 & 31,5 \\
\hline 12 & 31,1 & 30,5 & 31,5 & 32,1 & 32,8 & 33,0 & 33,0 & 31,6 & 30,1 & 31,7 \\
\hline 13 & 23,0 & 22,8 & 23,3 & 23,8 & 25,6 & 25,3 & 25,6 & 25,2 & 24,7 & 24,3 \\
\hline 14 & 21,6 & 23,1 & 24,8 & 25,4 & 26,4 & 25,8 & 26,2 & 24,8 & 24,5 & 24,7 \\
\hline 15 & 24,3 & 25,0 & 27,3 & 28,6 & 28,5 & 28,7 & 28,9 & 29,2 & 28,6 & 27,7 \\
\hline 16 & 29,4 & 29,0 & 29,7 & 30,6 & 30,9 & 31,9 & 31,6 & 30,3 & 28,9 & 30,3 \\
\hline 17 & 26,3 & 27,4 & 28,6 & 24,3 & 22,8 & 22,2 & 22,6 & 22,4 & 22,2 & 24,3 \\
\hline 18 & 24,9 & 26,0 & 26,2 & 26,0 & 28,4 & 29,2 & 28,5 & 28,1 & 27,5 & 27,2 \\
\hline 19 & 22,3 & 23,1 & 23,4 & 24,1 & 23,5 & 25,8 & 25,1 & 25,1 & 24,0 & 24,0 \\
\hline 20 & 27,3 & 26,2 & 27,3 & 28,4 & 28,6 & 29,1 & 29,0 & 28,7 & 28,0 & 28,1 \\
\hline 21 & 21,4 & 23,8 & 24,8 & 25,7 & 26,3 & 25,9 & 26,0 & 25,6 & 24,6 & 24,9 \\
\hline 22 & 21,5 & 25,1 & 24,9 & 26,5 & 27,9 & 28,9 & 29,0 & 29,2 & 28,5 & 26,8 \\
\hline 23 & 22,7 & 25,5 & 25,5 & 26,8 & 28,0 & 24,5 & 24,1 & 25,6 & 25,6 & 25,4 \\
\hline 24 & 22,4 & 24,3 & 26,0 & 27,1 & 27,3 & 26,1 & 23,1 & 21,0 & 22,3 & 24,4 \\
\hline 25 & 25,5 & 26,6 & 28,2 & 29,5 & 30,4 & 30,9 & 30,9 & 31,0 & 25,6 & 28,7 \\
\hline 26 & 22,4 & 23,1 & 24,2 & 26,5 & 27,7 & 28,2 & 24,7 & 24,4 & 25,6 & 25,2 \\
\hline 27 & 26,5 & 28,0 & 29,4 & 30,2 & 30,6 & 29,1 & 29,3 & 26,7 & 26,8 & 28,5 \\
\hline 28 & 24,1 & 24,3 & 21,1 & 21,9 & 22,5 & 22,7 & 22,6 & 22,4 & 22,5 & 22,7 \\
\hline Média horária & 25,0 & 25,9 & 26,9 & 27,7 & 28,3 & 28,4 & 28,0 & 27,3 & 26,4 & 27,1 \\
\hline
\end{tabular}


Apêndice 34. Dados diários do índice de temperatura e umidade no período das 9 - 17 h, no tratamento com nebulização, durante o período experimental

\begin{tabular}{|c|c|c|c|c|c|c|c|c|c|c|}
\hline \multicolumn{10}{|c|}{ TRATAMENTO COM NEBULIZAÇÃO - THI } & \multirow{2}{*}{$\begin{array}{l}\text { Média } \\
\text { Diária }\end{array}$} \\
\hline Dia/hora & 9 & 10 & 11 & 12 & 13 & 14 & 15 & 16 & 17 & \\
\hline 7 & 71,9 & 72,3 & 74,2 & 75,0 & 74,9 & 74,7 & 73,8 & 72,3 & 69,9 & 73,2 \\
\hline 8 & 70,3 & 72,6 & 74,1 & 75,4 & 75,8 & 76,7 & 76,5 & 76,3 & 75,3 & 74,8 \\
\hline 9 & 73,2 & 74,7 & 75,8 & 76,8 & 76,9 & 77,0 & 76,8 & 76,9 & 75,9 & 76,0 \\
\hline 10 & 75,3 & 76,0 & 76,8 & 76,9 & 77,1 & 77,6 & 77,8 & 76,9 & 76,2 & 76,7 \\
\hline 11 & 73,7 & 76,2 & 78,9 & 81,0 & 81,1 & 81,2 & 80,5 & 79,5 & 77,9 & 78,9 \\
\hline 12 & 78,2 & 78,3 & 79,2 & 79,7 & 80,3 & 80,6 & 80,0 & 79,2 & 78,6 & 79,3 \\
\hline 13 & 72,1 & 71,9 & 72,4 & 72,6 & 74,2 & 74,0 & 73,9 & 73,4 & 72,9 & 73,0 \\
\hline 14 & 69,1 & 70,6 & 72,1 & 72,8 & 73,7 & 73,9 & 74,1 & 73,6 & 72,7 & 72,5 \\
\hline 15 & 71,0 & 72,5 & 74,9 & 76,9 & 77,4 & 77,7 & 77,3 & 77,9 & 77,2 & 75,9 \\
\hline 16 & 76,7 & 76,8 & 77,2 & 78,0 & 78,5 & 79,1 & 78,7 & 78,2 & 77,1 & 77,8 \\
\hline 17 & 75,2 & 76,2 & 77,4 & 73,7 & 71,9 & 71,3 & 71,3 & 71,1 & 70,9 & 73,2 \\
\hline 18 & 72,7 & 74,0 & 74,7 & 75,0 & 76,7 & 77,0 & 76,6 & 75,8 & 75,5 & 75,3 \\
\hline 19 & 70,0 & 70,4 & 71,1 & 71,1 & 70,7 & 72,6 & 72,4 & 72,5 & 71,5 & 71,4 \\
\hline 20 & 71,9 & 72,0 & 72,8 & 73,3 & 74,1 & 74,4 & 74,3 & 74,1 & 72,8 & 73,3 \\
\hline 21 & 68,9 & 70,6 & 71,9 & 73,3 & 73,7 & 73,3 & 73,5 & 73,0 & 72,4 & 72,3 \\
\hline 22 & 68,8 & 71,6 & 72,4 & 74,6 & 75,5 & 77,0 & 76,5 & 76,6 & 76,3 & 74,4 \\
\hline 23 & 70,9 & 72,5 & 73,7 & 75,3 & 76,9 & 73,9 & 72,5 & 74,2 & 74,8 & 73,9 \\
\hline 24 & 70,7 & 72,3 & 74,3 & 75,3 & 75,6 & 74,5 & 72,0 & 69,3 & 70,7 & 72,8 \\
\hline 25 & 73,9 & 74,7 & 76,7 & 77,4 & 78,2 & 78,8 & 78,8 & 79,0 & 74,4 & 76,9 \\
\hline 26 & 71,4 & 72,0 & 73,2 & 75,1 & 76,4 & 77,3 & 73,1 & 73,0 & 74,4 & 74,0 \\
\hline 27 & 75,2 & 76,2 & 78,0 & 78,9 & 79,5 & 78,8 & 78,3 & 75,8 & 76,1 & 77,4 \\
\hline 28 & 72,4 & 72,4 & 69,5 & 70,1 & 70,3 & 70,6 & 70,7 & 70,5 & 70,9 & 70,8 \\
\hline Média horária & 72,4 & 73,5 & 74,6 & 75,4 & 75,9 & 76,0 & 75,4 & 75,0 & 74,3 & 74,7 \\
\hline
\end{tabular}


Apêndice 35. Dados diários do índice do globo negro e umidade no período das 9 - 17 h, no tratamento com nebulização, durante o período experimental

\begin{tabular}{|c|c|c|c|c|c|c|c|c|c|c|}
\hline \multicolumn{10}{|c|}{ TRATAMENTO COM NEBULIZAÇÃO - BGHI } & \multirow{2}{*}{$\begin{array}{l}\text { Média } \\
\text { Diária }\end{array}$} \\
\hline Dia/hora & 9 & 10 & 11 & 12 & 13 & 14 & 15 & 16 & 17 & \\
\hline 7 & 72,5 & 72,6 & 74,7 & 75,6 & 75,3 & 75,2 & 74,1 & 72,7 & 69,8 & 73,6 \\
\hline 8 & 72,5 & 73,2 & 74,6 & 75,5 & 75,8 & 77,2 & 76,9 & 76,6 & 75,4 & 75,3 \\
\hline 9 & 75,1 & 75,2 & 76,4 & 77,4 & 77,5 & 77,7 & 77,0 & 77,1 & 75,9 & 76,6 \\
\hline 10 & 76,9 & 76,4 & 77,2 & 77,5 & 77,7 & 78,2 & 78,3 & 77,1 & 76,3 & 77,3 \\
\hline 11 & 75,3 & 76,4 & 79,5 & 81,6 & 81,6 & 81,5 & 80,4 & 79,2 & 77,7 & 79,3 \\
\hline 12 & 78,6 & 78,2 & 79,3 & 79,9 & 80,5 & 80,8 & 80,3 & 79,2 & 78,5 & 79,5 \\
\hline 13 & 71,9 & 71,9 & 72,4 & 72,7 & 74,4 & 73,9 & 73,9 & 73,4 & 72,9 & 73,1 \\
\hline 14 & 69,3 & 70,8 & 72,5 & 73,1 & 73,9 & 73,7 & 73,9 & 72,9 & 72,3 & 72,5 \\
\hline 15 & 72,1 & 73,0 & 75,5 & 77,1 & 77,2 & 77,5 & 77,4 & 77,6 & 76,9 & 76,0 \\
\hline 16 & 77,8 & 77,1 & 77,6 & 78,3 & 78,8 & 79,5 & 79,0 & 78,1 & 76,9 & 78,1 \\
\hline 17 & 75,4 & 76,4 & 77,6 & 73,4 & 71,8 & 71,1 & 71,2 & 71,0 & 70,7 & 73,2 \\
\hline 18 & 72,8 & 74,2 & 74,7 & 74,9 & 77,0 & 77,5 & 76,6 & 76,0 & 75,6 & 75,5 \\
\hline 19 & 69,9 & 70,6 & 71,2 & 71,5 & 70,8 & 73,0 & 72,4 & 72,5 & 71,5 & 71,5 \\
\hline 20 & 73,7 & 72,4 & 73,2 & 74,0 & 74,4 & 74,7 & 74,5 & 74,2 & 73,0 & 73,8 \\
\hline 21 & 68,9 & 71,2 & 72,2 & 73,4 & 73,9 & 73,5 & 73,7 & 73,1 & 72,5 & 72,5 \\
\hline 22 & 69,0 & 72,9 & 72,8 & 75,2 & 76,1 & 77,5 & 76,9 & 76,9 & 76,3 & 74,8 \\
\hline 23 & 71,1 & 74,0 & 74,1 & 75,8 & 77,1 & 73,5 & 72,5 & 74,4 & 74,7 & 74,1 \\
\hline 24 & 70,8 & 72,8 & 74,7 & 75,7 & 75,8 & 74,4 & 71,7 & 69,1 & 70,7 & 72,9 \\
\hline 25 & 74,2 & 75,1 & 77,0 & 77,9 & 78,7 & 79,2 & 79,1 & 79,4 & 74,3 & 77,2 \\
\hline 26 & 71,3 & 72,1 & 73,3 & 75,7 & 76,7 & 77,4 & 72,9 & 73,1 & 74,3 & 74,1 \\
\hline 27 & 75,5 & 76,9 & 78,3 & 79,2 & 79,7 & 78,8 & 78,6 & 75,8 & 76,0 & 77,7 \\
\hline 28 & 72,7 & 72,9 & 69,4 & 70,1 & 70,5 & 70,7 & 70,7 & 70,6 & 70,8 & 70,9 \\
\hline Média horária & 73,1 & 73,9 & 74,9 & 75,7 & 76,2 & 76,2 & 75,5 & 75,0 & 74,2 & 75,0 \\
\hline
\end{tabular}


Apêndice 36. Dados diários da entalpia no período das $9-17$ h, no tratamento com nebulização, durante o período experimental

\begin{tabular}{|c|c|c|c|c|c|c|c|c|c|c|}
\hline \multicolumn{10}{|c|}{ TRAT AMENTO COM NEBULIZAÇÃO - H (KJ/kg ar seco) } & \multirow{2}{*}{$\begin{array}{l}\text { Média } \\
\text { Diária }\end{array}$} \\
\hline Dia/hora & 9 & 10 & 11 & 12 & 13 & 14 & 15 & 16 & 17 & \\
\hline 7 & 74,5 & 74,5 & 77,1 & 75,9 & 75,3 & 71,8 & 70,1 & 69,2 & 67,4 & 72,9 \\
\hline 8 & 70,8 & 74,8 & 77,5 & 77,0 & 76,3 & 75,5 & 74,3 & 73,1 & 73,2 & 74,7 \\
\hline 9 & 76,5 & 76,4 & 74,7 & 73,8 & 71,0 & 71,3 & 70,7 & 71,8 & 71,4 & 73,1 \\
\hline 10 & 75,1 & 73,0 & 72,9 & 70,1 & 70,0 & 70,9 & 71,0 & 69,4 & 70,2 & 71,4 \\
\hline 11 & 74,8 & 78,0 & 81,0 & 81,4 & 79,8 & 80,2 & 80,0 & 86,4 & 83,6 & 80,6 \\
\hline 12 & 78,5 & 79,2 & 81,0 & 81,3 & 81,6 & 82,6 & 79,9 & 79,8 & 82,7 & 80,7 \\
\hline 13 & 79,3 & 79,7 & 80,2 & 79,1 & 80,5 & 79,5 & 78,1 & 76,9 & 76,5 & 78,9 \\
\hline 14 & 70,1 & 72,0 & 73,4 & 74,0 & 74,0 & 76,0 & 75,0 & 76,3 & 74,1 & 73,9 \\
\hline 15 & 72,3 & 74,9 & 78,0 & 81,7 & 83,3 & 83,9 & 82,1 & 82,5 & 81,2 & 80,0 \\
\hline 16 & 81,0 & 79,6 & 79,1 & 79,3 & 80,6 & 79,7 & 78,8 & 80,0 & 79,4 & 79,7 \\
\hline 17 & 83,1 & 83,4 & 84,7 & 81,3 & 79,5 & 77,9 & 76,5 & 76,5 & 77,8 & 80,1 \\
\hline 18 & 74,9 & 77,6 & 79,3 & 81,7 & 82,1 & 81,1 & 79,4 & 75,9 & 78,3 & 78,9 \\
\hline 19 & 70,9 & 71,0 & 72,6 & 70,8 & 70,0 & 71,8 & 72,2 & 72,5 & 71,9 & 71,5 \\
\hline 20 & 68,1 & 67,4 & 67,6 & 67,3 & 68,6 & 68,4 & 67,9 & 67,7 & 65,2 & 67,6 \\
\hline 21 & 69,0 & 70,2 & 71,7 & 74,6 & 74,4 & 74,3 & 74,5 & 73,2 & 74,5 & 72,9 \\
\hline 22 & 69,1 & 73,3 & 74,5 & 80,0 & 78,9 & 82,1 & 78,4 & 77,9 & 77,8 & 76,9 \\
\hline 23 & 75,2 & 77,4 & 79,2 & 82,7 & 84,6 & 81,0 & 76,9 & 80,8 & 82,8 & 80,1 \\
\hline 24 & 75,1 & 77,0 & 80,3 & 80,6 & 80,3 & 78,8 & 77,5 & 71,8 & 75,1 & 77,4 \\
\hline 25 & 79,6 & 79,5 & 83,2 & 82,0 & 82,2 & 82,5 & 81,9 & 83,1 & 80,5 & 81,6 \\
\hline 26 & 78,5 & 79,4 & 81,3 & 83,3 & 83,9 & 85,5 & 76,6 & 78,8 & 80,5 & 80,9 \\
\hline 27 & 82,4 & 83,1 & 84,9 & 86,6 & 87,5 & 90,3 & 87,2 & 83,4 & 84,7 & 85,6 \\
\hline 28 & 77,4 & 77,7 & 73,0 & 73,5 & 72,6 & 73,0 & 73,9 & 73,8 & 75,0 & 74,4 \\
\hline Média horária & 75,3 & 76,3 & 77,6 & 78,1 & 78,0 & 78,1 & 76,5 & 76,4 & 76,5 & 77,0 \\
\hline
\end{tabular}


Apêndice 37. Dados diários de temperatura de bulbo seco no período das 9 - 17 h, no ambiente externo, durante o período experimental

\begin{tabular}{|c|ccccccccc|c|}
\hline \multicolumn{10}{|c}{} & \multicolumn{10}{c|}{ EXTERNO - Tbs } & \multicolumn{1}{c}{ Média } \\
\cline { 1 - 8 } Dia/hora & 9 & 10 & 11 & 12 & 13 & 14 & 15 & 16 & 17 & Diária \\
\hline 7 & 21,0 & 22,4 & 25,1 & 27,2 & 28,8 & 28,8 & 30,5 & 31,7 & 32,7 & 27,6 \\
9 & 22,9 & 24,6 & 27,3 & 29,3 & 30,7 & 32,1 & 32,0 & 32,0 & 32,2 & 29,2 \\
10 & 25,7 & 27,4 & 29,7 & 30,9 & 31,6 & 32,8 & 33,5 & 34,5 & 33,7 & 31,1 \\
11 & 23,4 & 25,6 & 27,9 & 31,2 & 33,5 & 35,6 & 35,9 & 34,5 & 31,1 & 31,0 \\
12 & 30,0 & 31,0 & 31,2 & 32,2 & 33,8 & 33,8 & 34,4 & 34,9 & 33,0 & 32,7 \\
13 & 21,4 & 21,7 & 21,5 & 22,1 & 23,1 & 26,0 & 26,0 & 26,2 & 25,2 & 23,7 \\
14 & 19,3 & 21,0 & 22,9 & 24,6 & 25,0 & 26,7 & 26,9 & 27,1 & 27,0 & 24,5 \\
15 & 21,8 & 23,0 & 24,4 & 26,8 & 29,0 & 29,9 & 29,6 & 29,7 & 31,0 & 27,2 \\
16 & 28,0 & 29,2 & 29,7 & 30,1 & 31,5 & 31,2 & 33,1 & 33,0 & 31,0 & 30,8 \\
17 & 24,2 & 26,5 & 28,2 & 30,4 & 24,9 & 21,8 & 21,2 & 21,8 & 21,8 & 24,5 \\
18 & 23,2 & 24,7 & 26,0 & 26,8 & 26,5 & 29,1 & 30,8 & 30,1 & 29,0 & 27,4 \\
19 & 21,0 & 21,9 & 23,0 & 23,3 & 24,2 & 23,4 & 26,9 & 26,5 & 26,5 & 24,1 \\
20 & 24,5 & 25,7 & 26,8 & 27,9 & 28,9 & 29,3 & 30,0 & 30,1 & 30,0 & 28,1 \\
21 & 20,4 & 21,2 & 23,3 & 24,2 & 25,5 & 28,3 & 30,1 & 30,5 & 29,1 & 25,9 \\
22 & 24,1 & 24,4 & 24,6 & 25,1 & 25,5 & 26,3 & 27,1 & 27,6 & 27,9 & 25,8 \\
23 & 25,6 & 25,6 & 26,0 & 26,3 & 26,6 & 26,9 & 27,1 & 27,5 & 27,5 & 26,6 \\
24 & 24,8 & 24,9 & 25,2 & 25,2 & 25,8 & 26,2 & 26,3 & & & 25,5 \\
25 & 26,3 & 26,8 & 29,6 & 30,9 & 31,7 & 32,7 & 32,5 & 33,2 & 33,2 & 30,8 \\
26 & 21,2 & 22,1 & 24,0 & 27,3 & 29,4 & 30,0 & 24,9 & 24,4 & 26,4 & 25,5 \\
27 & 27,1 & 28,4 & 30,6 & 31,6 & 32,4 & 29,9 & 30,2 & 26,4 & 26,8 & 29,3 \\
28 & 23,8 & 23,6 & 19,9 & 21,6 & 21,9 & 22,1 & 21,7 & 21,6 & 21,7 & 22,0 \\
\hline Média horária & 23,8 & 24,8 & 26,0 & 27,4 & 28,1 & 28,7 & 29,1 & 29,2 & 28,8 & 27,3 \\
\hline
\end{tabular}


Apêndice 38. Dados diários de umidade relativa no período das $9-17 \mathrm{~h}$, no ambiente externo, durante o período experimental

\begin{tabular}{|c|c|c|c|c|c|c|c|c|c|c|}
\hline \multicolumn{10}{|c|}{ EXTERNO - UR } & \multirow{2}{*}{$\begin{array}{l}\text { Média } \\
\text { Diária }\end{array}$} \\
\hline Dia/hora & 9 & 10 & 11 & 12 & 13 & 14 & 15 & 16 & 17 & \\
\hline 7 & & & & & & & & & & \\
\hline 8 & 64,8 & 65,4 & 61,0 & 56,6 & 52,3 & 47,9 & 38,5 & 35,6 & 31,5 & 50,4 \\
\hline 9 & 71,5 & 65,4 & 56,2 & 47,6 & 37,3 & 31,2 & 28,2 & 29,5 & 28,9 & 44,0 \\
\hline 10 & 53,8 & 48,1 & 41,8 & 35,1 & 30,7 & 26,1 & 26,5 & 25,2 & 25,2 & 34,7 \\
\hline 11 & 61,6 & 57,2 & 50,7 & 45,6 & 38,9 & 30,7 & 29,2 & 34,2 & 48,4 & 44,1 \\
\hline 12 & 44,1 & 41,7 & 43,2 & 41,9 & 39,9 & 38,1 & 37,2 & 35,6 & 39,2 & 40,1 \\
\hline 13 & 99,4 & 99,6 & 99,6 & 92,5 & 81,3 & 68,1 & 64,4 & 63,9 & 64,4 & 81,5 \\
\hline 14 & 85,3 & 77,1 & 69,6 & 65,1 & 60,5 & 55,3 & 52,8 & 52,6 & 49,8 & 63,1 \\
\hline 15 & 73,3 & 70,0 & 67,1 & 61,6 & 57,3 & 52,9 & 54,7 & 56,0 & 49,0 & 60,2 \\
\hline 16 & 56,6 & 52,4 & 50,7 & 49,2 & 45,6 & 46,0 & 40,4 & 39,7 & 43,6 & 47,1 \\
\hline 17 & 88,3 & 76,9 & 69,0 & 63,3 & 78,7 & 87,2 & 89,4 & 87,7 & 87,7 & 80,9 \\
\hline 18 & 75,2 & 71,0 & 68,8 & 68,4 & 73,2 & 62,9 & 56,7 & 54,8 & 58,1 & 65,4 \\
\hline 19 & 79,5 & 76,2 & 72,7 & 72,5 & 66,7 & 67,3 & 58,7 & 58,4 & 59,9 & 68,0 \\
\hline 20 & 59,6 & 54,6 & 49,6 & 44,9 & 41,4 & 40,2 & 39,9 & 38,2 & 35,6 & 44,9 \\
\hline 21 & 81,8 & 76,6 & 69,5 & 65,7 & 62,5 & 61,1 & 61,0 & 59,4 & 59,1 & 66,3 \\
\hline 22 & 60,0 & 60,1 & 60,3 & 60,4 & 60,7 & 60,8 & 60,7 & 60,5 & 60,2 & 60,4 \\
\hline 23 & 60,9 & 61,2 & 61,3 & 61,5 & 61,5 & 61,8 & 61,7 & 61,6 & 61,6 & 61,5 \\
\hline 24 & 62,9 & 63,3 & 63,3 & 63,6 & 64,1 & 63,8 & 63,8 & & & 63,5 \\
\hline 25 & 71,0 & 67,7 & 63,1 & 58,1 & 53,2 & 50,2 & 49,3 & 49,8 & 49,4 & 56,9 \\
\hline 26 & 94,5 & 93,0 & 84,8 & 73,5 & 66,0 & 63,3 & 72,9 & 79,2 & 72,1 & 77,7 \\
\hline 27 & 71,6 & 67,9 & 63,2 & 59,2 & 59,1 & 70,4 & 67,9 & 74,4 & 76,1 & 67,7 \\
\hline 28 & 77,9 & 80,2 & 92,7 & 86,5 & 80,3 & 80,3 & 82,0 & 84,4 & 84,8 & 83,2 \\
\hline Média horária & 71,1 & 67,9 & 64,7 & 60,6 & 57,7 & 55,5 & 54,1 & 54,0 & 54,2 & 60,0 \\
\hline
\end{tabular}


Apêndice 39. Dados diários do índice de temperatura e umidade no período das 9 - 17 h, no ambiente externo, durante o período experimental

\begin{tabular}{|c|c|c|c|c|c|c|c|c|c|c|}
\hline \multicolumn{10}{|c|}{ EXTERNO - THI } & \multirow{2}{*}{$\begin{array}{l}\text { Média } \\
\text { Diária }\end{array}$} \\
\hline Dia/hora & 9 & 10 & 11 & 12 & 13 & 14 & 15 & 16 & 17 & \\
\hline 7 & & & & & & & & & & \\
\hline 8 & 67,7 & 69,7 & 72,9 & 75,3 & 77,0 & 76,5 & 77,5 & 78,7 & 79,2 & 75,0 \\
\hline 9 & 70,8 & 72,7 & 75,4 & 77,1 & 77,6 & 78,5 & 77,8 & 78,1 & 78,2 & 76,3 \\
\hline 10 & 73,0 & 74,7 & 76,9 & 77,5 & 77,7 & 78,3 & 79,4 & 80,5 & 79,4 & 77,5 \\
\hline 11 & 70,8 & 73,2 & 75,6 & 79,4 & 81,5 & 82,9 & 83,1 & 82,2 & 79,6 & 78,7 \\
\hline 12 & 77,6 & 78,6 & 79,1 & 80,3 & 82,1 & 81,8 & 82,5 & 82,8 & 80,9 & 80,6 \\
\hline 13 & 70,8 & 71,2 & 70,9 & 71,3 & 72,0 & 74,7 & 74,5 & 74,7 & 73,3 & 72,6 \\
\hline 14 & 67,1 & 68,7 & 70,7 & 72,6 & 72,7 & 74,6 & 74,6 & 74,8 & 74,4 & 72,2 \\
\hline 15 & 69,6 & 70,8 & 72,5 & 75,3 & 77,8 & 78,5 & 78,3 & 78,6 & 79,6 & 75,7 \\
\hline 16 & 76,4 & 77,5 & 78,0 & 78,4 & 79,8 & 79,5 & 81,2 & 80,9 & 78,9 & 79,0 \\
\hline 17 & 73,9 & 76,2 & 77,8 & 80,3 & 74,1 & 70,6 & 69,9 & 70,6 & 70,6 & 73,8 \\
\hline 18 & 71,6 & 73,3 & 74,9 & 75,9 & 75,9 & 78,5 & 80,2 & 79,0 & 77,9 & 76,3 \\
\hline 19 & 69,0 & 69,9 & 71,1 & 71,6 & 72,2 & 71,3 & 75,2 & 74,6 & 74,8 & 72,2 \\
\hline 20 & 72,0 & 73,1 & 74,1 & 75,0 & 75,8 & 76,2 & 77,1 & 77,0 & 76,4 & 75,2 \\
\hline 21 & 68,3 & 69,0 & 71,3 & 72,2 & 73,6 & 77,2 & 79,6 & 80,0 & 78,1 & 74,4 \\
\hline 22 & 71,5 & 71,9 & 72,2 & 72,8 & 73,4 & 74,6 & 75,6 & 76,3 & 76,6 & 73,9 \\
\hline 23 & 73,5 & 73,6 & 74,2 & 74,6 & 75,0 & 75,5 & 75,7 & 76,2 & 76,2 & 75,0 \\
\hline 24 & 72,7 & 72,9 & 73,2 & 73,3 & 74,1 & 74,7 & 74,9 & & & 73,7 \\
\hline 25 & 75,5 & 75,9 & 79,2 & 80,4 & 81,0 & 81,9 & 81,6 & 82,5 & 82,5 & 80,1 \\
\hline 26 & 70,2 & 71,3 & 73,4 & 77,0 & 79,2 & 79,7 & 73,7 & 73,5 & 75,7 & 74,9 \\
\hline 27 & 76,6 & 78,0 & 80,5 & 81,5 & 82,6 & 80,2 & 80,4 & 75,8 & 76,5 & 79,1 \\
\hline 28 & 72,6 & 72,5 & 68,3 & 70,3 & 70,2 & 70,5 & 70,1 & 70,1 & 70,3 & 70,5 \\
\hline Média horária & 72,0 & 73,1 & 74,4 & 75,8 & 76,4 & 77,0 & 77,3 & 77,3 & 77,0 & 75,6 \\
\hline
\end{tabular}


Apêndice 40. Dados diários do índice de temperatura de globo negro e umidade no período das 9 - 17 h, no ambiente externo, durante o período experimental

\begin{tabular}{|c|cccccccccc|c|}
\hline \multicolumn{10}{|c|}{ EXTERNO - H (KJ/kg ar seco) } & & Média \\
\cline { 1 - 7 } Dia/hora & 9 & 10 & 11 & 12 & 13 & 14 & 15 & 16 & 17 & Diária \\
\hline 7 & & & & & & & & & & \\
8 & 64,5 & 68,4 & 73,7 & 77,5 & 79,5 & 76,9 & 75,3 & 76,3 & 75,6 & 74,2 \\
9 & 72,2 & 74,5 & 77,6 & 78,0 & 75,0 & 74,1 & 71,8 & 72,6 & 72,7 & 74,3 \\
10 & 71,8 & 73,3 & 75,4 & 74,0 & 72,6 & 71,8 & 73,6 & 74,8 & 73,0 & 73,4 \\
11 & 69,6 & 73,2 & 76,1 & 82,0 & 83,3 & 82,0 & 81,5 & 82,3 & 83,7 & 79,3 \\
12 & 77,7 & 78,7 & 80,4 & 82,2 & 85,0 & 83,6 & 84,5 & 84,3 & 82,2 & 82,1 \\
13 & 79,1 & 80,1 & 79,5 & 78,6 & 77,3 & 79,8 & 78,2 & 78,5 & 75,7 & 78,5 \\
14 & 67,5 & 69,1 & 71,5 & 74,3 & 73,2 & 75,4 & 74,6 & 75,0 & 73,2 & 72,6 \\
15 & 70,0 & 71,9 & 74,7 & 79,1 & 83,1 & 83,0 & 83,3 & 84,4 & 83,7 & 79,3 \\
16 & 79,7 & 80,7 & 81,1 & 81,2 & 82,9 & 82,3 & 83,3 & 82,5 & 80,1 & 81,5 \\
17 & 83,9 & 86,2 & 87,5 & 91,4 & 81,7 & 75,5 & 74,6 & 75,7 & 75,7 & 81,4 \\
18 & 74,9 & 77,4 & 80,4 & 82,7 & 84,3 & 86,8 & 88,4 & 84,9 & 83,6 & 82,6 \\
19 & 70,2 & 71,5 & 73,0 & 74,0 & 74,0 & 72,1 & 77,8 & 76,5 & 77,3 & 74,0 \\
20 & 71,5 & 72,1 & 72,6 & 72,8 & 73,2 & 73,5 & 75,0 & 74,1 & 72,2 & 73,0 \\
21 & 69,2 & 69,7 & 72,7 & 73,5 & 75,5 & 83,3 & 88,9 & 89,2 & 84,5 & 78,5 \\
22 & 70,6 & 71,4 & 72,1 & 73,4 & 74,7 & 77,2 & 79,4 & 80,8 & 81,5 & 75,7 \\
23 & 75,0 & 75,2 & 76,6 & 77,6 & 78,4 & 79,4 & 80,0 & 81,1 & 81,1 & 78,3 \\
24 & 73,8 & 74,3 & 75,1 & 75,3 & 77,2 & 78,5 & 78,8 & & & 76,1 \\
25 & 82,5 & 82,3 & 88,5 & 89,6 & 88,8 & 89,5 & 88,6 & 90,8 & 90,6 & 87,9 \\
26 & 76,5 & 78,8 & 81,6 & 87,1 & 89,7 & 90,1 & 78,9 & 80,3 & 83,4 & 82,9 \\
27 & 85,4 & 87,5 & 92,0 & 92,7 & 95,5 & 94,2 & 93,7 & 84,3 & 86,8 & 90,2 \\
28 & 77,9 & 78,3 & 71,7 & 74,7 & 73,1 & 73,6 & 73,2 & 73,8 & 74,3 & 74,5 \\
\hline Média horária & 74,5 & 75,9 & 77,8 & 79,6 & 79,9 & 80,1 & 80,2 & 80,1 & 79,5 & 78,6 \\
\hline
\end{tabular}

